"Harvest Histories: A Social History of Mexican Farm Workers in Canada since 1974"

by

\author{
Naomi Alisa Calnitsky \\ B.A. (Hons.), M.A.
}

A thesis submitted to the Faculty of Graduate and Postdoctoral Affairs in partial fulfillment of the requirements for the degree of

\title{
Doctor of
}

Philosophy in

History

\author{
Carleton University \\ Ottawa, Ontario
}

(C) 2017

Naomi Calnitsky 


\begin{abstract}
While concerns and debates about an increased presence of non-citizen guest workers in agriculture in Canada have only more recently begun to enter the public arena, this dissertation probes how migrant agricultural workers have occupied a longer and more complex place in Canadian history than most Canadians may approximate. It explores the historical precedents of seasonal farm labour in Canada through the lens of the interior or the personal on the one hand, through an oral history approach, and the external or the structural on the other, in dialogue with existing scholarship and through a critical assessment of the archive. Specifically, it considers the evolution of seasonal farm work in Manitoba and British Columbia, and traces the eventual rise of an "offshore" labour scheme as a dominant model for agriculture at a national scale. Taking 1974 as a point of departure for the study of circular farm labour migration between Mexico and Canada, the study revisits questions surrounding Canadian views of what constitutes the ideal or injurious migrant worker, to ask critical questions about how managed farm labour migration schemes evolved in Canadian history. In addition, the dissertation explores how Mexican farm workers' migration to Canada since 1974 formed a part of a wider and extended world of Mexican migration, and seeks to record and celebrate Mexican contributions to modern Canadian agriculture in historical contexts involving diverse actors. In exploring the contexts that have driven Mexican out-migration and transnational integration, it bridges oral accounts with a broader history that sets Mexican northward migration in hemispheric context. It reads agricultural migration upon various planes, including corporeality, experience, identity, masculinity, legality, "contra-modernity," and the management of mobilities.
\end{abstract}




\section{Acknowledgements}

A great number of people and forces of circumstance have come together to spawn and support this work to help achieve the goal of offering a more comprehensive history of Mexican farm labour in Canada than that which currently exists. I first would like to extend a big thankyou to Dr. Michel Hogue in the Department of History at Carleton University for reviewing a draft and offering insightful comments on structure and organization. In Winnipeg, Tyler Pierce proved invaluable as copy editor for the dissertation. Thanks especially to the members of my examination committee for constructive and encouraging comments on refining the work and guidance on how to work out its kinks. Staff at the Universidad Nacional Autónoma de México (U.N.A.M.) Escuela de Extensión en Canadá in Gatineau encouraged my development of conversational Mexican Spanish, an invaluable resource in the field. Professors of History and Anthropology at the University of Manitoba were instrumental in drawing me into the field and shaping my early scholarly inspirations as an undergraduate.

The Commonwealth Scholarship program at the University of Otago, Dunedin, New Zealand, supported my completion of a Master's thesis in Pacific history, where my early research interests in South Pacific colonial and labour history would develop alongside an interest in contemporary patterns of trans-national and seasonal farm labour migration in the region. Supervisors at Otago, including Drs. Angela Wanhalla and Tony Ballantyne offered their expertise in New Zealand and Pacific History; Angela encouraged me to travel to Samoa to pursue oral history research and Tony oriented my dissertation toward New Zealand's relationship with the Pacific. Tony in particular offered invaluable direction on archives relevant to my evolving research interests on Pacific labour history. 
My interest in Mexico and its complexities was first sparked and maintained by a number of opportunities to travel there. My connections with Mexico developed first as a visitor and volunteer farmworker. I first travelled to Mexico City via Cuba, to numerous towns, cities and historical sites as well as rural regions including Mexico City, Chalma, Teotihuacan, Morelia, Pátzcuaro, Tacámbaro, Guadalajara, and other locations in Michoacán and Jalisco. On return trips to Mexico I was able to visit Mazatlán, Puebla and Oaxaca and spend more time in the Federal District. Prior to the onset of this project, I had numerous opportunities to engage in fruit harvesting work in Canada and New Zealand, including apple thinning and harvest work in Summerland, British Columbia, cherry work in Kelowna alongside Mexican farmworkers at Valley Orchards, and apple, nectarine and cherry harvest work in Roxburgh in Central Otago, New Zealand alongside seasonal migrant workers from Vanuatu and elsewhere. At Carleton, Christine Hughes offered valuable insights into her own field research with Guatemalan farmworkers in Quebec, and I was able to meet Enrique Florescano, to discuss the project and re-orient it more closely within Mexican scholarship and research bodies engaged with work on migration. I also gained inspiration from the work of fellow graduate students at Carleton and I was supported by a graduate scholarship, several teaching assistantships, a Peter Browne Memorial Scholarship, travel bursaries, and grading posts at the University of Manitoba. I have presented findings linked to this dissertation at Concordia University, Carleton University, York University, Dalhousie University, and Ryerson University, for the Congress of Latin American and Caribbean Studies (CALACS) in Quebec City and San José, the University of Massachusetts at Amherst, and the American Society for Environmental History (ASEH). More recently, my interest in the photographic work, Juchitán de la Mujeres, was shared at the McGill-Queens Graduate Conference in 
History and University of British Columbia Art History and Visual Arts (AHVA) Symposium and findings from Manitoba and British Colulmbia shared at the Oral History Association 50th Annual Conference in Long Beach, California in 2016. Archival staff at the Bancroft Library, University of California Berkeley, the Vancouver City Archives, Library and Archives Canada (LAC), the Smithsonian Institution, Washington, the Legislative Library of Manitoba, Manitoba Archives, B.C. Archives, Victoria, Archives of Chilliwack and Vernon, and the Kelowna Public Archives should also be thanked here. Volunteers and staff with the Agricultural Workers Alliance and Winnipeg-based Migrant Worker Solidarity Network all proved helpful including Gustavo Mejicanos in Portage la Prairie; Raul Gatica and Gil of Chiapas; Alejandra of Colombia in Surrey; and Jodi-Dueck Read and Thomas Novak in Winnipeg. Jodi introduced me to the work of Lionel Cantú and shared her own experiences of fieldwork with Mexican farmworkers in Manitoba. The support of my partner, Paolo, who accompanied me on numerous journeys into the field, including in British Columbia, was invaluable, and the intellectual climate and supportive environment provided by my parents throughout my time as a graduate student made this work's completion possible. My brother David and sister Shauna also proved highly supportive.

Thanks also go to all the inspiring scholars of Latin American history who encourage their readership to think and read beyond the boundaries of Latin America and the Caribbean world, offering daily incentives to continue on work in the field. The final thanks go to all of those workers, both men and women, who opened their hearts and doors to my study, enriching the direction of the work and offering new and engaging pathways toward sociability and friendship. I dedicate this work to them. 


\title{
Author's Note
}

In the preparation of this thesis, I have prematurely destroyed the majority of notes related to my fieldwork. This is solely my responsibility. The supervisors of my thesis were not able to access this material, nor were the members of my examination board.

\begin{abstract}
A Note on Terminology
The use of the terms Aboriginal, Indigenous, First Nations and Native occur throughout this work and should not be viewed as interchangeable. The term Native is used primarily in instances where the journalists, authors or government documents cited do so and should not be taken as a given for regular usage. Where possible, all of these terms are capitalized.
\end{abstract}




\section{Table of Contents}

Abstract.......................................................................

Acknowledgements.........................................................ii

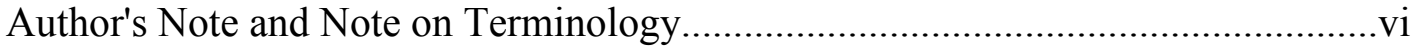

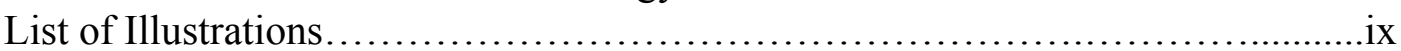

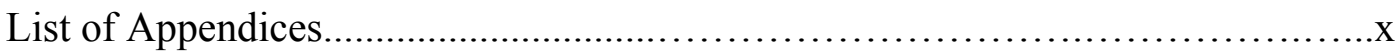

List of Appendices.......................................................................

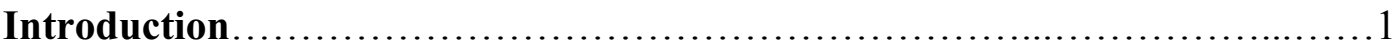

1. Excavating Rural Space in Manitoba and the British Columbian West.......38

1.1 The Colonial Origins of Canadian Agricultural Practice.........................39

1.2 Farm Labour in Manitoba: Antecedents and Transformations...................44

1.3 Settling British Columbia: Labour and Migration from the Margins............50

1.4 A Flourishing of Fruits: Rural Hired Help in British Columbia..................57

1.5 A "Fruit-Growing Heaven on Earth": Life and Production in the Okanagan.....63

1.6 Connecting Worlds: South Asian Immigrant Labour in British Columbia.........67

\section{2. "Skilled, Productive, and Dependable": Origins of the Canadian Seasonal}

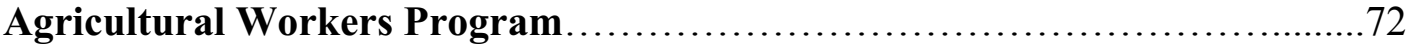

2.1 The Foundations of Foreign Seasonal Farm Labour in Canada.................73

2.2 "Most Mexicans have a lot of very good friends among Indians in Canada":

Evolving Labour Patterns on Manitoba Farms................................ 84

2.3 Debating "Offshore” Hiring Practices in British Columbia.....................95

2.4 From "Vectors of Disease" to Casualties of Industry: Canadian Anxieties and

Migrant Health........................................................... 98

2.5 Migrant Grievaces Expressed: The Case of a Cranberry Farm................ 104

2.6 Encounters with Migrants: Canadian Currents..............................107

3. "It is the Rainbow We See Shining / Es El Arco Iris Que Vemos Lucir":

Views from The South...........................................................................115

3.1 Placing Mexican Migration on the Map...................................117

3.2 "Some farmers have given me the names of other farmers who horse-whip their Mexicans": Farm Labour Relations in Interwar United States...............128 
3.3 The Bracero Years (1942-1964).

3.4 El Movimiento and La Causa: Geographies of Injustice in an Era of Civil

Rights

3.5 Connections with Home: Corridors of Survival and Exchange.

\section{4. "There is not much work that is nice / No Hay Mucho Trabajo Que Está}

Bonito": Findings from Canadian Fields......................................170

4.1 Manitoba-Mexico Connections: Early Interviews with Farmworkers

4.2 Field Findings I: Manitoba................................................. 183

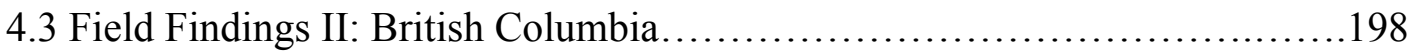

4.4 Canadian Viticulture and the New Migrant Presence.........................217

4.5 Histories from "Below": Some Reflections...............................220

5. Migration and the Mexican Body: Cultural Crossings........................223

5.1 Mexican Identity and Cultural Resiliency in the Modern World................227

5.2 Secret Histories of Gender: Migration and Machismo.........................233

5.3 Carving A "Third Space": Alternate Models of Community and Diaspora

Formation.

5.4 "Excluding Agricultural Workers from a Protective Regime Contributes

Substantially to the Violation of Protected Freedoms": Migrants vs. the Law....243

5.5 Reconciling Human Rights Discourses with Migrant Realities...............252

5.6 The Elephant in the Room: Media Performances and Farm Workers...........256

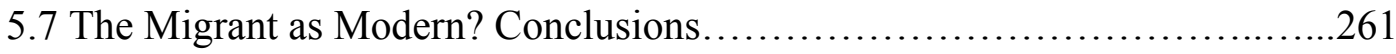

"How it Found its Way to Our Table": Conclusions............................264

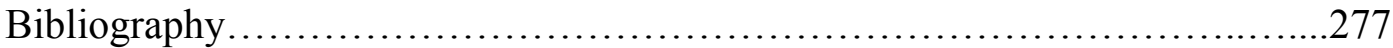

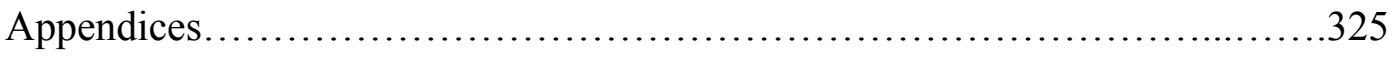




\section{List of Illustrations}

Fig. 1 “Migrant Farm Workers Need Public Health Care............................................11

Fig. 2 Inhabitants of Salt Spring Island, Spring 1940...............................................56

Fig. 3 A Young Woman on a Ladder Picking Apples from the Top Branches of a Local

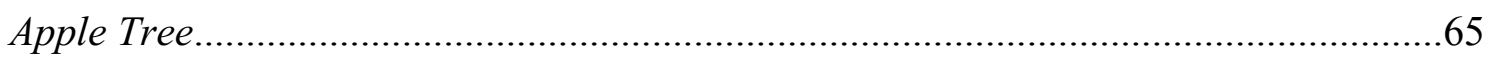

Fig. 4 Adult and Children Workers, 1968...........................................145

Fig. 5 A Bracero Lies on a Stretcher and Receives Medical Treatment.........................150

Fig. 6 An Official Examines a Bracero's Hands for Calluses...............................151

Fig. 7 Dolores Huerta, at Podium, Speaks During an Unidentified Meeting...............157

Fig. 8 United Farm Workers Officials, 1976 ........................................158

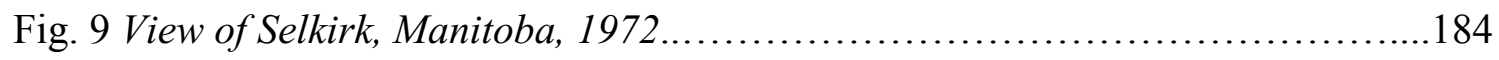

Fig. 10 Greenhouse Landscapes: Canada and Mexico.................................................186

Fig. 11 Window Display, Agricultural Workers Alliance Portage la Prairie................. 194

Fig. 12 Mexican Migrant Worker Housing, Kelowna...............................203

Fig. 13 The Zucca Melon Harvest in Oliver..................................................................209

Fig. 14 Mexican Migrant Worker Housing, Oliver ................................213

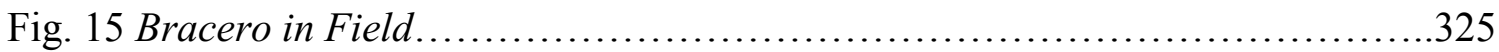

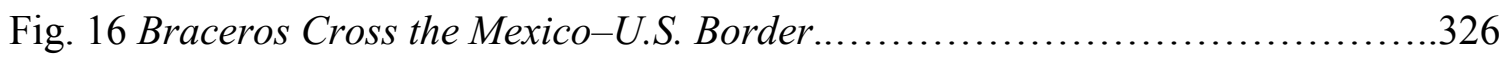

Fig. 17 Braceros Pick Lettuce and Fill it into Toro Lettuce Boxes.....................327

Fig. 18 Portrait of a Bracero Standing in a Californian Field......................................328

Fig. 19 Braceros Pick Strawberries and Fill them into Boxes.....................................329

Fig. 20 Braceros Sit in Beds in a Living Quarter of a Californian Camp.................330

Fig. 21 Two Braceros Lean Each on a Living Quarter in a Bracero Camp..............331

Fig. 22 Two Men Cooking in a Kitchen of Migrant Camp, 1944........................332 


\section{List of Appendices}

Appendix 1: Bracero Era Photographs....................................325

Appendix 2: Log of Oral Histories........................................333

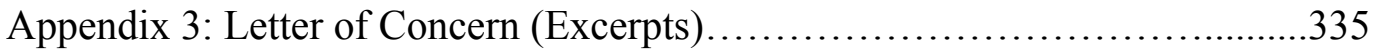

Appendix 4: Oral Consent Form..........................................337

Appendix 5: Interview Questionnaire.....................................338

Appendix 6: Table of Interviews with Location of Employment, Region/Town

Of Origin and Occupational Background..................................339

Appendix 7: Glossary of Spanish Terms.......................................341 


\begin{tabular}{|c|c|}
\hline & Abbreviations \\
\hline AFL-CIO & $\begin{array}{l}\text { American Federation of Labour / Congress of Industrial } \\
\text { Organizations }\end{array}$ \\
\hline ALRA & Agricultural Labor Relations Act (California) \\
\hline AWA/ATA & $\begin{array}{l}\text { Agricultural Workers Alliance / l'Alliance des } \\
\text { Travailleurs Agricoles (Canada) }\end{array}$ \\
\hline AWOC & Agricultural Workers Organizing Committee (AFL-CIO) \\
\hline BWITALP & $\begin{array}{l}\text { British West Indies Temporary Alien Labor Program } \\
\text { (1943-1977, US) }\end{array}$ \\
\hline CFA & Committee on Freedom of Association of the ILO \\
\hline $\mathrm{CNC}$ & Confederación Nacional Campesina (México) \\
\hline $\mathrm{H}-2 \mathrm{~A}$ & Temporary Agricultural Labor Classification (US) \\
\hline $\mathrm{H}-2 \mathrm{~B}$ & Temporary non-Agricultural Labor Classification (US) \\
\hline ILO & International Labour Organization \\
\hline INS & Immigration and Naturalization Service (US) \\
\hline IOM & International Organization for Migration \\
\hline IRCA & Immigration Control and Reform Act (US, 1986) \\
\hline FARMS & Foreign Agricultural Resource Management Services \\
\hline FERME & $\begin{array}{l}\text { Fondacion des Entreprises en Recrutement de Main- } \\
\text { dòuve Agricole Étrangerè }\end{array}$ \\
\hline LAC & Library and Archives Canada (Ottawa) \\
\hline MOU & Memorandum of Understanding, (Canada-Mexico, 1974) \\
\hline MSPA & Migrant and Seasonal Agricultural Worker Protection Act \\
\hline MWSN & Migrant Worker Solidarity Network \\
\hline NACFL & National Advisory Committee on Farm Labor (US) \\
\hline NFWA & National Farmworkers Association (US) \\
\hline NGO & Non-Governmental Organization \\
\hline PCUN & $\begin{array}{l}\text { Pineros y Campesinos Unidos del Noroeste / } \\
\text { Northwest Treeplanters and Farmworkers United (US) }\end{array}$ \\
\hline PLM & Partido Liberal Mexicano (México/US) \\
\hline PRI & Institutional Party of the Revolution (Mexico) \\
\hline PSWPS & Pacific Seasonal Worker Pilot Scheme (Australia) \\
\hline RSE & Recognized Seasonal Employer Scheme (New Zealand) \\
\hline SAWP & Seasonal Agricultural Worker Program \\
\hline STPS & Secretería del Trabajo y Prevision Social (México) \\
\hline UFW & United Farm Workers of America (US) \\
\hline UFCW & United Food and Commercial Workers Union (Canada) \\
\hline WVIP & Willamette Valley Immigration Project (Oregon) \\
\hline
\end{tabular}




\section{Introduction: Unearthing Harvest Histories}

"Behind every fruit and vegetable for sale in the supermarket lies an unknown world of toil and skill.,"1

"I was harvesting squash in the field near my village one day, when my patrón came and said, 'Irena, you should go to Canada. There's now a program there for women.' And I said, 'How can I go to Canada, if I haven't even been to Mexico City?”2

This study takes as its general time frame the period 1974 to the present through which to explore the arrival of Mexican farm labour to Canada, and considers changes wrought by earlier decades for the formation of agricultural labour policies in Canada. While my field research was carried out in Manitoba and British Columbia (and additionally, to an extent, in Quebec), many of the participants in this study had prior encounters of agricultural work in other provinces, or former experience as migrant workers in the United States. For this and other reasons, I depart, when necessary, from the central scope of my study, which focuses primarily on the period 1974 to the present in chronology and on the experiences of Mexican farm workers in two provinces in geographic focus, to consider how patterns in agricultural labour hiring have fed into and shaped the period I explore. In British Columbia, seasonal workers from Mexico did not arrive to work through temporary contracts until 2004. I mine field findings in Canada and focus on the historical emergence of the Seasonal Agricultural Worker's Program

\footnotetext{
${ }^{1}$ Frank Bardacke, Trampling out the Vintage: César Chávez and the Two Souls of the United Farm Workers (London: Verso, 2011), 30.

${ }^{2}$ Deborah Barndt, Tangled Routes: Women on the Tomato Trail (Boulder, CO: Rowman \& Littlefield, 2001), 192.
} 
on a hemispheric scale, and shaped, as I suggest, by critical and formative patterns in historical emeregence of farm labour climates of Mexico and the United States over the course of the twentieth century. The dissertation highlights a number of key themes, including citizenship, "race," ethnicity and national orientation, human rights, and gender, as these categories were defined in Canadian immigration and migration policies and statecraft, and as they took shape in varying regional contexts.

Specifically, my study draws on a history of Mexican migration as it operated in a North American context, taking the late nineteenth century as a point of departure for locating Mexican emigration for farm work and other jobs across the border. This encompassed industrial labour migration for work on railroads and mines, and later on, migration to cities and suburbs for engagement in gardening and work in the service and hospitality industries. The study looks to the national and international levels of analysis, as a means to place the history of Mexican farm labour migration to Canada in a broader context. The role played by "migration management" in a Canadian context was, as this work will demonstrate, significant in terms of the way Canada sought to frame and structure its guest work programs without "disturbing the "national order of things,"” an idea introduced by migration scholars Martin Geiger and Antoine Pécoud. ${ }^{3}$

Despite this, labour management practices, by virtue of their attempt to render cross-border mobility into a relatively smooth and simple process, often risk disturbing the natural order of things when it comes to the interests of those involved. A central research question of this work is rooted in an effort to better define how migrant

${ }^{3}$ Martin Geiger and Antoine Pécoud eds., Disciplining the Transnational Mobility of People (Basingstoke et. al.: Palgrave Macmillan, 2013), 2. In this work, Martin Geiger introduces the category of "disciplining" into the lexicon of international migration management studies, offering an archeology of state governance over migration flows. See “The Transformation of Migration Politics: From Migration Control to Disciplining Mobility,” 15-40. 
trajectories or life stories, often characterized by increased cosmopolitanism, opportunities for wage earning, and transnationalism, were also shaped by political restrictions, labour management practices, and limited modes of entry. It seeks to discover how migrant destinies were set to a significant extent by the agency of individuals but also made manifest within the strictures of state-managed migration schemes. Such schemes also have their own fragmented history that I seek to chart out here. Shaped by shifting trends in Canadian immigration policy, and climates of farm labour scarcity, the social history of farm work in Canada has undergone a number of distinctive shifts since the end of the nineteenth century. ${ }^{4}$ In many ways, as evident in the chosen title of this work, the study is an effort to write a social history of Mexican farmworker migration to Canada with an eye to its historical antecedents. In short, the primary purpose of this study is to distill an improved understanding of the ways in which Mexican migrant farmworkers have contributed to modern Canadian agricultural success.

Influenced in part by the transnational turn and post-structuralist (and "postnational") emphases and efforts to decode historiography penned from the point of view of the nation, this work focuses on shifting experiments in farm labour management in the Canadian twentieth century to discern a clearer picture of how farm labour schemes have evolved. As Eric Wolf suggests, "nation," "society" and "culture" are abstracted and better understood as "bundles of relationships" even though they are often viewed as "abstract and bounded entities." Canada's "Offshore Program" began in 1966 in

${ }^{4}$ See Donald Avery, Dangerous Foreigners: European Immigrant Workers and Labour Radicalism in Canada, 1896-1932 (Toronto: McClelland and Stewart, 1979) and Avery, Reluctant Host: Canada's Response to Immigrant Workers, 1896-1994 (Toronto: McClelland and Stewart, 1995).

${ }^{5}$ Cited in Tony Ballantyne, Orientalism and Race: Aryanism in the British Empire (Basingstoke: Palgrave UK, 2002), 1. On a "post-national world" as shaped by migration, see also Katherine Tonkiss, Migration and Identity in a PostNational World (Houndmills, Basingstoke, Hampshire; New York, NY: Palgrave Macmillan, 2013). 
Southwestern Ontario. I take 1974 as a starting point for centering this study since the management of Mexican farmworker arrivals to Canada did not occur officially until that year. In Mexico, the Ministry of Labour and Social Planning, or la Secretaría del Trabajo y Previsión Social (STPS) became the ministry responsible for managing and recruiting migrant farm workers travelling to Canada. The Fondacion des Entreprises en Recrutement de Main-dòure Agricole Étrangerè (FERME) manages seasonal agricultural migration in Quebec, while in B.C., labour management was delegated to the Mexican Consulate. I break down the history of the SAWP in Canada to a spectrum of social and political levels, seeing numerous actors, including employers, migrants, consular officials, union workers, politicians and bureacrats, media makers, and migrants' families as all playing critical shaping and driving roles. Economic preferences and interests of employers often influenced migrants' lives; employers had the power to deeply shape migrants' lives, especially in the quotidian sense of everyday experiences, the nature of intimate relationships formed on farms, the quality and standards of worker housing, and other interrelated issues connected with worker mobility between farm sites and towns or nearby cities.

While Canadian communities and rural town dwellers played a somewhat less important role in shaping migrant histories, migrant advocacy groups, existing Latin American communities, and local communities would still inflect these pasts. Canada's Seasonal Agricultural Workers Program has let migrants cross national boundaries and imprint a temporary presence on rural and small-town landscapes. In light of the rurality associated with the subject matter considered, this study operates in dialogue with a "rural turn" in Canadian historiography that explores the evolution of ethnic diversity 
and rural landownership, and with a literature on seasonal economies shaped in part by the work of Paige Raibmon. While the term "seasonal worker" risks serving as a euphemism it is also common currency in official and academic discourses. In a globalized world where natural ecologies and the rhythm of the seasons are increasingly disrupted by global trade flows in both goods and people, the term seasonal may require further modification. Despite this, from a historiographical point of view, many borderlands historians and historians of the American West turn to the term "seasonal economies" to denote the ways in which Amerindians' relationships with the land underwent change as settler colonization underwent expansion, and while I use "seasonal" often in this study to describe labour programs as well as workers or individuals, the term should nevertheless not be taken at face value.

The American literature on Mexican migration is predominant, and in this tendency, there are obstacles and opportunities for Canadian approaches to engaging with a Mexican migrant presence in our past. A cultural historiography of migration, that explores leisure, gender, and consumption, as seen in the scholarship of José Alamillo, Lionel Cantú and others, informs my approach, especially in my turn towards culture in Chapter Five. In reading seasonal farm work through a contemporary historical lens, I also give attention to its historical antecedents. More deeply rooted histories of homesteading, settlement, family farming and land ownership form a foundation for contemporary developments while state management practices also have their own historical narrative and dialogue that this study highlights through findings from archived documents and discourses.

Migration has thus operated on numerous historical levels. To help draw 
bridges between my own oral history findings and the associated interdisciplinary scholarship on labour and migration, I mine agricultural, economic and social data gathered by the state, make use of a wide range of secondary approaches, and read the journalistic record on Canadian migrant farm labour with a critical eye. A small collection of scholarly monographs have dealt directly with the topic of SAWP and this scholarship is growing, including work from Tanya Basok, Vic Satzsewich, and Leigh Binford, in addition to a number of relevant monographs on seasonal migrant work dealing with the United States, from David Griffith, Cindy Hahamovitch and others. ${ }^{6}$ Recent work by Christina Gabriel and Laura Macdonald on the role of what they term "civil society advocacy" in the realm of migrants' rights in Canada helps complicate the story more recently as it has related to the entrance of Canadian unions into migrant farmworker politics, legal collisions and the performance of migrant advocacy work in Canada, as has the work of Michelle Lowry and Peter Nyers. ${ }^{7}$ This study also works in conversation with dissertation literature on seasonality and labour and Mexican economic history. My understanding of Mexican migrant problems as ones that fundamentally

\footnotetext{
${ }^{6}$ For Canadian SAWP-related monographs see Tanya Basok, Tortillas and Tomatoes: Transmigrant Mexican Harvesters in Canada (Montreal and Kingston: McGill-Queens University Press, 2002); Vic Satzewich, Racism and the Incorporation of Foreign Labour: Farm Labour Migration to Canada since 1945 (London; New York: Routledge, 1991); and Leigh Binford, Tomorrow We're All Going to the Harvest: Temporary Foreign Worker Programs and Neoliberal Political Economy (Austin: University of Texas, 2013). See also David Griffith, American Guestworkers: Jamaicans and Mexicans in the U.S. Labor Market (University Park: Pennsylvania State University Press, 2006) and Cindy Hahamovitch, No Man's Land: Jamaican Guestworkers in America and the Global History of Deportable Labor (Princeton: Princeton University Press, 2011).

${ }^{7}$ See Laura Macdonald and Christina Gabriel, "Domestic Transnationalism: Legal Advocacy for Mexican Migrant Workers' Rights in Canada," Citizenship Studies 18:3-4 (June 2014): 243-58 and "Citizenship at the Margins: The Canadian Seasonal Agricultural Worker Program and Civil Society Advocacy," Politics and Policy 39:1 (2011): 45-67. On global migrants' rights movements see Michelle Lowry and Peter Nyers, eds., "Introduction: Global Movements for Refugee and Migrant Rights," pp. 2-4 in Lowry and Nyers, eds., Special issue of Refuge: Canada's Periodical on Refugees 21:3 (May 2003). Lowry and Nyers raise the agency-victimhood debate as it relates to refugees and migrants and their global advocates.

${ }^{8}$ See for example, Maria Louise DiGiano, "Privatizing the Commons? A Political Ecology of Mexico's 1992 Agrarian Reform in Quintana Roo, Yucatan Peninsula," (PhD Thesis, University of Florida, 2011), and
} 
transcend borders would alter my research trajectory as the project progressed. ${ }^{9}$ In situating seasonal workers' histories within broader structures of Canadian history, Mexico-centered viewpoints are given privilege in a context of a Canadian historical foundation of agricultural development that made foreign migration possible. My oral history methodology and influences are discussed in more detail in Chapter Four.

Canada's growing non-citizen workforce has been comprised of farm and food processing workers but also workers in other sectors, and for this reason, essentializing the Mexican or Latino migrant as the sole participant in the "factories in the fields," even in a Canadian context, risks simplifying a larger story. ${ }^{10}$ I intervene in and complicate the existing body of literature by taking an historical vantage point toward Mexican migration to Canada, using field findings to enliven current understandings and debates over "offshore" encounters and exchanges. I also draw inspiration from revisionist historical approaches to farm labour, discussed in more detail in Chapter Three, that seek to re-inscribe agency into a historiographical narrative often propelled for the most part by narratives of exploitation and victimhood.

Jenna Hennebry, "Globalization and the Mexican-Canadian Seasonal Agricultural Worker Progam: Power, Racialization and Transnationalism in Temporary Migration," (PhD, Sociology, University of Western Ontario, 2006). For a dissertation study of the SAWP with a focus on law see Robert Marc Russo, "Solidarity Forever, Canadians Never: SAWP Workers in Canada” PhD Thesis (Law), UBC, 2012 and Russo's short article on legal conflict relating to SAWP workers in British Columbia, "Temporarily Unchained: The Drive Unionize Foreign Seasonal Agricultural Workers in Canada-A Comment on Greenway Farms and UFCW,” BC Studies 169 (Spring 2011): 131-41. Dissertations informing this study include work from Shelley Ketchell on "incarceration" in Japanese-Canadian farm work, Kimberly Knowles on Caribbean processing workers, Theresa Healy on Mexican autoworkers, Katie Hinnencamp on the Niagara Peninsula, and Lloyd Wong on racism in the Okanagan Valley.

${ }^{9}$ See Deborah Barndt, Tangled Routes. On migratory farm labor's "translocal" manifestations in the context of the emergence of Chicano political activism across states, see Marc Simon Rodriguez, The Tejano Diaspora: Mexican Americanism and Ethnic Politics in Texas and Wisconsin (Chapel Hill: University of North Carolina Press, 2011). Vicki Ruiz points to the Latino/a term as denoting "nativity or long-term residence in the United States." See Vicki L. Ruiz, "Class Acts: Latina Feminist Traditions, 1900-1930," AHA Presidential Address, American Historical Review 121.1 (2016), 1.

${ }^{10}$ Kelly Lytle-Hernandez refers to agriculture in the American West as a "factory floor" that required increasing numbers of migrants for planting and harvest work. See Kelly Lytle-Hernández, Migra! A History of the U.S. Border Patrol (Berkeley and Los Angeles: University of California Press, 2010), 23. 
For Peter Li, oral history could offer a "false impression of being haphazard and unscientific"; despite this, oral history is for Li the best means to write labour history and is correlated to experiences of discrimination in Canadian history. ${ }^{11}$ Other pioneering historians of ethnic history have made use of oral accounts. Pamela Sugiman's oral accounts offer a revisionist cultural approach to the internment years as remembered through the eyes of participant-victims, while Valerie Matsumoto's approach to farm life, land ownership, and agrarian community development among Japanese-Americans in Cortez, California used memories and oral accounts as devices through which to become better acquainted with cultural and social history. ${ }^{12}$

The numbers of Mexican participants implicated in the Canadian Seasonal Agricultural Workers Program (SAWP) between 1974 and 2011 totaled an estimated 225,000, not including Caribbean sending-state workers, with 16,500 workers drawn from Mexico in 2011. ${ }^{13}$ Meanwhile, the world migrant worker count in 2010 comprised an estimated half of the total number of international migrants. ${ }^{14}$ Canadian media often depicted the rise in temporary foreign workers in a critical light, as one Globe and Mail article made comment: "Whereas permanent immigrants are a net gain, temporary ones do nothing for our development and often harm their lives." 15 If one is to agree with this logic one must also address the reasons why temporary migrants have continued to come to Canada to work and why the Canadian state rendered such openings available.

\footnotetext{
${ }^{11}$ Peter S. Li, “Constructing Immigrants' Work Worlds from Oral Testimonies" in Work, Ethnicity and Oral History, Edited by Dorothy E. Moore and James H. Morrison (International Education Centre, 1988), 149.

12 See Pamela Sugiman, “Life is Sweet': Vulnerability and Composure in the Wartime Narratives of Japanese Canadians," Journal of Canadian Studies 43.1 (2009): 186-218 and Valerie Matsumoto, Farming the Home Place: A Japanese American Community in California, 1919-1982 (Ithaca: Cornell University Press, 1993).

${ }^{13}$ Government of Mexico Chamber of Deputies / Cámara de Diputados, "Response to Point Resolution," Parliamentary Gazette, year XV, number 3542, Wednesday, June 27, 2012.

${ }^{14}$ Kristin Surak, “Guest Workers: A Taxonomy,” New Left Review 84, November-December 2013, 85.

${ }^{15}$ Doug Sanders, "Foreign Workers Won't Be Temporary if we Make them Permanent," The Globe and Mail, April 26, 2014.
} 
In the context of "modern" conflicts, then, newer, heuristic terms are

required for the narration of contemporary migrant histories. While this study will occasionally engage with the term "modern" to analyze recent trends surrounding migrant work, it is used only in those contexts when no other term might intervene to improve a depiction of an event or phenomenon connected with migrants' worlds or lives. Arcury and Quandt define social justice for farmworkers as a set of working and living environments wherein "health and safety hazards are addressed," a "living wage" is secured, freedoms from discrimination are achieved, and access to educational, health and social service resources are made available (See Fig. 1). ${ }^{16}$ This ideal picture of a world in which social justice is achievable for farm workers is theoretically attainable but would require consistent commitment of states and employers alike. In Canada, migrant outreach groups working in solidarity with guest workers have also included unions, NGOs and activist groups operating in tandem with a growing migrant presence. Canadian church workers have also played a prominent role in their efforts to improve migrant worlds, performing spiritual outreach work in small town centres and rural outposts, especially in "hot-spots" where a migrant presence was more saturated, and in this way, church workers became implicated in migrants' worlds in new ways. In Chapter Three, Mexican migration history is considered to unearth how migration schemes shaped (or failed to shape) Mexican emigration for agriculture. ${ }^{17}$

\footnotetext{
${ }^{16}$ Thomas Arcury and Sara Quandt, eds., Latino Farmworkers in Eastern United States: Health, Safety and Justice (New York; London: Spring, 2009), 2. In my field research I found church involvement with farmworkers in both Lake Country, British Columbia and in south-western Manitoba. In Winfield, one church was found to provide Spanish-language services for Catholic Mexican farm workers. On daily struggles and Mexican migrants see Patricia Zavella, I'm Neither Here nor There: Mexicans' Quotidian Struggles with Migration and Poverty (Durham: Duke University Press, 2011). On the ethics of migration see also Joseph Carens, "Live-In Domestics, Seasonal Workers, and Others Hard to Locate on the Map of Democracy," Journal of Political Philosophy 16 (4) (2008): 419-45.

${ }^{17}$ On family dynamics and bracero migrations, see Ana Elizabeth Rosas, Abrazando el Espíritu: Bracero Families Confront the U.S.-Mexico Border (Berkeley and Los Angeles: University of California Press, 2014).
} 
In this respect, the dissertation also considers deviations from the "fold" of managed labour to chart how informal migration routes characteristic to twentieth-century America would disrupt earlier "managed" migration patterns and corridors. ${ }^{18}$

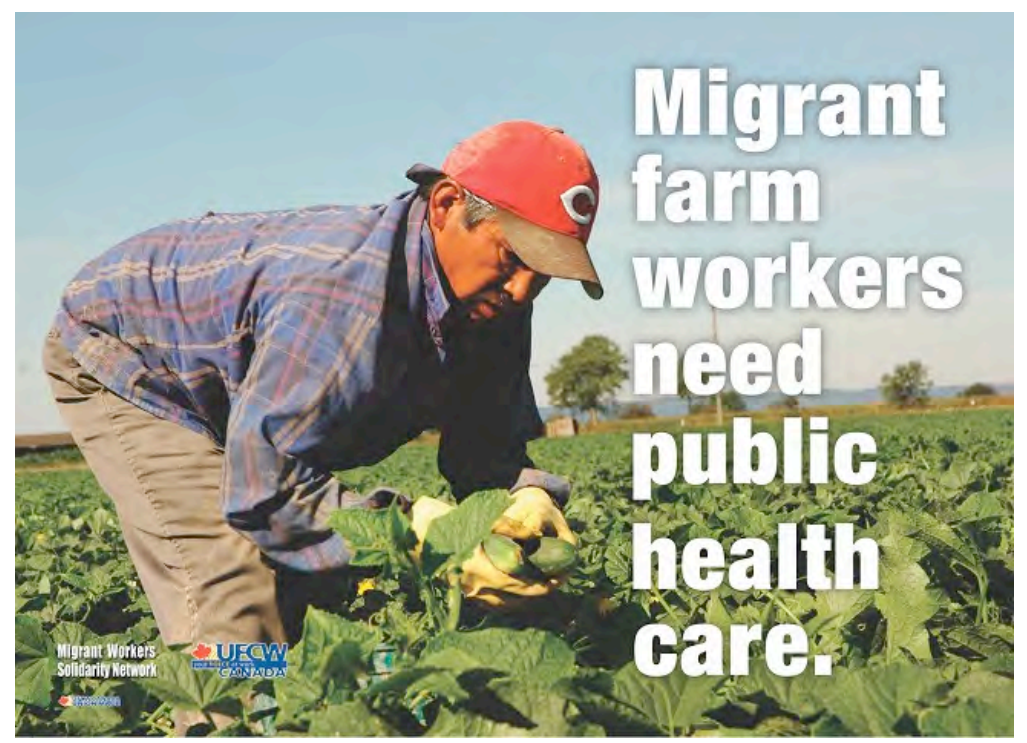

Fig. 1 "Migrant Farm Workers Need Public Health Care."

(Postcard, Migrant Workers Solidarity Network / UFCW Canada)

Note the forceful wording used by the creators of this postcard, in their effort to promote migrant advocacy and send a message across.

In locating geography and poverty as primary drivers of migrant markets and behaviors, I suggest that studying the interconnected worlds of labour in Mexico, the U.S. and Canada in the twentieth and twenty-first centuries may enhance the central focus of this study in ways that can fruitfully complicate existing academic narratives of the SAWP.

A central aim of my research deals with how a historical arc of migration and

\footnotetext{
18 On the historical emergence of Mexican South Chicago, see for example, Michael Innis-Jiménez, Steel Barrio: The Great Mexican Migration to South Chicago, 1915-1940 (New York: New York University Press, 2013).
} 
transnational culture came to operate in a hemispheric context of newly formed migration avenues. The work of David Gutiérrez turns to geography and space to pinpoint how Mexicans in the Southwest carved out a "third space" that became embedded in rural and urban niches as a survival mechanism and means to enable existing transnational culture to flourish vis-à-vis American society and culture at large. ${ }^{19}$ I revisit this concept in Chapter Five. In Canada, seasonal agricultural workers often sit in a grey zone or contested terrain (especially from political and legal vantage points) that evades easy classification in mainstream definitions and understandings of the nation. The extent to which the Canadian national imaginary has stretched to accommodate migrant workers into the national body politic proved unhinged at best and conflictual at worst, relegating the migrant farm worker to an object of disinterest, neglect, spite or political abandon, or a concern for the care and attention of special-interest groups alone. In placing more marginal histories and alternate cultural narratives upon a focused plane, my work intervenes in an existing Canadian historiography of farm labour still sometimes preoccupied with the immigrant experience. Scholarship on Latino communities often deals with cultural questions, yet in Canada the literature has not yet adopted such a focus; most Canadian works adopt economistic or race-based approaches to Mexican labour. ${ }^{20}$ My last chapter adds this angle of vision, treating culture as a defining element of this social history.

\footnotetext{
${ }^{19}$ Ibid., 10. For a series of studies on Mexican identity and Latino history in the United States, see David Gutiérrez, ed., Walls and Mirrors: Mexican Americans, Mexican Immigrants, and the Politics of Ethnicity (Berkeley and London: University of California Press, 1995) and David Gutierrez, Between Two Worlds: Mexican Immigrants in the United States (Wilmington, Del: Scholarly Resources, 1996). Walls and Mirrors details the emergence of Mexican American society and its partial undoing in the 1930s.

${ }^{20}$ See, for e.g. Sean Mills, A Place in the Sun: Haiti, Haitians, and the Remaking of Quebec (Montreal and
} 
The evolving literature to date on the SAWP in Canada has often pointed to injustices and the labour circulation inflexibility associated with the program; SAWP workers experienced "unfreedoms," a term coined by Tanya Basok to denote how the program came to operate. More recently, efforts have been made to lobby the Justin Trudeau government to forge pathways towards citizenship for migrant farmworkers. ${ }^{21}$ Another central research question of this study is to discover whether or not the SAWP has functioned as a model or as one ridden with contradictions. While Canadian history was not shaped by slavery in the American sense, it was difficult for colonial French Canada to evade the phenomenon of Indian slavery, which was made legal in New France in $1709 .{ }^{22}$ While such underemphasized aspects of Canadian history are rarely celebrated in the form of public history, domestic slavery was built into the social fabric and past of French Canada for much of the eighteenth century. Canada would go on to diverge in many respects from the style of plantation agriculture that predominated in the Chesapeke and American South, but it would rely on a continual supply of European immigrants to develop and cultivate the land for the production of food, "productivity" being a key word in its divergence from former patterns of subsistence, including foraging, hunting, and fishing that were the mainstay of Canada's pre-colonial and early modern past.

\footnotetext{
Kingston: Mcgill-Queens University Press, 2016); Elinor Barr, Swedes in Canada: Invisible Immigrants (Toronto: University of Toronto Press, 2015); Franca Iacovetta, Such Hardworking People: Italian Immigrants in Postwar Toronto (Montreal and Kingston: McGill-Queens University Press, 1993); and Bruce Elliot, Irish Migrants in the Canadas: A New Approach (Montreal and Kingston: McGill-Queens University Press, 2004). Similarly, in the U.S. literature, ethnic histories that adopt regional focuses are common. See for example Lori Flores, Grounds for Dreaming: Mexican Americans, Mexican Immigrants and the California Farmworker Movement (New Haven: Yale University Press, 2016).

${ }^{21}$ See, for instance, Alyse Kotyk, "Migrant Farmworkers Call on Trudeau for Permanent Residency," Rabble, January 28, 2016.
} 
The arrival of farmworkers through non-legal corridors did not shape the Canadian agricultural past in the way that it did America, where, more recently, one farmer opted to "outsource" and "offshore" his farm operations entirely to Mexico rather than rely on a continually unstable migrant workforce and a perpetual shortage of workers. $^{23}$ Despite a climate of legality in Canadian farm labour recruitment, agricultural workers, Canadian and otherwise, often were the exception in labour rights and standards. In postwar British Columbia, farmworkers consistently encountered limited advances in labour legislation. Moreover, in the province, farm labour was a category of work carried out "almost exclusively by ethnic minorities." ${ }^{24}$ A 1983 Human Rights Commission recorded the observation of one farmworker spokesperson, Raj Chouan: "We work in the fields, reaping the two harvests, the sweet harvest that is found on your tables, and the bitter harvest that is our daily life..."25 Chouan more recently spoke at a Vancouver protest against Mexico's blacklisting of migrants seeking to join unions in Canada. ${ }^{26}$ Migrant groups in British Columbia have, since the early twentieth century, played a central role in agricultural cultivation, were often victimized by discrimination and sometimes excluded from agricultural landownership.

In addition to the archive, both small and large, I look to media accounts, old and new, for evidence of the ways in which popular opinion and public dialogues inflected

\footnotetext{
${ }^{22}$ Brett Rushforth, "A Little Flesh We Offer You": The Origins of Indian Slavery in New France," The William and Mary Quarterly, Third Series, 60.4 (October 2003): 777-808. Slavery existed in colonial Canada to a limited extent in domestic service in French colonial households, with the first slave brought to Quebec in 1629. French Canada hosted over 4,000 slaves from the late seventeenth century through the early nineteenth century. See Kenneth Donovan, "Slaves and their Owners in Ile Royale, 1713-1760," Acadiensis XXV, 1 (Autumn 1995): 5. On the slaving world of the Comanches, including slave raids into Northern and central Mexico, see Pekka Hämäläinen, "Children of the Sun," (Ch. 6), pp. 239-91 in The Comanche Empire (New Haven and London: Yale University Press, 2008) and on northern New Spain see Ned Blackhawk, Violence over the Land: Indians and Empires in the Early American West (Cambridge, MA: Harvard University Press, 2006).

23 Julia Preston, "Short on Labor, Farmers in U.S. Shift to Mexico," The New York Times, September 5, 2007.

${ }^{24}$ Eleanor Wachtel; Human Rights Commission of British Columbia, What this Country Did to Us, it Did To Itself: A Report of the B.C. Human Rights Commission on Farmworkers \& Domestic Workers (Victoria: Human Rights Commission of British Columbia, February 1983), 4.
} 
Canadian understandings and framings of farm work. Mexican media was quick to critique the conditions faced by farmworkers in Canada, as one Informador article pointed out: "Hay tamaños establecidos que no se respetan, desde si tienen baño o no; o si en espacios para cuatro igual meten a seis / There are established rights that are not respected, if you have a bathroom or not; or if in a space for four they put six."27 Conversely, early and formative media accounts from Manitoba suggested that labour linkages between Mexico and Manitoba often bettered material conditions of families at home. Notwithstanding rosier depictions, Canadian accounts of agricultural guest work often highlight a theme of "bitter harvest." In Mexican media, truths were revealed in alternate journalistic contexts framed by alternate interests. Similarly, during the Bracero years, popular print culture in Mexico warned Mexican men of the travails awaiting them on American farms, and preceding the United Farm Workers era, printed cartoons in Chavez's newspaper, El Macriado, were infused with satire.

\section{National or Post-national History? A Note on Sources and the Scope of the Work}

As the internet revolution has increasingly made activist resources available at the click of a button, a digital "archive" of modern knowledge concerning migrant worker experiences, as framed by migrant worker advocates and workers themselves, is now more readily accessible than ever before. While this work highlights two provincial case studies for the purposes of developing a body of field research, it also widens its scope to a national scale. Since Ontario and Quebec have taken in the largest numbers of SAWP workers, developments taking place in both provinces are addressed, with specific emphasis placed upon those transformations that took place in Ontario's 
agricultural workforce in the 1960s when Canada was first beginning to articulate and implement its "offshore" policy and program for agriculture. In Quebec, the more recent hiring of Guatemalan farmworkers has provoked much controversy both in terms of the ways in which migrants have been "managed" as well as the ways they have formed a new, highly vulnerable and precarious trans-national agricultural working class. My work also intentionally adopts a hemispheric vantage point with an eye to the international ramifications of contemporary labour migration flows in farm work from South to North. Not the first study of Mexican labour to adopt a chronologically wide approach to the topic to distill an informed historical interpretation, Mize and Swords' Consuming Mexican Labor: From the Bracero Program to NAFTA, adopts as its timeline the period 1942-2009 as a window to locate transitions in the "consumption" of Mexican labour power beyond the Mexican border. While my chronological scope is framed as a study that begins in 1974, in fact my study also locates and explores prior developments in agricultural labour history that had profound ramifications for twentieth- and twenty-first century industrial farm labour climates in both Canada and North America.

Taken into a twenty-first century context, Harald Bauder describes migrants as playing increasingly integral role in the workings of national economies: Migrants...will provide labour power and skills that make economies globally

\footnotetext{
${ }^{25}$ Ibid., 17. In the case of the SAWP, circular migration to Canada often proved beneficial for participants, allowing many returning workers to develop bonds on farms. Return workers often gained an enhanced status as preferred workers, named back to the same farm the following year, this process offering a sort of social glue that could help mitigate the psychological or emotional difficulties encountered in temporary migration schemes involving travel to unfamiliar locations.

${ }^{26}$ See UFCW Canada, "Vancouver protest on International Migrants Day,” December 19, 2011.

${ }^{27}$ Insitituto de los Mexicanos en el Exterior, "Advierten." 
competitive...At the same time, migrants will continue to generate political tensions, suffer from labour exploitation, and be excluded from equal opportunities, and be seen as a threat to society. ${ }^{28}$

Tensions such as these have come to perforate contemporary scholarly as well as journalistic framings of the Canadian SAWP, while in other cases, as with the Bracero Program questions of intercultural (or domestic versus "foreign") labour competition and economic questions often came to the fore. While international migration has accelerated, the nature of contemporary migration has also changed, now shaped more directly by temporary and precarious labour migrants, as host nations have cast a wider net of flexibility (concurrent with exclusivity), as arbiters of policies to allow crossborder mobility for work oriented closely around economic imperatives and needs. Evidence indicating that temporary arrivals have begun to exceed permanent migrants to Canada as of 2006 has confirmed this trend. ${ }^{29}$

In a Canadian historical landscape of agrarian development, modernity and change, foreign guest worker arrivals became natural extensions of historical processes common in the Canadian twentieth century that involved a flexibility of boundaries around the nation's abiding "open door" toward immigrants and temporary workers, as had occurred with the taking in of non-traditional migrants from Central and Southern Europe. Internal developments in labour management reshaped rural labour orientations in the Canadian twentieth century, as state-orchestrated migrations of First Nations

\footnotetext{
${ }^{28}$ Harald Bauder, Immigration and Settlement: Challenges, Experiences, and Opportunities (Toronto: Canadian Scholars Press, 2012), 1. See also Patricia Tomic, Ricardo Trumper, and Luis Aguilar, "The Social Cost of 'Healthy' Agriculture: The Differential Rights of Migrant Workers in the Okanagan” (Chapter 5) and Shaghayegh Yousefi, "Improving Health, Safety and Housing Conditions of Mexican Farm Workers in British Columbia: A Farmer's Perspective" (Chapter 6), in Eugenie Depatie-Pelletier and Khan Rahi, eds, Mistreatment of Temporary Foreign Workers in Canada: Overcoming Regulatory Barriers and Realities on the Ground (Montréal: Centre Métropolis du Québec-Immigration et métropoles, December 2011).

29 Ibid., 26. 
people in agriculture in the mid-1960s shaped harvest work in Ontario before the arrival of Caribbean seasonal workers. This dimension of labour management, alongside transnational migrations from the United States that served Ontario's tobacco sector in the early postwar period, form and constitute important antecedents to Canada's "offshore" scheme. While the organized migration of First Nations' labour from Northern Ontario to Southwestern Ontario for agricultural jobs preceded the onset of the Caribbean scheme, as did circular mobility from Southern U.S. states to Southwestern Ontario, in provinces like British Columbia, seasonal farm labour recruitment generally operated along local avenues. ${ }^{30}$ While intersections between class and race, as played out in Canadian rural settings, offer a key interface to consider histories of farm work in a Canadian context, other lenses, such as nationality and gender also play out in this study, which adopts a regional, then national, and ultimately, international approach.

\section{Finding A Common Ground: Field Methodologies}

As part of my study on temporary seasonal migration from Vanuatu to Central Otago, New Zealand, I interviewed Ni-Vanuatu farmworkers employed on orchards and vineyards in near the small rural towns of Roxburgh, Cromwell, and Alexandra, to shed light on the ways in which New Zealand forged its own model for temporary seasonal agricultural migration by making use of the labour resources and capabilities of its surrounding region. Contemporary labour patterns and seasonal models forged by First World nation states were reimagined and contextualized as being fundamentally hinged upon a longer and broader past with important ramifications for the history of the colonialism in the region. By 
extending such an approach to the study of seasonal labour and migration histories in North America, this study casts an equally wide thematic and historical net, one that envisions webs of connections, migration "worlds," and corridors as fundamentally constitutive of narrower definitions of migrant labour and migrant labour schemes as defined by other disciplines that take migration and labour as an object of study. The "corridor" concept is considered more closely in Chapter 3.

The goal of research is to "discover what is unknown, to question what is thought to be known, and to rediscover knowledge that has become lost," and whenever research is conducted across cultures, whether it be of an anthropological or ethnological nature or a project of oral history, the social logistics of the research practice should be considered and re-evaluated at all stages. ${ }^{31}$ This work expands on contemporary bodies of knowledge about guest work, to focus in on lived and quotidian experiences from a Mexican angle of vision. ${ }^{32}$ Discussed in more detail in Chapter Four, oral history’s challenge in working with real human participants is not only to successfully fill a void absent in the documentary record, but also ensure that its approaches and practices are of a sound, collaborative, and contributive nature. My work seeks to give better context to farm labour's development and evolution in two provinces and consider divergent "views" from Mexico that range from Latin American government proceedings and ${ }^{30}$ See Satzewich, Racism. On Native-settler divergence in ideas about and impacts upon the land in New England see William Cronon, Changes in the Land: Indians, Colonists and the Ecology of New England (New York: Hill and Wang, 2003).

${ }^{31}$ University of Otago, "Pacific Research Protocols" (University Council Approved Nov. 2011), 9. Linda TuhiwaiSmith's Decolonizing Methodologies: Research and Indigenous Peoples (London: Zed Books, 1999) has much to offer in this regard. In Oral History off the Record, Anna Sheftel and Stacey Zembrzycki collect approaches on oral history as practiced by Canadian historians with an emphasis on the nuances and challenges of the practice. See Anna Sheftel and Stacey Zembrzycki, Oral History off the Record: Toward an Ethnography of Practice (New York: Pagrave Macmillan, 2013). Both Concordia University and the University of Winnipeg have oral history centres where focused attention is given to the practice. The Oral History Association (OHA), Southwest Oral History Association (SOHA), and Canadian Oral History Association (COHA) are also devoted to the practice of oral history.

32 On transitions between social and cultural history see, for example, George Steinmetz, ed., The Politics of Method in the Human Sciences: Positivism and its Epistemological Others (Durham and London: Duke University Press, 2005). 
records to academic, especially anthropological, as well as journalistic opinions to equally highlight government officials and workers' concerns. This view from Mexico also encompasses an exploration of the historiography of migrant farm work that is touched upon in Chapter Three. Chapter Three additionally refers to approaches taken in other oral history scholarship linked to Mexican migration, most significantly, the revisionist thematic approaches to histories of farm labour organizing taken by Frank Bardacke that re-write narratives of implied victimhood, the multi-pronged urban, regional and gender-sensitive approaches to the study of Mexican and Latino migration used in the work of Judith Adler Hellman, Margaret Grey, Lionel Cantú, and others, and the trans-national and inter-generational angles used by Deborah Cohen in her oral history study of bracero lives, that often served a model for my own approach.

The span of my own research, which took place over three consecutive summers, allowed me to develop recurring ties with individual workers who, after having established a sense of friendship and recognition, were oftentimes more willing to converse and share more stories later on upon a second meeting. I discuss my field experiences in more depth in Chapter Four. While I began the field study with a structured questionnaire, I turned to a more informal approach as a better means to access a more nuanced understanding of personal pasts and opinions on the work in Canada. In doing so it allowed alternate narratives to enter into dialogue with prestructured expectations. Upon the completion of interviews, worker narratives were reinterpreted and situated within the broader context of Mexican history and in terms of political and economic frameworks and historical developments linked to "race," class, indigeneity, capitalism, and labour. 
In privileging oral history research as a tool to engage with unwritten lived history, the study draws inspiration from a literature on managed agricultural migration that includes the work of Eileen Suárez Findlay on male Puerto Rican farmworker migration to postwar United States and Deborah Cohen's field exploration of bracero lives. ${ }^{33}$ This body of literature has paid more direct attention to the ways in which government schemes impacted migrant farmworkers in American history. I also consider the Mexican seasonal presence in Canada in terms of prior migration routes and lived encounters with a larger world of migration. In seeing farmworker pasts as complex and nuanced, this work departs from many of the sociological critiques of the SAWP that underscore themes like exploitation and injustice. In underscoring worker agency, then, I seek to problematize assumptions about migrant pasts in Canada to highlight evidence that categorically disrupts master narratives, which consistently emphasize farm workers' ostensibly subaltern status.

Without a wholesale dependence on oral interviews to constitute the body of the work, oral histories are used as windows or access points from which to discern a deeper analysis. In using shared authority as a methodological starting point for the pursuit of field interviews, I seek out a reading of what Lyotard referred to as "little stories" to maintain an understanding of minority and colonized cultural groups. Oral history

${ }^{33}$ Eileen J. Suárez Findlay, We are Left without a Father Here: Masculinity, Domesticity and Migration in Postwar Puerto Rico (Durham and London: Duke University Press, 2014); and Deborah Cohen, Braceros:

Migrant Citizens and Transnational Subjects in the Postwar United States and Mexico (Chapel Hill: University of North Carolina Press, 2011).

34 See Mark Riley and David Harvey, "Oral histories, farm practice and uncovering meaning in the countryside," Social and Cultural Geography 8.3 (2007): 391.

35 Mark Riley and David Harvey, "Talking Geography: On Oral History and the Practice of Geography," Social and Cultural Geography 8.3 (2007): 345. Other key transitions in the practice have included its origins in the postwar "renaissance of memory" as a means to access people's history, the emergence of "post-positivist" emphases on subjectivity as well as memory, and developments involving a renewed interest in the role of the oral historian as "interviewer and analyst" (345-6).

${ }^{36}$ Allessandro Portelli, The Death of Luigi Trastelli and Other Stories (Albany: State University of New York Press, 1991), 56. 
approaches from Britain, in particular the pioneering work of George Ewart Evans, locate oral knowledge in the countryside as a key repository of the past, with subversive "strands" of knowledge often found in oral accounts. ${ }^{34}$ Mark Riley and David Harvey chart a transition in oral history practice from a formative period in which oral history served as a "heroic process of reclaiming 'the voice of the past," towards its status as a more politicized task, "whereby the historian plays an active role in the (re)constitution of the past, narrating histories and...literally 'writing culture.", ${ }^{, 35}$ Allesandro Portelli additionally points to "oral sources" as a "necessary (not a sufficient) condition for a history of the non-hegemonic classes." 36 (Italics mine.)

Economic contexts critically remade domestic social histories interlinked with new patterns of internal as well as trans-national mobility. A context of Mexican administrative transitions, liberalization, economic reform, and changes in the structure of democracy would have important ramifications for the organization of labour. ${ }^{37}$ In the context of a changing economic climate in Mexico, my oral history interviews pay attention to the ways in which globalization and opportunities for work outside of Mexico inflected migrants' pasts. Much international migration scholarship discusses structure, interpreting racialized (or even entrenched "imperial") boundaries as imposing constraints on the migration process, with negative impacts for workers from the Global South. ${ }^{38}$ Canada is also increasingly framed, in the view from Latin America, in an emergent role as the "other" northern destination for Mexican migrants, as evident in Flores, Pantaleón, and Gómez’s Hacia Otro Norte: Mexicanos en Canadá or, "Towards

\footnotetext{
${ }^{37}$ A.S. Dillingham, "Indigenismo Occupied: Indigenous Youth and Mexico's Democratic Opening," The Americas: A Quarterly Review of Latin American History 72.4 (October 2015): 550.

${ }^{38}$ See, for instance, Adrian A. Smith, "Troubling 'Project Canada': The Caribbean and the Making of Unfree Migrant Labour,” Canadian Journal of Latin American and Caribbean Studies 40.2 (July 2015): 274-93.
} 
another North, Mexicans in Canada" $\left(2015 .^{39}\right.$

Studies of labour and gender have proved common in the literature on globalization in Mexico, and these themes inflect the approach I take in this work. ${ }^{40}$ For historians of farm work, gender was also a significant category or lens. Valerie Matsumoto describes a mostly male Chinese farm workforce in California prior to 1882 and their exposure "vigilante violence," paving the way for Japanese arrivals. ${ }^{41}$ Other studies of masculinity in Mexican history, and among Mexican migrants in particular, have considered how manliness, sexual orientation, family life, household structures, patterns of reproduction, and masculinity's intersection with religion inflected migrant pasts. Masculinity studies that interrogate themes like bread winning or leisure among Mexican farmworkers additionally connect dots between space and gender in small town rural landscapes and settings. ${ }^{42}$

Still other historical studies of Mexican social formations connect themes encompassing borders and the generation of new social climates and legal spaces. Omar Valerio-Jiménez re-evaluates the nineteenth century Southern border region as a transformed social, political, and cultural space as legal systems to the North and South of the Rio Grande diverged. ${ }^{43}$ Borderlands historians have also begun to tune into the ${ }^{39}$ See Sara Maria Lara Flores, Jorge Pantaleón, and Martha J. Sánchez Gómez, eds., Hacia Otro Norte: Mexicanos en
Canadá (Buenos Aires: Consejo Latinoamericano de Ciencias Sociales, 2015).
${ }^{40}$ See Teresa Healy (Canadian Labour Congress), Gendered Struggles against Globalization in Mexico
(Aldershot, U.K.: Ashgate Publishing Ltd., 2008) and Deep Integration in North America: Security and
Prosperity for Whom? (Ottawa: Canadian Labour Congress / Congrès du travail du Canada, 2007).
${ }^{41}$ Matsumoto, Farming the Home Place, 20-1. Near the same time in New Zealand, where Chinese worked as miners in
the Otago goldfields, a restrictive bill would ultimately come to define discrimination against an 'Asiatic' influx in 1896.
See Tony Ballantyne, Orientalism and Race: Aryanism in the British Empire (Houndmills et. al.: Palgrave Macmillan,
${ }^{2002), 80 .}$
${ }^{42}$ See Camille Guerin-Gonzales and Carl Strikwerda, eds., The Politics of Immigrant Workers: Labor Activism and
Migration in the World Economy since 1830 (New York: Holmes and Meier, 1998). See also Mike Donaldson et. al.,
eds, Migrant Men: Critical Studies of Masculinity and the Migration Experience (New York: Routledge, 2009). 
ways in which borderlands generated opportunities for migrants entering shifting political terrain to flee unwanted circumstances at home. Borders often set dislocated or relocated groups into new socioeconomic configurations and politicized relationships.

Others have drawn links between nation-making practices and agriculture; as

Matsumoto notes, early Japanese farmers in California had to start their plantings anew after discriminatory three-year land leases expired. ${ }^{44}$ In a context of increased attention to ways in which political demarcations have inflected histories of farm work, alongside racialized boundaries that were a product of a collision of cultures in varying contexts of settler colonization that manifested themselves differently from one region to another, this work reads migrant field hand histories against a longer backdrop of historical change as well as continuity.

In Canada, a trend of farm labour management would in effect contribute to a "racialization" of the country's contemporary temporary labour markets. Guatemalan farm workers, before travelling to Canada, were advised about practices concerning hygiene and were instructed to refrain from sexual relationships while on contract in Canada. ${ }^{45}$ Critiques within Canada, from organized labour, also complicate the story;

${ }^{43}$ Mexican tejana women often pursued new freedoms to engage in divorce once incorporated into the United States, escaping the influence of the Catholic Church on new Texan laws. See Chapter Five in Valerio-Jiménez, River of Hope. A growing body of scholarship has disrupted concrete understandings of the past as studied within the limiting context of national history. See also Albert Hurtado, Herbert Eugene Bolton: Historian of the American Borderlands (Berkeley: University of California Press, 2012); David Bacon, Communities without Borders: Images and Voices from the World of Migration (Ithaca: ILR Press, 2006); Oscar J. Martínez, "Border People: Life and Society in the U.S.-Mexico Borderlands," The Oral History Reader 24.1 (1997): 132-6; and Benjamin Johnson and Andrew R. Graybill, eds., Bridging National Borders in North America: Transnational and Comparative Histories (Durham: Duke University Press, 2010). See also Sheila McManus, The Line Which Separates: Race, Gender and the Making of the Alberta-Montana Borderlands (Edmonton: University of Alberta Press, 2005); Michel Hogue, Metis and the Medicine Line: Creating A Border and Dividing A People (Chapel Hill: University of North Carolina Press, 2015); and George Díaz, Border Contraband: A History of Smuggling Across the Rio Grande (Austin: University of Texas Press, 2015).

${ }^{44}$ See Matsumoto, Farming the Home Place, 17-18. On the Japanese in Canada see also W. Peter Ward, The Japanese In Canada (Pamphlet) (Ottawa: Canadian Historical Association Canada's Ethnic Groups Series, 1982). In this survey study Ward describes the earliest migrants as "sojourners" who were rapidly taken into the workforce of "labour hungry" British Columbia (see 9).

${ }^{45}$ See Karl Flecker, Canadian Labour Congress, Canada's Temporary Foreign Worker Program (TFWP): 
the Canadian Labour Congress has noted how cases of overt racism and neglect have pervaded the experiences of foreign farmworkers in Canada. In addition, the study draws insights on race relations from a longer legacy of labour migration from Mexico that has origins in the mid-nineteenth century. ${ }^{46}$

Without privileging any singular interpretation, this study seeks to shed further light on existing debates and write foreign farmworkers into Canadian historiography. Informed by Judith Adler Hellman's work, which reconsiders Mexican migrant worlds in emotional, personal and psychological terms, and Natalie Molina's recent work on the state of "deportability" among Mexicans and Mexican Americans in interwar United States, I consider migrant pasts in Canada from a multiplicity of angles. ${ }^{47}$ In the formative, colonial context, Canada's social history of settled rural life sprang largely from the political and economic structures planted by early British colonists who sought to safeguard the paradigm of rights to a propertied existence. ${ }^{48}$ While a Canadian rural demographic was increasingly undermined as the twentieth century progressed and the number of farms was greatly reduced, surviving farms would expand in size after the Second World War to form the foundation for the recruitment of offshore workers to the Prairie region.

Embedded in this study is Paul Schuster Taylor's career of research on Mexican

\footnotetext{
Model Program or Mistake? (Ottawa: Canadian Labour Congress, 2011).

${ }^{46}$ See for example, Marie Mora and Alberto Dávila Labour Market Issues Along the U.S.-Mexico Border (Tucson: University of Arizona Press, 2009) and Josiah Heyman, Life and Labour on the Border: Working People of Northeastern Sonora: 1886-1986 (Tucson: University of Arizona Press, 1991).

${ }^{47}$ See Judith Adler Hellman, Mexican Lives (New York: The New Press, 1994) and The World of Mexican Migrants and Natalie Molina, How Race is Made in America: Immigration, Citizenship and Historical Power of Racial Scripts, American Crossroads Series (Berkeley and Los Angeles: University of California Press, 2014). On the formation of the U.S.--Mexico border, see, Joseph Richard Werne, The Imaginary Line: A History of the United States and Mexican Boundary Survey, 1848-1857 (Fort Worth: Texas Christian University, 2007) and on borderlands culture, conflict and identity see Oscar J. Martínez, Troublesome Border (Tucson: University of Arizona Press, 1988).

${ }^{48}$ On colonial British Columbia as seen through the colonial press in comparative context with New Zealand,
} 
labour in the United States; inspired by Taylor's methodological approach for interviews in the field, and his impressive record of field notes, observations, and published work about social relations between hired Mexican labour and American employers in the late 1920s and early 1930s, I read Taylor's work in terms of his positioning and the situated contexts in which his multi-volume study was rooted. As Abraham Hoffman has detailed, Taylor's monograph series on Mexican labour had "lasting value and quality" and Taylor had, "in the absence of hard data on the internal migration of Mexican workers, devised his own methods of obtaining needed information;" Hoffman notes that Taylor in fact began his field research in the Napa grape fields in 1927, but found that he had arrived during the wrong season; he then turned to a study of Mexican labour on the Southern Pacific Railroad and pursued his first agricultural field study in the Imperial Valley. ${ }^{49}$ If anything, his body of work confirms the critical historical legacy played by Mexican labour in American history.

In pursuing his research, Taylor found he was able to find improved spaces for interviewing farmworkers in social places: cafés, bars, pool halls, and barbershops, rather than the fields. ${ }^{50}$ Similarly, Deborah Cohen found barbershops in Mexico to be useful locations to conduct oral history interviews. An approach similar to this one functioned well in Manitoba and, in certain cases, in British Columbia. When found outside of supermarkets or second hand stores, the potential to interview farmworkers improved, while the interviewing process was sometimes more difficult to carry out on farms. Paul Gates wrote of Taylor that he

see Kenton Storey, Settler Anxiety at the Outposts of Empire: Press Coverage of Indigenous Resistance and Rebellion (Vancouver: UBC Press, 2016).

${ }^{49}$ Abraham Hoffman, “An Unusual Monument: Paul S. Taylor's Mexican Labor in the United States Monograph Series," Pacific Historical Review 45.2 (1976), 258, 261-2.

${ }^{50}$ Linda Gordon, Dorothea Lange: A Life Beyond Limits (New York: Norton, 2009), 143. 
set an example for scholars to have the courage of their convictions...to present their facts no matter how unpopular this may make them with self-serving politicians who play the game of greedy economic interests attempting to monopolize natural resources made valuable at public expense. ${ }^{51}$

Taylor's documentation of patterns of segregation in small southern towns would mirror modern-day depictions on film of social divisions between residents and guest workers in Leamington, Ontario. In my first season of fieldwork I failed to secure any formal, short or long interviews with farmworkers in Manitoba; after revising my signed consent form approach upon suggestion from the Research Ethics Board, I pursued an oral consent method in the field. All notes from interviews were destroyed upon the field project's completion, and the notes were in my possession until their transcription into text; my dissertation supervisors and examination committee were not able to access this material. Unbeknownst to me as my own research progressed, my interviewing strategy would closely mirror that of Taylor, as Hoffman describes:

[Taylor] learned to make the most effective use of his pencil and notebook.... On those occasions where direct note-taking was not possible, Taylor endeavored to make his notes at the earliest opportunity. 'Perhaps I would stop under a tree half a mile away, pull out my notebook and make my notes. ${ }^{, 52}$

His interviews often "ranged in size from one sentence to lengthy conversations." ${ }^{, 53}$ In my own case, stopping to take notes nearby, or in my car, proved the easiest method for setting interviews down in stone, when notes could not be taken during interviews.

${ }^{51}$ Elizabeth Stephens, and Linda Jordan; Bancroft Library. "Guide to the Paul Schuster Taylor Papers, 1660-1997 (bulk 1895-1984)," (Berkeley: University of California Berkeley, 1998), 4.

52 Hoffman, “An Unusual Monument," 263.

53 Ibid., 264. 
Taylor also collected data about "movements of workers" from "labor agencies used by railroads, steel companies, packing plants, beet-sugar companies, and other users of Mexican labor," and directly from company employers, with employers proving "very cooperative in providing information and...quite candid in their interviews." ${ }^{, 54}$

Richard Cándida Smith has suggested that oral history sets old and new techniques for writing history against one another. ${ }^{55}$ As a female interviewer, I did not view my own gender as a concrete obstacle in my ability to secure or perform oral history research. In addition to this, my own position as a Canadian researcher with prior experience having travelled throughout Mexico, both rural and urban, gave me an advantage that would have made the study more difficult to perform had I had no prior experience with or knowledge of Mexican culture or geography (See Appendix 6, “Table of Interviews with Location of Employment, Region/Town of Origin and Occupational Background" for a breakdown of the sending states). I did not approach interviews with the view that I functioned on different terms than participants; thus, I sought out a balanced dialogue that would allow each participant to relate their story on their own terms. The relative "precarity" of farmworkers additionally positioned participants in a somewhat more accessible state in relation to the goals of this project, making participants more susceptible and likely to engage in a study such as mine.

\section{Imagining "Offshore" Workers}

Just as Thomas King underscores "imagined" narratives of First Nations, I think

\footnotetext{
54 Ibid., 265.

55 Richard Cándida Smith, “Analytic Strategies for Oral History Interviews,” pp. 711-31 in Handbook

of Interview Research: Context and Method, Edited by Jaber Gubrium and James Holstein (Thousand
} Oaks: Sage Publications, 2002), 711. 
critically about narratives promoted in Canadian journalistic readings of foreign farmworkers, including their oftentimes-categorical framing through journalistic mediation. ${ }^{56}$ Following from Richard White's imagining of a "middle ground" defined as more than a "compromise between opposing interests" but rather, a space or mediation between two interacting groups, the SAWP's past might be read as one equally ridden with conflicts of interest and examples of compromises made. ${ }^{57}$ As Gerald Friesen suggests, if the national past is better understood as a collection of diverse narratives, or if Canadian history is in fact comprised of fragments, then the historian's task is more daunting: to locate coherent narratives within the context of that fragmentation. ${ }^{58}$ Other critiques of nationalist historical imaginaries have located alternate perspectives on Canadian nation building, de-constructing imagined masterrace narratives as inherently mythological. ${ }^{59}$

Linked to the practice of oral history is the question of memory, which, for my purposes, often helps shed light on migrant workers' depictions of former contracts or experiences in Canada. Rafael Samuel points to history's objectivity "in principle" and memory as a "plaything of the emotions. ${ }^{\circ 0}$ Memory may serve as an emotional or

\footnotetext{
${ }^{56}$ On journalist's depictions of foreign farm workers in Ontario see Harald Bauder and Margot Corbin, "Foreign Farmworkers in Ontario: Representations in the Newsprint Media," Immigrant Labour Project, University of Guelph, 2002. On colonial origins of the newspaper as a form of public culture, see Michael Eamon, Imprinting Britain: Newspapers, Sociability, and the Shaping of British North America (Montreal and Kingston: McGillQueens University Press, 2015).

${ }^{57}$ Richard White, The Middle Ground: Indians, Empires and Republics in the Great Lakes Region, 16501815 (New York: Cambridge University Press, 1991; 20th Anniv. Ed., 2011), xii. Studies of migration in North America have also explored the concept of drain, by which able-bodied labour is removed from a sending region. This discourse has had resonance in studies of the Caribbean where rural households and economies were reshaped by the loss of manpower at home; in Mexico, the liquidation of able-bodied male labour from Jalisco in the twentieth century would have transformative effects on regional terrain.

${ }^{58}$ Gerald Friesen, River Road: Essays on Manitoba and Prairie History (Winnipeg: University of Manitoba Press, 1996), 232.

${ }^{59}$ See, for example, Daniel Francis, “Your Majesty’s Realm: The Myth of the Master Race,” p.52-87 (Chapter Three) in National Dreams: Myth, Memory, and Canadian History (Vancouver: Arsenal Pulp Press, 2002).

${ }^{60}$ Raphael Samuel, Theatres of Memory: Past and Present in Contemporary Culture (London: Verso, 1994), xi.
} 
psychological counterpoint to archival or state-based knowledge, especially those facts memory provides that often risk evading inclusion in the textual record. In the case of Latin American migration, since migration is often an intrinsically personal endeavour, oral history is often an ideal way to access lived pasts. ${ }^{61}$ In Latin America, historians of labour have considered women, social histories of the working class, and labour's intersection with politics, especially in regional contexts, focusing especially on workers' lives in agriculture, mining and manufacturing/industry. ${ }^{62}$ Silences are also important to consider when oral history participants fit into a category of precarity or vulnerability.

Recent attention in Prairie historiography has considered the role of ethnic groups in the making of cultural landscapes and the cultural mosaic; Frances Swyripa's study on settler experiences in Storied Landscapes is evidence of this trend ${ }^{63}$ Ethnic history has now dovetailed with gender history, when told through the eyes of immigrant groups initially defined by a "marginal" identity or positioning. ${ }^{64}$ More broadly, the question of colonial anxiety in connection with expanded immigration waves from non-traditional sending countries informs my study of contemporary patterns of temporary migration into the Canadian fold. Mariana Valverde's attention to moral panics in English Canada sought to tease out the roots of social anxiety. ${ }^{65}$

61 The oral record has also increasingly been taken up as a useful resource for research in the scientific community. The Hawaiian mo'olelo (oral mythology) is used in Patrick Von Kirsch's study, A Shark Going Inland is My Chief (Berkeley: University of California Press, 2012), alongside his scientific archaeological database.

${ }^{62}$ Ibid., 6.

${ }^{63}$ See Frances Swyripa, Storied Landscapes: Ethno-religious Identity and the Canadian Prairies (Winnipeg: University of Manitoba Press, 2015). See also Ryan Eyford, White Settler Reserve: New Iceland and the Colonization of the Canadian West (Vancouver: UBC Press, 2016).

${ }^{64}$ See for example, Marlene Epp, Franca Iacovetta and Frances Swyripa, eds. Sisters or Strangers? Immigrant, Ethnic and Racialized Women in Canadian History (Toronto: University of Toronto Press, 2004).

${ }^{65}$ Mariana Valverde, The Age of Light, Soap and Water: Moral Reform in English Canada, 1885-1925 (Toronto: University of Toronto Press, 2008), xi. 
Canadian anxieties would turn up in the archives and in journalistic discourse. Reaction and anxiety served as historical agents, reworking the outcomes of guest work programs and allowing Canadian policy to diverge from the United States. ${ }^{66}$

As embattled spaces, journalistic accounts have vied for the attention of a Canadian readership. While discourses of vulnerability in migration literature are common, this study does not privilege vulnerability as an all-encompassing or defining discursive category. Indeed, illegality has often played a role in farm workers' vulnerabilities. The management of Fijian and Tongan Pacific Island labour in agriculture in 1960s and 1970s New Zealand via state-endorsed work schemes set out new opportunities for regional labour integration near to the same time that Canada developed its agricultural labour policies with the Caribbean and Mexico. ${ }^{67}$ In North America, migration trends were often contingent on bi-lateral decisions made by host nations; managed migration schemes were set by national governments as temporary migrants were invited to perform the more dangerous, dirty and demanding tasks. In South America, migration and the traversing of borders equally shape agricultural and mining work. ${ }^{68}$

If agricultural production in Canada is intertwined with labour migration, then the histories of the two must be narrated together. In imagining migrant bodies as agents of transformation, migrant bodies might be viewed as having rewritten the nature of work and mobility across borders. In counterpoint to the migrant's body is

\footnotetext{
${ }^{66}$ See for instance Luis Aguiar, Ann Marie McKinnon, and Dixon Sookraj, "Racialization and the Repertoires of Racism: Reaction to Jamaicans in the Okanagan Valley," BC Studies 168 (Winter 2010/2011): 65. The article considers racial dynamics in the Okanagan Valley region by rereading media portrayals of temporary Jamaican migrant workers and students. Thanks to Luis for agreeing to meet while in Kelowna to discuss my project.

${ }^{67}$ See Calnitsky, "Colonized Pasts."

${ }^{68}$ Rising incomes in Chile bred a new lack of interest on the part of even lower income residents to perform agricultural harvest work.
} 
the state's role as a gatekeeper, and in this respect, governmentality theory may offer a useful framework to locate guest work in a context of political change. ${ }^{69}$ The triumph of a hegemonic liberalism supported through the passivity and consent of the body politic might be viewed as a political backdrop to the evolution of Canadian policies connected with immigration and temporary migration schemes, while current criticism of temporary labour policies as exacerbated by Harper-era conservatism reframe Canadian policies toward migrant workers in terms of the "damage done" as a result of economistic approaches to migration. ${ }^{70}$

This study is imagined as a social history. ${ }^{71}$ While the study seeks to highlight human "facts" and interactions, nature is also read as a historical category with profound influence over migrants' pasts. ${ }^{72}$ This was the case for a group of Mexican orchard workers who lost all of their material possessions to a wildfire in north-central Washington State in July of $2014 .{ }^{73}$ Environmental revisionist histories have done much to reshape understandings of the ways in which natural factors helped determine historical outcomes. In Omar Valerio-Jiménez's River of Hope, the Rio Bravo (or Rio Grande) plays a definite role in its interaction with the social history of the borderland region.

${ }^{69}$ On the theoretical uses of governmentality, see for example, William Walters, Governmentality: Critical Encounters (Oxon; New York: Routledge, 2012).

${ }^{70}$ See Jean-Francois Constant and Michel Ducharme, eds., Liberalism and Hegemony: Debating the Canadian Liberal Revolution (Toronto: University of Toronto Press, 2009).

${ }^{71}$ In Mexican historiography, social history approaches have gained increased currency. As Enrique Florescano observes, the Annales School propelled a renovation in Mexican historiography, setting the field upon previously uncharted terrain, and promoted a more "persuasive reading of [the] economic and social structure." See his National Narratives in Mexico: A History (Norman: University of Oklahoma Press, 2006), 359.

${ }^{72}$ For an environmental history of Mexico City see Vera Candiani, Dreaming of Dry Land: Environmental Transformation in Colonial Mexico City (Stanford: Stanford University Press, 2014).

${ }^{73}$ See Andy Mannix, "Labourers Lost a Lot to Fast-Moving Wildfire," Seattle Times, July 23, 2014. 


\section{Migration and Historical Scripts: The Interstices of Politics and Labour}

After the terms of the Treaty of Guadalupe were set in the nineteenth century, social dislocations wrought by migration allowed borderlands communities to remake their lives in new social, legal and cross-cultural climates. In the twentieth century, with Mexico's postwar adjustment to new neo-liberal rules of trade, Mexico re-forged its relationship with its northern neighbor to move beyond former emphases on socialism and economic nationalization pursued in post-revolution decades. In linking political and economic history to the social history of rural life, this work sits at the intersection between "people's history" and studies of governmentality.

The forces that have uprooted workers to render them seasonally mobile are, I suggest, not new, yet contemporary labour mobility inevitably became embedded in modern agricultural systems, which, in light of their scale, would require workers from afar to meet tasks viewed as undesirable in local eyes. Trans-Atlantic mobilities were central to farming cultures in early post-Confederation Canada. Mobile workers were similarly critical to American Southwest, and in the multicultural world of farm labour in

California, the Mexican worker did not constitute an agricultural backbone until 1910.

In this work, migrant psychologies define experience and are central to promoting a sense individual variation. Mexican migration is framed as "tangled" and the structural

history of international relations understood as "entangled." "74 This study also looks, where possible, at connections between migrants and nations in a climate of "postnational" developments where national identities are increasingly unsettled by international migration. ${ }^{75}$ Approaches that think "under" and "across" nations are useful

\footnotetext{
${ }^{74}$ See, for e.g., Julia McClure, "Poverty, Power and Knowledge: An Early Entangled History of Hispaniola," Canadian Journal of Latin American and Caribbean Studies 38.2 (2013): 197-219.

75 See, for e.g., Tonkiss,Migration and Identity , and Tanya Basok, "Post-national Citizenship,Social Exclusion and Migrants Rights.” Citizenship Studies, 8.1 (March 2004).
} 
when considering migrant trajectories. ${ }^{76}$ This is also a study of competing discourses. One the one hand, historical discourses that place immigration at the forefront for understanding the multi-cultural mosaic tell one national narrative, while those emerging increasingly from Latin American scholars and Canadian scholars concerned more with the porousness of borders and the arrival of a globalized world intervene to offer a more inclusive approach to national history. ${ }^{77}$ David Scott Fitzgerald and David Cook-Martín have stressed how Canadian immigration policy has been moulded by "administrative discretion, coded language about a group's suitability, and secret circulars that allowed ethnic selection with fewer diplomatic costs than would be incurred by explicitly naming a hierarchy of groups." ${ }^{, 78}$ A decline in Canadian immigration models driven by "ethnic selection" in did not take place until the 1960 s. $^{79}$

Canada's agricultural history included the arrival of farm workers from afar as early as the mid-nineteenth century in British Columbia; Hawaiians (or "kanakas," as they were called) performed harvest work on cranberry farms at Fort Langley in the Fraser Valley. ${ }^{80}$ In same region today, Mexican migrant berry pickers now perform similar tasks. In early twentieth century California, farm labour was relegated primarily to immigrant groups. ${ }^{81}$ Yet, agriculture did not always constitute the exclusive domain of the foreigner; in British Columbia, rural prejudice defined inter-ethnic hostilities and Anglo-Canadian nativism.

\footnotetext{
76 Tony Ballantyne, "Thinking Local: Knowledge, Sociability and Community in Gore's Intellectual Life, 1875-1914,” New Zealand Journal of History 44.2 (2010): 138.

${ }^{77}$ In the United States, scholars of Mexican migration including George Sánchez, Kelly Lytle Hernandez and Camille Guerin-Gonzales have performed this role.

${ }^{76}$ David Scott Fitzgerald and David Cook-Martín, Culling the Masses: The Democratic Origins of Racism Immigration Policy in the Americas (Cambridge, Mass.: Harvard University Press, 2014), 142.

79 Ibid., 146. Latin Americans gained eligibility for immigration to Canada "with restrictions" in 1956 (See 145).

${ }^{80}$ Tom Koppell, Kanaka: The Untold Story of Hawaiian Pioneers in British Columbia and the Pacific Northwest (Vancouver and Toronto: Whitecap Books, 1995), 44. At 1856, Koppell notes, the Fort was exporting massive quantities of cranberries, some "469 twenty-four gallon barrels," to San Francisco markets.
} 
In looking at contemporary patterns in farmworker housing in this study I incorporate a spatial approach influenced in part by historians' interest in the spatial turn; I also consider photography and the visual record's intersection with histories of farm work in the United States ${ }^{82}$ For SAWP workers, shared housing could help forge new social connections. Farmworkers' housing was often constructed in accordance with practical concerns, yet housing standards in both Canada and the United States were often inflected by differential standards shaped according to assumptions about race. Orchardists in Corona,

California constructed adobe housing for Mexican families at work in the lemon and orange groves, turning beet farmers for practical housing models. ${ }^{83}$ While overcrowding and inadequate fridge space was an issue for Mexican greenhouse workers in Leamington, spacious cabins available for vineyard workers in Okanagan Falls, B.C. offered a more comfortable setting. Town centres and retail spaces in Canada additionally offered farm workers out of doors spaces that quickly became niches for recreational life, including soccer matches (in Oliver and Delta) and fishing (in East Selkirk). The spatial turn has similarly inflected Gunther Peck's work on the role of padrones or labor contractors who in effect functioned as "spatial entrepreneurs" in arbitrating over immigrant labour in the eras they operated (in Peck's case, 1880 through 1930). ${ }^{84}$

\footnotetext{
${ }^{81}$ Camille Guerin-Gonzales, "The International Migration of Workers and Segmented Labor: Mexican Immigrant Workers in California Industrial Agriculture, 1900-1940," in Guerin-Gonzales and Strikwerda, eds., The Politics of Immigrant Workers, 188.

${ }^{82}$ For a history of Canadian housing, see for example, Peter Ward, History of Domestic Space: Privacy and the Canadian Home (Vancouver: UBC Press, 2009), 3.

${ }^{83}$ Ibid., 180. Citrus growers in California developed an interest in building permanent housing for Mexican migrant harvest workers during the First World War, when white labour was scarce and growers were in the midst of a transition away from dependence on predominantly Japanese crews.

${ }^{84}$ See Gunther Peck, Reinventing Free Labor: Padrones and Immigrant Workers in the North American West, 1880-1930 (Cambridge and New York: Cambridge University Press, 2000).
} 
Encounters with nature, including bug-bites, and agricultural technology like agrochemicals, shaped farm worker experiences in positive and negative ways, with the natural environment often proving as hazardous as man-made conditions of the workplace. ${ }^{85}$ In his narrative of the United Farm Workers movement, Frank Bardacke recounts a grape picker's recollection of environmental danger: "It wasn't bad—except for the rattlesnakes." photographic record of harvest labour was similarly defined by interconnections with the land. Birds-eye-view depictions of farm workers published in Canadian newspaper images would contrast markedly with the humanistic visual portraits taken of farmworkers in earlier eras (See, for example, Appendix 1, Bracero Era Photographs). ${ }^{87}$

The study locates the SAWP in a wider context of the increased role played by noncitizen workers in the national economies of the twentieth and twenty-first century North America. Brinda Sarathy describes, for instance, how Latino migrant labour has constituted an especially overshadowed component of the contemporary American forestry sector; while often disinclined to speak about experiences in the woods, these workers were often grateful to access work. Temporary forestry workers were plagued by discrimination in wages and partiality of treatment across ethnic lines: "A revolving door of compliant labor has been tapped, creating a mechanism that ensures the suppression of complaints from guest workers. ${ }^{98}$ This trend found a mirror in British Columbia, when SAWP workers were threatened with repatriation for voicing complaints. ${ }^{89}$

\footnotetext{
${ }^{88}$ See Sarathy and Casanova, "Guest Workers or Unauthorized Immigrants? The Case of Forest Workers in the United States,” Policy Sciences 41.2 (2008): 97, 100, 111. See also Michele Melton, Michael DeBonis, and Eytan Krasilovsky, "Maltreatment \& Injustice: An Overview of the Plight of Latin Forest Workers in the Southeast" (Santa Fe: Forest Guild Research Paper, August 2007) and Arcury and Quant, Latin Farmworkers in the Eastern United States, 18. See also U.S. Citizenship and Immigration Services, "H-2B Temporary Non-Agricultural Workers.” The history of Latino participation in forestry is still developing. See the recent work of Mario Jimenez Sifuentez, the son of farmworkers from Ontario, Oregon, Of Forests and Fields: Mexican Labor in the Pacific Northwest (New Brunswick, NJ: Rutgers University Press, 2016).

${ }^{89}$ Elise Hahn, "You Wanna Go Home?" Canadian Association for Latin American and Caribbean Studies, Laval University, May 16-18, 2014. 
Migrant forestry workers were often relegated to the shadows of society. In the Pacific Northwest, the interests of forestry and farm workers often merged, beneficially under the wing of collaborative activism, despite persisting challenges faced by agricultural labour interests and movements in the region. ${ }^{90}$ In Canada, the United Food and Commercial Workers' Union performed a similar function for Mexican workers, offering opportunities for representation with moderate but limited success; as Laura Macdonald and Christina Gabriel suggest, the reduced agency of the state as a protector of migrants' interests induced other components from among civil society to step in to defend migrants' interests. ${ }^{91}$ Gabriel and Macdonald's work represents an important addition to the recent political science literature on the bureaucratic and legal evolution of the Canadian SAWP. As Sarathy's work has also shown, the citizen/non-citizen binary was often inflected by other ambiguities characteristic to the world of labour, including the "temporary permanence" of certain industries, the deepseated labour dependencies and asymmetries of power built upon a foundation of ethnonational segmentation and visa streams that allow in workers without having a full regime of labour rights and protections built into them. These themes found many echoes in the history of Canada's Seasonal Agricultural Worker Program and the associated "Offshore Program" that preceded it.

\footnotetext{
${ }^{90}$ See the work of Lynn Stephen on the Northwest Treeplanters and Farmworkers United / Pineros y Campesions Unidos del Noroeste. The PCUN Formed in 1985 by graduates of the Colegio César Chávez in Mt. Angel, Oregon to voice grievances for workers in a host climate not protective of their rights. See Lynn Stephen, The Story of PCUN and the Farmworker Movement in Oregon (Eugene, OR: University of Oregon Center for Latino/a and Latin American Studies, 2012). The Willamette Valley Immigration Project (WVIP) formed in 1977, presented forestry workers' challenges through interviews, describing how they received threats of deportation and protested INS policies leading to the arrest of forestry workers in Washington and Marion counties, and WVIP staff launched a protest after arrests and deportations. The WVIP staff ultimately staffed the PCUN, offering a service wing or Centro de Servicios para Campesinos, much in the same way that AWA in Canada served as an outreach arm of the UFCW for farmworkers. On Mexican community emergence in Oregon see also Erlinda Gonzales-Berry and Marcela Mendoza, Mexicanos in Oregon: Their Stories, Their Lives (Corvallis: Oregon State University Press, 2010).

${ }^{91}$ See Gabriel and Macdonald, "Domestic Transnationalism."
} 


\section{Structure of the Work}

The first chapter explores the foundations of agricultural settlement and rural conceptions of place as they developed in Southern British Columbia and Manitoba, paving the way for the rise of commercial agriculture and modern migrant farm work.

Reading rural change on a local level, it explores the history of the farmland regions of the Fraser and Okanagan valleys and Southwestern Manitoba. ${ }^{92}$ Chapter Two charts the SAWP's development on a national scale and locates debates taking place in Manitoba and B.C. over the tentative arrival of foreign farm workers. Chapter Three zooms the lens out further, to explore how farm labour segmentation operated in a North American context. Using a mixture of archival sources and a reading of secondary studies, it turns to Mexican labour emigration history to decode the migration climate for emigrant workers in the twentieth century. Chapter Four showcases the testimonies of seasonal workers, their perspectives on work, labour and leisure in British Columbia and rural Manitoba from field findings collected between 2012 and 2015. The final chapter decodes the trans-national "character" of migration history through lenses of family, religion, culture, masculinity, modernity, postmodernity, and Mexicanidad (or Mexicanness), departing from an explicitly political approach, and probes migration's intersection with Canadian legal and print culture in a context of the "modern" problems that have arisen in connection with the arrival of temporary farm workers.

\footnotetext{
92 These two provinces were chosen as access points to study of Mexican migration to Canada for logistical reasons, but also for capacity to function as book-ends in the historical arc of the SAWP's evolution in Canada; Manitoba was among the first (of initially four) provinces to take part in the program and British Columbia was the most recent. As a native of Manitoba, my first encounter with Mexican farmworkers in Canada was in Southwestern Manitoba. Moreover, the feasibility of conducting a case study of this province was made more concrete by virtue of my having a home base in Winnipeg. In addition, having had some former experience in orchard work, my interest in the seasonal harvest economies of British Columbia was already well established.
} 


\section{Excavating Rural Space in Manitoba and the British Columbian West}

"The people of the province are realizing as they never did before that the soil is the greatest producer of wealth there is..."1

This chapter draws on received Canadian rural and immigration historiography, as well as archival findings, to sketch out the longer backdrop of agricultural settlement and production, or broader historical timeline, upon which seasonal farmworkers now sit. In doing so it considers themes such as the colonial reordering of rural space, the European foundations of rural landownership and land rights, early networks of agricultural commodity exchange and intercolonial routes of marketing that saw the export of early Canadian produce, and a rise in Canadian productivity leading to Canada's embeddedness in larger chains of domestic and international consumption and supply. In exploring how labour patterns were intertwined with these larger structural forces, the chapter will also foreshadow how early patterns of labour "management" over rural work would play out.

In order to strike a balance between Canadian and non-Canadian narratives in the study as a whole, this chapter emphasizes Canadian history as a window into the ways in which, foundationally, European settlers' faith in agricultural cultivation served as a signifier and promise of national prosperity. Sections 1.4 and 1.5 present narratives that are sourced primarily from archives, while the other sections draw mainly from a secondary literature focused upon change at the regional level. The story of European migration for farm work and seasonal labour is in effect set in a wider context of rural

\footnotetext{
${ }^{1}$ Department of Agriculture Alberta, Annual Report of the Department of Agriculture of the Province of Alberta, 1914 (Order of the Legislative Assembly; Edmonton: J.W. Jeffery, Government Printer, 1915 ), 8.
} 
immigration history. Indeed, immigration is ingrained into Canada's national identity and consciousness; Canada is often imagined as a nation of immigrants. Despite this reality, settlements on our eastern shores were created in the wake of a transatlantic commerce in cod that generated, at first, only impermanent and seasonal migration patterns. ${ }^{2}$ Thus, the transition from seasonal to permanent or settled was a key dichotomy that impacted how early modern and early post-Confederation Canadian history played out. In addition, while farm work is often imagined as a European endeavour, the role of First Nations' labour is often overshadowed. While Sarah Carter's scholarship has done much to redress this imbalance, dealing with the ways in which Native communities were repositioned as potential farmers in a failed national experiment, other rural networks would in fact tie in Aboriginal labour into new patterns of wage earning on orchards and farms. ${ }^{3}$ Postwar experiments with managed farm work in Ontario, and Aboriginal participation in southwestern Manitoba, would allow a diversification of the Canadian farm labour force in the twentieth century.

\subsection{The Colonial Origins of Canadian Agricultural Practice}

In this section, I draw connections with the past to help inform contemporary currents and trends. In the Prairie West, multi-cultural and multi-ethnic migrations and interactions with the physical environment came to define the character of early rural settlements. The immigrant's rural existence was made safe through the treaty system, which framed First Nations as "good and loyal subjects of Her Majesty the Queen."4

\footnotetext{
${ }^{2}$ On the Newfoundland cod fishery see Peter E. Pope, Fish Into Wine: The Newfoundland Plantation in the Seventeenth Century (Chapel Hill: University of North Carolina Press, 2004).

${ }^{3}$ See Sarah Carter, Lost Harvests: Prairie Indian Reserve Farmers and Government Policy (Montreal and Kingston: McGill-Queen's University Press, 1990).

4 "Treaties 1 and 2 between Her Majesty the Queen and the Chippewa and Cree Indians of Manitoba and Country Adjacent with Adhesions," Treaty Relations Commission of Manitoba.
} 
Treaty 1, signed at Lower Fort Garry in 1871, included the region that is home to many of the Portage la Prairie farms that have hired foreign workers and would impact the Ojibway and Dakota communities of southern Manitoba. In this way, the Crown contracted an agreement to draw land divisions between colonists and First Nations.

The First Nations were also, significantly, the first cultivators of food in the lands we now call Canada, "first" constituting a key historical word; the Algonquin cultivated Indian corn, squash and kidney beans, all readily adopted by settlers, while Champlain would cultivate a garden plot as early as 1604, incorporating native crops into his household landscape at Quebec. ${ }^{5}$ In New France, Intendant Jean Talon promoted the cultivation of flax as well as other industrial pursuits like shipbuilding, as a means to boost economic sustenance in the colony. Many Hudson's Bay Company forts built gardens around their trading post settlements, and this fashioning of colonial space was often understood in terms of the remaking of public and private worlds, shaped especially by patterns of domesticity modeled on Europe. ${ }^{6}$ In other instances across the British colonial world, the reshaping of the colonial landscape took the form of colonial gardens that transplanted a reordering of space to suit British colonial tastes and desires. ${ }^{7}$ In colonial New Zealand, the presence of gardens and growing of foods in fledgling missionary spaces was deemed a signal of civilization. ${ }^{8}$

While agricultural cultivation was not the unique introduction of Europeans in

${ }^{5}$ Robert Leslie Jones, History of Agriculture in Ontario, 1613-1880 (Toronto: University of Toronto Press, 1946, 5. Legislative Library of Manitoba.

${ }^{6}$ See, for example, Adele Perry, "Is Your Garden in England, Sir: James Douglas' Archive and the Politics of Home," History Workshop Journal 70 (Autumn 2010: 67-85.

${ }^{7}$ See Eugenia Herbert, Flora's Empire: British Gardens in India (Philadelphia: University of Pennsylvania Press, 2011). On land changes in New England see Cronon, Changes in the Land.

${ }^{8}$ See Tony Ballantyne, "Making Place, Reordering Space," in Entanglements of Empire: Missionaries, Maori and the Question of the Body (Durham and London: Duke University Press, 2014). In Orientalism and Race,

Ballantyne also describes how nineteenth century colonials like John Turnbull Thompson, surveyor of Otago at mid-century and later, Surveyor General of New Zealand, imagined Europeanization of the land through the eventual disappearance or dying out of the Maori and their replacement by "fair-haired" and industrial rural colonists (73). 
the New World, it came to represent a fusion of interests across cultures. Orchards soon became a common sight along the Petit Côte near today's Ontario-Michigan border, where plum, apple, peaches, and especially pear trees followed transatlantic routes with impacts on the regional terrain. ${ }^{9}$ Likewise, in Spanish colonial California, missionaries cultivated vineyards and gardens, while apple growing pioneers like John Chapman introduced Old World seeds to "domesticate the frontier." ${ }^{10}$ While early modern Canadian settlers imported staple consumables from Europe that could not be procured locally, efforts to reshape New World landscapes balanced local avenues of trade with imported foodstuffs and goods, and with new efforts to carve out rural space through fledgling gardens, orchards, and farms.

Immigrant populations would eventually arrive from those "alternate" and nontraditional European sending countries located in Central, Eastern, Northern, and Southern Europe (rather than the British Isles and France) and their growing presence, especially in the Prairie West, would effectively rewrite the national rural landscape in profound ways. North America drew in a full quarter of Iceland's population in the 1880s and many would disperse across the wheat farms of the Prairies, while other minority groups of varying religious denominations and cultural norms, including Finns, Swedes, Hutterites, Doukhobors, and Mennonites, would form rural settlements and enclaves across the Prairie West. In addition to the heterogeneous and diverse array of Christian colonists arriving from European, Central and Eastern European Jews participated in new patterns of Prairie rural landownership and the burgeoning urban life

${ }^{9}$ Inter-cultural borrowing in French Canada helped constitute French colonial agriculture in Canada. Fruit tree seeds and plants accompanied missionaries to Southern Ontario, where forested lands had first to be cleared to make way for farmland. See Jones, History of Agriculture, 4-8.

${ }^{10}$ Michael Pollan, The Botany of Desire: A Plant's Eye View of the World (New York: Random House, 2002), 4-5. On California missions see Steven Hackel, Children of Coyote, Missionaries of Saint Francis: Indian-Spanish Relations in Colonial California, 1769-1850 (Chapel Hill: University of North Carolina Press, 2005). 
of growing Prairie metropolises like Winnipeg. ${ }^{11}$ Homesteaders contributed to rural development in the Prairies in response to federal measures allowing such a trend to take root, while in British Columbia, a pre-emption system of cheap and easy land procurement would prevail in the second part of the nineteenth century.

Ontario's migrant population's connection with the British Isles would also impact the ways in which early patterns of agricultural colonial commerce would take shape. Transatlantic commercial webs developed early on. ${ }^{12}$ By 1870 , the tobacco crop had taken on great importance in southern Ontario, totaling 400,000 pounds and with a full $87 \%$ of the crop cultivated in Essex, Kent, and Bothwell. ${ }^{13}$ This sector would employ significant numbers of "offshore" workers in the postwar period. In the 1870s, market gardening also grew dramatically. ${ }^{14}$ Ontario served as a launching pad for migrants moving further west and as a centre for apiary production with bee farming appearing more prominently in Ontario in $1880 .^{15}$

In Manitoba, the late 1870 s saw the arrival of new farming machinery and in the first twelve years of Manitoba's existence, the provincial agricultural ministry recorded "definite agricultural progress" in contradistinction to the former period under the Council of Assinaboia. ${ }^{16}$ By 1882 , Manitoba had a total of 250,000 acres under

\footnotetext{
${ }^{11}$ On Jewish farming colonies in Manitoba see Allan Levine, Coming of Age: A History of the Jewish People in Manitoba (Winnipeg: Heartland, 2009). The "short-lived" efforts of Jewish prairie farmers in the Moosomin area of Saskatchewan would build a colony dubbed "New Jerusalem" (See 77). The Jewish Heritage Center of Western Canada in Winnipeg holds a significant archive related to the Jewish farming colonies in the West. On the emergence of immigrant groups in Prairie urban life see Royden Loewen and Gerald Friesen, eds., Immigrants in Prairie Cities: Ethnic Diversity in Twentieth-Century Canada (Toronto: University of Toronto Press, 2009).

${ }^{12}$ Apples grown in 1870s Prince Edward County and the Niagara Peninsula found markets in London and Glasgow, while peaches, next in popularity, found markets in Ontario towns and were shipped to Halifax and some American cities. Ontario apples were actively marketed in the United Kingdom, replacing British domestic and continental European fruits.

14 Jones, History of Agriculture, 316.

15 Ibid., 318-20. This was especially true in the stretch of land between Hamilton and Toronto.

${ }^{16} \mathrm{Ibid}$. At this time an estimated 8,000 pounds of honey were exported from the province. J.H. Ellis., The Ministry of Agriculture in Manitoba, 1870-1970 (Winnipeg: Manitoba Dept. of Agriculture, 1970), 79.
} 
agricultural cultivation. ${ }^{17}$ Additionally, between 1878 and 1882, large numbers of British and Ontario migrants had settled in the Southwest rural reaches of the province.

The 1880-81 Ministry of Agriculture report described farmers successfully raising field and garden crops: “corn, timothy...clover, flax, hemp, buckwheat, turnips, carrots, and mangels" and "beets, beans, onions, cabbage, tomatoes, melons, cucumbers, citrons, strawberries, currants, gooseberries, raspberries, and rhubarb from seed." ${ }^{, 18}$ From this point onwards politicians had an expanded role in agricultural affairs, taking agricultural production under the purview of the province, which recorded levels of production and linked agricultural success with ideals of the wider economic welfare of the province and its inhabitants, signaling the early bureaucratization of the farming sector.

Canadian-grown products soon became increasingly exportable as production levels surpassed domestic needs. ${ }^{19}$ As farming technologies changed, so too did levels of productivity. Greenhouses and field irrigation systems allowed Prairie growers and Ontario farmers to expand their productive capacities in the second half of the twentieth century. By 1955, Manitoba greenhouse owners were in the practice of cultivating flowers and other plants in greenhouse environments. Seed sprouting, transplanting, and harvesting in indoor environments were depicted as innovations that would guarantee agricultural success. ${ }^{20}$ The early 1990s in Manitoba would also witness an expansion of

\footnotetext{
17 Ibid., 81 .

18 Ibid., 80 .

${ }^{19}$ Trade between England and the Dominion operated for years along webs of empire connecting British-Canadian settler worlds with the British Isles. Other settler nations like New Zealand, Australia and Argentina also had traded substantially in foodstuffs to serve British markets, especially in dairy and meat. In New Zealand, rural capabilities in the colony gave it an increasingly attractive role as "Britain's farm." In 1932, an Imperial Economic Conference (also known as the British Empire Economic Conference) in Ottawa revisited Britain's agricultural trade policies with its dominions, enacting policies to balance British needs and trade relationships with non-colonial countries like Argentina while giving preferential access to colonial products by placing the interests of British producers first, colonials second, and foreign countries third.

${ }^{20}$ CBC Winnipeg English Television Productions, "Country Calendar" [Feb. 23 1955], Archives of Manitoba. In Leamington, Ontario, in 1955, one cucumber greenhouse was featured in a film reel depicting this process.
} 
irrigation systems. Meanwhile, Ontario's greenhouse sector became so economically significant that it entered into competition with Florida-grown field tomatoes with both industries requiring the support of large numbers of migrant workers drawn primarily from the Caribbean and Mexico. ${ }^{21}$ In berries, a transition toward growing formerly wild crops of blueberries and cranberries in a more consistent and industrial way took place, often at the expense of flavour. While wild varieties of low-bush blueberries surfaced as marketable crop in Eastern Canada, cultivated high-bush varieties became common in the West. ${ }^{22}$ Some Canadian blueberry farmers used large nets to prevent birds from damaging fruits and planted trees that were reduced in stature to ease the harvesting process. After the Second World War, floriculture also grew dramatically, with Ontario flower growers competing with South American and American growers, causing slight decreases in the provincial output. ${ }^{23}$ On the whole, technological innovations in agricultural working landscapes amounted to increased horticultural output, commercial "success," and, ultimately, an increased need for migratory farm workers.

\subsection{Farm Labour in Manitoba: Antecedents and Transformations}

The European settlement at Red River was fraught with intercultural collisions, especially over the problem of accessing a stable food supply, and the transition to a settled economy rooted in agriculture there did not arrive without fits and starts. As Pekka Hämäläinen observed, historians are often prone to "sanitizing" histories

of colonial encounter. ${ }^{24}$ In 1811, Lord Selkirk received a massive Hudson’s Bay

${ }^{21}$ Barry Estabrook, Tomatoland: How Modern Industrial Agriculture Destroyed Our Most Alluring Fruit (Kansas City: Andrews McMeel, 2011), xviii.

${ }^{22}$ Statistics Canada; Jack Purdy, "High-tech Vegetables: : Canada's Booking Greenhouse Vegetable Industry," (Statistics Canada: Vista on the Agri-Food Industry and the Farm Community, 2005), 1.

23 Ibid., 10.

${ }^{24}$ See Hämäläinen, The Comanche Empire, 6. 
Company (HBC) land grant at Red River with rights to furnish European migrants as settlers. ${ }^{25}$ Competition over pemmican supplies peaked at Seven Oaks in 1816, between a coalition of Métis traders and Northwest Company men on the one hand, and HBC men and Red River Settlers on the other. ${ }^{26}$ Shifting encounters between Natives and newcomers were often defined by relationships of trade surrounding labour, food, intimacy, and domesticity. ${ }^{27}$

While the fur trade era was still defined by interdependencies and sexual bonds formed with Amerindian women, the appearance of European women would eventually accompany European agricultural settlements. Further south, as Shoshone historian Ned Blackhawk has charted, colonial discourses often condemned subsistence lifestyles of Amerindians to justify westward expansionism, as agent James Calhoun remarked of the "Pah Utahs" (Paiutes): "benumbed by cold, and enfeebled...by the food upon which they subsist; it consisting only of roots, vermin, insects of all kinds and everything that creeps, crawls, swims, flies or bounds, they may chance to overtake. ${ }^{, 28}$ In a similar vein, David Weber considers Spanish colonists" concepts of "barbarity" in their definitions of Native peoples of the American Southwest. ${ }^{29}$

\footnotetext{
25 See Anne Matheson Henderson, “The Lord Selkirk Settlement at Red River, Part 1," Manitoba Pageant 13.1 (Autumn 1967). Manitoba Historical Society.

${ }^{26}$ Lyle Dick, "Historical Writing on 'Seven Oaks': The Assertion of Anglo-Canadian Cultural Dominance in the West," abridged version of Lyle Dick, "The Seven Oaks Incident and the Construction of a Historical Tradition, 1816 to 1970 ," Journal of the CHA / Revue de la Societé Historique du Canada, New Series, No. 2 (1991): 91-113. Many accounts of this battle attribute the conflict to Métis grievances over settlers' goals of establishing an agricultural colony in the region and its potential encroachment upon Métis' hunting grounds.

27 Jennifer Brown's landmark study, Strangers in Blood: Fur Trade Company Families in Indian Country (1980) revisited the social ties and labour relationships dependent upon Aboriginal women that were implicit in fur trade economies, while Sylvia Van Kirk's Many Tender Ties (1996) focused on how country marriages between HBC men and Amerindian women redrew early modern social landscapes. See Jennifer S. Brown, Strangers in Blood: Fur Trade Families in Indian Country (Vancouver: University of British Columbia Press, 1980) and Sylvia Van Kirk, Many Tender Ties: Women in Fur Trade Society, 1670-1870 (Winnipeg: Watson and Dwyer, 1996). See also Susan Sleeper-Smith, Indian Women and French Men: Rethinking Cultural Encounter in the Western Great Lakes (Amherst: University of Massachusetts Press, 2001.

${ }^{28}$ See Blackhawk, Violence over the Land, 227.

${ }^{29}$ See David J. Weber, Bárbaros: Spaniards and their Savages in the Age of Enlightenment (New Haven: Yale University Press, 2005.
} 
At Red River, agriculture was implemented more formally in the 1820 s as Selkirk's settlers of Irish, Swiss, Scot, and German descent started growing potatoes, sugar beets, wheat, and canola, and raised cattle, poultry, pork, dairy products, and eggs. ${ }^{30}$ The project of settling the Canadian West took place primarily in the decades leading to the Great War, initially under the banner of John A. Macdonald's National Policy. ${ }^{31}$ Migration from East to West would impact the cultural landscape on the prairies, which had by the 1890 s become home to tens of thousands of small farms, while the advent of new political structures, including the formation of Manitoba in 1870, and of Saskatchewan and Alberta in 1905, would intersect with farming in new ways. Canada's heritage of pioneering and family farms laid a foundation for industrial agribusiness, and a mosaic of family farms, albeit in smaller numbers, would persist in the contemporary agricultural economy.

The Prairies would witness depopulation in rural areas during the Second World War and from the 1930s through to the 1990s, with the number of farms in the Prairie region dropping as the sizes of farms increased. Manitoba saw the rise of commercial market gardens and farms after the war, many of which are still family owned and operated. Despite some exceptions, women had not been eligible as independent homesteaders during the pioneering phase of prairie settlement. ${ }^{32}$ Victorian-era culture viewed farm work as demanding, demeaning, and requiring of masculine strength, and

\footnotetext{
${ }^{30}$ Avis Mysyk, "H State in Manitoba Farm Labour Force Formation," The Dynamics of Hired Farm Labour: Constraints and Community Responses, Edited by Jill L. Findeis et. al. (Wallingford, U.K.: CABI, 2002), 170-71.

${ }^{31}$ Lisa Chilton, "Managing Migrants: Toronto, 1820-1880," Canadian Historical Review 92.2 (June 2011): 232-3. While British migration grew between the 1840s and 1890s, polyglot cultural migrations from Central and Eastern Europe took hold after the 1880s through to the Great Depression.

${ }^{32}$ On formative prairie homesteading policies see Carter, Lost Harvests and Mary Kinnear, A Female Economy: Women's Work in a Prairie Province, 1870-1970 (Montreal; Ithaca: McGill-Queen's University Press, 1998), 85-6. In rural settler economies, First Nations women performed labour that rarely conformed with Victorian ideals, engaging in pursuits like trapping, raising crops, working with meat and hides, and harvesting prairie turnips, wild rice, or maple sugar.
} 
therefore unsuitable or incompatible with a cultivated feminine life, a realm of difficult work reserved for men. The harsh life of the settler was famously documented in Susanna Moodie's Roughing it in the Bush (1852), wherein potential immigrants were warned against blindly accepting the Eden-like narratives of settler life in Canada promoted in England. ${ }^{33}$ Victorian standards were in fact never firmly set in place as Canadian environments and realities reworked Victorian ideals. ${ }^{34}$ In some cases, intercultural rural exchanges took place as domestic farm goods like bread, butter and cookies were traded for First Nations' good like wild berries, and one early Manitoba homesteader Mrs. W.H. Lowe Sr., viewed First Nations as a "peaceable" group. ${ }^{35}$

Between 1941 and 1971 the gendered dynamics of farm labour in Manitoba underwent a shift toward an increased presence of women. In 1941, the farm workforce was 92,000, of whom only 1,000 were women, but by 1971, some 87,500 people worked on farms, of which only 48,000 were men. ${ }^{36}$ This dramatic shift seems to indicate a rebalancing of a rural workforce gender gap, whereby the farm workforce in wartime was, by and large, a category filled primarily by men. There was also a marked decrease in the number of farms. Toward the end of the century, the number of census farms growing marketable products in Manitoba dropped from over 29,000 in 1981 to 21,000 in $2001 .^{37}$

\footnotetext{
${ }^{33}$ See Susanna Moodie, Roughing it in the Bush; or, Life in Canada (Toronto: McClelland and Stewart, 1989).

34 In Prairie Canada, women worked in the fields when men weren't available and in exceptional times like Depression or wartime. Farm work was gendered with masculinity reserving difficult tasks for men. While women in Manitoba performed casual agricultural work, often participating in harvesting tasks, they also reigned over the domestic sphere. After the Second World War, women gained increased managerial tasks as well as opportunities to man machinery; farms also expanded their capabilities, turning to new kinds of fruits and crops, and the production of side-products derived from fruits.

35 Account of Mary Thomson, Portage la Prairie, Manitoba, 1907 in Kinnear, A Female Economy, 93 and Mrs. W.H. Lowe, Sr. "Homesteading in Manitoba," [before 1924], F.H.H. (Harry) Lowe fonds, P7276/12.
} 
In a 1968 Speech from the Throne, the Lieutenant Governor highlighted Manitoba's critical role as a supplier of "food to a sometimes hungry world." 38 In 1941, Manitoba had 33,000 acres of potatoes valued at \$2.3 million, this value growing to $\$ 17.5$ million by $1975 .^{39}$ The provincial farm output was $\$ 1.2$ billion in 1973 , almost twice the value of the previous year, making 1973 "a record year" for agricultural success. ${ }^{40}$ Intersecting with economic indicators was the question of the rural wage. The minimum wage in Manitoba in 1973 was $\$ 1.90$ compared to \$2.25 in British Columbia. ${ }^{41}$ The following year, Manitoba's Minimum Wage Board recommended that the Employment Standard Act be amended to "include persons employed in agriculture, fishing, fur farming or in the growing of horticultural and market garden produce for sale," indicating that prior to this time, minimum wage standards had not been applied to agricultural work. ${ }^{42}$ Manitoba also made efforts to instruct farmers in ideal ways to interact with workers, as government discourses alluded to rights issues connected with farm work, especially in cases where authority rested in the hands of the farmer. A 1987 leaflet, The Keys to Good Farm Labour Relations, instructed farm operators about how to retain a productive workforce by providing competitive wages and appropriate housing. ${ }^{43}$ Providing adequate training and sufficient free time for "private enjoyment" were viewed as the best practice, since a "well taught, trained worker" was a valued resource. ${ }^{44}$ Guidelines such as these alluded to the power relations of many rural workplaces and the psychological landscapes of employer-employee relationships.

\footnotetext{
${ }^{42}$ Ibid., 2.

${ }^{43}$ Manitoba Agriculture Employment Development Committee, "The Keys to Good Farm Labour Relations," (Employment and Immigration Canada, 1987), 1. Library and Archives Canada, hereafter LAC. To retain a productive worker, farmers were told to communicate clearly and offer a measure of responsibility and engagement to their employees. Farmers were also instructed to show empathy toward employees, emphasize their humanity, show tolerance and respect, and set out the terms of employment in a written contract. ${ }^{44}$ Ibid., 3. 
Class and "race" issues soon also became endemic to Canadian agriculture and played out in Manitoba in unique ways. The social make up of the farm labour force in postwar Manitoba included bands such as the Dakota Tipi who worked casually in the Portage la Prairie area, as Native bands often provided a "reserve army" of workers for farmers. ${ }^{45}$ In Washington State, farmer preferences for an Aboriginal workforce similarly found articulation in a climate that had been shaped for the most part by a white and Chinese rural presence. ${ }^{46}$

During the war, relocated Japanese were set to work in rural Manitoba, where the rural in this case was considered a place of exile and a marginal site within the nation. ${ }^{47}$ The move was designed to alleviate farm labour shortages in Manitoba and provide needed labour, and most internees discovered the conditions on farms to be "harsh and primitive. ${ }^{, 48}$ During this era, one seven year old, Toshio Suzuki, was evacuated from his family's berry farm in Pitt Meadows to a Manitoba sugar beet farm, comprising one of the 22,000 Japanese who were relocated from British Columbia to the Canadian interior or deported to Japan. ${ }^{49}$ Sugar beet work was also performed by Mexican harvest hands in America, as documented in Paul Taylor's and Frank Bajaras' work.

\footnotetext{
${ }^{45}$ Mysyk, "Role of the State," 172-3. On Native labour in the hop industry of the Pacific Northwest see also Paige Raibmon, "Meanings of Mobility on the Northwest Coast," pp. 175-95 in New Histories for Old: Changing Perspectives on Canada's Native Pasts, Edited by Susan Neylan and Ted Binnema (Vancouver: UBC Press, 2007).

${ }^{46}$ Paige Raibmon, "The Practice of Everyday Colonialism: Indigenous Women at Work in the Hop Fields and Tourist Industry of Puget Sound," Labor: Studies on Working Class History of the Americas 3.3 (2006): 32.

${ }^{47}$ One advertisement from the period "Do You Need Farm Help?" announced the removal of Japanese from B.C. and their sudden availability for Manitoba farmers. See Farmers of the Red River Valley and Adjacent Municipalities, "Do You Need Farm Help?" (Advertisement) and "World War II Experience - Sugar Beet Farms," National Association of Japanese Canadians, http:// www.najc.ca.

48 Ibid.

${ }^{49}$ BC Orchard Industry Museum Exhibition, Kelowna. See also Shelley Ikebuchi Ketchell, "Relocating Japanese Canadian History," (M.A. Thesis, Sociology, University of British Columbia, 2005) and"Carceral Ambivalence: Japanese Canadian 'Internment' and the Sugar Beet Programme during World War II," Surveillance \& Society 7.1 (2009): 21-35.
} 
Manitoba farmers would diversify their crops and turn to new machinery, irrigation and storage technologies to meet new standards and changing desires of the marketplace. As Avis Mysyk describes, farmers' experimentation with a diversity of crops followed individual trajectories of choice and preference:

In 1949, a farmer near Plum Coulee began to experiment with sugar beets. To these he added peas, sweet corn, cauliflower, beans, cucumbers and, later, strawberries, raspberries, and tomatoes. By 1958, he was producing seventeen tons of carrots on an acre and a quarter and, the following year, planned to try muskmelons, onions, potatoes, lettuce, and cabbage..$^{50}$

A farmer in Portage la Prairie enlarged his farm from 120 to 400 acres between 1960 and 1978, at which point he hired one hundred and thirty seasonal foreign farm workers; by 1989 the farm reached 450 acres, with produce limited to broccoli, carrots, asparagus and green, cooking and pickling onions. ${ }^{51}$ Evolving scales of output determined new labour needs that ultimately reshaped temporary labour policies in the province, needs also reflected in other provinces that led to an elasticity in national policies towards a greater inclusion of and dependence upon invited farmworkers.

\subsection{Settling British Columbia: Migration and Labour from the Margins}

British Columbia was long home to long home to migrant and immigrant communities from afar that faced challenges linked to the establishment of rural niches and economic sustenance derived from varying forms of agriculture and waged work. The expansion of reservation systems in the province in the nineteenth century

\footnotetext{
${ }^{50}$ Avis Mysyk, Manitoba Commerci al Market Gardening, 1945-1997: Class, Race and Ethnic Relations (Regina: Canadian Plains Research Centre, University of Regina, 2000), 22.

51 Ibid., 23.
} 
designated out Native space to render the colony safe and accessible to a migrant British population. Logging, mining, railroad, and fishing industries saw the province develop a heavily resource-dependent economy and historical trajectory, and these industries relied on a combination of European, Native and Asian workers whose tasks were often segmented according to the parameters of gender and nationality. Successive waves of gendered labour migration sustained economic projects in the province, while Aboriginal workers often entered new spaces of cross-cultural encounter in industrial colonial workplaces, as Renisa Mawani’s work has shown. ${ }^{52}$ Mawani pinpointed colonial labour sites as "contact zones" where labouring classes of differing cultural and ethnic backgrounds met and collided. For many of British Columbia's pioneering labour migrants, the province would offer opportunities to access land or join in industrial activity, signaling new opportunities to create prosperity, rear families, and build communities. Interlaced into the colony's agricultural and industrial past are themes of migration, settlement, technological innovation, discrimination through head taxes, cross-cultural integration, the production of cultural enclaves and niche economies, and the performance of labour. Indeed, contemporary realities and relations of privilege in productive settings in Southern British Columbia were shaped by longer histories of migration and settlement.

\footnotetext{
${ }^{52}$ See Renisa Mawani, Colonial Proximities: Cross-Racial Encounters and Juridicial Truths in British Columbia, 1871-1921 (Vancouver: University of British Columbia Press, 2009. The historical literature on race, labour, land, immigration, gender and cultural collisions in British Columbia, developed in part by Ted Ferguson, Peter Ward, Adele Perry, Ruth Sandwell, Cole Harris, Pamela Sugiman, Kenton Storey, and others, has done much to unearth the workings of Anglo-Canadian colonial culture that would inflect cultural encounter. See, for example, Ted Ferguson, $A$ White Man's Country: An Exercise in Canadian Prejudice (Garden City, NY: Doubleday, 1975; Peter Ward, White Canada Forever: Popular Attitudes and Public Policy toward Orientals in British Columbia (Third ed. (Montreal and Kingston: McGill-Queen's University Press, 2002; Adele Perry, On the Edge of Empire: Gender, Race and the Making of British Columbia, 1849-1871, (Buffalo, NY: University of Toronto Press, 2001; Ruth Sandwell, Contesting Rural Space: Land Policy and the Practices of Settlement, Salt Spring Island, British Columbia, 1859-91 (Kingston and Montreal: McGill-Queen's University Press, 2005;Cole Harris, Making Native Space: Colonialism, Resistance, and Reserves in British Columbia (Vancouver: UBC Press, 2002; Sugiman, "Life is Sweet"; and Storey, Settler Anxiety.
} 
Nature also played a critical role in defining the agricultural potential of a rugged and varied terrain moderated by ecological and geological diversity. ${ }^{53}$ Indeed, historians of British Columbia emphasize how material success, a rugged natural environment, and colonists' ability to harness the province's rich natural resources shaped early life in the colony. ${ }^{54}$ Ruth Sandwell and John Cherrington have documented histories of settlement, on Salt Spring Island and in the Fraser Valley, respectively, in the context of transitions in rural land-ownership. ${ }^{55}$ Other interdisciplinary emphases locate, more broadly, how colonized labour was indicative of an emergent "intimacies of four continents," forged in the wake of Angloimperialism. $^{56}$

In their search for personal wealth and a rural existence, Anglo-settlers were a growing class of colonists, agricultural and otherwise, who often conflicted openly, on their own terms and within a developing colonial political culture, with inflows of migrants from Asia also seeking to derive their wealth from the land. Under the guidance of the Colonial Office, the fledgling colony carved out a philosophical vision of colonization and settlement that sought to effectively manage questions relating to governance, lawlessness, land policies, and the "Native question." On Canadian Prairies, the HBC had informal powers as an agent of colonization, but remained responsible to the Colonial Office for the way its men interacted with Native

\footnotetext{
${ }^{53}$ Tony Ballantyne and Antoinette Burton, eds., Bodies in Contact: Rethinking Colonial Encounters in World History (Durham: Duke University Press, 2005), 1-2.

${ }^{54}$ Andrew Smith, "The Writing of British Columbia History," in Carl Berger, ed., Contemporary Approaches to Canadian History (Toronto: Copp Clark Pitman, 1987), 66-70.

${ }^{55}$ See Sandwell, Contesting Rural Space, and John Cherrington, The Fraser Valley: A History (Madeira Park, B.C.: Harbour Publishing, 1992). See also Cole Harris, The Resettlement of British Columbia: Essays on Colonialism and Geographical Change (Vancouver: UBC Press, 1997).

${ }^{56}$ Lisa Lowe, The Intimacies of Four Continents (Durham and London: Duke University Press, 2015), 19-20.
} 
groups. ${ }^{57}$ Colonial labour questions were often hotly debated in mid-nineteenth century

England. ${ }^{58}$ Herman Merivale, undersecretary of the Colonial Office, envisioned a

democratic colony based not around aristocratic hierarchies but a mass-based citizenship

that negated the gentleman's status in favour of the improved standard of living for the "great mass of mankind." 59 In Britain, colonial policies were hotly debated and often centred around questions of agrarian policy. ${ }^{60}$ Merivale proposed pragmatic policies that involved choosing either "insulation" or "amalgamation," in other words, reserve-based versus assimilative, “civilizing” policies to solve questions surrounding white settlement, land and Native policy. ${ }^{61}$ Merivale would influence the administrative policies of governor James Douglas, suggesting that colonists employ local Aboriginal labour for labour-intensive tasks such as clearing land for agriculture for minimal pay.

In British Columbia, farming was presented in colonists' discourses as an improvement upon nature, with agricultural pursuits often imagined as critical to sustaining the livelihoods of settlers. ${ }^{62}$ Settlement colonies also allowed for an inversion of class relations with the potential to establish more egalitarian societies, as David Cannadine suggests: "For much of the second quarter of the nineteenth century...sprigs of nobility and distant cousins set off for Canada, New Zealand and Australia" in search

\footnotetext{
${ }^{57}$ David McNab, "The Colonial Office and the Prairies in the Mid-Nineteenth Century," Prairie Forum 3.1 (1978): 23.

${ }^{58}$ Edward Beasley, Mid-Victorian Imperialists: British Gentlemen and the Empire of the Mind (New York: Routledge, 2005), 27.

${ }^{59}$ Ibid., 28.

${ }^{60}$ On British colonial agrarian policies see also Joseph Morgan Hodge, Triumph of the Expert: Agrarian Doctrines of Development and the Legacies of British Colonialism (Athens: Ohio University Press, 2007).

${ }^{61}$ Discourses of racial "amalgamation" are also considered in Damon Ieremia Salesa, Racial Crossings: Race, Intermarriage and the Victorian British Empire (Oxford: Oxford University Press, 2012). See David McNab, "Herman Merivale and Colonial Office Indian Policy in the Mid-Nineteenth Century," Canadian Journal of Native Studies 1.2 (1981): 277-93 and "Herman Merivale and the Native Question, 1837-1861," Albion: A Quarterly Journal Concern with British Studies 9.4 (Winter 1977): 359-84.

${ }^{62}$ Cole Harris and David Demeritt, "Farming and Rural Life," in Harris, The Resettlement, 219.
} 
of a "genteel life." 63 Agriculture did not develop uniformly but occurred in concentrated pockets: by 1891 , the province had 4,500 farmers, with 8,000 inhabitants employed in agriculture of a colonial population of 100,000 and most farming activity carried out in the southern part of Vancouver Island and across the Fraser Valley. ${ }^{64}$ Settlers in the Okanagan-Similkameen were among the first linked to export-oriented agriculture, gaining expertise in orchard farming as learned through "trial and error." ${ }^{, 65}$ The exportation of crops, now viewed in economic terms and working in response to increased outputs that moved beyond domestic needs, signaled the beginning of the end of an enclosed colonial economy rooted only in agrarian doctrines of self-sufficiency. Rural existences also offered a refuge for communities of Asian descent who faced unfriendliness in urban contexts. Chinese (and some Japanese) developed market gardens outside of Vancouver and in the Fraser Valley, and early Japanese-Canadian and Chinese-Canadian families performed berry farming throughout Southern British Columbia. ${ }^{66}$ Similarly, in California, Japanese Americans participated extensively in agriculture, especially between the years 1900 and 1941 with 39,500 Japanese Americans working in the farming sector in $1909 .{ }^{67}$ In the early post-internment years in America, many would return to agricultural areas and continue on in farming communities that would persist in postwar decades.

Governor James Douglas, in the hopes of enticing "sturdy British settlers" to the Fraser Valley district, offered rural plots of land for sale at \$2.50/acre, in stark comparison to Fraser Valley land today, now worth between $\$ 40,000$ and $\$ 60,000$

\footnotetext{
${ }^{63}$ David Cannadine, Ornamentalism: How the British Saw their Empire (Oxford; New York: Oxford University Press, 2001), 27-8.

${ }^{64}$ Harris and Demeritt, "Farming and Rural Life," 220.

${ }^{65}$ Ibid., 232-3.

${ }^{66}$ Ibid., 243-4.

${ }^{67}$ Matsumoto, Farming the Home Place, 23.
} 
per acre. ${ }^{68}$ Douglas placed Joseph Trutch in charge of securing land transactions and surveying most of the Western Fraser Valley. ${ }^{69}$ Competition with American migrants led colonial judge Matthew Baillie Begbie to ask Douglas to lower the price of land, and in 1861 , land was offered at a rate of $\$ 1.25 /$ acre. $^{70}$ Begbie's involvement with the PreEmption Act of 1860 helped concretize land ownership, and this system served as a colonial method designed to attract permanent migrants. By way of this system, migrants of British stock were preferred. The pre-emption system, however, did not generate sufficient numbers of settlers. ${ }^{71}$ While few aboriginals bought into the pre-emption system, they did on occasion. ${ }^{72}$ Its logic was to encourage pioneers to clear the land, farm it, and "make something of it." ${ }^{, 73}$ By 1870 , the Fraser's settler population was still relatively small, and many early agricultural settlements faced environmental dangers, including high incidences of floods.

As pioneering migrants increasingly secured access to land, the secondgeneration identities of their offspring were increasingly hyphenated ones, in which foreignness was muted by rootedness, belonging, and attachment to the land (See Fig. 3). In the Okanagan, labour fluctuated between a dependence on family help, local hired hands and, increasingly, migratory or itinerant workers who shaped arrivals and departures according to the demands of seasonal production. Inter-cultural conflicts in the valley were ever-present in the early years; one Okanagan orchardist, Adam Cumine,

\footnotetext{
${ }^{68}$ Cherrington, The Fraser Valley, 108.

${ }^{69}$ Ibid., 108-9.

${ }^{70}$ Ibid., 51-2; 108-9.

${ }^{71}$ Ibid., 109-110 and 253.

${ }^{72}$ On the pre-emption system see also Sandwell, Contesting Rural Space and Ruth Sandwell "Reading the Land: Rural Discourse and the Practice of Settlement, Salt Spring Island, British Columbia, 1859-1891," (PhD Dissertation, Simon Fraser University, 1997). See also British Columbia Department of Land and Works, GR 0567, "Land Sale Records," Originals, 1858-68.

${ }^{73}$ Salt Spring Island Archives, "Cathy Roland - Hawaiians," SSI Historical Society Address, Central Hall, October 9, 2002 (tape), ID 183.
} 


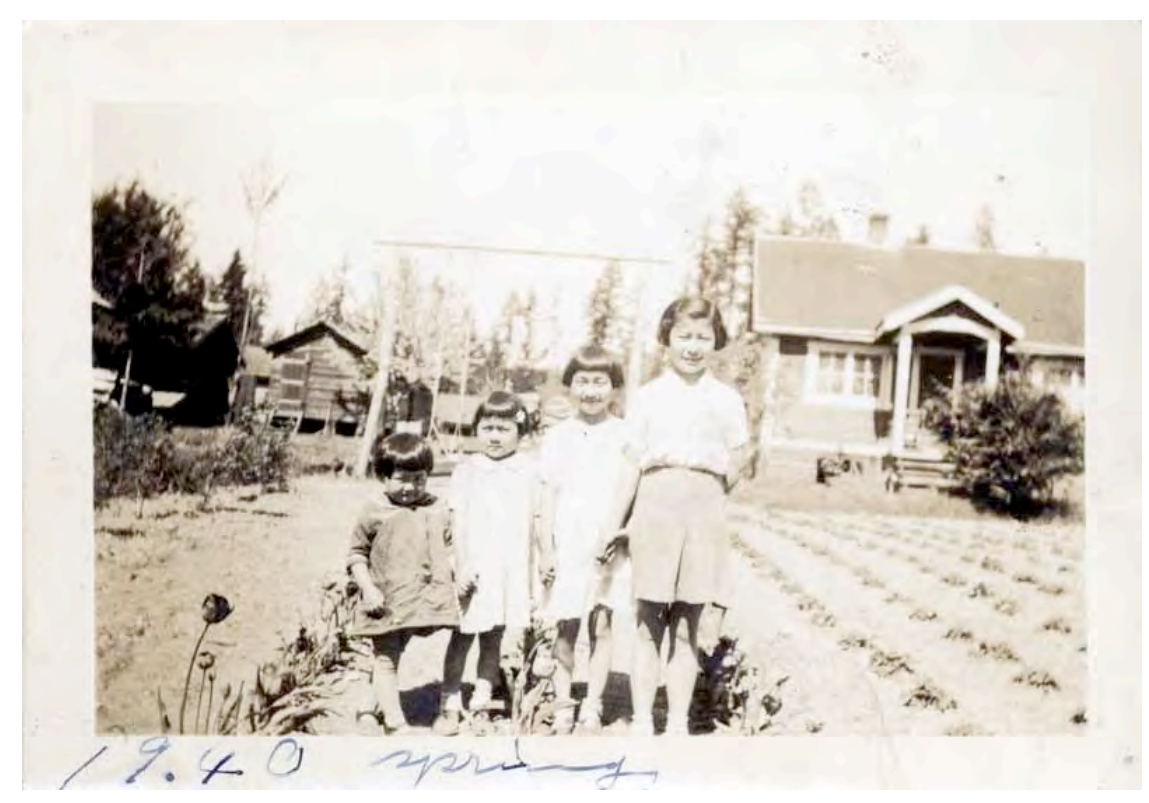

Fig. 2 Inhabitants of Salt Spring Island, Spring 1940

(Salt Spring Island Archives, Farming / 2004005035)

Note here the cultivation of land immediately adjacent to the house.

who arrived in Osoyoos in 1927 to farm twelve yacres, recorded his own and his community's ethnic prejudice against the Chinese:

In the early years we had an unwritten law that we would not allow Orientals into the Valley as they would soon put us out of business. Eventually a lone Chinaman arrived in Oliver. After a conference it was decided to remove him and a certain party was appointed to do the job. While the Chinaman was asleep $a$ sack was placed over his head, he was put into a Model T and taken to the top of the mountain and dumped in the brush. This solved the Oriental problem... During the next years we depended entirely on Doukhhobors for orchard help. $^{74}$ (Italics Mine)

\footnotetext{
${ }^{74}$ For an excerpt from Cumine's rural diary see Adam Cumine, "From Sagebrush to Fruit Trees in Osoyoos," $47^{\text {th }}$ Report of the Okanagan Historical Society, 1983, 131-136.
} 
Cumine additionally recorded his own early efforts to cultivate melons in the region. ${ }^{75}$

Osoyoos and Oliver, today prominent orchard and vineyard regions that employ a Mexican migrant farm working class, while founded for First World War veterans by Premier John Oliver, failed to receive a sufficient influx of veterans and the land was “thrown open to everyone," sparking a European influx. ${ }^{76}$ British Columbia's colonial paradigm of white settlement was often plagued by internal "contradictions...its settlers had to be white, but could not really be so," as Adele Perry argues; this contradiction, between labour needs and colonial desires, has continued to impact contemporary patterns defined by temporariness and guest work. ${ }^{77}$ Okanagan farmers and orchardists suffering labour shortages during the Second World War expressed interest in hiring Japanese, only to incite public protest. ${ }^{78}$ After the war, agricultural productivity in the province would expand and diversify and also come to incorporate viticulture on a more industrial scale.

\subsection{A Flourishing of Fruits: Rural Hired Help in British Columbia}

Canada's Dominion status within the British Empire would contribute to its development as a mecca for agriculture capable of feeding a growing settler population alongside the metropolitan demands of Europe. B.C. apples would come to enjoy a

\footnotetext{
${ }^{75}$ Ibid., 131-6. In the Kootenay region of eastern B.C. a promising fruit industry of cherries, apples, and pears also persisted until the Second World War.

76 Ibid., 131-5.

${ }_{77}^{77}$ Adele Perry, "Reproducing Colonialism in British Columbia, 1849-1871," in Bodies in Contact, 144-5.

${ }^{78}$ Ward, White Canada Forever, 197, n55. In the Fraser and Okanagan regions, Japanese Canadians were involved in fruit and berry production since as early as 1910. As Ward notes, campaigns to combat Oriental landownership contend that Asian access to land might endanger the future of the white farmer. Still, by 1921, some 22 square miles of land were in Asian hands and 20 more were under lease.
} 
high reputation and also receive preferential colonial tariffs that eased their accessibility to consumer markets in the United Kingdom. ${ }^{79}$ Canada was not the only colony to cultivate tree fruits for British consumer markets; the Jaffa orange trade from Mandate Palestine, which grew in the 1920 s, was another instance of a primarily export-oriented tree fruits industry. ${ }^{80}$ Tree fruit marketing strategies in interwar Canada addressed local needs, but also worked along colonial avenues of trade. In September 1934, a "small shipment of Red Williams (apples)" was forwarded to Liverpool via Montreal. ${ }^{81}$ Still, some Canadian fruits were considered unsuitable for British consumer standards. In 1934, Nova Scotian apples faced obstacles to accessing British markets as one Fruit Trade Commission representative thought it "a colossal blunder for the controlling interests to exclude apples of a quality British Columbia Growers are allowed to ship to Great Britain." ${ }^{, 82}$ As business climates shifted after the war, Canada's agricultural export markets were diversified and products reached an increasingly new range of consumers, especially in United States.

While southern British Columbia's fruit growing history is today recalled in local history exhibitions, exhibit narratives often focus on the pioneering efforts of settlers and the gendered brigades of labour that supported local productive industries, offering less attention to the webs of colonial commerce along which produce travelled. The archive, however, offers a counterpoint. In the 1930s, B.C. farmers were engaged in

\footnotetext{
${ }^{79}$ Harris with Demeritt, "Farming and Rural Life,"233.

${ }^{80}$ On the Jaffa orange trade to Britain see Ari Shavit, My Promised Land: The Triumph and Tragedy of Israel (New York: Spiegal and Grau: 2015).

${ }^{81}$ Dominion Marketing Board. Correspondence. Fruit Export Marketing Scheme (Folder no. 1), R194-531-E. LAC. Sept. 24, 1934 correspondence between W.B. Gornall of the Canadian Government Fruit Trade Commission and C.F. Burrows, Fruit Export Board of Canada.

82 Ibid.
} 
the business of exporting fruit and vegetable products for economic benefit. ${ }^{83}$ The archive also provides windows into labour conflicts surrounding harvesting and processing work; in the 1950s, fruit and vegetable workers in British Columbia were in some cases organized and represented by unions: in 1942 a project to unionize packinghouse workers was renewed after failed efforts in the 1930s, leading to the establishment of the Fruit and Vegetable Workers' Union. ${ }^{84}$ In 1958, the Federation of Fruit and Vegetable Workers certified union participation for workers in thirty-five British Columbia canneries and packinghouses. ${ }^{85}$ The provincial seasonal workforce in 1957 was estimated at three thousand workers, of whom an estimated one thousand were itinerants that worked only two to three months per year. ${ }^{86}$ By their nature, seasonal industries demanded itinerant workers, with labour responding in a sort of butterfly effect to the jobs made available for only a portion of the year.

In British Columbia in 1958, a swelling population made local labour available for fruit-related jobs while a "marked increase of immigrant labour" helped generate a secondary pool of workers. ${ }^{87}$ Fruit and vegetable workers in 1950s British Columbia sought out a shortened workday and workweek through union participation, despite

\footnotetext{
${ }^{83}$ Dominion Marketing Board. (BC Interior) Vegetable Marketing Scheme (Folder no. 2). R194-53-1-E. LAC. One 1934 farmer petition combated a proposal to regulate the marketing of interior-grown vegetables noting how critical markets for tomatoes, onions, lettuces, cantaloupes, potatoes, celery, and cucumbers sat outside provincial boundaries, thus requiring a significant portion of the crop to be exported.

84 “Fruit Industry-Fruit and Vegetable Workers' Union,” 23. Kelowna Public Archives.

85 "Submission to be presented by Federation Delegation to the Canadian Labour Congress, March 31st, 1958," 1. BC Federation of Fruit and Vegetable Workers' Unions, Local Unions No. 1 to 12, British Columbia Submission to BC Dept. of Labour, Board of Industrial Unions, Re: Hours of Work and Minimum Wages, 1958. Canadian Congress of Labour Records, LAC.

${ }^{86}$ Ibid. While the Federation sought to represent workers' rights to a decent workday, intending to protect its members from long hours and exploitation and raise concerns about worker health, in the fruit industry in British Columbia, employers were divorced from the requirement of respecting labour standards applicable to other sectors. Due to the particularities of rural work, with hours oriented around harvest tasks, divergent wage systems catered to the amount of labour performed rather than time devoted and this exceptional system has persisted in many cases across the Canadian agricultural sector.

${ }^{87}$ Ibid. 
organized labour's weakness in the agricultural sector. Apple-packing work in interwar British Columbia was gendered female and rendered white, and in 1950s British Columbia, fruit processing workers, mostly female, were often housewives from the nearby region who worked five or six months per year. ${ }^{88}$ The division of fruit labour in the harvesting, packaging and canning, and transporting stages developed a sophistication, sequence and logic to its segmentation. ${ }^{89}$ While harvest jobs are most often thought of as seasonal, so too was packing work, with most tasks completed by December, and night shifts common in some canneries (and in not more than two packinghouses) in 1957 , and are still common in the fruit industry today. ${ }^{90}$

Innovation caused advances in the fruit and vegetable sector with packinghouses introducing labour-saving technologies like conveyor belts, chain carriers, forklifts and pallets, and in canneries, automated coring and peeling machines. Yet, while labour-saving devices reshaped the industry, manual labour was still required and desired. ${ }^{93}$ In spite of innovation, the quality of the workforce was still deemed important for a successful product. Cherries required special care in picking, processing and transport. A.W. Watt, supervising horticulturalist, in 1975 observed: "[the] handling of cherries from the tree to distant markets such as Montreal and Toronto, is a very long road indeed, and requires special care at all stages" with worker's roles in handling

\footnotetext{
${ }^{88}$ Ibid. These women were often drawn from families that were more hard-pressed for income, as many families at the time had heads of households who produced "slim and insufficient incomes," causing wives and mothers to join the ranks of the fruit packing workforce, this also leading women to an inevitable exposure to highly demanding work conditions ("Submission," 3.) 
produce important; "the vibration, the dropping from belts... all add to the accumulation of bruising and defects, which appear in fruit offered to the consumers. ${ }^{.94}$ Fruit marketing success also depended on timely transport to market.

In addition, in spite of the added factor of technology, the intimate links between

farmers, the land, and the products they cultivated imbued social histories of production with emotion and, sometimes, spiritual worth. Jean Barman has written on the relationship between orchard care and spirituality in Vernon, British Columbia. ${ }^{95}$ Reverence for the land's yield could inflect a grower's behavior towards his crop and hired workforce. Orchardists managed multiple production-related tasks, including planting, irrigation, crop thinning, harvesting, packing and remuneration, while family members often performed physical work and management tasks, or supervised the sale of produce locally.

Known for its immense productivity, the Fraser Valley became a critical site of agricultural development not dissimilar to productive regions like the Skagit Valley, Washington, further south, which similarly depend on a migrant harvest workforce. A trend of seasonality of labour was prevalent in the Fraser Valley since at least the 1950s. ${ }^{96}$ Still, the Fraser comprised only one part of a larger mosaic of agricultural activity in the province. In 1962 alone, British Columbia's Lower Mainland grew

\footnotetext{
93 Jamaican SAWP workers in Ontario tomato processing plants, for example, often performed manual work in industrial settings, including manually peeling tomatoes with knives. See Kimberly Knowles, The Seasonal Agricultural Workers Program in Ontario: from the perspective of Jamaican migrants (M.A. Thesis, University Guelph, 1997). LAC.

94 “Cherries, 1975,” Horticultural Branch Records, 1975, GR 1461. B.C. Archives Victoria. Cherry harvest labour in the Okanagan was typically a task reserved for students or young people who completed the job at hand but often handled fruits in a rough manner that could damage the marketable crop. Report from A.C. Carter, Head of the Horticulture Branch.

${ }^{95}$ See Jean Barman, "The World that British Settlers Made: Class, Ethnicity and Private Education in the Okanagan Valley,” pp.600-26 in Peter Ward and A.J. McDonald, eds. British Columbia: Historical Readings (Vancouver: Douglas McIntyre, 1981).
} 
and marketed some 1.9 million pounds of blueberries. ${ }^{97}$ In 1963 , the province grew an estimated 296 million apples and 35 million pears, as well as peaches, apricots, plums, prunes, cherries, strawberries, raspberries, loganberries, blueberries, cranberries, and grapes. ${ }^{98}$ By 1970 , B.C. exported $\$ 8.85$ million in fruit and nursery products to the United States, United Kingdom, Japan, Korea, and elsewhere in the Pacific. ${ }^{99}$

Yet, despite times of intense productivity, the province also felt the scourge of high unemployment; South Okanagan MLA William Richards Bennett raised the issue of unemployment in 1975 , estimating it to hover at $100,000 .{ }^{100}$ Other social issues intersecting with labour included the prominence of children in the berry-harvesting sector. The B.C. Ministry of Labour in 1984 reported that the Employment Standards Branch was monitoring the "conditions governing child employment in the hand harvesting of fruit, berry and certain vegetable crops," and it had issued over 2,600 permits to growers to ensure the welfare and safety of children in agriculture. ${ }^{101}$ In addition field labour, hydroponics, developed in regions such as Delta, B.C., factored in to a new productive climate suited to the cultivation of more specific products in controlled environments but still requiring manual labour, while labour tactics among

\footnotetext{
${ }^{96}$ Central Fraser Valley Regional District Planning Dept.; E.L. Lee, "Regional Farmland Study; Central Fraser Valley Regional District," (September 1972) 22, City of Vancouver Archives. Locals performing seasonal jobs in the Fraser region during peak harvest times often found themselves with little or no work in winter months, and in addition to formally paid workers, family often performed demanding and unpaid work on British Columbian farms as they did in other circumstances across rural Canada. In 1951, the valley's agricultural workforce numbered more than 11,000, and between 1953 and 1955, seasonal workforces peaked in July, while fruit and vegetable workers lost work in winter months and processing workers lacking formal employment between November and June (18, 29).

${ }^{97}$ Ibid., Table 21, 28.

98 “Horticultural Newsletter, Vol. 43, No. 1," in "Horticultural Newsletter, 1963," in Publications of the Horticultural Branch, 1920-1963, GR 1189, B.C. Archives.

${ }^{99}$ Central Fraser Valley/Lee, "Regional Farmland Study," 23, City of Vancouver Archives. While dairy and poultry dominated agricultural pursuits in the Fraser, other activities included flower and bulb growing, beef, strawberries, raspberries, peas, beans, corn, cauliflower, broccoli, cucumbers and rhubarb (11).

${ }^{100}$ Province of British Columbia, Official Report of Debates of the Legislative Assembly (February 18, 1975June 26, 1975), 5th Session, 30th Parliament, 38-39.
} 
greenhouse owners were also often shared at the administrative level. ${ }^{102}$

British Columbia would in 2006 export some 26,000 metric tonnes of apples in worth $\$ 27.5$ million, while Ontario grew 14,000 exportable metric tonnes worth $\$ 8.2$ million. ${ }^{103}$ Despite high levels of production, Canada in 2010 embraced a globalized approach in importing a massive $\$ 189$ million's worth of apples from the United States, Chile, New Zealand, China and South Africa. ${ }^{104}$ This upside-down world of global commerce has not only seen foreign workers traversing borders to offer harvest help but also urbanites well-adjusted to the poetics of the global marketplace choosing imported apples over local ones.

\subsection{A "Fruit-Growing Heaven on Earth": Life and Production in the Okanagan}

The Okanagan has for over a century served as one of Canada's most prominent sites of fruit and wine cultivation, relying on high levels of seasonal migration. The diversity of labour in the Okanagan Valley was exceptional and also atypical to other agricultural regions in Canada. In suggesting a need for a more regionally inflected historiography of British Columbia, Jean Barman contends we should avoid "seeing British Columbia in terms of parts." ${ }^{105}$ Early patterns of migration for harvest work in the Okanagan commonly occurred within provincial boundaries. Local advancements in fruit growing would render the region unique, as Barman has noted, "the Okanagan

${ }^{101}$ Province of British Columbia, "Ministry of Labour Annual Report 1983-84," (Printed by the Authority of the Legislative Assembly), 4.

102 “Greenhouse Correspondence,” and “A Greenhouse Grower's Checklist,” Horticultural Branch Records, 1975, BC Archives.

${ }^{103}$ Market Analysis and Information Section, Horticulture and Cross Sectoral Division, Agriculture and AgriFood Canada, Government of Canada, "A Snapshot of the Canadian Apple Industry, 2010," (Her Majesty the Queen in Right of Canada, 2012), 11. The U.S. consumed 83\% of all Canadian apple exports in 2010, followed by the U.K. and Mexico (15).

104 Ibid., 7. The U.K. persists as a consumer of Canadian apples, importing \$1.75 million's worth in 2010 (11).

${ }^{105}$ Jean Barman, “Seeing British Columbia,” BC Studies 131 (2011): 9. 
Valley was transformed into a kind of fruit-growing heaven on earth." 106 Englishmen in the Okanagan first had Aboriginal wives but later abandoned them for "newcomer women. ${ }^{107}$ In the realm of farm work, desires for one class or gender of worker over another were often pitted against labour market realities and local conditions, while in the realm of land ownership, dynamics of race often defined the changing social climate of the region.

In the 1920s, Kelowna's Board of Trade advertised the city as an agricultural hot spot, to entice investment and settlement, with panoramic depictions of the city branding Kelowna as an attractive magnet for prospective settlers. ${ }^{108}$ Father Pandosy, town founder of Kelowna, had performed prior missionary work in Washington and was the first settler to plant an apple orchard and small vineyard in the valley. ${ }^{109}$ Fruit trees were cultivated formally in the Kelowna and Vernon districts before 1900, with orchards surfacing as a way for settlers to cultivate a stable food supply. ${ }^{110}$

Advertised as an inexpensive option for British migrants, the Okanagan was considered "almost fashionable" as a middle and upper class migrant destination. ${ }^{11}$ To this day it projects a hybrid mixture of the rural and the modern, of nature and city, its character shaped by the productive capacity and newer commercial interests, with an agricultural workforce now inflected by cultural diversity and guest work. The neighbouring Similkameen together with the Okanagan now denote wealth and resiliency, with thriving vineyard and orchard estates dotting the landscape. In the City of Kelowna's iconography, apples feature prominently and have contributed greatly to the economic viability of the city and its environs. ${ }^{112}$

A land boom led to the fast increase in the acreage of tree fruit cultivation 106 Ibid., 11.

107 Ibid. 
over the course of 1904-1905, and by 1911, the Okanagan was home to more than half of the apples trees present in the province, which at the time numbered almost 2 million. ${ }^{113}$ In 1946 the valley generated 10 million fifty-pound boxes of apples, with harvest work performed by both men and women (See Fig. 3). ${ }^{114}$

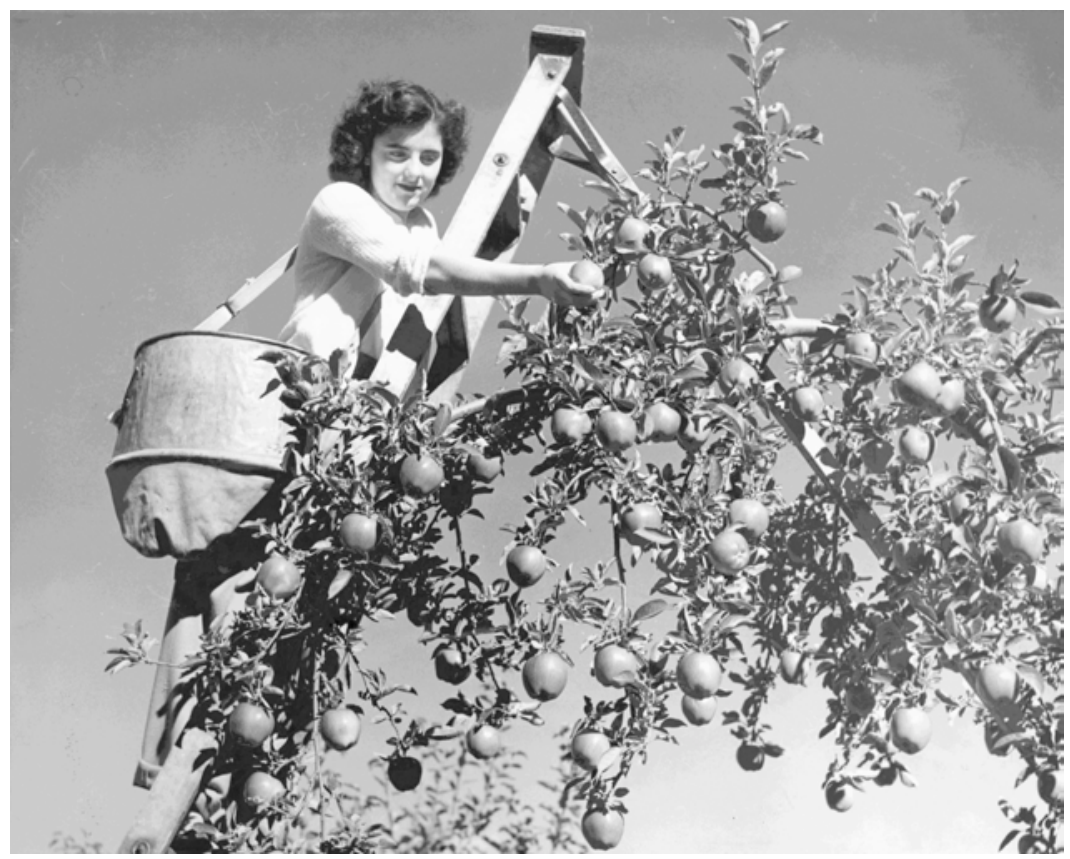

Fig. 3 "A young woman on a ladder picking apples from the top branches of a local apple tree." (c. 1950)

(Vernon Museum and Archives, Photographer Doug Kermode, GVMA 5998)

Note the ladder work required to perform this kind of harvesting.

108 BC Orchard Industry Museum Exhibition August 2012, "Pamphlet and Panorama Illustration."

${ }^{109}$ See Alice Lundy, "Father Pandosy Mission Site Turns 150 Years old in 2010," 74th edition of the Okanagan Historical Society (Richmond, B.C.: Thunderbird Press, 2010) 141. Pandosy was originally from Marseilles and was ordained at Fort Walla Walla, British Columbia, in 1848.

${ }^{110}$ Clement Battye, Reminiscences of a Nonagenerian Throughout the 20th Century, 11, Kelowna PublicArchives.

${ }^{111}$ Michael Gourlie, “Apple Wrapper Flappers: Women Fruit Packers in the Kelowna Area, 1913-1950,” Fruit Industry, Kelowna Public Archives. Apple packing in New Zealand was similarly important, with an "all-Kiwi" workforce performing this role in the 1950s; apples were individually wrapped in tissue then packed in boxes. A "National Apple Packing Contest" was even held in 1955 to showcase the task. See Sarah Johnson, Nga Taonga Sound and Vision blog, “An Apple A Day...” February 10, 2016, http://www.ngataonga.org.nz/blog/nz-history/anapple-a-day/. See also Radio New Zealand, "Sound Archives -Sarah Johnson,” http://www.radionz.co.nz/national/ programmes/ afternoons/audio/201788705/ sound-archives-sarah-johnston

${ }^{112}$ Kelowna's coat of arms, for example, features an apple tree with two apples situated above a lake and the words words "Fruitful in Unity."

113 “A New Organization for New Conditions," BC Fruit Growers Association, 2010.

114 Battye, Reminiscences, 11. 
The valley's rich labour history and heritage and markedly multi-cultural past was also one marked by discrimination and intolerance. Chinese initially took fruit packing jobs but were soon replaced by women who rose willingly to this task in the face of an ostensible Oriental threat and deepening presence in the valley. ${ }^{115}$ At one Vancouver meeting it was proposed women should step in to prevent an increased Oriental migrant presence. ${ }^{116}$ It was not until after First World War that women performed fruit packing work. ${ }^{117}$ This industry would eventually extend to other groups. ${ }^{118}$ As labour relations were shaped by gendered specifications, certain tasks were reserved for and performed by men only; men, for instance, long dominated planting work, as well as the transport and shipping aspects of the fruit industry. ${ }^{119}$ For women, packing jobs were sometimes seen as a blessing as they could offer relief from domestic woes, since the women could "mingle and talk as they moved from bin to bin." ${ }^{120}$ While the Okanagan's experience as a host of migrant agricultural labour did not extend to "offshore" workers until the twenty-first century, the shift was considered in British Columbia in the 1970s.

The products grown and prepared in the valley have undergone significant changes. In 1926, the Oliver region grew tobacco, tomatoes, and cantaloupes. ${ }^{121}$ While 115 Gourlie, “Apple Wrapper Flappers," 5. Japanese entering the Okanagan also made efforts to engage in sharecropping.

116 Ibid., 15.

117 Ibid. Known as "apple wrapper flappers," British Columbian women of the 1920s performed wrapping and packing tasks and earned as much as seven dollars a day at a rate of 4 cents per box packed.

${ }^{118}$ See for instance. "Takeo Arakawa Interview [sound recording]," [1972-04-2], AAAB0064. Interviewer: Maya Koizumi, Fonds PR-1993. Reynoldson Oral History Collection, B.C. Archives. Arakawa worked at a fruit packaging plant during the war in Winfield, BC.

${ }^{119}$ Gourlie, “Apple Wrapper Flappers," 8.

${ }^{120}$ Ibid, 20. The "high profile" of female workers would dissolve, however, as a result of the tray-pack innovation used in most packinghouses of the early 1950s, rendering the "days of wooden boxes and wrapping paper [as] clearly numbered" (27).

${ }^{121}$ For a time Oliver boasted a café "Cantaloupe Annie's" in honour of this agricultural heritage. On the Okanagan's social history see also Lloyd Wong, "Migrant Agricultural Labour: The Okanagan Experience," (Okanagan College); Mario Lanther, "A History of Social discrimination against farm-workers in the Okanagan-Similkameen, 1890-1983," (Kelowna, 1984); Doug Findlater Fonds, "Okanagan Fruit Pickers,” Kelowna Public Archives. 
British Columbia did not prove immune to racism, hostility or ethnic divisiveness, shifting immigration policies allowed new groups to plant roots in the soil and ultimately take part in creating prosperity and deriving sustenance from the land.

\subsection{Connecting Worlds: South Asian Immigrant Labour in British Columbia}

This final section draws on a developed secondary literature on Sikh transnational migration history and migration from the Indian Subcontinent across networks of the British imperial world, to briefly chart out the ways in which South Asian male settlers carved a permanent niche in British Columbia to make way for community development and established citizenship. This literature has been variously shaped by scholars like Hugh Johnston (on British Columbia) and Karen Leonard (on California), as well as Bruck LaBrack, Brian Keith Axel and Tony Ballantyne. I here consider the arrival of Indo-Canadians to Western Canada as it would lead to the formation of a rooted landed agricultural class that would ultimately come to employ Mexican guest workers on berry farms, orchards, nurseries, and farms throughout the Fraser and Okanagan Valleys and the municipalities around Greater Vancouver. Early patterns of South Asian migration to British Columbia were channeled in early years along gendered pathways and later defined by the chain migrations of families. Many Indo-Canadian families would tap in to agricultural opportunities as the fertile, productive regions of Southern British Columbia found parallels with the migrant-sending region of the Punjab where high crop yields, superior rural wages, and high population densities created strong emigration waves, especially among the majority landed Jat Sikh caste. ${ }^{122}$

\footnotetext{
${ }^{122}$ Hugh Johnston, The East Indians in Canada, Canada's Ethnic Groups Series (Ottawa: Canadian Historical Association, 1984), 3-4. In Orientalism and Race, Tony Ballantyne adds that in the Punjab, caste and hierarchy was rejected in favour of "egalitarian landholding conglomerates." (54)
} 
In the first decades of the twentieth century the Komagata Maru saga saw a crystallization of British Columbian rejections of Asiatic "incursions" into white colonial Canada. ${ }^{123}$ Southern British Columbia asborbed a mostly male population of Sikhs in the pioneering migration phase, who took part in the remaking of the social fabric of the provincial rural labour force as well as the forestry and milling industries. Early Punjabi migrants struggled for decades to gain recognition and a place in British Columbian society, although they were often mistakenly labeled as Hindoos despite the fact that the majority practiced Sikhism. ${ }^{124}$ In British Columbia, incoming migrants from Asia faced discrimination and were drawn in by the labour magnetism of industry and their own aspirations and imaginations of Canada as a land laden with opportunity. ${ }^{125}$ Mackenzie King, in his capacity as Deputy Minister of Labour, suggested that it was "desirable" and "necessary" for Canada to remain white, presuming that Canada's efforts to limit Oriental immigration were wholly natural. ${ }^{126}$ South Asians were by default lumped into the category of the Oriental alongside the Chinese and Japanese.

Asian migrants proved flexible, and in many instances more readily filled difficult jobs for economic compensation. ${ }^{127}$ After years of hardship, the Sikhs would ${ }^{123}$ See Ferguson, A White Man's Country.

${ }^{124}$ A politics of citizenship, suffrage and political inclusion would later define Sikh cultural struggles in the province, which had origins in conflicts with British Columbian immigration policies. During the same period in New Zealand, while Sikhs and "Hindoos" were initially preferred over Chinese or Japanese migrants, since they were "citizens" of the empire, an increasingly "colonial nationalist" orientation that idealized the white settler family had by the 1920s intervened to reconstruct South Asian migrants as unassimilable. See Ballantyne, Orientalism and Race, 80-2.

${ }^{125}$ The first Japanese migrants to Canada were similarly male and engaged in fishing, farming, sawmill, and railroad work. Consulate General of Japan in Vancouver, "History of BC-Japan Relations."

${ }^{126}$ Ferguson, White Man's Country, introductory pages.

127 On the diversity of ethnic working groups in California orchard industries of the nineteenth century see Richard Steven Street, Beasts of the Field: A Narrative History of California Farmworkers, 1769-1913 (Stanford: Stanford University Press, 2004). By 1908, British Columbia had already received 5000 migrants from the Punjab who were mostly Sikh. The first Sikh temples there mobilized members to combat an immigration ban placed on their co-religionists. 
consolidate ties to fertile landholdings in British Columbia, and in other North American destinations engaged in agricultural pursuits; they also settled in the fertile Imperial County, California, which shared a border with Mexico. In California's northern Sacramento Valley, Sikhs often turned to orchard ownership for "good financial return," orchards providing them with desired economic power in spite of the high physical demands and limited freedom and mobility required to

maintain them. ${ }^{128}$

In California, ethnicity governed the degree to which South Asians were extended political inclusion and many aspects of immigrant identities. Limitations on Asian land ownership in California, including a 1923 Alien Land Law, also shaped Punjabi struggles to smoothly effect rural settlement and prosperity in the state, and a bi-ethnic community would form between men from the Punjab and Mexican-American women, whose unions sprang from the gendered asymmetries caused by migration. ${ }^{129}$

South Asians eventually making their way into the British Columbian interior, and those who settled in Vancouver and New Westminster took up work in railway, sawmill, lumber, land clearing or seasonal farm jobs, their presence inciting renewed concerns over British Columbia's "white destiny." ${ }^{130}$ Some found work on the Canadian Pacific Railway or were hired at Sikh-owned operations such as Mayo

\footnotetext{
${ }^{128}$ Bruce LaBrack, "First Sikhs Face Major Problems: The History of the Sikhs," Sikh Sansar, June 1974. See also LaBrack, "Occupational Specialization among Rural California Sikhs: the Interplay of Culture, and Economics," Amerasia 9:2 (1982): 29-56. Thanks to Professor Tony Ballantyne for pointing me to the global scholarship of Hugh Johnston, Bruce LaBrack, Karen Leonard, and Brian Keith Axel.

${ }^{129}$ See Karen Leonard, "Punjabi Farmers and California's Alien Land Law," Agricultural History 59.4 (1985): 549-62 and Karen Leonard, Making Ethnic Choices: California's Punjabi Mexican Americans (Philadelphia: Temple University Press, 1994), 12-4.

${ }^{130}$ Ward, White Canada Forever, 80-3.
} 
Lumber on Vancouver Island, as many Sikh mill owners often went on to establish their own lumber companies after the First World War. ${ }^{131}$ Canadian quotas controlled migration from India until the introduction of a merit-based points system in $1962 .{ }^{132}$ As subjects of empire, early migrations followed colonial pathways. ${ }^{133}$ IndoCanadians' integration into Canadian society was since marked by trans-generational shifts. $^{134}$

While Indo-Canadian agriculturalists have extended authority over foreign or "offshore" workers, in some cases entering labour bargaining disputes, Indo-

Canadian farmworkers in the province also emerged as a newly vulnerable farm worker class; farmworkers in the Fraser Valley of Punjabi origin were involved in collective organizing in the 1980s when the Canadian Farmworkers' Union (CFU) promoted strike action leading to labour agreements, with the CFU surfacing in 2007 to lobby the province to implement better transport laws after three migrant farmworkers perished in an accident. ${ }^{135}$ Indo-Canadian small-bush berry pickers in blueberries, raspberries and strawberries in British Columbia were according to a 1998 study, mostly female and over the age of fifty. ${ }^{136}$

The cultural landscape of Southern B.C. was in many ways reshaped by the efforts of Indo-Canadians who formed rooted communities based in land ownership

\footnotetext{
${ }^{131}$ Jagpal, Becoming Canadians, 21; 52.

${ }^{132}$ Hugh Johnston, "The Sikhs of British Columbia: Their Philanthropy in Punjab," in Verne Dusenbery and Darshar Tatla, eds. Sikh Diaspora Philanthropy in Punjab (New Delhi: Oxford University Press, 2009), 191.

${ }^{133}$ Ibid., 169-70; 174. Emigrant Sikhs were often vehemently nationalistic and opposed British rule in India while working in the mills.

${ }^{134}$ Brian Keith Axel, The Nation's Tortured Body: Violence, Representation and the Formation of a Sikh Diaspora (Durham, N.C.: Duke University Press, 2001), 1.

${ }^{135}$ Ronald Mize and Alicia Swords, "Mexican Labor in Canada: From Temporary Workers to Precarious Labor,” in Consuming Mexican Labor, 232.

${ }^{136}$ Hugh Davies et. al., "Cytogenetic Analysis of South Asian Berry Pickers in British Columbia," Mutation Research 416 (1998): 102.
} 
and productivity. An out-of-doors labouring culture was preferred by this group and during the pioneering phase they rejected opportunities in urban domestic work to work instead on fruit ranches. In Kelowna, Sikhs performed mixed vegetable farming and orchard labour with the Sikh presence in the orchard industry dating as early as 1924 , and by 1934 , the Sikh community in Kelowna numbered $100 .{ }^{137}$ Sikhs emerged as a "preferred" group in the milling industry and were viewed as willing to work for "any" wage, with bunkhouse accommodations on early sawmills mirroring those housing Mexican farm hands in British Columbia today. ${ }^{138}$

\section{Conclusions}

This chapter began by exploring the origins of Canadian agricultural practice and took two provinces as case explorations through which to consider how practices of settlement, land procurement and land rights, and cultivation found their roots. In doing so, it draws from a large body of literature but also gives new insights from local history exhibitions, provincial archives and agricultural ministry records. In exploring the antecedents of commercial market gardening in Manitoba, it sheds light on a longer process of development, exchange and, ultimately, agrarian capitalism that came to shape the way foods were produced on industrial scale. In British Columbia, discourses of exclusion were more defined as they were cast against arriving migrants from Asia, yet with time, many diverse groups of varying origins would come to participate in agriculture and the project of finding wealth in the land.

\footnotetext{
${ }^{137}$ Jagpal, Becoming Canadians, 81-2.

${ }^{138}$ Ibid., 135.
} 


\section{2. "Skilled, Productive, and Dependable": Origins of the Canadian Seasonal Agricultural Workers Program}

"These workers have never had a path to citizenship."

This chapter offers a political or bureaucratic history of the emergence of the SAWP in 1974 in Canada, and includes developments in other provinces, especially Ontario, to describe the emergence of a national guest worker program developed for Canadian agricultural producers and designed to suit Canadian farmers' evolving labour needs. At the same time it is a labour history that gives attention to the shifting constitution of farm workforces in two provinces. In widening the scope to discuss developments taking place at the national level, it explores how the SAWP effected transformations on the constitution of the farm labour force in the province of Ontario. In providing Canadian farmers with seasonal workers, the SAWP sought to furnish the "ideal" migrant, best suited to Canadian working climates and needs. In this way, complementarity of labour needs and labour availability in the south served Canada's changing labour needs as it did in other guest work programs developed in the United States that are discussed in more depth in Chapter Three.

The SAWP would develop parameters to define the ideal agricultural migrant according to educational, marital, and rural statuses deemed acceptable by the state. In order to be eligible for a SAWP contract, the migrating worker had first to fulfill the certain qualifying conditions, including limits on educational attainment. ${ }^{2}$ In addition to

\footnotetext{
${ }^{1}$ Stan Raper (UFCW Director), "International Scholars visited AWA centre in Virgil, Ontario" (video posted to AWA Facebook, July 2, 2014).

${ }^{2}$ Recruited workers were to be farmers, "journeymen" or be engaged in agricultural activities, and also be between 22 and 45; they were to be "men and women, married or in a de facto union, preferably with children," and live in a rural area. Consulado General de Mexico en Montreal, "Seasonal Agricultural Work Program."
} 
setting out basic parameters for migration, Canada would also implement its own health standards in its requiring of a medical examination in the country of origin prior to the migration process. In this chapter, I first give a general overview of changing patterns of agricultural production in Canada and the reasons certain industries would develop a need to incorporate non-Canadian workers; I then provide an archeology of the debates that took place in two provinces over the potential (and eventual) practice of hiring workers from Mexico, and move on to a discussion of the ways in which worker health was debated in conjunction with the potential onset of the SAWP program in Canada.Finally, I consider a specific example of worker grievances, as they were articulated on a British Columbia cranberry farm, and a discussion changing currents of migrant work in Canada that takes the study into a twenty-first century context.

\subsection{The Foundations of Foreign Seasonal Farm Labour in Canada}

Political considerations have loomed large in defining histories of guest work and did much to give shape to the movement of seasonal agricultural workers across borders. The United Nations International Convention on the Protection of all Migrant Workers and their Families defines a seasonal worker as "a migrant worker whose work by its character is dependent on seasonal conditions and is performed only during part of the year."3 Caribbean seasonal workers in postwar United States worked in Florida sugarcane, and on apple orchards in Eastern states. ${ }^{4}$ The American tradition of recruiting guest labour from the Caribbean but later curtailing it would ultimately have

consequences for Canada, where, for many years, Canadian politicians had refused to temporarily admit workers from the Caribbean. In 1966, a combination of farmer needs

\footnotetext{
${ }^{3}$ United Nations, "International Conv ention on the Protection of the Rights of All Migrant Workers and Members of their Families" (A/RES/45/158), 69th Plenary, December 18, 1990.

4 See "The West Indies (BWI) Temporary Alien Labor Program: 1943-1977," (Washington: U.S. Government Printing Office, 1978), 2. University of Florida Digital Collections. 
and Caribbean nations' requests for temporary admittance led Canada to introduce its “Offshore Program.”

While Canadian streams for admitting temporary farm workers have undergone shifts and diversification in recent years, this chapter focuses on postwar trends and foundations and emergent practices of recruitment of foreign farm workers. In the United States, recent shifts in farm labour recruitment practices have similarly occurred, including the more widespread use of farm labour contractors (FLCs). The SAWP's precedents in a Caribbean scheme for agriculture was contingent upon earlier American developments. During the Second World War, concurrently with the Bracero Program, a British West Indies Temporary Alien Labor Program (BWITALP) in 1943 first took seasonal Caribbean migrants to the United States, to work primarily along the Eastern seaboard. The BWITALP encompassed diverse regions and industries, from tobacco labour in Connecticut, cherry orchard labour in Wisconsin, tomato work in Indiana, corn work in Idaho, asparagus work in Illinois, and pea work in California, with the need for West Indian workers made more acute in 1964 upon the termination of the Bracero Program. Caribbean workers, in effect, filled a void or met a shortage, to become the most significant body of agricultural workers in America. When this program was curtailed in the 1950s, Caribbean countries turned to Canada with requests that it open its doors to seasonal workers, a request that was initially met with skepticism.

From a hemispheric vantage point, Canada was late in the game as an employer of farm workers sourced from Mexico. Throughout the 1940s and 1950s, Canada

\footnotetext{
${ }^{5}$ Philip Martin, “California: Trends, FLCS, AB 20,” Rural Migration News 21.4 (October 2015). California has led the way in this practice, having 4,100 contractors registered of a national total of 9,300 in 2015. ${ }^{6}$ On early agricultural policymaking in Canada, see Satzewich, Racism and the Incorporation of Foreign Labour.
} 
ignored requests from Caribbean nations to allow migrant agricultural workers to work seasonally on Ontario farms. ${ }^{6}$ By the mid-1960s, however, the stage had been set for the entry of Caribbean farm workers, leading to an eventual extension of this program to Mexico in 1974. Early diplomatic effort forwarded by Commonwealth Caribbean nations requested that Canada open its doors to seasonal workers in light of developments in the south-eastern United States where Caribbean farmworker migration was increasingly curtailed. Vic Satzewich identifies two sources of pressure toward Canada to open its doors to Caribbean seasonal workers: the first from Caribbean governments and the second from farmers and food processors in Ontario in conjunction with their Members of Parliament. ${ }^{7}$ The idea of admitting Caribbean labour to Canada was first put forward in 1947 when the British Colonial Office and the United Kingdom's High Commission in Ottawa requested that Ontario open its doors to Caribbean seasonal workers to fill jobs in the apple and tobacco industries. ${ }^{8}$ Canada initially resisted the proposal, and would receive official requests in 1952 from Jamaica and in 1954 from Barbados for seasonal labour accommodation. ${ }^{9}$

Before the Offshore Program began in 1966 in Ontario, the province mobilized internal sources of labour to help meets harvest needs. In 1964, some two hundred and fifty Aboriginal workers sourced from northern Ontario under the direction of the Department of Labour were transported to work in Southern Ontario for the fruit and vegetable sector. ${ }^{10}$ In 1965-66, the Ontario Ministry of Agriculture reported that farm

${ }_{8}^{7}$ Satzewich, Racism, 146.

8 Ibid., 147.

${ }^{6}$ Mysyk, Manitoba Commercial Market Gardening, 4.

${ }^{9}$ For a vivid visual account see Vincenzo Pietropaolo, Harvest Pilgrims: Mexican and Caribbean Migrant Farm Workers in Canada (Toronto: Between the Lines Press, 2009.

${ }^{10}$ Mysyk, Manitoba Commercial Market Gardening, 81. 
labour was full-time and casual, with recruitment falling under the wing of the National Employment Service. ${ }^{11}$ In 1965, a Farm Labour Co-ordinator was appointed to aid in labour management to help coordinate an "Indian program" in particular that had undergone expansion that year. ${ }^{12}$ In the Ministry of Agriculture's report from 1966, it was noted under "Farm Labor Service" that in 1965, Native recruits in Ontario were offered a single-direction fare to take them to agricultural worksites. ${ }^{13}$ The Farm Labour Service worked in co-ordination with the Department of Indian Affairs to recruit Native workers: some 549 in 1965 and 361 the following year. ${ }^{14}$ At this time, American migrant labour filled Ontario tobacco shortages, with Ontario's Department of Agriculture noting in 1966 that "a special program" hired American workers who "had completed [the tobacco] harvest in the United States and were thus available for this work in Ontario," this group being drawn primarily from the states of Georgia, Kentucky, Tennessee, Florida, and the Carolinas. ${ }^{15}$ A mixture of local and American labour thus met Ontario's seasonal farm labour needs prior to the introduction of a scheme involving Caribbean-sending countries.

In 1966, the face of seasonal farm labour in Ontario underwent a transformation in character that would have profound ramifications in years to come. The 1967 Minister of Agriculture's 1967 report from Ontario notes:

For the first time in 1966 permission was granted for the entry of workers

\footnotetext{
${ }^{11}$ Department of Agriculture, Province of Ontario, "Farm Labor Service," The Minister of Agriculture's Report for the Fiscal Year Ending March 31, 1966 (Toronto: Legislative Asssembly of Ontario; Frank Fogg, Printer to the Queen's Most Excellent Majesty, 1966), 139. Elizabeth Dafoe Library, Winnipeg.

12 Ibid., 140.

13 Ibid.

${ }^{14}$ Department of Agriculture, Province of Ontario, "Farm Labor Service," (1967), 98.

15 Department of Agriculture, Province of Ontario, The Minister of Agriculture's Report for the Fiscal Year Ending March 31, 1966, 140 and Satzewich, Racism and the Incorporation of Foreign Labour, 73.
} 
from the British West Indies for fruit and vegetable harvesting in Ontario. This arrangement was also extended to the processing industry. Twenty-eight employers took advantage of the program in 1966 employing 148 workers. ${ }^{16}$

This report would, however, fail to shed light on a number of conflicts that would emerge. In the program's first year, a religious rift between Caribbean hired hands and one Canadian employer over the issue of working on Saturdays arose when a number of working men spoke out against farmer requests that they perform work on Saturdays; the workers' religious affiliation as Seventh Day Adventists prohibited them from meeting this request, and the workers in question were immediately sent home. ${ }^{17}$ In this case, religious priorities collided with practicalities of the industrial workweek, with religious difference not accepted by an employer who failed to make concessions. That year, Canada took in 264 seasonal workers from the Caribbean, and this number rose dramatically, to over one thousand, the following year. ${ }^{18}$

Indeed, this trajectory of labour change in Ontario has evaded the gaze of existing labour historiography in Canada, despite some attention from a sociological literature preoccupied with the history of "race-relations" in agriculture. ${ }^{19}$ When critically revisiting invited seasonal labour transformations on Canadian farms, a good formulation for understanding the eventual rise in recruiting from afar may have much to do with the phenomenon of numbers; the "reservoir" of willing migrants located beyond Canada's borders has allowed a started program to continue and "succeed" in circumstances where local labour was absent or less than willing to perform lengthy and physically-demanding jobs at low pay.

\footnotetext{
16 Ibid., 98-99. In addition, two processing firms took some 116 "well-received workers."

${ }^{17}$ Satzewich, Racism and the Incorporation of Foreign Labour, 114.
} 
Still, farm labour experiments in Canada have an earlier history. During the

Second World War the Dominion Government rendered conscientious objectors, German Prisoners of War and interned Japanese available to work on farms. ${ }^{20}$ In the late $1960 \mathrm{~s}$ Canada also furnished agriculturalists with labour from military sources and psychiatric hospitals, and, in early 1970s Quebec, convicts were drawn from penitentiaries to aid in apple labour. ${ }^{21}$ Ontario farmers often found it difficult to retain workers for an entire harvest season, causing migration management paradigms to emerge.

With the arrival of workers from the West Indies, Ontario apple growers would come to view this new labour source as a reliable one that could meet the needs of an entire harvest season. ${ }^{22}$ As Veena Verma suggests, SAWP participants became structurally crucial and embedded in Ontario's apple, tobacco, and greenhouse sectors as a "quest for reliable labour" came to permeate the SAWP's mandate. ${ }^{23}$ Still, the rate of deportability associated with the program was often profound. In 1973 alone, 140 Caribbean nationals were deported from Canada over the course of their temporary work contracts, for a host of reasons including health-related, breaching of contracts, and refusals to work. ${ }^{24}$ Repatriations show imperfections in a program caused from deficiencies on both sides: workers failing to meet employer demands in Canadian workplaces and employers with unrealistic expectations, failing to recognize the rights and vulnerabilities of their employees.

\footnotetext{
${ }^{18}$ Satzewich, Racism and the Incorporation of Foreign Labour, 111.

${ }^{19}$ For a sociological account, see for example, Adriana Gabriela Paz Ramirez, "Embodying and Resisting Labour Apartheid: Racism and Mexican Farm Workers in Canada’s Seasonal Agricultural Workers Program” (M.A., Sociology, UBC, 2013).

20 Ibid., 73.

21 Ibid.

22 Ibid., 112.

${ }^{23}$ Veena Verma, "Remembering and Responsibility," LegalEase C.K.U.T. 90.3 Nov. 2011. Verma's scholarship on the legal questions that have intersected with Canada's incorporation of temporary foreign farm workers has contributed much to the development of this field.

${ }^{24}$ Satzewich, Racism, 140.
} 
Jamaican participants in the SAWP, according to one study by Kimberly Knowles, did not accept the academic perspective of "un-freedom" associated with migrant work, and similarly, a number of participants in my study would reinforce this model. ${ }^{25}$ In Knowles' study material improvements resulting from seasonal migration could deter further migration. The SAWP offered travel abroad opportunities, generating a high candidacy rate for a program whose recruitment process was often "unpleasant and undignified." ${ }^{26}$ Studies such as Knowles' reveal how "offshore" recruitment practices were multi-dimensional, offering positives and negatives for participants, who revealed varying opinions as it was experienced in real time.

While the SAWP's top-down management style continues to limit mobility in Canada my field findings from Rutland, British Columbia, reveal that in one case a worker was seeking out work on a different orchard in order to lengthen his Canadian contract; in this case, the worker was hoping for a longer contract in British Columbia to improve his potential to earn wages in Canada. ${ }^{27}$ This willingness to bend rules, more common among migrant Mexican nationals in the United States, reveals that the imperfections of managed migration schemes risk failing to account for the needs of participants in failing to provide sufficient months of work.

Significantly, the SAWP's origins stemmed from two major industries: tobacco cultivation and apples, two industries that required significant manpower to maintain production at numerous stages. By 1938, Ontario's tobacco crop had gained significance in the counties along Lake Erie. ${ }^{28}$ Changing levels of production in Canada would create ${ }^{25}$ Knowles, "The Seasonal Agricultural Workers Program in Ontario," abstract. ${ }^{26}$ Ibid., 2.

${ }^{27}$ One case with a Mexican national employed at an apple orchard in the Lake Country area of the Okanagan Valley, British Columbia, was dissatisfied with only receiving a few weeks of work and was looking to locate a different employer who might hire him on.

${ }^{28}$ Bert Hudgins, “Tobacco Growing in Southwestern Ontario,” Economic Geography 14.3 (July 1938): 223. 
changing labour dynamics, including an eventual upsurge in Canada's migrant farm labour presence. After Britain indicated a "preference for the Empire-grown product" in 1897, the Essex and Kent counties began to cultivate the crop, and by 1920 almost all production was located on "heavy soils" in Essex and Kent in the western Ontario peninsula or Old Belt. ${ }^{29}$ As described in Stinson and Murwin's 1941 study, an expansion of acreage planted to tobacco in Ontario in the 1930s saw 17,000 acres of plantings of flue-cured tobacco in 1930 rise to 64,000 acres by 1939 and profit rise from 12 to almost 80 million pounds. ${ }^{30}$ Stinson and Murwin noted that, at this time, the varieties of tobacco cultivated in Ontario included White and Yellow Mammoth, Gold Dollar, Duquesne, White Stem Orinoco, and Bonanza. ${ }^{31}$ The "New Belt," which became a centre for fine tobacco cultivation, used the kiln method for curing, a practice still made use of today.

Flue-cured tobacco cultivation in Ontario proved a labour-intensive industry that would increasingly rely on mobile workforces after the war, first from the United States, and later, the Caribbean as well as Mexico. Tanya Basok notes that in 1965, there were efforts to incorporate urban Canadian workers into the tobacco fields, yet urban-sourced workers were known to often abandon work after they were paid and also suffered high rates of alcoholism. ${ }^{32}$ As kiln temperatures and weather conditions could impact the curing process and working season on tobacco estates, the ability to control temperatures was fundamental. The harvest depended on carefully choosing leaves for uniformity and

\footnotetext{
${ }^{29}$ Ibid., 223-226. Norfolk County in 1935 generated two-thirds of Ontario's tobacco crop, forming a "New Belt" of tobacco cultivated on sandier soil. At 1938, Canada grew \$50 million worth of tobacco with three-quarters cultivated in Ontario, while the St. Lawrence River tobacco district near Montreal and the Fraser Valley grew much of the remainder.

${ }^{30}$ F.A. Stinson and H.F. Murwin, "Flue-Cured Tobacco Growing in Ontario" (Ottawa: Published by the Authority of Hon. James Goldiner, Minister of Agriculture, 1941), 3. Library at Library and Archives Canada.

31 Ibid., 6-7.

${ }^{32}$ Basok, Tortillas and Tomatoes. 
quality, while curing involved three stages_-yellowing, color-fixing and drying out the stem and leaf - before the cured tobacco was cooled and taken in for "handling." 33 The harvesting stage was critical for growers, and peak labour seasons of transplanting and harvesting required higher numbers. Ontario's tobacco growers initially relied on American migrants, with more than 2,000 arriving in $1958 .{ }^{34}$ In 1966 , Canada consented to import West Indian migrants to Ontario to labour in tobacco, as well as apple and cannery work. Simcoe and York hired "smaller concentrations" of seasonal workers. ${ }^{35}$ The Elgin County Archives describes transitions in the tobacco workforce: "transients" from Quebec in the late 1960s were replaced by "offshore" workers in the later twentieth century, a group "perceived as steady and dependable."36

With its "Offshore Program," Canada enabled tobacco growers to source nonnationals as temporary workers. Those employed in tobacco faced strenuous conditions in harvesting months that often surpassed the conditions of work most were prepared to endure, and for this reason, seasonal tobacco workers often moved on to work in other areas like apples once they completed a harvest, apple work serving as an incentive to finish their term of work in the tobacco fields. ${ }^{37} \mathrm{~A}$ worker in Vincenzo Pietropaolo's visually impressive documentary study of Canadian harvest workers, Harvest Pilgrims, recounted the dangerous and trying conditions of work:

\footnotetext{
${ }^{33}$ Stinson and Murwin, "Flue-Cured T obacco Growing," 1-3. The central purpose of flue-curing is to transform a fresh green leaf with a high moisture content to one that is bright yellow with little moisture, and the leaf must undergo energy release or starvation in the warmed kiln. Seasonal factors affected flue curing as wetter seasons generated a high- moisture crop while drier seasons reduced growth, creating a smaller crop.

${ }^{34}$ Robert. J. Morse, "Seasonal Agricultural Employment in the Flue-cured Tobacco Farming Industry of Southern Ontario" (University of Guelph: M.A. Thesis, 1985) 33. Microfiche, LAC.

${ }^{35}$ Morse, "Seasonal Agricultural Employment," 19. Morse notes that Haldimand-Norfolk, Oxford, Elgin and Brant counties also had high concentrations of tobacco cultivation.

${ }^{36}$ Elgin County Archives, "The Workers," Tobacco in Elgin County. http://www.elgin.ca/ElginCounty/CulturalServices/Archives/tobacco/workers.html, Accessed Dec.15, 2015.

${ }^{37}$ Morse, "Seasonal Agricultural Employment," 85.81
} 
Tobacco...[is] a crop that cannot stand waiting, and so you have to go every day no matter what the weather, rain or not. They spray it, and you have to work in that condition, and sometimes when you're picking tobacco that thing catches in your eye, so it burns a lot. ${ }^{38}$

Tobacco work continues to feature in the trans-provincial geographies of many SAWP workers sourced from Mexico, and a number of workers I interviewed in Oliver, British Columbia, described having former experience in Ontario tobacco fields.

As the SAWP expanded and developed, so too did the diversity of industries that would participate. Floricultural jobs entered the repertoire of the SAWP early on. ${ }^{39}$ Tulip growers of Dutch descent in St. Catharines, Ontario, who annually grow tulips to beautify the City of Ottawa have employed Mexican nationals who, in St. Catherines today, are often seen visiting town to shop at the local Wal-Mart. ${ }^{40}$ Pioneer Flower Farms was among the first in its sector to take advantage of the opportunity to hire SAWP workers, its labour demands marked by seasonality, peaking in the spring and fall months. This Canadian company would benefit from seasonal workers' consistent return, with its peak labour needs characterized by the hiring of approximately 170 seasonal workers, most drawn from Mexico. The tulip, which has long functioned as a symbol of cultivated beauty for the National Capital region, is often equated with wealth and perfection, and in Canada it emerged as an important public symbol in the late 1960s when it was widely planted to beautify the national capital. Canadian tulip farmers

\footnotetext{
${ }^{38}$ Pietropaolo, Harvest Pilgrims, 47. Pietropaolo's photographs have been publicly exhibited at Toronto's Harbourfront in 1993, in Zacatecas in 2010 at the Museum of Migration, as well as in Winnipeg and Thunder Bay in 2012.

39 Floricultural labour is another understudied element in Canadian labour historiography, despite the sector's importance to the Canadian economy and its growing role as an employer of migrant workers.

${ }^{40}$ Field Findings, St. Catherines, Ontario, June 2013. Pioneer also cultivates irises, daffodils, lilies and hyacinths and ships its flowers in temperature-controlled trucks to markets throughout North America. See Pick Ontario, "Pioneer Flower Farms."
} 
farmers also often give hired workers social mobility: one Mexican worker achieved the rank of foreman after six years of work in the greenhouse. ${ }^{41}$ This migrant sector has helped reshape a cultivated out-of-doors aesthetic in Canada while the workers' presence persists as a largely invisible phenomenon, begging the question: could Canada fully bloom without the aid of this behind-the-scenes workforce?

Indeed, trans-national agricultural work in Canada has engendered both bitter and sweet outcomes. The SAWP has been termed the "“crème de la crème' of migrant worker schemes," selecting the "heartiest who could tolerate a few months of backbreaking work in our fields" in order to earn more than they might have at home. ${ }^{42}$ In 2002, Mexican agricultural migration to Canada generated $\$ 80$ million in remittances, a structurally positive effect. ${ }^{43}$ Ties formed through return migration to specific farms strengthened bonds between farm owners and returning workers, with 3,000 "named back" in 1996 of 4200 Mexican workers hired that year, indicating the prevalence of this practice. ${ }^{44}$ Isolation and discrimination were common ingredients in production chains that indisputably segmented working groups. In Southwest Ontario, Tanya Basok was "bombarded...with questions about their rights" as workers shared tales of "abuses they had experienced on Canadian farms." ${ }^{45}$ Canada would tie migrating workers to employers such that SAWP workers could not circulate freely on the Canadian labour market, yet despite problems, some farms provided welcoming working environments for migrants.

\footnotetext{
${ }^{41}$ Amuchastegui, "Farming it Out," This Magazine, May-June, 2006.

42 Ibid.

${ }^{43}$ Deborah Barndt, "Fruits of injustice: Women in the Post-N.A.F.T.A. food system," in Mexico In Transition Neoliberal Globalism, the State and Civil Society, edited by Gerardo Otero, (London and New York: Zed Books, 2004), 37.

${ }^{44}$ Diocese of London, "Part 1," 62 n.3.

${ }^{45}$ See Tanya Basok, "Post-national Citizenship,” 52.
} 


\section{2 "Most Mexicans have a lot of very good friends among Indians in Canada":} Evolving Labour Patterns on Manitoba Farms

This section turns to an exploration of the ways in which rural work shortages were addressed in Manitoba, to open a window into the trends and debates that took place in the province as non-Canadian seasonal workers were introduced on farms. Prior to the era of online advertisements for work placed by Growers Associations and statemanaged farm labour schemes, farm labour was often procured locally, with a high dependence on family help. In 1920, the Manitoba Ministry of Agriculture and Immigration suggested ways farmers might secure needed help, one advertisement indicating that a "fairly liberal number of married couples [were] seeking engagement on farms. ${ }^{, 46}$ The strategy of linking rural labour markets with willing hands through local ads also predominated in postwar British Columbia where orchardists often placed local advertisements indicating the numbers required, the nature and location of the job, and accommodation conditions on-site to find help during peak harvest months.

As Manitoba farmers in the 1970s sought rights to hire farm help from Mexico, New Democratic Party (NDP) members came out in opposition to the introduction of an "offshore" policy. The Mexican seasonal presence in the province was met with protest from fellow farm workers when in 1976 some twenty members of the Manitoba Farm Workers Association combated the importation of Mexican agricultural workers in Winnipeg through a public picket at the offices of Canada Manpower. ${ }^{47}$ Still, farmer preferences and desires would rule the day as their agricultural labour demands grew.

\footnotetext{
46 "Engage Permanent Farm Help Now," in "Entire Male Animals at Large; Engage Farm Help Now - November 1920" (Digitized Image of Manitoba Bank Bulletin Intelligence Service, Winnipeg, Manitoba, November 1920), in Agricultural Instruction Posters, A 0236, GR8299, Archives of Manitoba.

${ }^{47}$ Mysyk, "Role of the State," 178.
} 
As farmers in the province became more willing to hire foreign workers to meet peak harvest needs, policies were shaped in alignment with changing demands of production. In 1975, Manitoba grew potatoes, green cabbage, carrots in "liberal supply," cooking onions, beets, cauliflower, celery, corn, slicing cucumbers, eggplants, parsnips, green peppers, pumpkins, radishes, various squash, and field tomatoes. ${ }^{48}$ Manitoba's long growing season allows it to grow a fifth of the national potato crop and the province is the second most important provider of potatoes nationally, cultivating the majority of its field potatoes in the southwest part of the province. ${ }^{49}$ In 2012, Macdonald, Manitoba, was suggested to me as a potential site for field research with SAWP workers from Mexico who were sent to work on potato farms in the vicinity. ${ }^{50}$ While Manitoba employed 400 Mexican guest workers in agriculture in 2012, Saskatchewan employed fewer, in the range of one hundred. ${ }^{51}$ One strawberry, broccoli, carrot, cooking and green onion, and asparagus farm in Portage la Prairie that hires eighty Mexican workers annually (Connery's Riverdale) had origins in the St. Vital area but relocated to Portage for its superior soil conditions. ${ }^{52}$ Greenhouse floriculture additionally shaped the provincial guest worker dynamic, but field harvest jobs took in the highest numbers.

In studying the SAWP in two western provinces in more depth, it is important to note that Western Canada has seen far less reliance upon migrant Caribbean seasonal

\footnotetext{
${ }^{48}$ Agriculture Canada, "Fruit, Vegetab le and Honey Crop and Market Report" and "Canada, Department of Agriculture Fruit and Vegetable Division, 1975," Horticultural Branch records, 1975, GR 1461 Box 1 File 2, B.C. Archives, Victoria.

${ }^{49}$ Government of Manitoba, "Commodities: Special Crops: Potatoes," (http://www.gov.mb.ca) Accessed 10 Nov. 2011. A crop grown since prior to the First World War, some 80,000 acres in Manitoba are today planted with potatoes.

${ }^{50}$ June 2012 correspondence with Gustavo Mejicanos of the Agricultural Workers Alliance Office, Portage la Prairie, Manitoba. While I did make one field visit to Macdonald, I found no SAWP workers there but was able to get a sense of the rural landscape and remoteness of the location; I similarly visited other more remote northern locations in British Columbia where it was reported SAWP workers were sent, such as Kamloops, without finding any workers or securing interviews.

${ }^{51}$ Migrant Worker Solidarity Network (MWSN) Meeting Proceedings, April 26, 2012.

${ }^{52}$ Bill Redekop, "Farm Family Grieves Amid Busy Season," Winnipeg Free Press, July 52012.
} 
labour than has Eastern Canada, perhaps because of geography, however British Columbia, in particular the Okanagan Valley, has still seen an intake of Caribbean seasonal harvest workers. Varying obstructions to seasonal workers' rights to join unions in Canada also made working climates differ from one province to the next. ${ }^{53}$ In 1990 , the Prairies produced $\$ 33$ million in field vegetables and \$103 million in potatoes, dominating the potato crop alongside Atlantic Canada ${ }^{54}$ Manitoba's floricultural output was also economically significant that year, providing economic opportunities for SAWP workers.

Early news accounts from Manitoba traced the nuances of guest work, offering windows into the emotional landscapes of farm work. The 1985 earthquake in Mexico City had reverberations among Mexican migrant farmworkers Manitoba, with the Winnipeg Free Press reporting how "hundreds of Mexican labourers" in Canada to harvest fruits and vegetables were "cut off from their families following a devastating earthquake in their homeland...63 of the farm workers had been scheduled to return to Mexico City but couldn't because the airport was closed." ${ }^{55}$ That year, Canada employed just over 700 farm workers from Mexico. ${ }^{56}$ One Canadian, who worked alongside fourteen Mexican workers in Portage la Prairie, Jacob Bueckert, recounted the experience of Salvador Rengel, a thirty-year-old farmworker with family near the Mexico City who harvested broccoli, and whose fellow itinerant farmworkers in Portage were unable to secure any information about the earthquake; Rengel had worked in Canada seven years as a farmworker, and confessed that in light of the

${ }^{53}$ See for e.g. Valerie Dugale, “Migrant Workers Organize," Our Times 28.3. (2009).

${ }^{54}$ Mysyk, Manitoba Commercial Market Gardening, 13-5.

55 "Migrant Labourers Anxious for News: Communications in Chaos After Quake; Mexican Field Workers Fear for their Families," Winnipeg Free Press, Saturday, Sept. 21, 1985. Winnipeg Free Press Archive.

${ }^{56}$ Ibid. 
earthquake, he still wished to remain in Canada to complete the harvest, "unless something serious happened to my family, then I would go." ${ }^{, 57}$ Family connections were important, but wage earning was more so. Ruptures in family life would surface as a common theme intersecting with migrant work, from this earlier phase through to twenty-first century contexts.

For Manitoba farmers, farmworker wages rarely constituted a primary expense. In 1991, wages comprised only $8.5 \%$ of total farm expenses in Manitoba while croprelated expenses $(25 \%)$ and machinery $(20 \%)$ were principal costs. ${ }^{58}$ Methods were also set to monitor and regulate the sale of vegetables, as marketing boards established prices and set regulations over how and which products could be commercially sold. Most vegetable and potato farms that hired SAWP workers were affiliated with Peak of the Market, a "grower-oriented" vegetable supplier operating in Manitoba for more than seventy years that set supply controls over 120 vegetable varieties. ${ }^{59}$ Marketing boards had a unity of aims: to protect, maintain, and stabilize farmer incomes and negotiate prices for specific commodities, rendering farmers" "opportunities and returns" upon an equal plane. ${ }^{60}$ Ontario marketing boards carried out similar function; in 1968, Ontario's Apple Marketing Commission set apple prices for retailers and promoted the "marketing of apple and apple products" while the Flue-Cured Tobacco Board was in charge of "auctioning all tobacco through warehouses at Delhi, Tillsonberg and Aylmer [Ontario]. ${ }^{, 61}$ While small-scale and local commerce at farmer's markets have since 
provided alternatives to the mass commodity chains guided by marketing boards, conflicts over the control and sale of produce are still known to occur and often depend on the scale of production rather than the variety of the product.

Despite increased academic and union-based attention to their presence, Manitoba's rural workers have still suffered a sort of invisibility. Avis Mysyk describes the farm hand experience as "shrouded in silence" especially for farm workers of "minority extraction. Aboriginal Canadians, Mexican Mennonites, Mexicans- none have written of their experiences, positive or negative, as farm labourers." ${ }^{.62}$ Manitoba farmers' reliance on the labour power of First Nations is perhaps the most overshadowed and the practice of hiring Native workers would persist in the 1970s when Mexican farm workers were first introduced to the province. ${ }^{63}$ In 1974, the Winnipeg Free Press

observed that the agreement signed between Canada and Mexico sought to "regulat[e] the flow and improve[e] the treatment of Mexican farm workers who help with domestic harvests," indicating a prior reliance on Mexican farm help not yet under auspices of the Memorandum of Understanding signed in June 1974; the memorandum would restrict employment to "Mexican nationals 18 years of age or older who had been recruited by the Mexican government," while "in the past, Mexican families...entered Canada individually to help mainly in fruit harvests. ${ }^{, 65}$ The program signaled a new labour relationship rooted in a new legal framework to provide economic opportunities

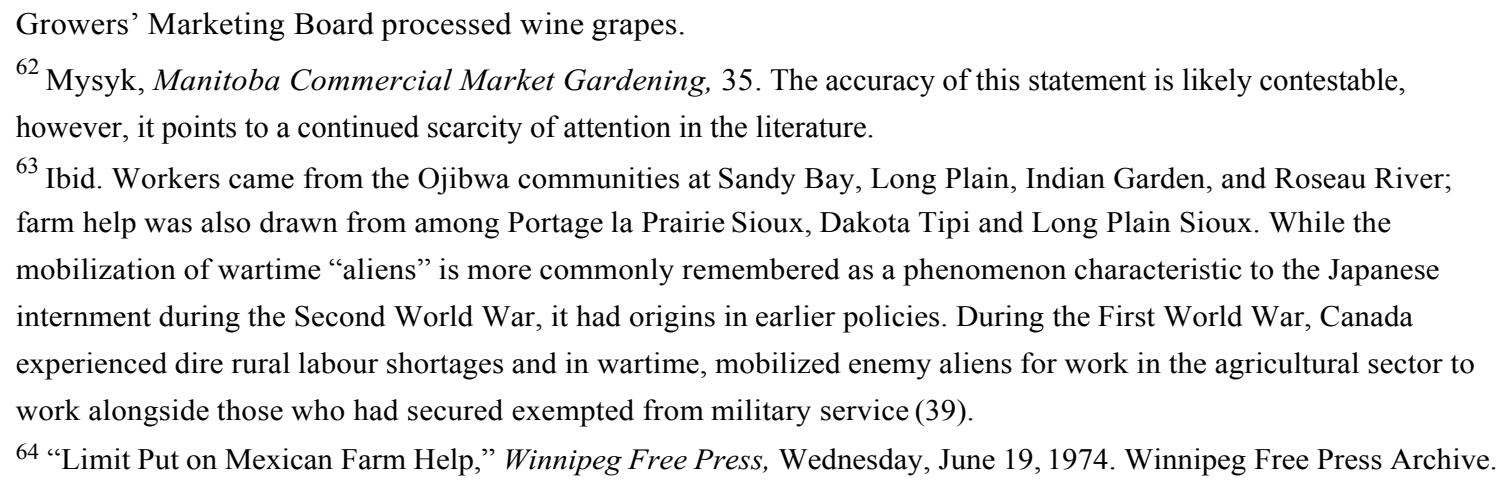


for migrants. Similar in many ways to the Bracero Program (1942-1964) established between the U.S. and Mexico, the memorandum together with its Seasonal Agricultural Workers' Program set a common ground to institutionalize circuits of farm labour integration between Canada and Mexico. ${ }^{65}$

In the news archive we also see public debates take place in Manitoba concerning the potentially advantageous impacts of inviting labour to perform farm work. Journalist Jack Francis noted new tensions in 1978 when an attempted phase-out of Mexican farm labour was proposed:

Canada Employment and Insurance, Manitoba Region, banned the use of any Mexican farm workers, in what has been termed a rather drastic experiment. The results should have been a warning to government employment officials that their program to phase out or drastically reduce dependence on foreign labour was trying to go too far, too fast... Manitoba's major vegetable growers are concerned that federal government policy aimed at easing Canadian unemployment by phasing out foreign farm labour could have the opposite effect by limiting production capability and thus reducing potential jobs for local workers. ${ }^{66}$

Portage la Prairie farmers, concerned over proposed limitations on the numbers of nonCanadians they could hire, expressed logical arguments linked to their own conditions of production; Ed Connery suggested Canada's Employment and Immigration Commission's proposed plan to admit only fourteen workers from Mexico for work on Portage farms in 1978 was "inadequate" to meet the needs of his "already planned crop production," and

${ }^{65}$ For the full text of the Memorandum signed in 1974 see "Canada-Mexico MOU on Cooperative Labour Activities," November 15, 1992, RG25-A-4, Department of External Affairs Records, LAC.

66 Jack Francis, "Vegetable Growers Fear Foreign Labour Phase-out Will Curb Production,” Winnipeg Free Press, February 17, 1978, Winnipeg Free Press Archive. 
efforts to reduce the number of Mexican arrivals to the province to a mere eight in 1979 and to none the following year presented farmers with a set of "insurmountable problems" that might lead to a "cutback in current output." ${ }^{67}$ Mexican farm workers were depicted as "skilled, productive, and dependable" and as setting "a good example for local Native and Métis...many of whom haven't had the opportunity to develop a work habit." ${ }^{, 68}$ Connery praised his Aboriginal workforce but described the Mexican group as amenable to his needs when he admitted that he had hired "some super native people...excellent workers who have been here for years. But it takes time, as in any industry, to develop a skilled work force with good working habits. And that's where the Mexicans help a lot." ${ }^{, 69}$ It is clear that the attempted phase-out of Mexican migrant labour arrivals in the late 1970s was at odds with farmer ideals and desires.

With employer needs ultimately guiding policy decisions, Canadian farmers were still first required make efforts to hire locally and then demonstrate that local labour markets were insufficient. In 1974, a Winkler, Manitoba, potato grower hired nine Mexicans to perform truck-driving tasks after a "Canada-wide search" for workers failed to meet his need. ${ }^{70}$ Canadian farmers that hire through the parameters of the SAWP are required to furnish the Human Resources and Skills Development Canada (HRSDC) with evidence they first sought local labour. ${ }^{71}$ The government did not, however, consistently fall prey to employer requests. When in 1958, Manitoba sugar beet farmers expressed interest in hiring Mexicans, their petitions to the government were refused. ${ }^{72}$

\footnotetext{
67 Ibid.

68 Ibid.

${ }^{69}$ Ibid.

${ }^{70}$ Mysyk, Manitoba Commercial Market Gardening, 48. Original cit. Manitoba Department of Agriculture and Immigration, 1959.

${ }^{71}$ Gibb, "Farm Workers from Afar," 5-7.

72 Ibid.
} 
In addition to tensions connected with geography and locality, conditions on the ground shaped the history of hired hands in the province. In Manitoba, the housing conditions of itinerant Aboriginal farm workers were often degraded; discrepancies between what were described as "adequate" or even "comfortable" housing units provided for Mexican workers in Manitoba contrasted with "woefully inadequate" living conditions given to Aboriginal workers on southern Manitoba sugar beet farms where "shacks and old milk trucks" served as accommodation. ${ }^{73}$ Despite these stark realities it was in fact the provincial government's view in the mid-1970s that Aboriginal workers should predominate as the hired farm workforce in the province. A 1976 farm labour review commissioned by the Government of Manitoba entitled “The Right Thing for the Wrong Reason" advised that imported workforces from Mexico should be "phased out by 1980" and replaced fully with an Aboriginal labour force; the review calculated that some 435 First Nations were available to fulfill a demand of 104 full-time and 126 part-time farm workers. ${ }^{74}$ Inter-cultural rifts and bonds would also emerge across cultures, between First Nations and Mexican workers in Manitoba:

Despite complaints that Mexicans were taking jobs away from Canadians, 'Mexicans and Natives have indicated no hard feelings toward each other this year,' said one grower...The Mexican consul general at the time noted that 'Most Mexicans have a lot of very good friends among Indians in Canada. They identify with them as workmates'... One Mexican worker admitted that he detected 'some bitterness' on the part of local labourers that summer although another said they just ignore it: 'We say we don't understand Indian. ${ }^{75}$

\footnotetext{
$\overline{73}$ Mysyk, Manitoba Commercial Market Gardening, 49. The issue of constructing housing for seasonal Mexican farmworkers was met either through the use of shared trailer accommodations (as in East Selkirk and Portage la Prairie), or dorm-style accommodations in Marquette for a male Mexican guest workforce.

${ }^{74}$ Ibid., 50-1.

${ }^{75}$ Ibid., 51. 
Manitoba growers insisted that Mexican workers generated economic productivity for the province, contending that imported workers were better suited to “menial labour" and functioned as more highly motivated workers. ${ }^{76}$ In Manitoba, farmers' arguments were coloured by personal preferences and psychologies. Many farmers were less than keen to employ non-Canadians and relied instead on family help and local workers, while others agitated publicly for the right to hire offshore:

One farmer in the Portage area refuses to grow broccoli unless the government allows him to import offshore workers for the job....If he is allowed the Mexican workers, other ancillary jobs will be created. The agreement between the growers, farmworkers' association and federal and provincial governments calls for growers to create four jobs for every Mexican they import. ${ }^{77}$

Thus, the Mexican program in Manitoba was not without controversy and it mirrored trends taking place in other provinces. In 1981, "offshore" jobs available nationally in Canada were on a steady increase, with 6,000 arriving that year from Mexico and the Caribbean. $^{78}$

Patterns of wages and hours of work have also evolved since the early years of the program. In 1983, farmworkers "flown in from Mexico" earned $\$ 4.50$ per hour harvesting Manitoba produce with a workday of 8-12 hours. ${ }^{79}$ One Portage area farmer described how "the Mexicans will put in the extra time that the average Canadian won't. The Mexicans do come here to make money. They're only here for a short period of time. ${ }^{80}$ News also often made reference to wages available in Mexico; in 1983, one farmer at Marquette said his foreign workers:

\footnotetext{
${ }^{76}$ Ibid., 52-3. Foreign farmworkers hired in Manitoba increased in the first decade and a half of the program, with nine employed in 1974, eighteen in 1978, 41 in 1982, and 75 in 1991.

77 “Farmers Favour Mexicans over Local Labourers,” Winnipeg Free Press, June 11, 1981, 4. Winnipeg Free Press Archive.
} 
live on the farm and are ready to work at any time. Working by a conveyer belt from which he plucked celery stalks to pack with machine-like precision inside cardboard boxes, Teofilo Jimenez said he liked his job at Itzke's farm. 'I come to work.' ...Jimenez, 33, said he earns about $\$ 10$ a day in Mexico, where he supports a wife and five children. ${ }^{81}$

The same farm would also hire members of the Long Plains Indian Reserve; in 1983, Rose Assinaboine worked at Itzke for eight consecutive years and admitted to having "no quarrel with the Mexican workers. 'I'm just as fast as them.",

Debates over the sourcing of labour from Mexico intensified into the twenty-first century as the hiring of foreign workers increased. In Manitoba, discourses citing unemployment were persuasive, yet farm work's difficult nature was cited in counterpoint and as a justification to hire from afar: "the number of Manitobans looking for work exceed the 350-odd positions available during the peak of the vegetable-picking season," yet "not all those looking for work were necessarily well-trained or motivated enough to persevere with difficult farm work. ${ }^{\circledR 83}$ While foreign farmworkers were viewed as a logistical necessity, since they were non-nationals Canadian politicians often depicted them as less than desirable while dissenting politicians viewed them as less than necessary. The diversity and economic significance of Manitoba produce, as documented in

\footnotetext{
${ }^{78}$ Ibid. On contemporary working climates in Canada see David Camfield, Canadian Labour in Crisis: Reinventing the Workers Movement (Blackpoint, NS: Fernwood, 2011).

79 "Farmers laud willing Mexican labour: Numbers of 'offshore workers' being reduced every year, official says," Winnipeg Free Press, Saturday, August 20, 1983, 4. Winnipeg Free Press Archive.

${ }^{80}$ Ibid.

81 Ibid.

82 Ibid.

83 Ibid.
} 
the Manitoba Agriculture Yearbooks, in 1982 included asparagus worth $\$ 300,000$, cauliflower worth above $\$ 600,000$, cabbage $\$ 800,000$, broccoli $\$ 400,000$, cucumbers $\$ 580,000$, carrots $\$ 1.3$ million, and onions $\$ 1.5$ million. ${ }^{84}$ In 1983 , Manitoba’s potato harvest was valued at $\$ 27$ million. ${ }^{85}$ Manitoba-grown asparagus found its way to supermarkets throughout the province. Embedded in local, national, and cross-border markets, Manitoba-grown vegetables were worth a total of $\$ 15$ million in 1999, finding consumers in Saskatchewan, Alberta, Ontario, and the United States. ${ }^{86}$ By 2002 Manitoba vegetables were worth $\$ 22$ million and greenhouses hired 1,130 people paying $\$ 7.7$ million in wages. ${ }^{87}$ Perhaps surprisingly, in 2008-9, the Yearbook describes Manitoba's agricultural foods sector as still sitting on a strong foundation of family farms. ${ }^{88}$ As agriculture's impact expanded into the twenty-first century, growers diversified their workforces, the sorts of crops cultivated, and their marketing tactics to stay afloat.

\subsection{Debating “Offshore” Hiring Practices in British Columbia}

The province of British Columbia would not take part in a seasonal labour

program with Mexico until 2004, much later than other provinces such as Ontario, Quebec, Manitoba, and Nova Scotia, which hired seasonal agricultural workers at its

\footnotetext{
${ }^{84}$ Manitoba Agriculture, Food and Rural Initiatives, Manitoba Agriculture Yearbook, 1982 (Winnipeg: Manitoba Agriculture, Food and Rural Initiatives, 1982), 18-19.

${ }^{85}$ Manitoba Agriculture Yearbook, 1983, 6. Strawberries acreage rose by 22\% over the course of 1982-3, while raspberry acreage expanded from 25 to 35 over the same period. In 1983, some $\$ 5.9$ million in greenhouse and mushroom products were recorded alongside $\$ 8.75$ million in nursery products and sod. Manitoba greenhouses was also implicated in larger networks of capitalistic exchange; one East Selkirk family-owned greenhouse that hires on SAWP

workers to cultivate flowers, herbs, trees and shrubs markets its flower baskets at The Home Depot. As Manitoba greenhouse growers competed with Ontario, British Columbia and the United States, mushroom production emerged at new facilities to "displace" some American imports (20).

${ }^{86}$ See Manitoba Agriculture Yearbook, 1999. A long harvest season in 1999 saw growers struggling to retain strawberry and raspberry pickers for the full duration of the harvest.

Manitoba Agriculture Yearbook, 2002, 40-42.

${ }^{87}$ Manitoba Agriculture Yearbook, 2006, 39. In 2006, Manitoba grew beets, gherkins, lettuce and spinach, peas, peppers, radishes, and turnips and more traditional crops and was home to seven mushroom growers including six gourmet companies and one conventional and specialty operation. Manitoba Agriculture Yearbook 2006, 38.

${ }^{88}$ Manitoba Agriculture, Food and Rural Initiative, Annual Report, 2008-2009 (Winnipeg, Government of Manitoba, 2009), 6. 
onset in 1974. As farm labour needs fluctuated in B.C. in its postwar decades, employers and growers' associations would consider and debate the use of Mexican labour to serve their needs. As early as 1957, the Fruit Growers' Association of British Columbia asked the province if it would consider hiring Mexican or Filipino labour to perform seasonal agricultural work, to be "moved to various parts of the province as required. ${ }^{89}$ In 1974, the year that the SAWP began in four provinces, there was talk of employing a Mexican labour force to harvest berries in the Fraser Valley, with a number of growers expressing interest in this option; at this time there had already been "a move to acquire Mexican labour" in Chilliwack area hop fields. ${ }^{90}$ President of the Fraser Valley Fruit and Vegetable Growers' Association Nick de Waal pointed to the potential "difficulties" involved in hiring Mexican workers who would have to be guaranteed a minimum of six months of work in Canada and would also have to be provided with housing. ${ }^{91}$ Fraser Valley agriculturalists, including strawberry, raspberry, and cucumber farmers at the time expressed difficulties in obtaining sufficient workers to meet their harvest demands. ${ }^{92}$ In an effort to promote a policy shift De Waal maintained that in every occupation there was dignity, and that in Mt. Vernon, Washington it was apparent that Mexican farm hands served as a "conscientious" workforce. ${ }^{93}$

The option of employing Mexican agricultural workers came under debate again in British Columbia in 1975. At a meeting of the Okanagan Agricultural Manpower Advisory Committee at B.C. Tree Fruits Limited, Kelowna, in April 1975, the "Mexican Program" was discussed, and Ray Holland of Hop Company, Chilliwack,

\footnotetext{
89 Tomic, Trumper and Aguiar, “The Social Cost of 'Healthy’ Agriculture,” 59.

90 “Mexicans would be 'good workers," Chilliwack Progress, Wednesday, December 4, 1974, Chilliwack Archives, British Columbia.

91 Ibid.

${ }^{92}$ Ibid.

93 Ibid.
} 
recorded how he was, "approached last winter by East Indian contractors and since they couldn't get Mexicans, had hired 25 East Indian workers and so far were very satisfied." ${ }^{94}$ Holland noted "about 30 to 40 East Indian workers were employed in the Okanagan" and "when questioned about the Mexican Program" confirmed that "at present there is a surplus of unemployed workers in the province." 95 In an effort to locate the most fitting conditions for resorting to an imported workforce, Holland stated:

The hop Company at Chilliwack and the Daffodil Growers in Saanich had no difficulty in obtaining sufficient workers; it would be very difficult to bring in Mexican workers while this kind of situation prevails...The only way the Mexican program could be implemented would be in the case of there being no Canadian workers available..$^{96}$ (Italics mine.)

While the option of sourcing Mexican labour in B.C. was considered and debated in 1975 it was rejected in accordance with the logic of hiring from among a more local pool of labour.

The choice to shelve the option of importing foreign workers was maintained in British Columbia throughout the first three decades of the Canadian SAWP until BCSAWP entered the scene. Local residents, including Anglophone Canadians in Kelowna in fact still perform food processing-related jobs year-round. ${ }^{97}$ In the first year of the BCSAWP program, eleven farmers hired 47 "offshore" workers whose numbers

94 “Tree Fruits, 1975. Horticultural Branch Records, 1975. GR 1461, BC Archives, Victoria.

95 Ibid.

96 Ibid.

${ }^{97}$ Field Findings, Kelowna and Winfield, August 2012. One local Anglo-Canadian worker I met in Lake Country was employed, for example, in a local fruit leather factory. British Columbian employers have long relied on often young and itinerant workers, including from Quebec willing to perform seasonal harvests, and local British Columbia residents who migrated internally from adjacent regions. Quebec youth still offer peak harvest help in many orchard sectors, however their importance has been dampened by accelerated seasonal migrations from Mexico and the 
increased to 690 the next year under sixty-seven employers and to 1200 in $2006 .{ }^{98}$ The Okanagan took in a good proportion of workers, employing one third of all Mexican seasonal workers in $2008 .{ }^{99}$ Vineyards often proved among the most worker-friendly sites as they were well-equipped to offer their workers quality accommodation, yet Mexican seasonal workers in the province often found themselves in workplace situations that functioned under "fairly rigid circumstances." 100 The migrant presence in Canadian grape harvests would increase with the onset of the BCSAWP in 2004. The 2008 B.C. Grape Growers' Association Newsletter wrote of "access" to temporary foreign agricultural workers as the "only way we will be able to meet our current and future labour needs." Still, many vineyards continue to operate without this help. In 2012, the entry of offshore workers into the Okanagan Valley wine industry received national media attention. ${ }^{102} \mathrm{In}$ Oliver in 2012, one wine grower of Romanian descent described having enlisted some Mexican help. ${ }^{103}$ Indeed, the Mexican migrant has offered a seasonal body of labour for British Columbian agriculture, albeit one that now detracts from the ability of local workers to participate in local agricultural labour markets.

Caribbean, which has flooded the aricultural job market in many high-production regions such as Pitt Meadows, Delta, Ladner, Abbotsford, Mission, Oliver, Osoyoos, Okanagan Falls, Kelowna and Lake Country, Vernon, and Kamloops.

${ }^{98}$ Tomic, Trumper and Aguiar, “The Social Cost of 'Healthy’ Agriculture,” 59.

99 Ibid.

100 Ibid., 63.

101 Ibid., 58.

${ }^{102}$ Wendy Stueck, "Mexican Labourers Keep B.C. Wine Flowing," Globe and Mail, Oct. 14, 2011.

${ }^{103}$ Field findings, Oliver, August 2012. Wine growing regions across the border were also long dependent on Mexican workforce, including the California's wine industry. 


\subsection{From "Vectors of Disease" to Casualties of Industry: Canadian Anxieties and Migrant Health}

This section turns to the history of health management practices, as the theme of health inflected official discourses surrounding the potential arrival of foreign farm workers to Canada. Fitzgerald and Cook-Martín note that Canada had a "eugenics movement" that mirrored the American one closely, as Canada "made similar recommendations about selecting immigrants by race and health, which were sometimes put into practice." ${ }^{\prime 104}$ Initial anxieties from Canadian officials arose in response to news of the expansion of Canada's "Offshore Program" to Mexico. Ontario's Health Ministry recorded its concerns, articulated in light of a potentially significant new Mexican presence in the province. Matters of health were of concern to provincial officials especially in light of the proposed group's intended participation in the food industry.

A memorandum in 1974 concerning the "Health Screening of Mexican Agricultural Workers" suggested new measures would need to be introduced to test Mexican workers for intestinal parasites such that their "health screening [would] ...comply with Ontario requirements. ${ }^{" 105}$ Anxiety over health conditions of migrants was often linked specifically to notions about protecting Canadians first from any infiltration of disease, as the provincial Minister of Health stressed the weight of health screening in 1974:

I would appreciate your advising me of arrangements made for health screening procedures for these workers. Health screening is deemed very important as some

\footnotetext{
${ }^{104}$ David Scott Fitzgerald and David Cook-Martin, Culling the Masses, 144.

105 “Mexican Seasonal Workers, 1974," Immigration Branch RG76 1208, LAC.
} 
of this group may be carriers of disease and their occupation will, or may involve food processing or preparation. It is strongly recommended that these workers and other similar groups be permitted entry into Canada only upon compliance with a health screening examination of sufficient quality to detect those conditions which could pose a health risk to residents of this country. It is considered a matter warranting prompt attention in view of the imminence of the current harvest season in parts of this province. ${ }^{106}$

Further correspondence noted that the Mexican government was to be responsible for "selecting only bona fide agricultural workers and ensuring by a medical certificate that each worker is free from any infectious or communicable disease." 107

The responsibility of health screening was to be divided between the two nations. The Mexican program was expected to run smoothly, with few health concerns predicted to emerge. ${ }^{108}$ What the Minister of Health failed to predict at the time were, ironically, the problems relating to migrant health that would result specifically from their involvement with the Canadian program as a result of agri-business practices, including the heavy use of agro-chemicals and high incidence of transport-related accidents that would impact many, and cause injuries and even fatalities to participant workers.

Migrants are often viewed as "potential vectors of disease," and often unfoundedly; in most cases migrants' health issues were known to occur more commonly after a period of working and living in Canada. ${ }^{109}$ Housing practices in Canada could also

\footnotetext{
106 Ibid.

107 Ibid.

108 Ibid

${ }^{109}$ Kerry Preibisch and Jenna Hennebry, “Temporary Migration, Chronic Effects: The Health of International Migrant Workers in Canada," Canadian Medical Association Journal 183.9 (2011): 1033-38.
} 
help spread disease resulting from

overcrowded housing for farm workers... Poor sanitation and inadequate means to refrigerate and heat food, along with insufficient toilet and handwashing facilities at worksites, may also heighten the risk of farm workers developing and spreading enteric, food-and waterborne diseases. ${ }^{110}$

Preibisch and Hennebry concluded that the "implications for Canada's food system, given the increasing numbers of migrant workers employed in agriculture, meat processing and food services" were a major public health concern. ${ }^{111}$ For this reason, the authors suggested the provision of health screening measures at the end of each working term in Canada instead of solely as a prerequisite for migration.

Health concerns would become a key issue for Mexican and Caribbean migrants facing hazardous workplace conditions. In June 2012, Luis Perez Dzul, a seasonal Mexican blueberry farm worker contracted brain cancer as a result of pesticide exposure during a B.C. work contract and, after undergoing surgery, was "ordered home...only to die two weeks later in Mexico." ${ }^{112}$ Sacrifices like these were sometimes reported in small newspaper accounts yet were rarely emphasized in mainstream media. One Oaxacan farmworker injured at a tobacco farm in a tractor accident was told to take one day off in bed and then proceeded to work the next day even though his "side hurt for weeks" and he may have "broken some ribs." 113 Offshore workers still face obstacles to achieving health-care access in Canada, as one Oaxacan-born volunteer at the Agricultural Workers Alliance in Surrey commented:

\footnotetext{
$\overline{110}$ Ibid.

${ }^{111}$ Ibid.

${ }^{112}$ See David P. Ball, "A Crisis in Migrant Health: migrants are bearing the brunt of health-care cuts," Briarpatch Magazine, November 8, 2012.

${ }^{113}$ Mize and Swords, Consuming Mexican Labor, 215.
} 
"This is not an isolated area of migrant workers versus health care. It's all connected:

through health, we can see the most basic aspects of how things are not working." "114

Health concerns among farmworkers are not a new phenomenon. In 1987,

Oregon used 16 million pounds of pesticides the generated short- and long-term health

defects for the farm workforce, and illnesses from farm work in Oregon have ranged

from poisonings, rashes, and cancers, to birth defects and cases of infertility. ${ }^{115}$ In

Canada, foreign farmworkers often experienced stress, headaches, high blood pressure

and other problems, often from carbamate pesticide exposure in fields that were "just

sprayed." ${ }^{116}$ Repatriations resulting from health issues among farm workers were a

common theme in Canada with a remarkable 787 cases of repatriation taking place

over a ten-year span of 2001-11. ${ }^{117}$ Migrants from central Mexico and southern Jamaica

in southwestern Ontario faced persistent environmental perils including sun,

noise, and other man-made hazards. ${ }^{118}$ While Mexico recruits workers without a

criminal record, capable of performing agricultural work and meeting requirements

prescribed by Canada for an ostensibly healthy workforce, in numerous cases the

months and years spent in Canada also placed workers at risk. Many of these issues have

been increasingly addressed by activist and migrant justice groups, who have drawn

increased public attention to the intersections between migrant fatalities and risks of

injury and Canadian policies toward migrant farmworkers in the sphere of

accessibility to healthcare services and labour rights in the event of sickness or injury.

\footnotetext{
${ }^{114}$ Field Findings, August 2011, AWA Surrey Office, Surrey, British Columbia.

115 Lynn Stephen, The Story of PCUN and the Farmworker Movement in Oregon (Eugene: University of Oregon Center for Latino/a and Latin American Studies, July 2012), 18. The PCUN campaigned to help migrants achieve amnesty in the late 1980 s and sought to increase farmworker wages, fought pesticide use and collected knowledge about working conditions. See also Stephanie Farquhar et. al, "Promoting the Occupational Health of Indigenous Farmworkers," Journal of Immigrant and Minority Health 10 (2008): 269-80. Indigenous identity was often correlated with low-level remuneration among immigrant farmworkers in the United States.

${ }^{116}$ Gibb, "Farmworkers from afar,"22-3.

${ }^{117}$ See Aaron M. Orkin et al.,"Medical Repatriation of Migrant Farm Workers in Ontario: A Descriptive Analysis," Canadian Medical Association Journal 2.3 (2014): 192-8.

${ }^{118}$ McLaughlin, "Migration and Health," iii; 3-4.
} 
For reasons involving the interaction between health, and working and living environments, migrant worker housing in Ontario was filed as a public health issue with regulations legislated in accordance with Ontario's 1983 Health Protection and Promotion Act. ${ }^{119}$ A full 17\% of Mexican farmworkers in Ontario experienced a workplace accident with a musko-skeletal injury as a result, and migrants often faced "distinct barriers to health access and compensation." ${ }^{120}$ Illnesses and accidents often first surfaced in Canadian production zones. While mental health issues among farmworkers in Canada is still understudied, studies from the United States have helped identify mental health as an issue intersecting with farm work. ${ }^{121}$ The medical examination in the country of origin, undertaken by medical practitioners in sending countries prior to acceptance in Canada, was designed to ensure workers would arrive in Canada free of any pre-existing health concerns. ${ }^{122}$ Medical tests performed in Mexico typically included blood and urine tests, chest radiography, and a general physical examination. ${ }^{123}$ In some cases, migrants failed to communicate their own health concerns until a problem was significant enough to obstruct their ability to work.

In the town of Winston, British Columbia, Christian outreach workers came to the aid of one apple orchard worker employed through the SAWP who had fallen from an orchard ladder and had injured his leg; despite the injury, the orchard owner failed to

\footnotetext{
${ }^{119}$ See, for example, Archives of Ontario, Health Protection and Promotion Act - Migrant Farmworker Housing, 1983, RG 10-26. Similarly in Florida and the State of New York, migrant worker housing was considered a public health issue. See, for example, New York State Department of Health, Migrant Farmworker Housing, http://www.health.ny.gov/regulations/nycrr/title_10/part_15/ Accessed December 1, 2015.

${ }^{120}$ Anelyse Weiler, “'Hot potatoes' and migrant farm worker health,” Sustain Ontario, March 26, 2015, http://sustainontario.com/2015/03/26/26033/news/hot-potatoes-and-migrant-farm-worker-health, Accessed December 1, 2015.

${ }^{121}$ See for example, "Mexican migrants to the US risk 'clinically significant' mental-health problems, study Finds," University of California Davis Health System, ScienceDaily April 4, 2011.

${ }^{122}$ McLaughlin, "Migration and Health," 4. See also Justicia 4 Migrant Workers, "BC Government Violating Canada Health Act," March 22, 2006, and Otero and Preibisch, "The Wild West?" for a report on the health of SAWP workers in British Columbia.

${ }^{123}$ Orkin et al. "Medical Repatriation," 192.
} 
provide assistance or sick pay for the worker's recovery, which lasted several weeks. ${ }^{124}$

In Manitoba, migrant worker advocates have similarly worked to better seasonal farmworkers' access to healthcare in Manitoba. ${ }^{125}$ In May 2013, the Migrant Workers Solidarity Network in Winnipeg organized an event to launch a report seeking out improved rights for the province's temporary farmworkers. ${ }^{126}$ Immediately following the launch, Manitoba announced plans to extend health coverage to the estimated four hundred farmworkers who labour seasonally in the province. Without the efforts of migrant support organizations, the province would not have extended any effort in this regard.

Interconnected with questions of health are factors connected with workplace safety and transport, as seasonal histories were marked by workplace dangers resulting from improper training or exposure to harmful chemicals. As field realities reworked migrant lives, harvest hands were often made more vulnerable than the average worker. Illness, injury, and workplace deaths were a common occurrence among SAWP workers. Toronto's No One is Illegal honoured the life of temporary worker Ned Peart in 2012 who perished at a tobacco kiln. Accidents and fatalities were often linked to transport issues while illnesses and musko-skeletal problems were often born from the use of agrochemicals and the performance of stoop labour. In 2008, Lionel Campbell, of Jamaican origin, after having worked two seasons planting, spraying, and picking cucumbers, was repatriated to Jamaica after his hospitalization for chest pain and a fluid build-up in his lung; workplace chemicals burned his eyes and nostrils, the spray sometimes so

\footnotetext{
${ }^{124}$ Field Findings, Winlaw, British Columbia, August 2012.

${ }^{125}$ See Lynne Fernandez, "Steeling the NDP's Resolve: Migrant farmworkers need access to public healthcare" (Winnipeg: Canadian Centre for Policy Alternatives Manitoba Office, 2010). At a Migrant Worker Solidarity Network meeting in Winnipeg in June 2012 a committee was formed to lobby Manitoba so that it might extend Mexican seasonal workers' access to provincial health insurance rather than private insurance.

${ }^{126}$ See Read, Zell and Fernandez, "Migrant Voices.” 103
} 
heavy he could "taste it," while Eloid Drummond, 39, of Jamaica was injured at a sweet pepper greenhouse near London, Ontario. ${ }^{127}$ Concerns relating to migrant justice, born from such cases, often went unresolved, another symptom of a politics of abandon associated with the hiring of temporary foreign workers. As initial public health concerns over the importation of workers from Mexico created an early discourse of health debates surrounding the program, workplace conditions on greenhouses and farms would ultimately transform public debates into those centered in discourses of worker health.

\subsection{Migrant Grievances Expressed: The Case of a Cranberry Farm}

Linked to problems of workplace inconsistencies, this section considers how twenty-first century expressions of dissent were manifested in British Columbia among Mexican field hands who migrated for temporary farm work contracts under the umbrella of the BCSAWP program. For as long as migrant agricultural workers have been in the employ of a cultural group different from their own, cultural antagonisms could generate conflicts of interest and experiences marked by certain measures of injustice. This was also true of the Bracero era that set Mexican guest workers in the employ of American farmers. In British Columbia, worker grievances help illustrate how migrant workers were rendered vulnerable due to the arbitrariness of conditions set by their Canadian employers. While working and housing conditions in B.C. were often considered better than previous contracts, wages, and contract lengths were not necessarily viewed as superior. ${ }^{128}$ Justicia 4 Migrant Workers, an activist NGO focused on rights and conditions of migrant workers in Canada, which has a B.C. chapter, has publicly defended the rights

\footnotetext{
${ }^{127}$ Wendy Leung, "Local Food = Ethical Food? Doesn't always work that way," The Globe and Mail, February 14, 2012.

${ }^{128}$ Field Findings, Abbotsford, British Columbia, September 2014. In Pitt Meadows, I encountered a worker who recounted memories of overcrowded housing conditions during a former work contract he had had as a greenhouse worker in Ontario.
} 
of guest workers in Canada including those who encountered arbitrary terminations of employment in the province. ${ }^{129}$ Other NGOs, such as the Niagara Migrant Workers Interest Group (NMWIG) and the New Canadians Centre Peterborough, through its Migrant Farm Workers Project, have played important roles in making efforts to improve the conditions of seasonal workers on the ground. Indeed, NGOs have played a critical supporting role in contemporary migrant politics at numerous local, regional/provincial and national levels. Specific grievances against employment conditions would emerge and find articulation in British Columbia to contest the status quo and practices in the workplace viewed as unsuitable from Mexican workers' points of view and from the point of view of a collective voice.

A letter of grievance written up by a group of Mexican SAWP workers employed at an East Indian-owned blueberry farm in Pitt Meadows made their own particular grievances known in writing in 2006. Among the grievances listed were insufficient hours of work, uncomfortable weather conditions, inadequate locations to eat during work breaks, health concerns, crammed living quarters, employer harassment, and occasional abuse. This letter drafted by workers showcased the challenges they faced as Mexican migrants in particular and as experienced on a British Columbian berry farm. Above all, the letter demonstrated a manifestation of worker agency, authorship, and lack of complacency with given working conditions in Canada; it highlighted cases of unforgivable mistreatment, cultural divergence leading to conflict, worker precarity, inadequate accommodation, and the neglect of a number of essential and fundamental worker needs during the agricultural workday.

\footnotetext{
${ }^{129}$ When presenting the grievance letter to an undergraduate labour studies class in May, 2016 at the University of Manitoba, the students expressed mixed opinions about the degree to which the listed grievances were or were not justified.
} 
The grievance letter opens with the following statement:

We are asking for the prompt intervention of the relevant authorities given that many problems exist for us... who feel disappointed and harmed, both morally and economically, with regards to the Seasonal Agricultural Worker Program between Mexico and Canada. ${ }^{130}$

The letter goes on to delineate difficulties of the working day, lack of washrooms onsite, challenges relating to transport, and intimidation experienced on the farm. Similar reports drafted on these and related issues, often without direct worker collaboration or authorship, have considered how the migrant farm workforce in B.C. often faced limited rights and inconsistent workplace treatment. ${ }^{131}$ A 2008 Canadian Centre for Policy Alternatives (CCPA) report traced a reduced presence of Indo-Canadian farmworkers in British Columbia since 2004 accompanied by a rapid rise in Mexican seasonal migration. ${ }^{132}$ Housing concerns of farmworkers were often defined by a lack of privacy, male-female conflict often shaped social relationships, and in some cases different groups of workers were "pit[ted] against one another." ${ }^{\text {133 }}$ Employers had arbitrary power over workers, and migrant workers' rights often underwent "deterioration."134 Grievances, often expressed with the aid of legal workers, took migrant concerns to the forefront, and written documents continue to serve as key sites of agency in the migrant worker's struggle for a future free of injustice.

\footnotetext{
${ }^{130}$ I have included excerpts from this "Letter of Concern from the Mexican Agricultural Workers of the Golden Eagle Group Farm, Pitt Meadows," as part of Appendix Three.

${ }^{131}$ See David Fairey et. al., Cultivating Farmworkers' Rights: Ending the Exploitation of Immigrant and Migrant Farmworkers in B.C. (Vancouver: CCPA-BC; Justicia 4 Migrant Workers; Progressive Intercultural Community Services; BC Federation of Labour, June 2008): 5; 10. Fairey highlights grievances of BC farmworkers, arguing they were susceptible to unique economic challenges and advocated restructuring such that occupation-specific rather than employer-specific contracts could be introduced.

132 Ibid., 13. The report points to labour dependencies in B.C. as shaped by race and class, with farm labour consistently drawn from the outside, including from South Asia and Japan.

${ }^{133}$ Ibid., 52-3.

134 Ibid. 


\subsection{Encounters with Migrants: Canadian Currents}

In response to the shifting needs and concerns of migrant workers, seasonal migrant histories in Canada were marked by interventions from small and rural Canadian communities, especially from among those connected with churches, unions, and advocacy groups performing outreach work. These Canadian networks served to support migrants' lives in cultural, spiritual and qualitative terms. Since the early 1970s, the parishes of the Diocese of London, for instance, performed outreach initiatives for agricultural workers within its 21,350 square kilometre area in Ontario and since 2003 its Office of Social Justice, replaced in 2006 by a Migrant Workers Ministry, extended efforts to target the needs of foreign farmworkers employed in the area. ${ }^{135}$ Shifts within the Canadian labour movement also led to the incorporation of themes of inclusivity and rights-based demands for temporary farm workers, while in some cases organized labor posed a dissenting voice towards the foreign worker due to a climate of labour competition and discourses surrounding how to define policies that could be deemed sufficiently "Canadian."

Seasonal farmworkers' relationship to the Canadian labour movement would undergo a series of transitions, from an initial period of social exclusion, toward a more inclusive period in which organized labour extended efforts toward migrants leading to increased chances for workers to claim rights in Canada. Leamington, Ontario would become a hotbed for temporary labour migration, surfacing as the home of the highest area for the concentration of greenhouse vegetable production in North America. ${ }^{136}$

${ }^{135}$ Diocese of London, "Part 1-A Snapshot of the Current Reality," A Snapshot in Time: Report on the Migrant Workers Ministry, 2011. http://wp.dol.ca/webportal/uploads Snapshot_report_in_PDF_Current_ Realities1.pdf Accessed 1 January 2017.

${ }^{136}$ Basok, "Post-national Citizenship," 51. 
In addition to changing landscapes of production, Canada's invited farm workforce was increasingly diversified in the twenty-first century. One "Modesto," from Guatemala

City, Guatemala, ended up in Montreal after four years of seasonal farm work in Quebec in strawberries and greenhouse work; after a period working as an agricultural migrant, Modesto ultimately claimed refugee status and returned to Canada, finding work in construction and gardening. ${ }^{137}$ Drawn to Quebec when the temporary agricultural labour program commenced in 2004, Modesto navigated a transnational experience as a migrant wage earner in Canada then forged an independent migration path via refugee status, outside the parameters of farm work. The work he obtained in agriculture was viewed as good, with wages ranging from $\$ 7$ to $\$ 9$ per hour, increasing from one year to the next. His Canadian employer was contento (agreeable) and his accommodation costs of $\$ 30$ per week were considered reasonable. Urban life in Montreal after years as a temporary agricultural worker was admittedly superior to life in Guatemala, and to Modesto's rural Quebec experience, since the city offered increased independence and control over his personal and daily affairs.

Modesto's experience had echoes in American migration patterns where agricultural contracts later make way for urban wage-earning opportunities in the service or construction industries or in landscaping. ${ }^{138}$ Guatemalan agricultural migrants

\footnotetext{
${ }^{137}$ Interview with “Modesto," Tuesday, May 13, 2014, Montreal, Quebec. I found Modesto by chance while visiting a Salvadoran restaurant located near Jean-Talon market in Montreal while living in a nearby neighborhood and was able to conduct an interview. Guatemalans experienced a perceived elevation in social status in Canada, and many did not share the perception that seasonal schemes enforced "unfreedom," as promoted in some scholarly accounts. Patriarchal trends were often reinforced at home as a result of migrant men's experiences in Canada as Guatemalan women at home's status was reduced upon the return of male heads of households. See Christine Hughes, "Those Left Behind: Impacts of Migration on Guatemalan women," FOCALPoint Publications Archive, June 2011. Guatemalan migration to Quebec reached 700 in 2005 while the number of farmworkers of Mexican and Caribbean origin correspondingly dropped by 800 . Guatemalan labour migration to the United States is also common with access to forestry labour through temporary work contracts. North-South Institute; Maxwell Brem, Migrant Workers in Canada: A Review of the Canadian Seasonal Agricultural Program: Policy Brief (Lois Ross, ed. Ottawa: The North-South Institute, 2006), 16.

${ }^{138}$ See Kirk Johnson, “Hiring Locally for Farm Work is no Cure-All,” New York Times, October 5, 2011.
} 
were required to pay high fees to participate in a scheme organized jointly by the International Organization for Migration (IOM) and Guatemalan state, yet, after charges of corruption and ten years of involvement in the management of Guatemalan farmworkers' arrival to Quebec farms, the IOM was expelled from the country. ${ }^{139}$ Guatemalan farmworkers would, despite perceived mobility, still encounter injustices in Canada and faced challenges adjusting to the expectations of work in the fields, while cross-cultural and language differences made cultural collisions more acute.

The extension of Latin American labour to Canada might also be viewed in terms of internal and regionally-inflected shifts. Mexican and Central American workers emerged as the "farmworkers of choice" in the eastern United States, while in Floridan cane cutting, workers from Jamaica and the Bahamas pervaded as a dominant farm workforce after the Second World War. ${ }^{140}$ The Canadian shift to include Guatemala took on a separate bureaucratic character, with a temporary labour migration stream constructed as a pilot program and an "increasingly successful program" with direct benefits to the workers from the point of view of the IOM and Guatemalan state. ${ }^{141}$ In official and state discourses, managed migration was portrayed as beneficial to migrants with top-down evaluations of labour exchange schemes often built on assumptions

\footnotetext{
139 Rural Migration News, UC Davis, “Canada, Mexico," Rural Migration News 20.1, (January 2013) and Gwendolyn Muir, "The Cost of Managed Migration," Briar Patch Magazine, Feb. 8, 2016. The pull of Canadian agriculture has seen mostly male Guatemalans fill over 15,000 jobs since 2003, with an estimated 6,000 migrating annually today, up from an initial 200 workers in 2003. A Foreign Worker Program (FWP) first took migrants from Guatemala to Quebec in 2002, with the initial hope of furnishing workers for Canada's meat, construction, and tourism industries. See North-South Institute; Brem, Migrant Workers in Canada, 16.

${ }^{140}$ Hahamovitch, The Fruits of Their Labour, 200. See also H-2 Worker (dir. Stephanie Black, Valley Filmworks, 1990), which puts a spotlight on the Caribbean cane sugar cutting labourers employed in Florida on temporary visas between the Second World War and the 1990s.

${ }^{141}$ Guatemala's 2008 working notebooks on temporary agricultural workers in Canada highlighted the role played by Guatemalan consular officials as inspectors of labour conditions and arbitrators of conflicts either between workers or with employers. The notebooks affirmed the idea that Canadian employers were compliant with Canadian labour codes. International Organization for Migration and Ministry of Foreign Affairs, Guatemala; Ministry of Labor and Social Provision, Working Notebooks on Migration (25): Second Evaluation - Temporary Agricultural Workers to Canada (Guatemala, C.A.: March 2008).
} 
centred in economic calculations, labour compatibility, and bilateral labour exchange schemes' efficacy and efficiency. ${ }^{142}$ While the Canadian SAWP experienced no intervention from the IOM in the sphere of migrant management, countries like Guatemala, with weaker administrative apparatuses in comparison to Mexico, when organizing the transference of farm workers to Canada, made use of IOM intervention and coordination. Martin Geiger and Antoine Pécoud's work on the understudied role of international organizations (or IO's) in shaping trans-national migration policies is informative in this respect. As Geiger and Pécoud suggest, according to their advocates, the involvement of IOs would enable greater international cooperation, which would lead to policies that pay greater attention to human rights and development imperatives. Yet, at times, interventions by IOs seem to reinforce existing imbalances, as these organisations primarily tend to align themselves with the interests and agenda of developed receiving states. ${ }^{143}$

Geiger and Pécoud make the case that the "complex institutional setting" or positioning of IO's has served to compromise their integrity vis-à-vis questions relating to migrants' rights and welfare in receiving states. ${ }^{144}$ While Guatemalans encountered conflict in Canada, including a high incidence of deportation and tensions with employers, those

\footnotetext{
142 Guatemalan agricultural migrants recruited outside the parameters of the SAWP faced different circumstances than Mexicans recruited within its parameters. Guatemalan farm workers were, for instance, required to pay for their own housing costs in Quebec. Mayra Roffe Gutman and Annie Lapalme, "Cheap Labour: Seasonal Agricultural Workers in Quebec," Focal Archive, November 2010.

143 See Martin Geiger and Antoine Pécoud, "International Organizations and the Politics of Migration,"Journal of Ethnic and Migration Studies 40.6 (2014), article abstract. See also Martin Geiger and Antoine Pécoud, eds., The Politics of International Migration Management (Basingstoke, et. al.: Palgrave Macmillan, 2010) and on how IO's frame migration and make recommendations on its governance, see Antoine Pécoud, Depoliticizing Migration: Global Governance and International Migration Narratives (Basingstoke, UK: Palgrave, 2015). In this work, Pécoud discusses the emergence of international migration narratives and their intersection with new models of international migration governance and conceptions of state sovereignty. Significantly, critics of international migration governance or migration management politics, such as Amnesty International, note that such narratives need credibility from the perspective of migrants as well as states (see 21).

144 Ibid. 
responsible for coordinating and maintaining migration schemes often presented a narrative that describe migration schemes as operating well or adequately, when in reality numerous problems abounded. In dealing with states rather than individuals, IOs activities effectively risked reflecting dominant interests rather than subaltern ones.

Canada has yet to sign the UN Convention on the Rights of Migrant Workers and their Families, as the parameters of the convention came to conflict with many Canadian practices. Social anxieties surrounding a migrant worker presence pervaded communities like Leamington where migrants were often perceived as potential thieves: "Here we go to Zellers ('and Canadian Tire,' adds his roommate') and they stare at us to make sure we won't steal. The same when we go to yard sales"; migrants instead formed relationships with resident Latin Americans who could offer them a better sense of community and place: "they play soccer with some of them and purchase food from others." ${ }^{145}$ In Canada, NGOs that functioned as pro-migrant organizations also performed critical outreach work not provided by the state. ${ }^{146}$

In Canada, political life did in fact see efforts to improve agricultural labour relations, however, innovative efforts to improve legislation were often quickly reversed. Ontario's New Democratic Party (NDP) also made efforts to extend organizing rights to foreign workers in the early 1990s through an Agriculture Labour Relations Act (ALRA) that was soon after repealed by the Conservative government. ${ }^{147}$ The NDP's efforts mirrored similar ones across the border that sought to empower and humanize the farm labour sector, from the establishment of the National Farm Workers' Association,

${ }^{145}$ Ibid., 55-6.

${ }^{146}$ The Migrant Worker Coalition formed in Leamington in 2002, for instance, made bicycles available to workers while Justicia 4 Migrant Workers (J4MW) made migrant causes known to the public at large, promoting the dissemination of knowledge about migrant worker concerns. Basok, "Post-national Citizenship," 59-60, and Justicia 4 Migrant Workers; Adriana Paz, "Harvest of Injustice: The Oppression of Migrant Workers on Canadian Farms," June 22, 2008.

${ }^{147}$ Ibid., 62, n.9. 
precursor to the United Farm Workers union, to the implementation of historic agricultural labour legislation in California in 1975. Most judicial and political questions in Canada facing guest workers in agriculture were associated with labour codes and collective bargaining rights. In Ontario, farmworkers were excluded from collective bargaining rights in 1943 and 1948 due to the limited ability of farmers to earn a profit; this lasted through to 1990 when farmworkers earned rights to unionize but not strike under the terms of the ALRA. The Supreme Court offered Ontario eighteen months to craft a decision such that farmworkers' rights would be protected under the Canadian Charter of Rights and Freedoms, and in 2002 the Agricultural Employees Protection Act (AEPA) granted farmworkers the right to form associations but failed to require employers to engage in collective bargaining with temporary farmworkers. ${ }^{148}$

The legal implications of guest worker programs were often complex and subject to heated conflict and debate, especially in the realm of universal labour rights. While the ILO opposed the Ontario ruling, declaring collective bargaining a universal human right, the SAWP, as it has functioned in Ontario, served as an exception to the ostensibly universalized rule. ${ }^{149}$ Conversely, in Quebec, the provincial Labour Relations Board in 2010 ruled that workers, "whether ... [they] are seasonal or year-round...should have the constitutional right to organize and bargain collectively." 150 This freedom, granted in Quebec and other provinces like B.C., Manitoba and Saskatchewan, generated results for organized labour with union locals formed among Mexican seasonal employees in the Fraser Valley and in the Montreal area, as well as a temporary certification in Manitoba. Still, in provinces such as Alberta and Ontario, limited rights for temporary workers

\footnotetext{
${ }^{148}$ Aziz Choudry and Mark Thomas, "Labour Struggles for Workplace Justice: Migrant and Immigrant Worker Organizing in Canada," Journal of Industrial Relations 55.2 (April 2013): 216.

${ }^{149}$ UFCW Canada, “The Status of Migrant Farmworkers in Canada, 2010-2011,” (Executive Summary): 6.

${ }^{150}$ Choudry and Thomas, "Labour Struggles," 217.
} 
prevail.

Since its initial phase, the SAWP has branched out into a number of divergent migration streams that have reshaped contemporary migration avenues. In 2002, a Stream for Lower-Skilled Occupations (SLSO) was introduced to address worker shortages in lower skilled jobs, including in agriculture, a form of liberalization of Canada's institutional architecture for temporary labour migration, and in 2011, an "Agricultural Stream" was introduced; where these streams diverged from the SAWP was primarily in the area of recruitment, whereby Canadian employers were given the freedom to deal directly with private brokers and hire from any foreign country. ${ }^{152}$ In addition to news coverage and photo-essays such as Vincenzo Pietropaolo’s Harvest Pilgrims, Canadian filmmakers have taken up the question of migrant work. Min Sook Lee sought permission to film on two Leamington farms employing migrant workers from Mexico for her National Film Board documentary, El Contrato, a the film that instructed Canadian audiences about SAWP workers" "unfreedoms" in Ontario. ${ }^{151} \mathrm{El}$ Contrato recounts overwork through the eyes of workers and varying gradations of racism extended by local community members while also relating worker-centered account of the ways in which long periods of family separation have impacted worker psychologies. Migrant stories, as they have been interlaced with the skeleton of power governing the SAWP — local, provincial, and federal — help give a human face to a history that might be told otherwise in terms of numbers. Such stories form a natural counterpoint to the largely bureaucratic history considered in this chapter.

\footnotetext{
${ }^{151}$ Lee's social justice aims include a mandate of informing the public about the vulnerability of guest workers in the Canadian farm sector. Other themes included class biases imparted by Mexican consular officials given the mandate to maintain the smooth functioning of the program.

${ }^{152}$ Miya Narushima and Ana Sanchez, "Employers Paradoxical Views about Temporary Foreign Migrant Workers' Health," International Journal for Equity in Health 13.65 (2014): 3-4.
} 


\section{Conclusions}

This chapter has recovered official viewpoints, opinions, and debates that took place in Canada, among politicians as well as employers, to reveal the many mixed positions taken toward the idea of sourcing non-Canadian workers to perform temporary contracts on Canadian farms. While the health of migrants was initially of concern to Canadian officials, newer public health issues would emerge in connection with patterns in migrant farmworker accommodation and many migrant farmworkers' health would undergo deterioration as a result of their participation in industrial farming techniques in Canada. Despite numerous variations in patterns of farm labour management in Canada and the United States, continuities are discernible including the consistent sourcing of seasonal farm workforces from the Caribbean, Mexico, and adjacent Central American countries such as Guatemala.

While labour flows were "controlled" from above, in many cases, the collective labour rights of temporary farmworkers were impeded in Canada, with migrant advocates and workers speaking out against injustices. Canadian currents in migrant advocacy have included the participation of church workers, union networks, legal workers, resident Latin Americans, and numerous local and provincial NGOs who have taken steps to address migrant farmworker causes in real time. The next chapter turns to Mexico and to explore those economic and social transformations that were most critical in re-forging its international migration climate in twentieth century. In doing so, it draws connections between contemporary North American trends in farm work and earlier eras, finding commonalities in how mobility, seasonality, and agriculture went hand in hand over the course of the twentieth century. It places Mexican migration "on the map" to reveal a broader arc of migration within which the Canadian SAWP can be better understood. 


\section{3. "It is the Rainbow We See Shining" / Es el Arco Iris Que Vemos Lucir: Views from the South}

"The history of resistance in the Mexican labour movement is filled with the tragedies of possibilities."

The United States has exerted a powerful pull upon Mexican labourers since at least the mid-nineteenth century. As this chapter will show, the history of migrant harvest workers' struggles in the United States would follow a unique trajectory, in terms of shifts in the agency and organization of farm labour across decades; of related aspirational efforts to bargain and strike for labour rights; the emergence of illegal migration corridors and permanent migration outcomes; and the rise of governmentdevised temporary work schemes and state efforts to solve and resolve issues concerning migration and migrant illegality. While agricultural migrants crossing borders became more visible in the U.S. during the 1910s and 20s prior to the dramatic Mexican repatriation campaigns of the 1930s, they would not be integrated into a bilateral, statemanaged migration scheme until the onset of the Bracero Program in 1942, also known as the Mexican Farm Labour Program (MFLP), an intergovernmental migration arrangement conceived during the wartime labour shortage. The Bracero era would introduce the Mexican farmhand into the American Southwest and Pacific Northwest, with a smaller presence in southern states, as well as railroad labour into the Midwest, as the United States adopted a model that departed from earlier patterns in which labour contractors at the border predominated as mediating agents for cross-border mobilities.

\footnotetext{
${ }^{1}$ Teresa Healy, "Contesting Restructuring, Transforming Representation: Autoworkers and the Gendered Struggle for Counter-Hegemony in Mexico” (Ph.D Thesis, Political Science, Carleton, 1999), 12.
} 
The U.S. would also introduce other farm labour schemes involving Puerto Rican and "West Indian" workers, which drew in rural manpower through state-formulated contracts to serve agricultural needs along the Eastern Seaboard. While the connections with schemes adopted in Canada in the 1960s and 1970s are not readily apparent, American developments would in fact impact Canadian policy, most critically as a result of the Caribbean farm labour migration phase-outs in the United States after the war. In exploring themes of labour militancy, organization, cross-collaboration, and the impact of "managed" farm labour schemes in the United States, the chapter engages with a broad period of time to unearth the key themes and moments that served to shape the twentieth century emigration climate for the Mexican "proletarian" or day-labouring class. In this chapter, emphasis is given to patterns in migration for farm work, yet this emphasis is made in the broader context of migration that the chapter seeks to address.

This chapter thinks transnationally, to suggest that the "view" from Mexico remains a critical part of the story. The chapter forwards the argument that modern Mexican developments and ideas, especially in the context of Mexico's evolving and developing transnational relationships were equally relevant agents of change alongside the narratives of entry articulated by northern states through their establishment of avenues for organized labour migration. The development of a contemporary Mexican presence outside of Mexico, which is considered more broadly in cultural terms in Chapter Five, should be understood as an extension of competing processes that have included but were not limited to American histories of expansionism and colonization, revolutionary upheaval in Mexico, changing climates of industrial agriculture in the United States, diverse multi-ethnic immigration histories, the inter-cultural world of farm work, histories of labour consciousness and militancy as well as Chicano activism 
and civil rights struggles, American labour entry streams and labour management practices, and histories of transnational capitalism. In exploring the ramifications of Mexican emigration in the twentieth century for farm work, but also the persistence and transformation of agricultural production in Mexico, the chapter considers the critical changes that took place in recruitment and the segregation of farm labour markets between the interwar, wartime, and postwar eras in the United States with an eye to the effects of such changes upon the farm labour migration climate in Canada.

\subsection{Placing Mexican Migration on the Map}

In an effort to trace the root causes of Mexican emigration, this section begins by assessing the prevailing trends in Mexican emigration in the twentieth century, as well as a number of key authors that have worked to reshape the wide, existing body of scholarship on Mexican migration and labour abroad. Additionally, in an effort to locate the "view" from the South, it occasionally draws in Chicano scholarship and primary sources to unlock myriad perspectives that have been forwarded on the phenomenon. One Mexican language news report, for instance, in describing Canadian agricultural jobs, observed:

The climate in Canada is very cruel, if you go to Ontario in February or March you need somewhere that is free from cold drafts, otherwise you will not sleep and you can die of cold. Of course, there are cases that meet the standards of housing, but others don't. ${ }^{2}$

The Mexican Revolution produced a flood of migrants into the United States during the 1910s, and the cross-border movement of Mexican bodies would accelerate during the

2 Insitituto de los Mexicanos en el Exterior, "Advierten de irregularidades en programa de jornaleros en Canadá," Informador, http://www.informador.com.mx/jalisco/2009/160546/6/advierten-de-irregularidades-en-programa-dejornaleros-en-canada.htm, Accessed September 1, 2014 
revolutionary period during which time economic developments in the U.S. and political events in Mexico reworked migration patterns and outcomes. The interwar years were thus historically eventful for Mexican fieldhands at work outside of Mexico as they saw migration extend to new agricultural regions and also featured a period of dramatic removal of Mexican migrants and nationals during the Great Depression (1929-1939) and Dust Bowl years.

The effects of the Depression on Mexico's economy promoted social changes, including a mass expulsion of Chinese from the country in 1931, a reduction in state revenues, and unemployment compounded by the mass return of migrants from across the border. ${ }^{3}$ Meanwhile, in Depression-era America, a context of the limited resources for relief aid and accusations that Mexicans were holding jobs needed by U.S. citizens fed into the climate of pressure that fueled a federal deportation policy and the voluntary return of many, with 400,000 to 1 million Mexican nationals (some estimates say 2 million) leaving the United States during the period of "removal."4 California would, in 2006, author an apology for the repatriation campaign formulated by the Hoover administration, which used the motto "American jobs for real Americans." ${ }^{, 5}$ The repatriation era continues to be informative in both a historical context of labour desirability and in more contemporary contexts involving invited transnational workforces, in Canada, the United States, and elsewhere.

In order to map out the social landscape facing Mexican farmworkers during the

\footnotetext{
${ }^{3}$ Paulo Drinot and Alan Knight, eds., The Great Depression in Latin America (Durham: Duke University Press, 2014), 13-4.

${ }^{4}$ Historians' Mailbox, "INS Records for 1930s Repatriations," March 3, 2014, Department of Homeland Security, US Citizenship and Immigration Services.

5 Joe Dunn (Interviewed by Melissa Block), “Remembering California's Deportation Program, January 2, 2006 , National Public Radio (NPR), http://www.npr.org/templates/story/story.php?storyId=5079627, Accessed Sept. 12015.
} 
interwar period, this chapter draws from the field archive of Paul Schuster Taylor, who pioneered the study of Mexican labour in the United States and left an extensive record of personal notes concerned with the expanding Mexican workforce of the 1920s and early 1930s. Linda Gordon described Taylor as a "humanist economist" whose field work prescribed agency to workers whose mere efforts to earn a living often led to overt labour conflict. ${ }^{6}$ Taylor's scholarship and field archive left a powerful account that was primarily concerned with the social and economic lives of Mexican workers, the way industrial labour relations worked across ethnic divides, interwar trends in labour recruiting and management, and pervading racisms that were at play on farms of the American South and Southwest as expressed by white farmers in relation to their workforces and manifested in rural settings. Cultural perceptions of employers and border officials and economic calculations of industrial employers and recruitment agents also dot the Taylor field archive and give critical insights into Depression-era farm labour relations. While much of his work pre-dates the Bracero era, it illuminates themes and continuities that were in many cases carried over from the interwar years.

While a small body of existing scholarship has concerned itself with Taylor's career and contributions and his marriage to the famed Great Depression-era photographer Dorothea Lange, this chapter highlights findings from his personal field record held at the Bancroft Library in Berkeley. Lange and Taylor would go on to document the great westward migrations of the 1930s in their 1939 work, An American Exodus: A Record of Human Erosion. Lange's famous portrait, Migrant Mother, taken of Florence Owens Thompson, during her series that documented migrant labour for the ${ }^{6}$ Linda Gordon, Dorothea Lange, 151. 
Farm Security Administration (formerly, the Resettlement Administration) captured the desperate state and level of displacement experienced by migrant families in the wake of the Dust Bowl and Great Depression. Migrant Mother was photographed on a visit Lange made to a pea picker's camp at Nipomo, California, and published in 1936, to soon emerge as a universalized depiction of "suffering in the face of adversity" during the Depression. ${ }^{7}$ As James Curtis suggests, Lange also considered herself a "clinical observer committed to a direct, unmanipulated recording of contemporary events" and had on the door of her darkroom a quote from positivist philosopher Francis Bacon:

The contemplation of things as they are

Without substitution or imposture

Without error or confusion

Is in itself a nobler thing

Than a whole harvest of invention. ${ }^{8}$

The Bracero era, in contrast to Taylor's interwar years, has been explored from an impressive variety of angles and interpretations. Still, Taylor's findings would mirror many contemporary patterns of labour segmentation, recruitment, and mistreatment experienced by modern-day migrant farmworkers. Viewed by some accounts as controversial, the Bracero Program would adopt diverse regional manifestations, generate rifts in American politics, and leave a permanent legacy of Mexican/Latino

${ }^{7}$ James C. Curtis, "Dorothea Lange, Migrant Mother, and the Culture of the Great Depression," Winterthur Portfolio 21.1 (Spring 1986): 1. Florence Owens Thompson would in fact complain about its publication in 1958 in a magazine called U.S. Camera. Lange would also go on to photograph tobacco farming in North Carolina and produce a series of photographs documenting farming lives and conditions in the American south. Significantly, Taylor would contribute financially to labour organizing in the region, providing funds for the Southern Tenant Farmers' Union or STFU. See Gordon, Dorothea Lange, Chapter 13, “Migrant Mother,” 241 and Chapter 15, "On the Road: The South," 259-78.

${ }^{8}$ Ibid. 
community formation throughout the U.S. ${ }^{9}$ Braceros were also remarkably documented in photographs, and many of the best scholarly accounts from the period are drawn from bracero worker testimonials and accounts from their offspring, or have derived new interpretations through explorations of media, as in Maria Herrera-Sobek's study of "folk" representations of the bracero experience within Mexico. ${ }^{10}$ Still others have explored the social ramifications of the program on regional life in Mexico. ${ }^{11}$

This chapter additionally explores trajectories of Mexican agricultural labour militancy and Chicano activism, to underscore the historical specificities of farm labour relations that give context to the divergent contexts of labour conflict and activism that emerged later on in Canada. Farm worker militancy in America often engendered strong reactionary responses from among employers, national politicians, and judges.

Bureaucratic labour laws were long in place in the United States to prevent farmworkers from attaining basic rights and protections, and it was not until outspoken efforts of Latino-led labour campaigns, as enshrined in the rise of the United Farm Workers movement, shifted the momentum such that politicians and the broader, consuming

\footnotetext{
${ }^{9}$ See Erasmo Gamboa, Mexican Labor and World War II: Braceros in the Pacific Northwest, 1942-1947 (Austin: University of Texas Press, 1990); Bardacke, Trampling out the Vintage; Cohen, Braceros; Kitty Calavita, Inside the State: the Bracero Program, Immigration and the I.N.S. (New York: Routledge, 1992); and John Mraz and Jaime Vélez-Storey, Uprooted: Braceros in the Hermanos Mayo Lens (University of Houston: Arte Público Press, 1996) / Trasterrados: Braceros Vistos por los Hermanos Mayo (Mexico, D.F.: Secretaría de Gobernación, Archivo General de la Nacion - México: Universidad Autónoma Metropolitana, 2005). On railroad bracero labour see also Barbara Driscoll, The Tracks North: The Railroad Bracero Program of World War II (Austin: University of Texas Press, 1999). The peones de vía of the bracero era were protected by measures implemented actively by the Mexican government, which sought to ensure protections for workers across the border; Mexico performed a collaborative role in ushering in the railroad Bracero Program, whose management characteristics were in some ways similar to the bilateral character of the Canadian SAWP.

${ }^{10}$ See Ernesto Galarza, Merchants of Labor: The Mexican Bracero Story (Charlotte, CA: McNally and Loftin, 1964); Galarza, Strangers in our Fields (Joint United States-Mexico Trade Union Committee, Washington, D.C., 1956); Maria Herrera-Sobek, The Bracero Experience Bracero Experience: Elitelore vs. Folklore (Los Angeles: UCLA Latin American Center Publications, University of California, 1979); and Luis Alfonso Herrera Robles, Memorias de Braceros: Olvido y Abandono en el Norte de México (1 ed. Cuidad Juárez: Colegio de Chihuahua, 2012). HerreraSobek privileged "folk" understandings of the program through interviews, and a media study of fiction and folk songs depicting bracero experiences as they came to impact a larger national consciousness. "Folk" representations of the program were collected through interviews and a media study of fiction and folk songs relating to bracero experiences.

${ }^{11}$ See for example, Richard Hancock, The Role of the Bracero in the Economic and Cultural Dynamics of Mexico: A Case Study of Chihuahua (Stanford: Hispanic American Society, 1959).
} 
public now considered agricultural workers' rights in a serious way. Currents of labour agitation that bled over into the United States from Mexico's revolutionary era (1910-17) would run through the Bracero era and were spawned by particular American conditions of mistreatment and exploitation.

In Mexico, the radical socialist vision implemented by the Cardenás administration offered a program that sought to implement the spirit of the revolution in concrete ways, including measures attempting to better the conditions of the peasantry, while an emergent farmworker politics would begin to take hold across the border in response to the unique conditions of industrial farming in America, shaped by conditions that fell largely outside of boundaries of benevolent protection and care offered by the state in Mexico. While the Bracero Program was an example of rationalized labour management enabled through a bilateral pact that guaranteed certain rights, abuses still prevailed on the ground, and the program operated imperfectly in many instances, just as the Canadian SAWP was plagued by social inconsistencies and imperfect labour norms. Many UFW leaders rose from humble beginnings as farmworkers, and the movement's successes stemmed from the efforts of its organizers who, in dialogue with worker concerns and elevated by their commitment to leadership, moved beyond the parameters of waged work and into the sphere of politicized action.

This optimistic period of farmworker agency made manifest by the UFW would take farmworker concerns onto new political terrain and rework contemporary discourses surrounding farm labour despite the movement's ultimate reduction in importance in the twenty-first century. The Railroad Bracero Program, coordinated bilaterally by the United States and Mexico, would diverge from regular labour 
exchange models, as Mexican state officials went to great lengths to ensure protections for recruits to the program. ${ }^{12}$ Dynamics like these allowed labour problems to become national concerns; at the same time, transnational labour issues often departed from the jurisdiction of the sending state, especially as workers traversed borders to encounter new labour climates. Canada, for example, as the employer of migrant labour from Mexico, has been able to set labour laws for migrants employed within its jurisdiction.

Many workers interviewed in this study also spent time as workers in the United States, and many of these worker's histories included but were not limited to agriculture. Prior migration trajectories often shaped employment decisions and migration tactics pursued later on. Additionally, the migration climate in the United States, especially the climate of illegality, could have the power to inform the migration logic of participants in the Canadian program. With the acceleration of the SAWP, Canada's legal framework for migration served as an alternative magnet for migrants and increasingly functioned as an alternative "northern" destination. ${ }^{13}$ At 2007, Mexico stood as the third most important source country providing temporary foreign workers to Canada. ${ }^{14}$ As national historiography’s tendency to homogenize understandings of the nation's past as one that might be understood as inherently "Canadian" or as one formed as a result of immigration waves to Canada still risks neglecting attention to the historical experiences of marginal groups who remain subsumed within national narratives.

\footnotetext{
${ }^{12}$ See Driscoll, The Tracks North. Mexico similarly expressed concerns over worker experiences in the Seasonal Agricultural Workers' Program but at the same time took action to obstruct migrants from participating in Canadian unions.

13 One departure from this trend has had to do with Canada's Temporary Foreign WorkerProgram(TFW), which led to the "illegalization" of migrants in Canada (some 200,000 in the Toronto area alone) as these vulnerable workers became enmeshed in a context of a race-to-the-bottom labourmarket. Controlledexit strategies were often limited with the TFW program as it was difficult to enforce deportation when contracts expired. Charity-Ann Hannan, Harald Bauder and John Shields, "Towards a Living Wage For All: Illegalized Migrant Workers in Canada and the Role of NGOs in Advocating for their Protection," Labour Pains, Capital Gains Conference, March27, 2015. On the role of the city as a refuge and theoretical questions related to space, geography, and the problem of asylum in the host country see also Jennifer Bagelman, Sanctuary City: A Suspended State (Basingstoke et al.: Palgrave Macmillan, 2016).

${ }^{14}$ Sandra Elgersma, Temporary Foreign Workers (PRB 07-11E), Library of Parliament Political and Social Affairs Division, Parliamentary Information and Research Service, 7 September 2007), 1-2.
} 
As landlessness, the swelling of the cities, overpopulation and limited reproductive rights for women in Mexico generated a mobile pool of ideal candidates for transnational migration, the Mexican twentieth century was shaped increasingly by outmigration and internal mobility. Circular farm labour migration from Mexico would take place against a broader backdrop of international trade relations and economic shifts that took a sharp turn in the 1970s. While revolutionary Mexico sought to empower campesinos and made efforts to nationalize the Mexican economy, a retreat toward neoliberal privatization and hemispheric integration would occur in the wake of Mexico's postwar economic “miracle."15 In the 1970s Mexico experienced internal shifts that saw migrants from central and southern Mexico form squatter settlements in Monterrey for instance, in response to an agrarian crisis. ${ }^{16}$ Such cases of internal displacement involving the Mexican peasantry would emerge as a salient feature of neoliberal restructuring that characterized the final decades of Mexico's twentieth century. The 1992 Agrarian Law, or Ley Agraria, removed ejido or communal lands and protections, harnessing productive land to the transnational marketplace. ${ }^{17}$

The shifting political climate in Mexico after the Second World War would

\footnotetext{
${ }^{15}$ The "Mexican Miracle" encompassed economic growth, industrial output and the modernization of Mexico's economy in the 1950s and 1960s and shift away from earlier import-substitution-industrialization policies.

${ }^{16}$ Gerardo Otero, Farewell to the Peasantry? Political Class Formation in Rural Mexico (Boulder: Westview Press, 1999), xi. Otero describes how Mexico underwent two distinct phases of economic liberalization since independence, the first taking place in the late nineteenth and early twentieth century, and the second, more modern phase commencing in the mid-1980s and lasting through to today. The new liberalism that characterized Mexico's second liberal overhaul was defined by new forms of privatized wealth made available through a retreat from state socialism. The second coming of liberalism also created new changes in the organization of Mexican agriculture.

${ }^{17}$ One measure from the neoliberal period that impacted rural classes greatly was the 1992 Agrarian Law, or Ley Agraria, which removed ejido lands and protections, harnessing productive land to the transnational marketplace; the sale and privatization of "formerly inalienable lands" restructured rural economies, reversing state commitments to provide for impoverished rural classes through guaranteed forms of land ownership. The original, revolutionary intent of Article 27 was to more equitably partition of Mexico's landed wealth through an institutionalized system of collective landownership, and the 1992 law sparked rural upheaval across Chiapas. Article 27 of Mexico's Constitution underwent revision, removing state responsibility to offer up more ejido lands. See DiGiano, "Privatizing the Commons," 46. On privatization and its impact on agriculture and community in Central America, see also Tyler Shipley, "Enlosing the Commons in Honduras," American Journal of Economics and Sociology 75.2 (2016): 456-487. 
reshape rural opportunities and the emergence of a Canadian agricultural scheme might be read against this backdrop. Mexican economic growth also came at the expense of social ills that were increasingly sidelined by industrial pursuits. ${ }^{18}$ Toward the end of the century, continental trade regimes allowed a strengthening of the Mexican middle class, a moneyed capitalist elite, and the rise of a highly stratified society. In the world of migration, narratives of economic or political progress often surface to denote "success stories"; historians, Frank Bajaras and Frank Bardacke, in their emphasis on migrant agency, often highlight Mexican migrants' power to influence their own worlds, while migration scholars, Jonathan Fox and Xochilt Bada, point to the economic agency implicit in the establishment of hometown associations, wherein philanthropic initiatives take place "from below" to be transferred to communities in Mexico. ${ }^{19}$

While the problem of poverty is not new to Mexico, demographic and economic changes made poverty a more prominent feature of the Mexican social structure in the twentieth century. ${ }^{20}$ Since the signing of the Treaty of Guadalupe Hidalgo or Tratato de Guadalupe Hidalgo in 1848, Greater Mexico has thrived beyond Mexico's national borders, with the Anglo-Texan cotton industry offering the earliest opportunities for tejano wage earning on plantation estate settings. ${ }^{21}$ Problems that could not be solved internally were, by default, solved in part by the outside world.

\footnotetext{
${ }^{18}$ See Mike Davis, Planet of Slums (London: Verso, 2006). The expansion of colonias populares or squatters' settlements along the Federal District's periphery took place as small farmers displaced by neoliberal reform migrated en masse to the outskirts of the capital (See 55). For an earlier account of internal displacement in Mexico as a result of the Revolution see Ageeth Sluis, Deco Body, Deco City: Female Spectacle and Modernity in Mexico City, 1900-1939 (Lincoln: University of Nebraska Press, 2016).

${ }^{19}$ See Jonathan Fox and Xochitl Bada, "Migrant Organization and Hometown Impacts in Rural Mexico," in Transnational Agrarian Movements Confronting Globalization, Edited by Saturnino M. Borras Jr. et. al. (Chichester, UK: Wiley-Blackwell, 2008), 267 and 274.

${ }^{20}$ On efforts to uplift the begging class through religious instruction and the provision of housing, see Silvia Marina Arrom, Containing the Poor: The Mexico City Poor House, 1774-1871 (Durham: Duke University Press, 2001). See also Silvia Marina Arrom and Servando Ortoll, ed., Riots in the Cities: Popular Politics and the Urban Poor in Latin America, 1765-1910 (Wilmington, Del: Scholarly Resources, 1996).

${ }^{21}$ On the idea of Greater Mexico see, for example, Héctor Calderón, Narratives of Greater Mexico: Essays
} 
The neoliberal period also saw shifts in national leadership. Mexican politics were long marked by a strong central figure in the president, and much scholarship has emerged around the study of Mexico's challenges with political democratization and a growing divide between the state and its citizens. ${ }^{22}$ With migration's rise under Vicente Fox, Mexican migrants gained new powers as collective agents operating transnationally, in some cases enjoying growing spending power outside Mexico, but were generally "subordinated" to the economic imperatives of capitalist exchange models prevalent in the United States. ${ }^{23}$ Rural people were increasingly pauperized as a result of state policies and the peasantry was quickly transformed into proletarians through the migration process. ${ }^{24}$ Disruptions to peasant livelihoods caused by trade policies, especially as they related to new tariff laws enabling American corn imports into Mexico, saw elements of the structural intervene with rural livelihoods.

Increasingly, historians of Latin America have worked in alternate frameworks, including the Atlantic framework and hemispheric theorizations to engage in revisionist historiography. ${ }^{25}$ Increased out-migration and hemispheric integration became another symptom of the extension of the liberal economic paradigm. While NAFTA jumpon Chicano Literary History, Genre and Borders (Austin: University of Texas Press, 2004) and Colin MacLachlan and William Beezley, El Gran Pueblo: A History of Greater Mexico (Upper Saddle River, NJ: Pearson, 2004). On the economic and social transitions resulting from the Anglo-Texan proclamation of Texan independence from Mexico in 1832 at San Felipe de Austin see Pekka Hämäläinen, Comanche Empire, 199-201. On Mexican inclusion in the Texan cotton industry in the early twentieth century see also Neil Foley, The White Scourge: Mexicans, Blacks and Poor Whites in Texan Cotton Culture (Berkeley and Los Angeles: University of California Press, 1997).

${ }^{22}$ Nora Hamilton, Mexico: Political, Social and Economic Evolution (New York: Oxford University Press, 2011), 107. López Portillo's presidency (1976-1982) was notably pro-business compared with the administration of Luis Echeverría Álvarez (1970-1976), while the administrations of Miguel de la Madrid (1982-8) and Carlos Salinas de Gortari (1988-94) straddled the neo-liberal re-structuring period when Mexico's national economy underwent dramatic changes.

${ }^{23}$ Raúl Delgado Wise, "Labour and Migration policies under Vicente Fox: Subordination to U.S. Economic and Geopolitical Interests," in Otero, ed., Mexico in Transition (2004): 152-3.

${ }^{24}$ Otero, Farewell to the Peasantry, 8; 10.

${ }^{25}$ See, for e.g., Felipe Fernández-Armesto, The Americas: A Hemispheric History (New York: Random House, 2003) and Bernard Bailyn and Patricia Denault, eds., Soundings in Atlantic History: Latent Structures and Intellectual

Currents, 1500-1830 (Cambridge, MA: Harvard University Press, 2009). 
started export-oriented growth in Mexico, it also took Mexico onto the stage of hemispheric trade, raising levels of production geared toward northern consumer markets and enabling American imports to disrupt rural production at home. ${ }^{26}$ NAFTA additionally took American agro-sectors into increased competition with Mexican produce, including tomatoes, flowers, berries, frozen vegetables, and asparagus. ${ }^{27}$ Latin American countries like Mexico, which embraced a "naked liberalism" unmediated by social questions and driven by economic prowess, saw the status of labour and the peasantry worsen and the status of the business class improve. ${ }^{28}$ Scholarly views on this third liberal "wave" often differ: Sarah Babb contends that while Mexico's neoliberal record worsened social welfare among the masses, it was not as "strikingly poor as some of its harshest critics might have expected." ${ }^{, 29}$ While increased trade, tourism, and export of manufactured goods shaped Mexico’s postwar prosperity, an era marked by "rigorous growth and political stability," the period between the 1960s and 90s witnessed profound economic shifts in the wake of what Louise Walker calls the Mexican Miracle’s "dissipation." ${ }^{30}$ In 2000, the National Action Party or Partido Acción Nacional (PAN) would revive party politics as the era of undisputed rule by the Institutional Party of the Revolution (PRI) came to a close; while Vicente Fox Quesada's presidency with the PAN (2000-2006) supported the interests of industry and business as well as the Roman Catholic Church and extolled the virtues of the free market system, Mexican economic development continued to develop along highly uneven lines, while Mexico's northern neighbor continued to exert immeasurable economic influence on migrants.

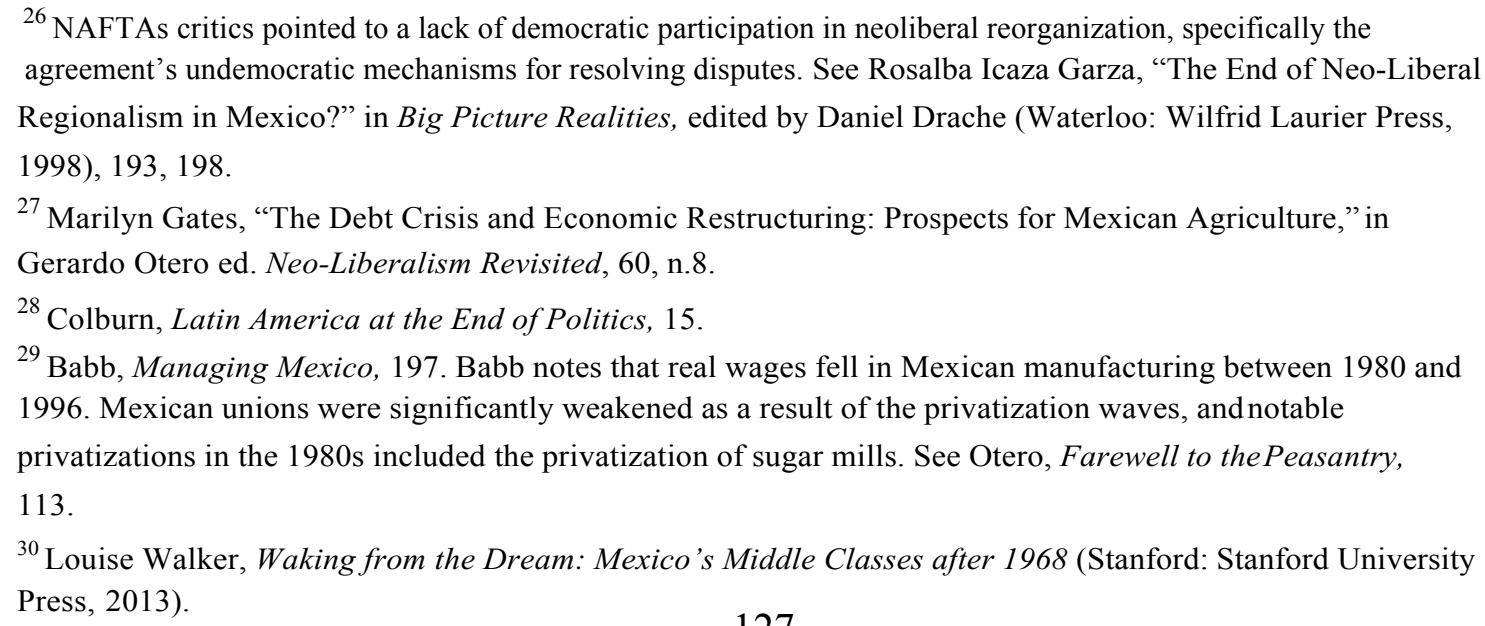




\section{2 "Some farmers have given me the names of other farmers who horse-whip their Mexicans": Farm Labour Relations in Interwar United States}

The dramatic rise in out-migration from Mexico caused by its Revolution, sparked by Francisco Ignacio Madero Gonzáles in 1910, would create a new labour climate across the border. Not all emigrants who traversed borders, however, were incorporated into the world of farm labour. As Mexican migrants increasingly characterized an extended space that transcended borders, the interwar era also saw a period of dramatic Mexican removal, oftentimes of citizens. ${ }^{31}$ A key window into this era is provided by the economist Paul Schuster Taylor, Lange's second husband, whose extensive field study of Mexican industrial and farm workers left a lasting resource for locating the trajectory of Mexican labour in late 1920 s and early 1930 s U.S.A. ${ }^{32}$ This section draws on findings from the Paul Taylor Papers to decode his critical observations on Mexican farm labour and industrial labour relations in the United States during these years, at a sensitive time in American history when intercultural competition for farm jobs would ultimately peak as a result of destitute migrant white labour newly seeking harvesting jobs in the West.

In the interwar United States, labour tended to flow toward locations where workers were most needed. During these years, the Mexican presence was most prominent in agricultural zones, including in cotton fields in Texas and Arizona, in sugar beet fields, in lettuce and citrus, in railroad construction, and at mining sites. As a consequence of the dislocations wrought by revolution and emerging patterns of labour

\footnotetext{
${ }^{31}$ The deportations of the 1930s were often unjust and sprang from a combination of economic crisis, racism, and arbitrary actions.

${ }^{32}$ Elements of this section were presented as "Mexican Interwar Farm Labour in the United States: Toward the Bracero Agreement," at Canadian Association of Latin American and Caribbean Studies (CALACS) Congress held in San José, Costa Rica, in July 2015. 
sourcing and recruitment at the border, the Mexican migrant would emerge as a primary backbone of commercial agriculture before the onset of the Great Depression. Long before the onset of the Mexican Farm Labour Program (MFLP) in 1942, the Mexican worker would offer American employers a potent combination of mobility and willingness to perform difficult physical labour on farms.

As the turmoil of the Mexican Revolution generated a campaign within the U.S. to promote order and repress the rights of labour, migration levels still rose in the $1920 \mathrm{~s}$ to serve the growing demands of American industrialization. ${ }^{33}$ Efforts to implement revolutionary approaches to better the working conditions across the border surfaced in Southern California, in Los Angeles in particular, where a Mexican workforce swelled as a result of demographic dislocations wrought by revolutionary upheaval. Magonismo quickly spread from Mexicali into California, encouraged by the formation of the Partido Liberal Mexicano (PLM) and its expansion into Los Angeles. ${ }^{34}$ Charismatic leadership, accompanied by real economic woes, combined to fuel labour radicalism across the border. Wobbly-led radicalism reached new heights during the war, when acts of sabotage in the fields between 1914 and 1917 cost growers an estimated \$10 million per year in destroyed crops. ${ }^{35}$ The Industrial Workers of the World (IWW), after joining forces with Magonistas active in California, articulated a more general goal of radicalism in service of worker consciousness, impacting workers of Mexican origin in the hop and vineyard industries, and in citrus and sugar refining.

\footnotetext{
${ }^{33}$ Oscar Martínez, Troublesome Border (Tucson: University of Arizona Press, 1988), 2 and Levario, “Cuando Vino la Mexicanada," 8-9.

34 Bardacke, Trampling Out the Vintage, 98. Media generated by the PLM, founded by Magón in 1905 in St. Louis, Missouri, acquired influence outside Mexico as the anarchist and bilingual publication of Ricardo Flores Magón, Regeneración, enjoyed a wide circulation in Los Angeles where it functioned as the most important Spanish-language paper in the city. PLM clubs were established in Los Angeles and other parts of the Southwest, the LA club reaching 400 members including farmworkers. Magón's brother, Enrique, would in fact work at a ranch in La Puente, California clearing trees as an migrant worker in exile. 35 Ibid., 51.
} 
The IWW advocated destructive methods including the burning of "barns, sheds, and haystacks," while the radical PLM traversed borders, forming links to Wobblies in California, their unity of interests proving attractive to a Mexican working-class presence there ${ }^{36}$ Organized militancy took on a more public definition and national realization at the height of the United Farm Workers era, which traversed states and sought, above all, to instill empathy in the American public at large for the cause of farmworkers. Under the wing of the UFW, previously anarchistic and radical modalities of labour solidarity were superseded by more popular influences, including spirituality and the cursillista religious fold.

In the 1920s, Mexicans participated in cross-border mobility and increasingly adopted a migratory nature within United States, often moving further north to the Great Lakes region to work in sugar beets, steel, and automobiles. Mexican families and single migrants were also drawn to seasonal labour regimes of Arizona, where agriculture, mining, and railroads functioned as magnets. ${ }^{37}$ Depression-era California saw the Mexican harvest worker enter into competition with hundreds of thousands of displaced white workers forced to pack up their lives and travel west in search of rural employment, at a time when California was already home to some 200,000 Mexican field workers. A new climate of labour competition conjoined with economic difficulty,

\footnotetext{
${ }^{36}$ Mexico's increasingly radical image did not fare well in the United States. Mexico's radical strains manifested in Magonismo generated worker slowdowns, strike activity and the destruction of field crops and in conjunction with the PLM, the IWW offered leadership over worker walkouts on California orchards and vineyards. In 1910, one IWWPLM local led a 1910 strike among Mexican gas and electric workers in San Diego. While introducing improvements for Mexican workers during this period, the Wobblies failed to produce a consistent union for farm workers, and their anti-capitalist mentality did not lend itself adequately to the creation of a formal farmworkers' union. See Bardacke, Trampling Out the Vintage, 51-3.

${ }^{37}$ Abraham Hoffman, Unwanted Mexican Americans in the Great Depression (Tucson: University of Arizona Press, 1974) 116-117, 122. Mexican migration to the industrializing north was a salient feature of the inter-war years, and these migrations produced scattered communities as well as more concentrated ones.
} 
would foment a policy of Mexican removal between 1929 to $1939 .{ }^{38}$ Abraham

Hoffman's work on the dynamics of Mexican removal during this period is particularly important.

Our knowledge of labour dynamics during the complex interwar period of cross-border migration and work, as read through the Taylor field archive, can be complicated in rich and meaningful ways. Taylor's first monograph would record:

Each annual wave has left its residue of Mexicans, great or small in number, who do not recede with the tide, but who winter on the farms or in the towns of the beet country, or in the cities of the North, to await there...the reopening of beet work in the spring; or who pass out of agriculture into the basic industries of the North. $^{39}$

Workers did not "recede with the tide" but instead wintered on farms, to await new harvest work opportunities in the spring. Taylor would also go on to perform research in Arandas, Jalisco, Mexico, a town that provided a high numbers of migrants. His first monograph, published in 1930, documented how a Mexican workforce in Texas served the onion harvest, with Texan agriculture dependent on a "reservoir" of Mexican

\footnotetext{
${ }^{38}$ Bardacke, Trampling out the Vintage, 46 and Rigoberto Gonzáles, "Mexican History, Culture and Consciousness in the Mexican Chicano Novel," Los Angeles Review of Books, Sept. 8, 2013. Under Cárdenas, return migrants who suffered repatriation would often not receive adequate aid from the state to become fully selfsustainable in Mexico. Manuel Gamio would provide an anthropological survey of the delta region of the Rio Bravo (or Rio Grande) in Mexico to aid in the "re-immigration" of Mexicans into the region from the United States. The influential the life and career of Manuel Gamio did much to influence the written record on Mexican agricultural work in interwar United States. See Casey Walsh, "Eugenic Acculturation: Manuel Gamio, Migration Studies and the Anthropology of Development in Mexico, 1910-1940," Latin American Perspectives 31.5 (2004): 118 and LytleHernández, Migra. See also Francisco E. Balderrama, Decade of Betrayal: Mexican Repatriation in the 1930s (Albuquerque: University of New Mexico Press, 1995) and Hoffman, "Stimulus to Repatriation." In Los Angeles, a repatriation campaign started in 1931 and ended in 1934, removing 13,000 of Mexican origin, with 50,000-75,000 removed from California in 1932 alone (Driscoll, The Tracks North, 47). On the Canadian Mennonite search for agrarian self-sufficiency in Mexico in the early 1920s, see Royden Loewen, Village Among Nations: "Canadian” Mennonites in a Transnational World (Toronto: University of Toronto Press, 2013).

${ }^{39}$ Paul Schuster Taylor, Mexican Labour in the United States, Vol. I, (Berkeley, Calif.: University of California Press, 1930), 97.
} 
labour located south of San Antonio. ${ }^{40}$ Yet, the tejano farmhand presence in Mexico had much deeper roots; in the years leading to the American Civil War, Mexican Texan or tejano workers had laboured alongside slaves on plantations. ${ }^{41}$ Mexican migrants were desired in Texas primarily as onion cutters, spinach harvesters, in cotton, and as general farmworkers.

While American farmers often hired Mexican nationals, they were not, in many instances, viewed as the preferred labour source. Despite this fact, many Texan counties had long traditions of employing Mexican rural labour that dated to the nineteenth century; from 1860s through the 1880s, the Mexican states of Coahuila, Matamoros, Cerralvo, and Nuevo León provided labour for Dimmit County, Texas, where African American and Mexican "cowboys" earned food and 10 dollars per month, while Americans earned better pay and bore ostensibly higher responsibilities. ${ }^{42}$ Painted signs advertising service to whites only would come to define racism in rural towns, including the Texan wheat town of Dimmit. ${ }^{43}$ Farmers often expressed how harvests could not be completed without the aid of Mexican muscle, while shrewd thinking often played into their economic calculations. Wages varied from one crop to another, and Mexicans often formed reservoirs of labour when peak seasons demanded additional farm help.

Narratives of Mexican workers' durability or efficiency prevailed, as did popular understandings of Mexicans' industriousness. Discourses of low-cost labour also shaped

${ }^{40}$ Taylor, Mexican Labour in the United States, Volume I, 295. On the period of immigration prior to 1940, see also Mark Reisler, By the Sweat of their Brow: Mexican Immigrant Labor in the United States, 19001940 (Westport: Greenwood Press, 1976).

${ }^{41}$ Omar S. Valerio-Jimenez, River of Hope: Forging Identity and Nation in the Rio Grande Borderlands (Durham and London: Duke University Press, 2013), 251.

${ }^{42}$ Taylor, Mexican Labour in the United States, Volume I, 300; 320-1. In the 1870s, temporary work agreements also offered American employers a chance to recruit Mexican nationals in accordance with their needs.

${ }^{43}$ MacLachlan and Beezley, eds., El Gran Pueblo, Fig. 11.3, 390. 
economic paradigms from this era. In the South Platte Valley, Colorado, Mexicans often took inferior wages, occasionally did not receive housing, and were often not aware of the "going rate," rarely insisting on equal pay with fellow workers. ${ }^{44}$ One farmer interviewed by Taylor perceived Mexican workers as being closer to nature: "The white men won't do the work on their hands and knees next to Mother Earth." ${ }^{45}$ In 1928, one Arizona Cotton Growers' Association official reported,

Those who have just come from Mexico are the best. They are fine. They don't know anything. After they have been here two or three years they get Americanized, want better houses, etc. and leave. The Mexicans are good, hard working pickers...they stay. The white pickers won't stay. They work a day or two and then go on." 46

Strikingly similar discourses would permeate employer understandings of the value of guest workers in Canada, and the same discourse would be repeated across the globe in twenty-first century New Zealand with reference to the lack of staying power of local harvest workers.

References to cultural difference also permeate the Taylor archive:

Orange pickers are practically all whites. The Mexicans are not careful enough...The Filipinos are more of a problem than the Mexicans. They are natty dressers and they attract the white girls. I have never heard of a Mexican who overstepped himself with a white woman. ${ }^{47}$ Harvest workers were often employed as whole family units, or as all-male labouring

\footnotetext{
${ }^{44}$ Taylor, Mexican Labour in the United States, Volume I, 144.

45 Ibid., 339.

${ }^{46}$ Mexican Labor in the U.S., "Field Notes Series A Set I," 6-7 (Carton 10), Paul Taylor Papers, Bancroft Library.

47 “Field Notes Series A Set I," 8 (Carton 10) Paul Taylor Papers.
} 
gangs, and this was true for many Mexican families. ${ }^{48}$ One citrus association in San Benito, Texas employed "gangs of Mexicans" while beets and carrots were "also harvested by gangs." ${ }^{49}$ Distorted perceptions concerning the housing needs of harvest workers were common, as Kleberg County Agricultural Agent in 1928 observed:

Yes, farmers don't have to put up such good houses for the Mexicans.

Often a farmer puts up a shack for the Mexican who clears the land and then tells the tenant since it was good enough for the former it should be good enough for $\operatorname{him}^{50}$ (Italics mine.)

Other discourses concerning the "freshness" of a given workforce impacted how long a worker might be of use to a farmer: "We should send a Mexican back to Mexico after three or four years. We should send back all the Mexicans unless they can prove that they are industrious and desirable." ${ }^{51}$ Logistical labour needs dictated perceptions about the Mexican worker: "Granted that the Mexicans are socially undesirable and don't assimilate...we have got to have some one to do this class of labor." 52

As cross-cultural prejudice prevailed so did more overt forms of physical abuse in the American South, often directed toward the farm workforce. The inspector in charge at Santa Fe Bridge, El Paso, believed that "whipping is the only effective deterrent to the Mexicans - the fear of punishment" while his men, along with the border patrol, frequented Mexican prostitutes who sold their services to white Americans. ${ }^{53}$ Another account described the frequent use of the horse-whip to instill discipline in farm

\footnotetext{
${ }^{48}$ Ibid., 10. A family in Taylor's account was hired to pick cotton in Phoenix, earning $\$ 10$ per day, and children employed alongside adults.

${ }^{49}$ Ibid., 22.

${ }^{50}$ Ibid., 25.

${ }^{51}$ Ibid., 39.

52 Ibid., 40.
} 
workers, a continuity from the era of plantation slavery:

The Mexicans have replaced Negroes in central and eastern Texas and even now in Arkansas, Louisiana, and Mississippi. Not ten percent of the mistreated Mexicans complain to the consul...Some farmers have given me the names of other farmers who horse-whip their Mexicans. The Mexicans sometimes are afraid to tell me about it even then. ${ }^{54}$ (Italics mine.)

The Mexican worker, "willing to [and does] work for almost nothing," offered staying power and a measure of vulnerability; at a silver and lead mine near Santa Rita, New Mexico, Mexicans did not perform "so much work" yet were "there when needed." 55 Competition between industry and agriculture for Mexican workers was also apparent"railroads knowingly lose Mexicans to the Arizona Cotton growers, beet growers, etc" — while discourses of plenty in relation to a Mexican workforce stemmed from realities on the Mexican side of the border. ${ }^{56}$ An El Paso County Agent believed labour was "plentiful on the Mexican side...for fear of deportation the Mexicans will work for less." ${ }^{57}$

The push of poverty was critical, as E.J. Walker of El Paso observed: "We get the most poverty-stricken Mexicans. Nobody but the most poverty-stricken will pick cotton." ${ }^{58}$ Still, the cotton workforce proved heterogeneous; employment agent J.R. Silva noted that the cotton labour force in 1928 included American, American-born Mexican and Mexican-born workers. ${ }^{59}$ Employment agents functioned as middlemen

53 Ibid., 16.

${ }^{54}$ Ibid., 60-61.

${ }^{55}$ Ibid., 11; 45.

${ }^{56}$ Interview with A.J. Milliken, Inspector in Charge U.S.I.S. at Santa Fe Bridge, El Paso. "Field Notes Series A Set I," 15-16 (Carton 10), Paul Taylor Papers.

57 "Field Notes Series A Set I," 86 (Carton 10), Paul Taylor Papers.

58 Ibid., 95. 
who provided labour where needed: Silva "furnished the Rock Island with two thousand Mexicans in 1926. ${ }^{60}$ Railroads developed a heavy reliance on Mexican labour, with Santa Fe shipping Mexicans in 1902 and Rock Island shipping Mexicans from about 1907. ${ }^{61}$ Many social continuities remained: the basic need for income among migrants was acute; it drove seasonal migration from South to North; seasonality dictated where workers migrated; and rural employers were often flexible in their hiring patterns.

These trends led to expanded mobility for Mexican nationals in the interwar years, with migration often leading to new rural and urban settlement formations. Still, the presence of the Mexican fieldhand in agriculture of the South had nineteenth century origins. ${ }^{62}$ As Omar Valerio-Jiménez describes, the border emerged as a "weapon of the weak," functioning as an obstacle as well as an opportunity, crossed in order to escape unfavorable circumstances. ${ }^{63}$ In the 1920s, Texas would also served as an access point for further inter-state mobilities. ${ }^{64}$ One of Taylor's interwar migrants began his story in El Paso, then moved on to numerous cities and jobs, including Santa Rita, Pittsburgh, a return move to Guadalajara, then to Chicago, Cheyenne, Salt Lake City, Portland,

\footnotetext{
${ }^{59}$ American-born Mexicans tended to have higher expectations for housing and social mobility, while those originating in Mexico were often more highly prone to exploitation.

${ }^{60}$ Ibid., 105.

${ }^{61}$ Ibid., 108. Taylor's record additionally gave evidence that, as early as 1896, American railroads were in the habit of employing Mexican contract labour. Other shocking reports of cold economic calculations on the part of farmers often merged potently with conniving labour practices: "The less you pay them the more work they will do." Report of William Pullian of Crystal City, Texas. "Field Notes Series A Set I,” 143 (Carton 10), Paul Taylor Papers.

${ }^{62}$ Valerio-Jiménez, River of Hope, 182.

${ }^{63}$ Ibid. Push factors causing cross-border migration included debt, slavery or abuse characteristic to nineteenth-century Mexico.

64 "Field Notes Series E Set I," 1 (Carton 10), Paul Taylor Papers. With the annexation of Texas and ensuing formation of tejano communities, "static" wages in Mexico led many to migrate north in search of superior wages, leading to new cultural tensions between Americano employers and tejanos hired to pick cotton and work among cattle. See Valerio-Jiménez, River of Hope. Mario Jimenez Sifuentez' work also points to the broader emergence of a Tejano diaspora in the Pacific Northwest, and more specifically the emergence of a Mexican-Texan or Tejano community in Oregon. See Sifuentez, Of Forests and Fields, 2 and Chapter Two, "Los Tejanos: The Texas-Mexican Diaspora in Oregon." There also emerged a complementary, cross-cultural collaboration between Mexican Texans and Nisei (second-generation Japanese) farming communities in Eastern Oregon, among whom, Mexican farmworkers found a "strong ally." (Sifuentez, 3, 36-8).
} 
Alaska, and finally, San Francisco, having taken up work on a railroad, and later as a barber, machinist's assistant and cannery worker.

Still, many American employers in the 1920s adhered to a strictly white workforce. Some lumber companies did not employ Mexican workers, while the Los Angeles United Concrete Pipe and Construction Company employed forty in cement handling and quarry labour then transitioned toward a solely American workforce: "As soon as white American labor became available we discontinued the Mexicans. At present we have but one Mexican employed in gang of eighty men." 65 The Mexican worker was a practical but imperfect solution. In other cases, discourses of efficiency ruled employer attitudes. Pacific Lumber of Scotia, California, in 1927 employed Mexican workers but found them a "rather undesirable and inefficient class of labor."66 Other accounts revealed worker performance as positive. ${ }^{67}$ For Hobart Estate Company it was not "company policy" to employ Mexicans, yet in 1926 the company employed twelve "good [Mexican] workers and as steady as any other class of laborers," but was dissatisfied with the group "on account of their manners of living, as they were not at all congenial with other nationalities, and...we do not expect to employ them in the future in any numbers." 68 Taylor's attention to social questions surrounding Mexican workforces made him a rarity in sociological narratives of his time, as political economists were concerned more with social questions facing white America.

A theme of desired labour but undesirable citizens would surface in an American context with manifestations in the enactment of new laws at the border. The first head tax applied to Mexican migrants to limit migration, along with a literacy test, came in 1917 , when Mexican migration hit unprecedented levels with dislocations caused by the revolution. ${ }^{69}$ Remuneration conflicts would also inflect working climates for Mexicans

\footnotetext{
65 "Statistics: Building and Lumber Industry, 1927" (Carton 11) Paul Taylor Papers.

${ }^{66}$ Ibid.

67 Ibid.

68 Ibid.

${ }^{69}$ Driscoll, The Tracks North, 42. 
in urban centres. ${ }^{70}$ In its relationship to potential farm workers, the state adopted selective forms of border control and management: a proviso would exempt agricultural workers from head taxes, due to economic conditions of a wartime worker scarcity in the fields. ${ }^{71}$ Mexican migration fell from 87,000 to 32,000 over $1924-5$ after a $\$ 10$ visa fee and $\$ 8$ head tax was introduced, and the U.S. Border Control was established in $1925^{72}$ In the 1930s, Mexican repatriados enjoyed free transport from border towns to the interior provided by the paternalistic-populist Mexican state, marking an increased role played by the Mexican revolutionary state in its efforts to deal with return migrants. ${ }^{73}$ An emergent politics of the border would reshape the U.S.-Mexico relationship for decades to come.

\subsection{The Bracero Years (1942-1964)}

When the Bracero Program began in 1942 it put Mexican farm labourers from areas deep within Mexico into contact with American farmers. The word bracero is drawn from the root word brazo, meaning arm, defining someone who works with their arms, and came to denote a manual labourer from Mexico engaged on a farm contract in America between 1942 and 1964. Braceros were concentrated for the most part in California, the site of fifty percent all contracts, and in Canada, a similar concentration of seasonal migrants occurred in Ontario and Quebec. Most braceros had little or no

${ }^{70}$ In complaints over refusal to pay wages, specific wage amounts were claimed, listed as pending, and specific amounts were collected as a result. "California-San Diego. 1932” (Carton 11), Paul Taylor Papers.

${ }^{71}$ Hoffman, "Stimulus to Repatriation," 206. See also Lytle-Hernández, Migra!, for a detailed history of the history of the U.S.-Mexico border patrol. See also Gloria Anzaldúa, Borderlands/La Frontera, 2nd ed. (San Francisco: Aunt Lute Books, 1999) for cultural conceptions of the border as an embattled space.

72 “Texas-El Paso County, 1925-1926," Carton 12, Paul Taylor Papers. The 1917 Immigration Act altered the balance of power at the border, as head taxes reduced Mexican inflows from 56,000 in 1916 to 3,100 the next year. In Migra!, Lytle-Hernández also notes that 1907 marked an immigration turning point in U.S. history when the Immigration Act required all immigrants to receive official authorization to enter the United States (see 2).

${ }^{73}$ Hoffman, Unwanted Mexican Americans, 135-6. On Cárdenas' supportive relationship with Communist Cuba see Renata Keller, Mexico's Cold War: Cuba, the United States, and the Legacy of the Mexican Revolution (Cambridge: Cambridge University Press, 2015). 
previous experience working abroad. The Bracero Program marked a departure from earlier decades, specifically in the scale of international mobility that took place. ${ }^{74}$ The Bracero Program was accompanied by a precondition that the scheme should not affect the local labour market adversely; this came in the form of Public Law 78 that included a legal decree that braceros could not be recruited if sufficient domestic labour was available to perform it. ${ }^{75}$ The arrival of the program ushered in a new era of agricultural contract labour at a scale previously not experienced in America, and it would transform the face of the U.S.-Mexico labour relationship with lasting consequences.

The scale of Bracero migration was unprecedented. The onset of the program coincided with the U.S. entry into the war and approximately 4.6 million bracero contracts took place between 1942 and 1964 (while some estimates record 5 million contracts). ${ }^{76}$ Domestic circumstances in Depression-era Mexico created conditions that would lead to an outpouring of bracero workers in the 1940s. While the Cárdenas' administration granted land to peasants en masse it failed to provide resources required to help peasants be productive, and the onset of the Bracero Program was viewed as an opportunity by many competing to cross the border and find work on the other side.

Negotiations to implement the scheme were completed in Mexico City between the

${ }^{74}$ When the Bracero era arrived it was not limited to agricultural work: participants were also involved in forestry and railroad labour, just as Latino forestry workers, pineros, were drawn from Mexico and Guatemala. While the Bracero Program ended in Oregon in 1947, braceros were still brought in intermittently to the state to work, in 1952 to Umatilla and Jackson counties, Hood River and Medford, and in 1958 to Medford for pear harvest work. Lynn Stephen, The Story of PCUN and the Farmworker Movement in Oregon (Eugene: University of Oregon Center for Latino/a and Latin American Studies, 2012), 8.

${ }^{75}$ Bardacke, Trampling Out the Vintage, 91.

${ }^{76}$ David Fitzgerald, "Mexican Migration to the United States" (Lecture, 53 mins.) 20 Years After NAFTA Conference, Center for US-Mexican Studies, UCTV UC San Diego-Latin America. For a comprehensive anthology of the bracero period in Spanish from Mexican and American scholars see also Jorge Durand, Braceros: Las Miradas Mexicana y Estadounidense: Antología (1945-1964) (1 ed. México: Senado de la República, LX Legislatura, 2007). See also Robles, Memorias de Braceros. 
Mexican Government and U.S. Secretary of Agriculture, as labour demands reached stark levels and dissatisfied letters "spelling out the frustrations of farmers" inundated the United States Department of Agriculture. ${ }^{77}$ Established first officially as part of a Public Law 45, and negotiated again in 1951 as part of a Public Law 78, the program's terms and conditions would remain essentially the same. As the war compelled agriculturalists to look beyond America for labour, the program, once enacted, let farmers across the United States but most prominently in the Southwest, Midwest, and Pacific Northwest hire a fully male Mexican harvest work force. ${ }^{78}$ As Americans increasingly abandoned farm life to serve the war effort, braceros filled jobs to sustain farms through the remainder of the war years and would continue to work another decade thereafter. ${ }^{79}$ For the most part unwanted due to labor competition during the Great Depression years, the Mexican fieldhand would return as the "man of steel" to help American farmers through a difficult and politically complex time.

The Mexican fieldhand was, however, not the only candidate for migration in 1940s U.S.A. In 1947, a Farm Labor Program that coincided with the Bracero Program was established and implemented with Puerto Rico to allow able-bodied men to work Northeastern United States farms; from 1948 to the 1990s over 420,000 Puerto Rican farm workers engaged in such contracts, with some 5000 in $1948 .{ }^{80}$ Puerto Rican farm workers were often called tomateros due to a connection with tomato work, but they also participated in other areas:

\footnotetext{
${ }^{77}$ Gamboa, Mexican Labor, 40.

${ }^{78}$ Ibid., xiii. Gamboa's is one of the best comprehensive regionally focused studies of the Bracero era, with an emphasis on the history of the program's operation in the states of Washington, Oregon, and Idaho.

${ }^{79}$ Ibid., 43-4. Mexican consulates in American towns were often distant from sites of employment, and the closest office for the Northwest was situated in Salt Lake City during the wartime period; a Mexican consulate was not established in Portland, Oregon until 1947. In Canada, the Mexican consulates remain important arbitrators of labour conditions and farm-site checks, and in some cases such as British Columbia, they are also involved in the management of SAWP workers.
} 
Puerto Ricans...planted and cut shade tobacco in the Connecticut River Valley; picked corn, blueberries, asparagus, broccoli, and onions in the Delaware River Valley; strawberries, cabbages, and carrots in New York; apples in New England and Washington; potatoes in Maine; peaches in South Carolina; avocados and lettuce in South Florida; and other crops like cranberries, oranges, and mushrooms in various places. ${ }^{81}$

The program effectively "extended" this pool of available labour into the United States. ${ }^{82}$ Puerto Ricans soon replaced Italian farmworkers in New Jersey and New York State. ${ }^{83}$ The program ultimately came to a close in 1993; despite this, Puerto Ricans continue work on farms.

The Bracero Program was phased out due to its unpopularity as public opinion and policy proved strong enough to reverse a large-scale and somewhat embedded managed farm labour scheme. As one Canadian Labour Congress representative espoused the belief that the SAWP will not be ending any time soon, farm labour schemes were often logistically difficult to reverse in practice once implemented. As dissatisfaction from the public and organized labour's belief's that the program constituted institutionalized exploitation came to a head, its legitimacy was undermined. Indeed, the acceptability of agricultural guest work schemes in Canada has faced similar challenges.

\footnotetext{
${ }^{80}$ Jorge Duany, “A Transnational Colonial Migration: Puerto Rico's Farm Labor Program,” New West Indian Guide 84.3-4 (2010): 233. On experiences of agricultural migrations from Puerto Rico to Michigan as they intersected with issues of domesticity see also Suárez Findlay, We are Left Without a Father Here.

81 Ibid.

82 Ibid. 236-7. Puerto Ricans working apple harvests in the state of New York were replaced by a Jamaican workforce, and a legal conflict in 1979 brought tensions to light when it was argued that West Indian workers were given preferential access to labor markets before the domestic supply, including Puerto Ricans, was fully exhausted.

${ }^{83}$ Hahamovitch, The Fruits of Their Labour, 200.
} 
The Bracero Program was a compromise built upon a rocky terrain of competing tensions, including growers' desire for a pool of low-cost labour, nativism seeking to reimpose control at the border, concerns over the state of local labour markets, and the continued relative invisibility of farm workers from the public eye. ${ }^{84}$ The Bracero years generated a social consensus that underpinned an emergent American belief that commercial farm labour was best performed by guest workers and was for the most part unsuited to American citizenry. ${ }^{85}$ During the program's existence, ranchers wanting to evade expensive and bureaucratic processes associated with hiring through legal avenues often hired illegal migrants, and undocumented migration would become the new norm in the wake of the program's demise. These emergent political asymmetries would be interpreted in Chicano narratives that described the border as a defining and dividing line that often worked against nature: Gloria E. Anzaldúa conceptualized the U.S.-Mexico border as a space where the Third World "grates against the first and bleeds."

During the Bracero era, much of the transport of workers occurred by rail in contrast to the air travel used in Canada to orient contracts precisely with seasonal needs. The two programs would equally take on regional dimensions, involving a mosaic of sending and host regions that specialized in different agricultural pursuits and offered different climates of work. The program also operated to a limited extent in southern states such as Arkansas. ${ }^{87}$ The scheme gained connotations in American media,

\footnotetext{
${ }^{84}$ Puerto Ricans have joined Haitians, other West Indians, and African Americans in engaging in farm work in New York State since the 1940s. Garcia-Colon and Melendez, "Enduring Migration," $97 ; 106$.

${ }^{85}$ Douglas Massey, Jorge Durand, and Nolan Malone, Beyond Smoke and Mirrors: Mexican Immigration in an Era of Economic Integration (New York: Russell Sage Foundation, 2002), 41.

${ }^{86}$ Anzaldúa, Borderlands/La Frontera, 25.

${ }^{87}$ Julie M. Weise's Corazón de Dixie: Mexicanos in the U.S. South since 1910 (Chapel Hill: University of North Carolina Press, 2015) complicates the historiography of the Bracero Program to consider how it operated in differing and unique ways in southern states like Arkansas; in Arkansas, for example, farmers faced more challenges in acquiring bracero workers than did farmers in states like Texas.
} 
described as imported colonialism and legalized slavery, as news exposés made abuses known. ${ }^{88}$ Just as the Canadian program introduced a privilege system where workers could be "named back" to a farm, braceros often retained contracts from one year to the next: one "Camacho," along with "a few others were made 'specials,' braceros who carried a plastic card (...[or] mica...) that allowed them to work for the same employer year after year without going through the formal contracting procedures..." 89 This system allowed a smoother flow of labour across without undue bureaucratic attention.

Workplace abandonment through desertions would also shape bracero trajectories in alternate ways. ${ }^{90}$ The bracero would also move across states and industries, to engage in diverse contracts, as has occurred in Canada through return contracts.

By the time the Agricultural Workers' Organizing Committee (AWOC) was formed within the AFL-CIO in 1960, Filipino farm workers were, in fact, the best organized rural working group in California, having had established their own unions and labour associations to work in their own interests (the Filipino Labour Union, or FLU and Filipino Agricultural Labor Association, or FALA promoting the interests of Filipino farm laborers and engaging, oftentimes successfully, in strike actions and collective bargaining with growers in the state.) However, increasingly in the early 1960s the bracero worker was also beginning to operate as an agent of resistance. In contrast to accounts that depicted the bracero as docile, lettuce workers took part in a series of strikes in the 1960 s that would in effect signal the beginning of the end of the program. ${ }^{91}$

\footnotetext{
${ }^{88}$ Contracts offered braceros were primarily allotted to the sending states of Jalisco, Guanajuato, Michoacán, and Zacatecas, while most of the work was performed in California and Texas.

${ }^{89}$ Bardacke, Trampling out the Vintage, 5.

${ }^{90}$ Desertion occurred in Canada with a recent case in British Columbia of a Mexican migrant disappearance involving four workers, revealing how imperfections in circular migration programs were at times known to occur. See "Mexican Migrant Workers in B.C. just Vanished," Huffington Post, July 29, 2015.

${ }^{91}$ Frank Bardacke [Interview], "United Farm Workers," Against the Grain, KPFA Radio, December 06, 2011. Braceros took part in strikes and collective action in the Imperial Valley, "America's winter garden." See Bardacke, Trampling out the Vintage, 22; 97-8.
} 
Bracero competition with local labour would in the end create mounting opposition to the scheme. Braceros were vulnerable in many ways: pea growers in Washington State engaged in the practice of "stockpiling" them, preventing the reserve group from securing any paid work. ${ }^{92}$ Pace issues also created conflicts in the fields. ${ }^{93}$ Pacific Northwest farmers often believed that braceros "performed better" if threatened. ${ }^{94}$ Long days were typical for the bracero and still typify modern-day farm work: in 2007 seasonal workers in Canada reportedly worked $12-15$ hour days. ${ }^{95}$ In Milton-Freewater, Oregon, braceros worked back-to-back day and night shifts; after a night shift they would often consume breakfast then "wander out where growers...would take them to pick cherries." ${ }^{96}$ Braceros also braved diverse environmental conditions and hazards, including extreme cold, lead poisoning, and exposure to pesticides, similar to the environmental hazards faced by those employed in Canadian greenhouses or fields. ${ }^{97}$

Despite the dependence on bracero workers, other options, including soliciting the help of youth, were considered. In the Pacific Northwest in wartime, to justify hiring a foreign workforce, farmers had to first seek out all available local labour, including schoolchildren. ${ }^{98}$ In certain counties in Idaho students comprised half of the rural workforce, and at the University of Washington students were let out of classes for a week or more to help with harvest labour that was deemed "patriotic." 99 In 1943, state governors in the Pacific Northwest were instructed to issue statements to enable the

92 Ibid., 65.

${ }^{93}$ Interview with Frank Bardacke, “United Farm Workers,” Against the Grain, KPFA Radio, July 28, 2015.

94 Gamboa, Mexican Labor, 59.

95 Jonathan Montpetit, "Migrant Workers Await Labour Board Ruling: Face Bitter Resistance over Union Drives," Winnipeg Free Press, Monday, July 30, 2007.

${ }^{96}$ Gamboa, Mexican Labor, 67.

${ }^{97}$ One bracero, after losing his sight, was sent home after a failed eye surgery, and accidents involving machinery were common. See Gamboa, Mexican Labor, 70.

${ }^{98}$ Washington State in 1943 suffered a deficiency of harvest workers when the yearly migration of "Canadian Indian berry pickers" was not expected in the Western areas of the state. Gamboa, Mexican Labor, 44.

${ }^{99}$ Gamboa, Mexican Labor, 45-6. 144 
dismissal of schoolchildren for harvest work. ${ }^{100}$ The role of children in agricultural work was often pervasive and persists into the present-day (See Fig. 4). ${ }^{101}$

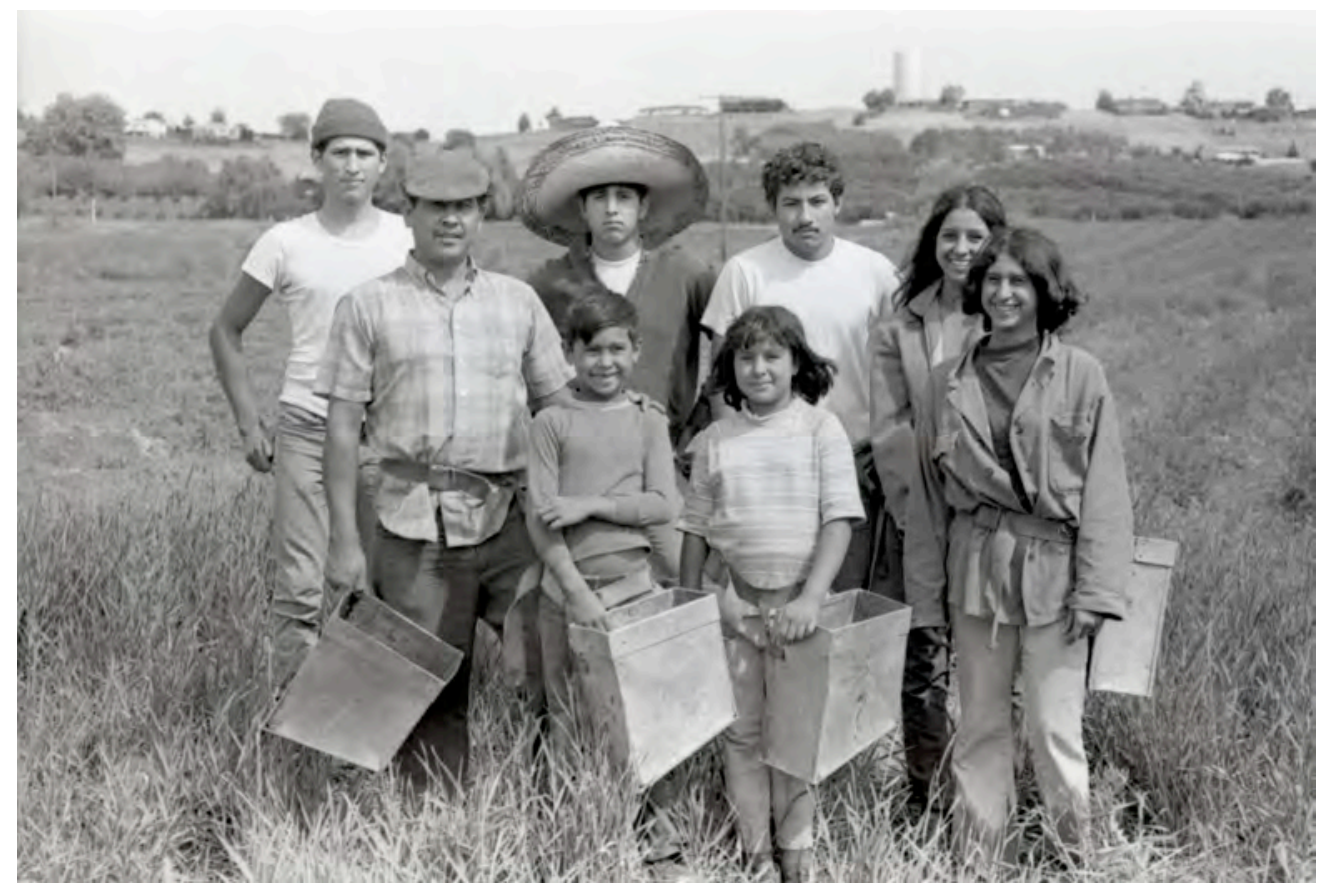

Fig. 4. "Adult and Children Workers, 1968."

(Irwin Nash Photographs of Yakima Valley Migrant Labor, 1967-1976, Manuscripts, Archives and Special Collections, Washington State University) ${ }^{102}$ Harvest work was often a multi-generational activity.

The "captivity" associated with braceros contracts, a thesis forwarded by some accounts, has had reverberations in the Canadian case; an Agricultural Workers' Alliance representative saw SAWP workers in Manitoba as equivalent to "modern-day slaves."103 A tool of the state and of capitalist logic, idealized guest workers often functioned as ${ }^{100}$ Ibid. Other communities were also mobilized for farm work in wartime including Japanese- Americans arranged by the War Relocation Authority to perform farm tasks in Oregon and Idaho.

${ }^{101}$ See Carmen Martínez Novo, Who Defines Indigenous? (Piscataway, NJ: Rutgers University Press, 2006) on tomato fieldworkers below legal working age in San Quintín, Mexico.

${ }^{102}$ Photograph courtesy of Greg Matthews, Metadata Librarian and Photographs Curator, Washington State University Libraries Manuscripts, Archives and Special Collections.

${ }^{103}$ AWA Portage La Prairie Office email correspondence, August 2011. 
projections of "capitalist and state desire." ${ }^{\text {104 }}$ Still, projects associated with social betterment also shaped the bracero era when, in the 1960s, efforts to extend opportunities for citizenship to many braceros were made. ${ }^{105}$ As Alicia Camacho notes, the bracero program functioned as a "labour loan" as flexibility and mobility imbued bracero bodies with a value that might be reaped only through the process of migration. ${ }^{106}$ Toward its demise, the Bracero Program fomented debates at the national level over its utility, practicality, and logic.

In October 1960, President John F. Kennedy gave consent to extend Public Law 78 allowing bracero contracts to continue. Kennedy admitted in public that the program negatively impacted local wages, while Secretary of Labour Arthur Goldberg became involved in the suppression of labour agitation in the Imperial Valley, coordinating the liquidation of lechugueros (lettuce workers) involved in strikes that year. Braceros engaged in labour unrest were rendered ineligible as ideal workers and were understood as threatening to American farmers' best interests. Debates in 1963 to extend the program two more years were inflected by competing issues: those in favour of having the program continue cited a need to supply enough "supplemental farm labour" when domestic labour was viewed as incapable of meeting peak harvest needs. ${ }^{107}$ In favour of the program's legality, Congresswoman Catherine May's promotion of extending the Mexican Farm Labor Authorization cited its positive attributes as anti-‘wetback': it reduced illegal arrivals from over one million to 30,000 since the program began. ${ }^{108}$

\footnotetext{
${ }^{104}$ Camacho, Migrant Imaginaries, 110.

${ }^{105}$ Gamboa, Mexican Labor, 62. See also Galarza, Merchants of Labor, and Galarza, Strangers in our Fields.

${ }^{106}$ Camacho, Migrant Imaginaries, 62-3.

${ }^{107}$ Catherine May Congressional Staff, "Form letter to House members regarding the Bracero Program, ca. 1963," 1. Washington State University Digital Collections, Catherine May Congressional Papers, 1959-1970.

108 Ibid. May also claimed the program cost the taxpayer "virtually nothing" since farmers were often willing to cover "all of the expenses," while the state paid the "necessary inspection procedures."
} 
May refuted a charge that importing workers drove down local wages, citing high farm labour wages in California and lower wages in non-bracero states like Mississippi and the Carolinas. ${ }^{109}$ The program was "misunderstood," as May urged an extension of the program to $1965 .{ }^{110}$ Others were less than keen about extending the program: W.J. Bassett located braceros as "victims" of a scheme that took "dishonorable advantage of their desperation." ${ }^{111}$ Bassett was against the extension of Public Law 78 since it perpetuated "unemployment, underemployment and poverty among domestic farm workers...the utterly deprived and truly disinherited of America" while braceros were a "pool of captive, docile, readily-exploitable labor."112 This fracturing of sentiment was rooted in impassioned social concerns, economic logic, anti-racist discourse, and sometimes nativistic domestic preferences.

While competition for bracero positions was high in Mexico, the program still proved controversial in the United States. As civil rights arguments came to the fore, the idea ending the Bracero scheme became linked to ideas of social justice. ${ }^{113}$ The program offered chances for material improvement: many apieros or celery workers soon purchased houses or established small businesses in Mexico, while others soon rented land in the United States and started their own farms. ${ }^{114}$ Workers' confidence often improved with time, with on-the-job attitudes shaped by the amount of time spent at work; by their final year, they often "expect[ed] to take over." ${ }^{115}$ Braceros did not enjoy

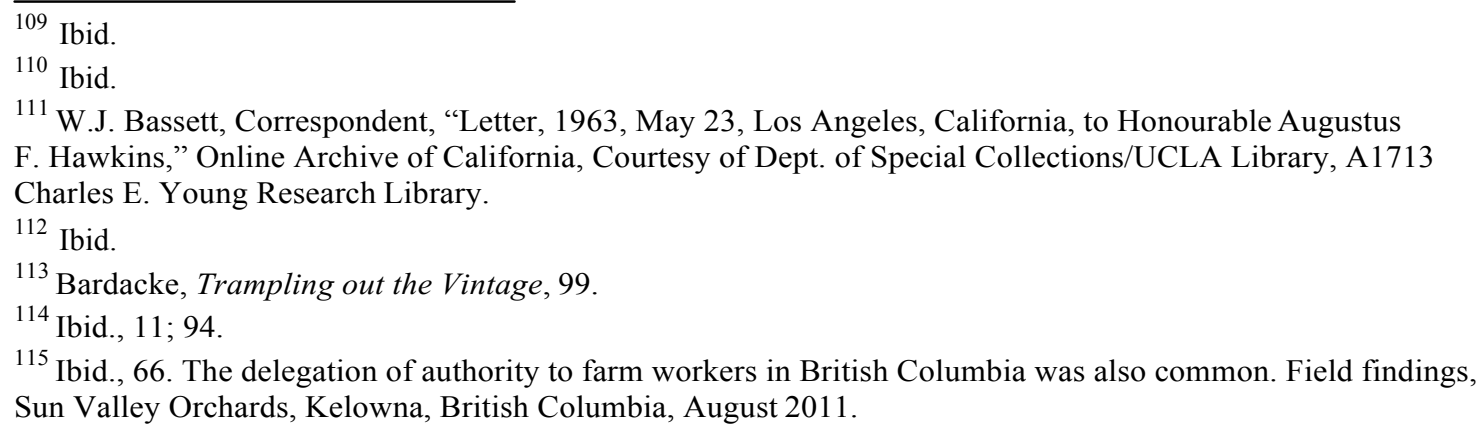


the same protections as American citizens, this trend finding a mirror in Canada. In Blythe, California, and the San Joaquin Delta in the 1940s and 50s, braceros had communal-style showers and washrooms that offered "no privacy."116 A British Columbian farmworker similarly recounted a former Ontario contract with memories of an overcrowded dorm without enough fridge space. ${ }^{117}$ Company store indebtedness was also common during the bracero years.

The Bracero era's legacy persists in hidden ways. In Oregon, where 15,000 Mexican nationals had worked as braceros, lasting Latino communities would emerge in rural towns throughout the Willamette Valley. ${ }^{118}$ In Oregon, braceros were initially hailed as saviours in local media, yet by the late 1940s they were increasingly depicted as sinister and labeled wetbacks or illegals. ${ }^{119}$ Oregon failed to enact progressive labour legislation for agricultural workers in later decades, becoming notorious for creating obstacles to fair working standards for farmworkers. Prior to 1990, farmworkers in Oregon were prohibited from picketing during a harvest. ${ }^{120}$ Legal frameworks often failed to adapt to protect the more vulnerable farmworker class.

According to Deborah Cohen, braceros considered themselves actors who shaped their own lives; they "fought for their rights... and made their world." ${ }^{121}$ Their migrations effectively reordered relations between their country and the United States.

\footnotetext{
${ }^{116}$ David Bacon, Communities without Borders: Images and Voices from the World of Migration (Ithaca: ILR Press, 2006) photo insert, Part Four. An extensive photograph collection and oral history archive relating to the history of braceros in the United States is also available online at http://braceroarchive.org/, offering an online collection of some five hundred interviews compiled by the Institute of Oral History, University of Texas-E1 Paso with the Smithsonian's National Museum of American History.

${ }^{117}$ Field findings Pitt Meadows, British Columbia, August 2012.

${ }^{118}$ Stephen, The Story of PCUN, 8.

119 Ibid., 9.

${ }^{120}$ Ibid., 6.

${ }^{121}$ Cohen, Braceros, 14.
} 
Cohen's testimonies with braceros revealed a willingness to relocate for work, as in her account of Felipe Castañeda who confessed his involvement created problems for his family life: "I went lots of times. Although life got better, the opportunity came at a cost." ${ }^{122}$ In the end, braceros actively exercised a measure of their own self-determination, in particular a "refusal to be seen as victims.","23

Just as braceros gave up family life to engage in jobs on the other side, undocumented migrants continue to navigate difficult situations in order to survive. Ten years into the program, Mexico under Adolpho Ruiz Cortes made efforts to “deter men's desire to cross" as border towns witnessed conflict between aspiring migrants and Mexican authorities. ${ }^{124}$ On the other side, anxieties in the United States over a feared "Mexican invasion" surfaced in the late 1940s, sparking "Operation Wetback," which saw the repatriation of many legal Mexican residents across the country.

Oral historians such as Mireya Loza, Cohen, and others have done much to contribute to a testimonial record of bracero lives. ${ }^{125}$ The children of braceros have also related their memories; one Mario Perez, whose father worked as a bracero in lemon orchards to eventually becoming a foreman, described a sense of pride in his father's work. $^{126}$ Sal Galaviz, another son of a bracero, recalled how his father obtained a green card and then citizenship after working in California and experiencing racism as a bracero in Texas. ${ }^{127}$ Oral accounts, alongside a large photographic record, offer critical

\footnotetext{
122 Ibid.

123 Ibid. As Cohen notes, Bracero contracts were in fact coveted by workers who migrated north toward the border region with the goal of crossing over into United States, and Mexicali was a critical sending node, offering a home base and port of entry for migration as well as a place of refuge for the families of men working across the border.

124 Cohen, Braceros, 209.

${ }^{125}$ Loza's interview with Plutarco Chavez Ruiz uncovers his recollections of time working as a bracero, including positive memories of Salinas, internal migration and return migration to Mexico. See Interview with Plutarco Chavez Ruiz [Mireya Loza], 2007, “Interview no. 1281," Institute of Oral History, University of Texas at E1 Paso, http://digitalcommons.utep.edu/interviews/1281/, Accessed Nov. 17, 2014.
} 
windows into the bracero years, shedding light on a time equally defined by order and adversity. Leonard Nadel's photographic archive from 1956 portrays the selection of braceros and their medical examinations in the United States, border crossing, and experiences of harvest work, leisure, and the provision of medical treatment (See Figs. 5 -6 and Appendix 1, Figs. 15-21). A number of Nadel's photographs are included here for the windows they offers into bracero pasts, including moments of travel, inspection, work, and recreation, yet his works may also be read critically. Nadel's work, produced for the Joint United States Trade Union Committee, recently came under the critical eye of Nicole Guidotti-Hernández, who places his positionality, directional intent, and power in context. $^{128}$

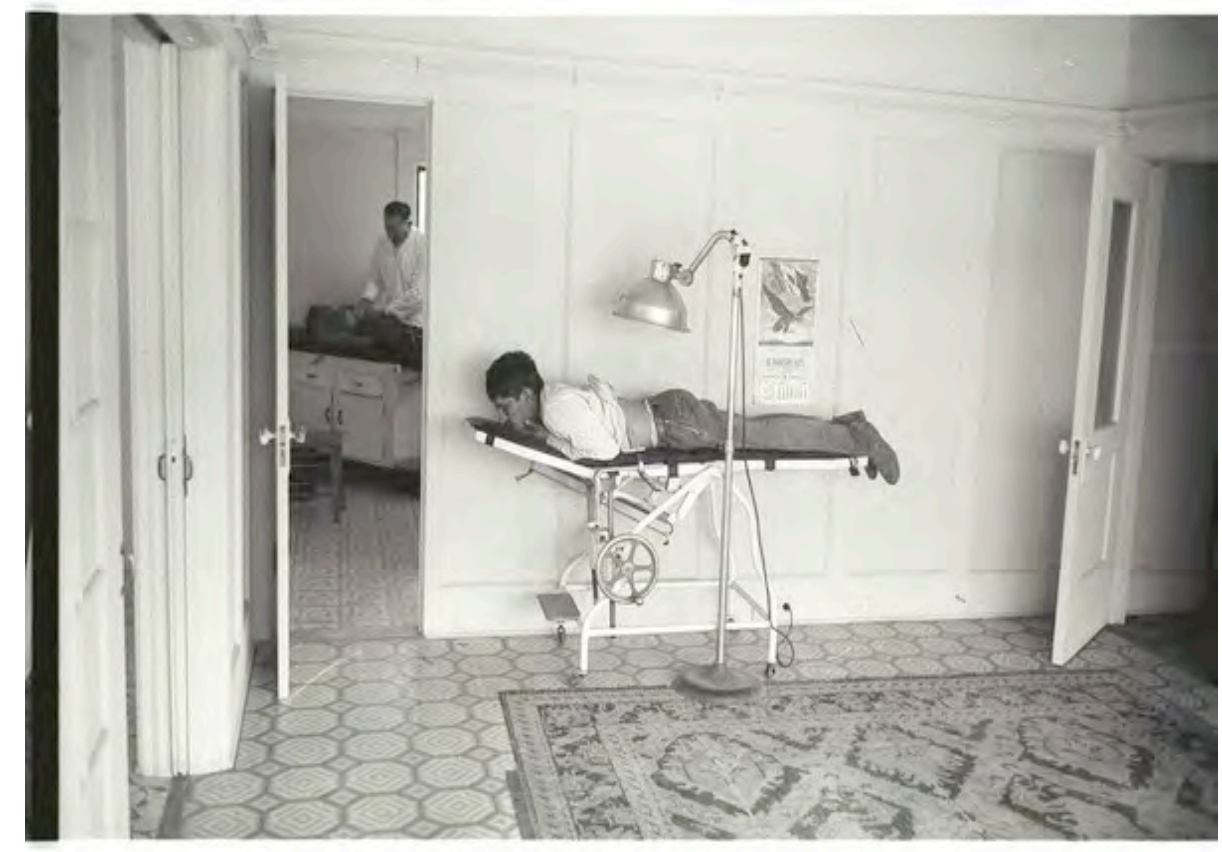

Fig. 5 "A bracero lies on a stretcher and receives medical treatment while the doctor examines another bracero in his clinical practice in the Salinas Valley, California." (Bracero History Archive, Leonard Nadel, NAD-2004.0138) ${ }^{129}$

Note the contrast between the bracero and his surroundings at this California clinic.

\footnotetext{
${ }^{126}$ Mario Perez, “The lemons are Freezing!” Bracero History Archive, Item \#3229.

127 Sal Galaviz, "The Promised land," in Bracero History Archive, Item \#3227.
} 


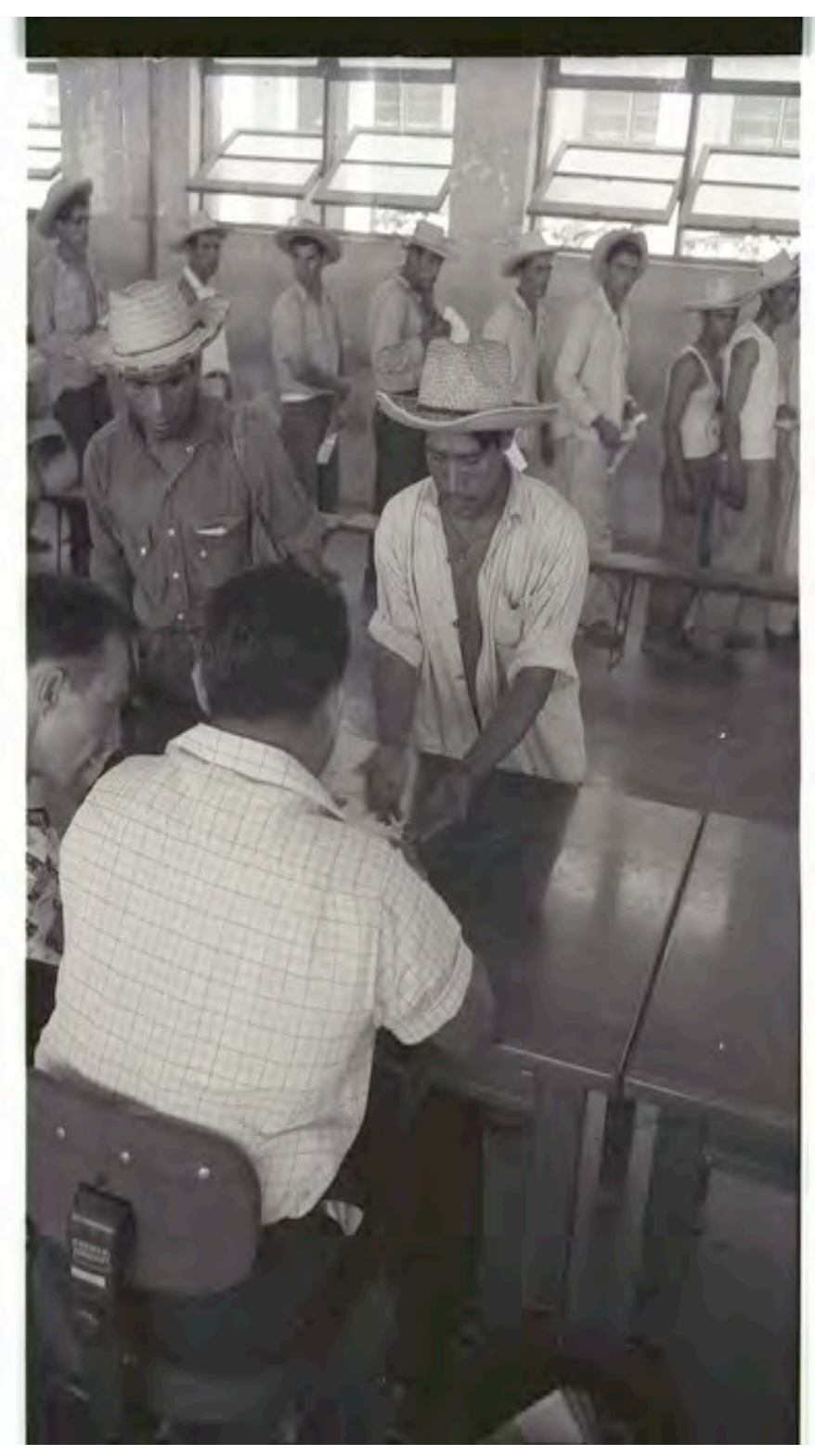

Fig. 6 "An official examines a bracero's hands for calluses during processing at the Monterrey Processing Center, Mexico."

(Bracero History Archive, NAD-200401381138)

Note the modest and similar attire of the workers in this photograph .

${ }^{128}$ See Nicole Guidotti-Hernández, “Bracero Lives and the Lack of Idleness in 'Free Time,' Lusophone Journal of Cultural Studies 1.2 (2013): 275-85. In this critique, the concept of leisure is interrogated, as Guidotti-Hernández points to the aesthetic impacts of the Nadel collection, including its propensity for "lingering." Guidotti-Hernández adds how, in the Nadel portraits, evidence of the homosocial and homoerotic were equally present (277).

${ }^{129}$ Figures 5 and 6 are reproduced here courtesy of the Division of Work \& Industry, National Museum of American History, Smithsonian Institution, for use in dissertation only, released on April. 29, 2013 for use in this dissertation by Kay Peterson, Archives Center, Kenneth E. Behring Center, Washington, D.C. and may not be duplicated for use in any additional article, book, film production, still photography, advertising, merchandising, exhibit or related use. 
The literature on the Bracero era may also be read from the point of view of a popular culture archive and in a context of wartime and postwar photojournalism, both of which opened new windows into culture, gender, labour, class, and identity. The Hermanos Mayo, five Spanish émigré photojournalists who ably documented Mexican class struggle and left an important photographic record of the Bracero era. ${ }^{130}$ The visual archive that exists from the period was greatly enriched by the four hundred black and white photographs of bracero workers left by the Mayo. Their camera lenses captured moments of departure at Estación de Ferrocarril Buenavista (Buenavista train station) in Mexico City when braceros left loved ones behind to depart for farm contracts. ${ }^{131}$ The Mayo transformed standards of visual reporting on Mexico, centering their lens on the working classes. Their images reveal braceros as hopeful recruits, awaiting travel, sporting white hats and amassed in crowds and line-ups in Mexico City. They traversed the border to capture braceros performing stoop labour and took portraits of individuals posing with farm tools. ${ }^{132}$ Their collection also includes more graphic depictions of braceros undergoing medical examinations in the nude. ${ }^{133}$ Indeed, the visual record left by the Brothers Mayo is an irreplaceable one that fits in with a wider collection of photography of bracero workers.

\footnotetext{
${ }^{130}$ For a comprehensive account of photograph and visual culture in Mexico see also John Mraz, Looking for Mexico: Modern Visual Culture and National Identity (Durham: Duke University Press, 2009), 160.

${ }^{131}$ See for e.g. images 6, 47, 48, 48, 70, 71, and 72 in photo index, in John Mraz y Jaime Vélez-Storey, Trasterrados: Braceros Vistos por los Hermanos Mayo (2005), 93; 99-100 and 103. Robarts Library, Toronto. The brothers Mayo took photographs of a series of Mexican strikes in 1958-9, when clashes took place between rail and oil workers and police. Their images reflected problems connected with a state stranglehold over union leadership, and the bureaucratic mechanisms through which the PRI. sought to control unions.

${ }^{132}$ Ibid., see image 33 in photo index, 97 in Trasterrados. Robarts Library, University of Toronto.

${ }^{133}$ Ibid., see images 43, 67, and 68, "Examen medico," and "Examen bucal a un aspirante," 99;102 in Trasterrados.
} 
A second valuable source of visual knowledge from the period comes from the Dorothea Lange collection. Lange was commissioned by the U.S. government to photograph bracero workers arriving to the United States, and while she differed greatly from the Mayo in terms of her German immigrant American background, her intimate connection with Taylor and her emergence as government photographer of the Great Depression and the Japanese wartime evacuation and incarceration at Manzanar situates her body of work as a critical visual historical resource, especially as a generator of images and imaginaries linked to the American working class and the social world of harvest workers in both the American West and the Deep South. ${ }^{134}$ Indeed, Lange would emerge as a "visual sociologist" of farm labour in America between the years 1935-41. ${ }^{135}$ One image taken by Lange in 1942 entitled "First Braceros" had a smiling bracero as its subject, looking out from a train window with a tag pinned to his jacket with the numbers 31/12. ${ }^{136}$ Lange's photographs of farm labour that preceded the bracero years included stark views of impoverishment and farm labour in the fields of the Imperial Valley. Photojournalists such as Frank Q. Brown also contributed striking photographs of braceros. ${ }^{137}$ Photos of seasonal workers engaged in harvest labour often accompany Canadian media accounts, while less photographic attention has been afforded to recruitment and none at all to modern processes of medical testing, marking a departure from earlier trends. ${ }^{138}$ The next section turns to the civil rights era, during which time, the farmworker cause in America was taken to new heights.

\footnotetext{
134 On Lange's life and career, see, for example, Linda Gordon, Dorothea Lange and on the post-war fate of her Manzanar collection, see L. Gordon and Gary Okihiro, Impounded: Dorothea Lange and the Censored Images of the Japanese Internment (New York: Norton, 2006).

${ }^{135}$ Gordon, Dorothea Lange, 209.

136 “First Braceros," photonegative, ca. 1942, Gift of Paul Taylor, A67.137.42042.7, Lange (Dorothea) Collection, 1919-1965. 


\subsection{El Movimiento and La Causa: Geographies of Injustice in an Era of Civil Rights}

This section charts the extent to which farmworker struggles in 1960s and 1970s

America were set within a broader climate of political mobilization that was more clearly shaped by civil rights narratives and demands. By the mid-1960s, a growing sense of solidarity, informed by civil rights activities, came to influence the American political stage across distinctions of cultural difference, and this era witnessed Latinos, nonLatinos, and churchmen all rally to the cause of the farmworker's struggle. The farmworker movement at this time was set within with broader struggles connected with Chicanismo, which became defined in El Movimiento of 1960s America, or the MexicanAmerican movement for civil rights, enhanced educational rights, ethnic pride and selfdetermination. ${ }^{139}$ One successful tactic borrowed from the civil rights movement, that of the boycott, to raise awareness over the mistreatment of Latino farmworkers, became a powerful tool of the United Farm Workers of America. The slogan “iSi se puede!” (Yes We Can), a hallmark of the UFW cause, had reverberations across America. After its "golden age" between the early 1960s and mid-1980s, the movement weakened, ceasing to persist as a pervasive force in the twenty-first century. Yet, despite assessments of the

\footnotetext{
${ }^{137}$ See for example Frank Q. Brown, "Mexican workers await legal employment in the United States, Mexicali," February 3, 1954. Part of the LA Times Photographic Archives, ca. 1918-1990, contributed by Library Special Collections, Charles E. Young Research Library, University of California Los Angeles.

${ }^{138}$ For a good example of photographic coverage of Mexican SAWP workers in Canadian media, see Wendy Stueck, "Mexican Labourers Keep B.C. Wine Flowing,” Globe and Mail, October 14, 2011.

${ }^{139}$ During this period, the Mexican American Youth Organization (MAYO) was founded in San Antonio in 1967 by José Angel Gutiérrez and others, inspired by the civil rights and black nationalism that was sweeping the country. In January, 1970, the Partido Nacional de la Raza Unida (United Race Party or National United Peoples Party) was born in Crystal City, Texas, to appeal to a Mexican American constituency and combat racism in Southern states where it was active. On the Chicano movement as a national phenomenon, see Marc Rodriguez, Rethinking the Chicano Movement (New York: Routledge, 2015). See also Rodriguez, The Tejano Diaspora. One of the most critical civil rights cases occurred in Orange County over the desegregation of schooling involving Mexican American students in Mendez vs. Westminster. See the recent work of Neil Foley, Mexicans in the Making of America (Cambridge: Harvard University Press, 2014).
} 
UFW as a movement that has entirely lost significance, it still performs work, with recent victories in the strawberry, rose, wine, and mushroom industries and recent agreements made with large-scale vegetable producers in California and dairy farms in Oregon. ${ }^{140}$

The UFW was deeply infused with spiritual inflections, especially the cursillista tradition, a religious trend taken from Spain to the United States in 1950 that offered a brand of Spanish-Catholicism championed by Mexican and Puerto Rican Americans unable to find a comfortable place within American church life. This palatable alternative served as a foundation for later trends in spiritual activism that blended well with the farmworker movement. Cursillistas blended Latino folk music with Spanish "liturgy" and the cursillo song De Colores was heralded as the UFW anthem. ${ }^{141}$ Ballads like De Colores inspired hope and pride among participants and were often sung at UFW gatherings, marches, and rallies. Music allowed an expression of spirituality and brand of Catholic identity that supported Latino identity politics, infusing La Causa or the farmworker struggle with a sense of purpose and unity. ${ }^{142}$ In addition, the cursillista use of religious symbols was in part an attempt to unify a wide group of people. ${ }^{143}$ Cursillismo also gave Christianity a more masculine character, placing emphasis on personal reflections on sinfulness. César Estrada Chávez assimilated Catholicism into his movement, tying spiritual and

\footnotetext{
${ }^{140}$ See ufw.org, “Our Vision.” Accessed 1 July 2015. For an alternate history of resistance to union participation among North American Mennonites see Janis Thiessen, Not Talking Union: An Oral History of Mennonites and Labour (Montreal and Kingston: McGill-Queens University Press, 2016).

${ }^{141}$ Bardacke, Trampling Out the Vintage, 63-5.

${ }^{142}$ The use of the term La Causa (The Cause) emerged in the wake of the 1965 Delano, California grape strike and the movement it represented was defined by non-violent negotiation to better the conditions Latino farmworkers across the United States.

${ }^{143}$ Bruce Neuberger, Lettuce Wars: Ten Years of Work and Struggle in the Fields of California (New York: Monthly Review Press, 2013), 222.
} 
religious themes with political mobilization and activism.

De Colores typified how farmworkers' challenges could be permeated with spiritual optimism and endurance:

De colores, de colores / Se visten los campos en la primavera / De colores, de colores / Son los pajaritos que vienen de afuera / De colores, de colores / Es el arco iris que vemos lucir ... In colors, in colors / The fields are dressed in the spring / In colors, in colors / Are the little birds that come from outside / In colors, in colors / Is the rainbow that we see shining.

The song invested faith in a Catholic identity shaped by the idea of God's grace, affirming: "Let us live in grace since we can," indicating a call for unity under its banner. It often accompanied the cry “ $¡$ Si Se Puede!,” denoting a call for political optimism.

The UFW saw a combination of male and female activism weave together a persistant campaign that promoted the interests of an often-voiceless class of worker. Dolores Huerta, instrumental as an organizer and speaker for the cause of migrant farmworkers, is often remembered as the adelita of the farmworkers' struggle, a term indicating a female revolutionary inspired to action, as Huerta presented a range of public faces ranging from "emotionality" and emphasis on family to "collaborative egalitarianism" and "courageous optimism" (see Fig. 7). ${ }^{144}$ In 1988 Huerta was violently assaulted by the police during a San Francisco protest rally. As Vice President of the United Farm Workers and a founding member of the National Farm Workers Association in 1962, the organization that preceded Chavez's union, Huerta made significant inroads into carving out improved rights and conditions for farmworkers.

\footnotetext{
${ }^{144}$ Stacey Sowards, "Rhetorical Agency as Haciendo Caras and Differential Consciousness Through Lens of Gender, Race, Ethnicity, and Class," Communication Theory 20 (2010): 223-4, 230-1.
} 


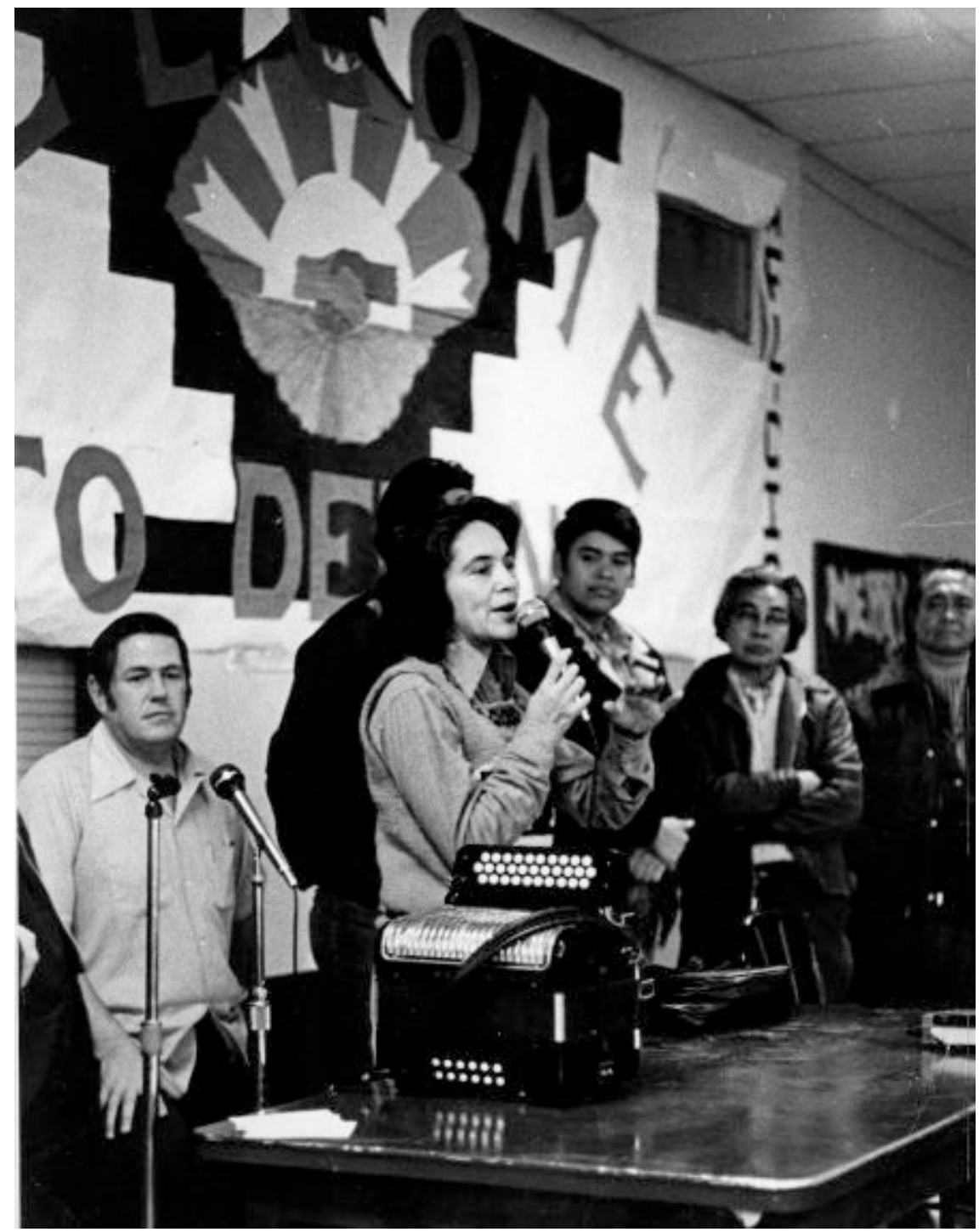

Fig. 7 'Dolores Huerta, at podium, speaks during an unidentified meeting in Delano, CA ${ }^{\prime 145}$

(Courtesy of Walter P. Reuther Library, Wayne State University)

Note Eliseo Medina in the Background, to the Right of Huerta.

During the Bracero years Huerta campaigned against the program's exploitative nature. During her first years with NFWA, Huerta was victimized by male chauvinism within the organization's administrative structure.

\footnotetext{
${ }^{145}$ Image 186, Photographer Ben Garza, Walter P. Reuther Library, Archives of Labor and Urban Affairs, Wayne State University. Image Use Agreement granted by Deborah Rice, Archivist.
} 


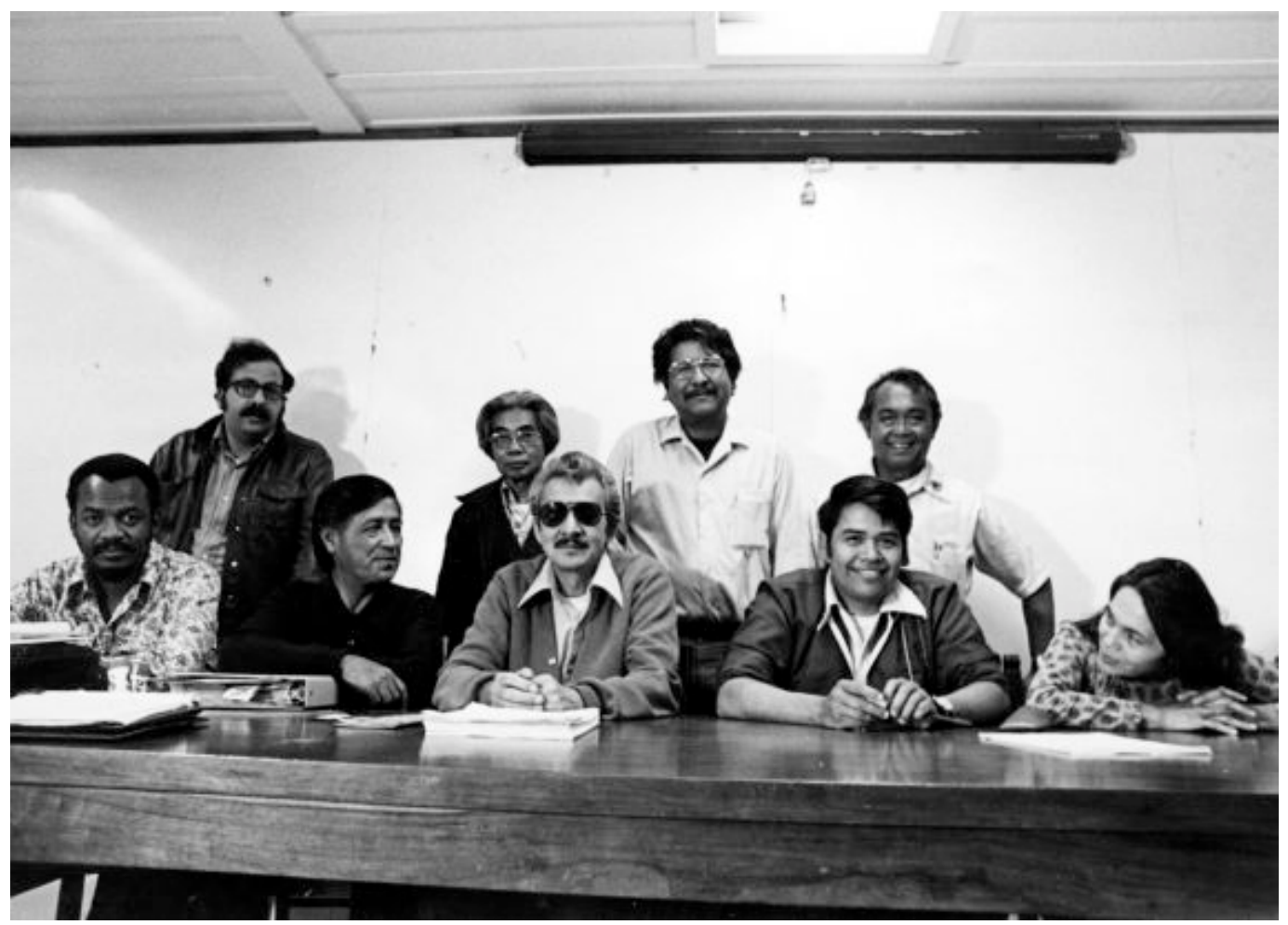

Fig. 8 "United Farm Workers Officials." June 10, 1976

Note Eliseo Medina in Front Row, Second From Right, Dolores Huerta, Front Row on the Right, and Cesar Chavez, Front Row, Second from the Left; A sense of courageous optimism found through solidarity pervaded the UFW leadership.

Cesar Chávez, born into life of a farmworker, came to view farm labour in exchange for a wage as "an affliction," an inescapable system of servitude. ${ }^{147} \mathrm{He}$ was also a critic of the Bracero Program, identifying the problems it had generated. In 1958, Chávez described bracero availability as complicating the situation for local workers:

Whole crews of locals have been displaced from their jobs to hire Braceros...a labor contractor, Eleuterio Gonzales, had a local crew of about forty men

\footnotetext{
${ }^{146}$ Image 252, Photographer Cathy Murphy, Walter P. Reuther Library, Archives of Labor and Urban Affairs, Wayne State University. Image Use Agreement granted by Deborah Rice, Archivist.

${ }^{147}$ Bardacke, Trampling Out the Vintage, 46.
} 
and...was asked by his employer to lay off these men and go pick up Braceros at the camp the following morning. So forty locals were displaced at once because there are plenty of Braceros in the area. ${ }^{148}$

In 1987 in Manitoba, a similar problem was identified, involving the ostensible loss of jobs for local First Nations residents:

Much of the criticism leveled against the offshore worker program comes from Indian bands who say many reserve residents seek but can't find farm work. They say they're at a disadvantage for first crack at the seasonal jobs because of transportation and accommodation problems...producers argue that offshore workers are faster and more reliable. ${ }^{149}$

These continuities in the management of workers across borders in the United States and Canada reveal that managed migration was in fact consistently controversial.

Print media was for Chávez a key means to publicly articulate farmworker concerns. Chávez created a newspaper to forge a "community of readers" that could lead to tangible community formation. ${ }^{150}$ When soon-to-be UFW organizer Eliseo Medina first read in 1965 about a farmworker campaign in Chávez’s newspaper, El Macriado, after spending four years as a farmworker, he recalled thinking: "all of a sudden, it was like Mexicans could do something and they could win." ${ }^{151}$ Printed matter played a key role in arousing ground-up consciousness. Born in Zacatecas, Medina was also the son of a bracero worker, and proceeded to rise within the UFW as an organizer, to lead the Chicago Grape Boycott. His lifelong activism in relation to immigration reform issues

\footnotetext{
${ }^{148}$ Ibid., 89. Original citation: César Chávez, Activity Report, Nov. 11, 1958, Archives of Labour and Urban Affairs Walter P. Reuther Library, Fred Ross Sr., Papers, Box 2, Wayne State.

149 Jane Armstrong, "Promises Fail to Stem Foreign Labor Flow," Winnipeg Free Press, May 4, 1987. Winnipeg Free Press Archive.

${ }^{150}$ Bardacke, Trampling Out the Vintage, 130.

${ }^{151}$ Ibid., 250.
} 
persists today. ${ }^{152}$ Medina saw the union as a radical vehicle for improvement and his organizational career was often shaped by strategizing tactics that sprang from practical and informal approaches. Many UFW organizers had personal links to farm labour, as descendants of farmworkers or as farmworkers themselves, yet the ranks of the UFW leadership would ultimately become a "vanguard" group, freed from ties to waged labour and thus better able to campaign for enlightened legislation.

The "Plan of Delano," drawn up in 1966 to specify aims of the farmworker movement, was not dissimilar to a modern-day account of farmworker grievances or a nineteenth century Mexican pronunciamento. ${ }^{153}$ The Plan was a manifesto of rights and dreams that offered a revolutionary approach to enunciating wanted improvements for farmworkers across the United States: "We are poor, we are humble...We do not want charity at the price of our dignity...we want a just wage, better working conditions, a decent future for our children." 154 Infused with a mission of endurance, the Plan of Delano also drew religious inspiration from the figure of Guadalupe, spiritual protector for all Mexicans, including those outside Mexico. The Virgin, who first entered Mexican history in 1531, is still considered a beloved religious and nationalistic symbol among the Mexican migrant community in the United States. ${ }^{155}$ As Valentina Napolitana argues, the shifting use of the Virgin's image is "indicative of changes in the collective imaginaries of colonial and post-colonial Mexico" and came to challenge the Augustinian Catholic influence over New Spain through an indigenous conceptualization

\footnotetext{
${ }^{152}$ In 2014, Medina fasted for progressive immigration reform. Medina sat at the forefront of the cause to organize America's farmworkers and manifested himself as a "public pest." See Miriam Pawell, The Union of their Dreams: Power, Hope and Struggle in César Chávez's Farm Worker Movement (New York: Bloomsbury, 2009), 48-9.

${ }^{153}$ For an account of rural grievances expressed in a liberal framework of equality and a departure from servitude see
} 
of divinity. ${ }^{156}$ La Guadalupana would emerge as a figure symbolizing protection for the Mexican nation in national and trans-national circumstances, a "mediator between liberation and submission" and a vehicle for the "inculturation and mestijaze of Christianity in the Americas. ${ }^{, 157}$ As one Mexican priest in Rome, Pascual Chávez Villanueva, in 2006 suggested, the Virgin was a "symbol for the battle for life" and characterized a mestizo Christianity. ${ }^{158}$

Churchmen and labour leaders often figured prominently in the social web that constituted the farmworker movement. In 1968, Father Mark Day, a Franciscan priest assigned to the farm worker movement performed a mass to conclude a fast by Chávez in Delano. The interrelationship between California bishops, Catholic growers, and the UFW was significant. ${ }^{159}$ Labour leadership played an equally important role:

George Meany of the AFL-CIO, initially skeptical of the idea of organizing agricultural workers, ultimately became wedded to the UFW cause, while the "Labor Priest" Monsignor Higgins served on the National Advisory Committee on Farm

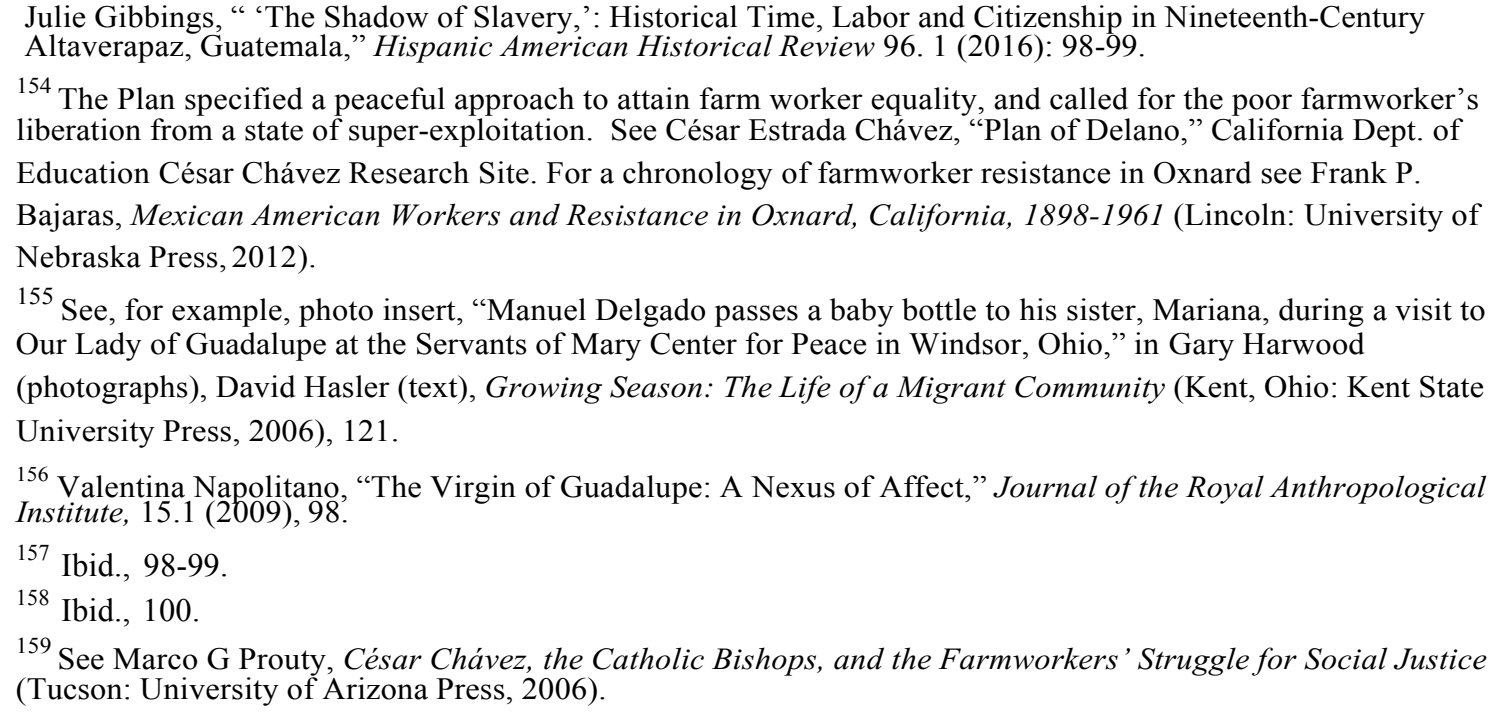


Labor. ${ }^{160}$ Since many agriculturalists contributed regularly to churches, competing interests often compromised bishops' priorities. Yet, as social justice concerns facing clergymen became more acute, churchmen soon became critical endorsers of

\section{La Causa.}

Public support from non-Latino community leaders and American consumers offered a spiritual and psychological bolster to promote progressive farmworker legislation. Organizers like Bill Esher, founder of the West Oakland Farmworker Association, had earlier experience in exposing first-hand the exploitation of bracero farmhand workers by engaging in farm work themselves. ${ }^{161}$ The UFW years connected the farmworker cause more directly with consumers and took the scale of farmworker issues to a new level in the public domain. The Agricultural Labor Relations Act or ALRA in California, implemented in 1975 after persistent UFW campaigning, made farm worker unions legal and offered rural wage earners increased protections. ${ }^{162}$ The ALRA effectively secured collective bargaining rights in law. ${ }^{163}$ This "golden age" of the United Farmworkers movement was, however, marked by moments of defeat. ${ }^{164}$

\footnotetext{
$\overline{160}$ Ibid.,18-19, 52,. See also John J. O’Brien, George G. Higgins and the Quest for Worker Justice (Lanham: Rowman and Littlefield, 2005) and Sean Segal, "Early Church Involvement in U.S. Farm Labor" (Senior Thesis, Catholic University of America, 2000).

${ }^{161}$ Bardacke, Trampling out the Vintage, 131. Esher's testimony from working in canteloupes detailed how "semienslaved Mexicans" were cheated out of "many thousands of dollars" by a grower's association.

162 Ibid., 484.

${ }^{163}$ Protections today in the Migrant and Seasonal Agricultural Worker Protection Act (MSPA) also set farm workers' rights nationwide and include access to safe housing, provision of a statement of earnings, and the paying of wages when due.

${ }^{164}$ Stephen, The Story of PCUN, 11.A series of conservative backlashes in numerous states in the 1970s, including in Oregon, Arizona, and Idaho saw collective action face staunch opposition; the 1970s and 80s saw a string of victories and defeats, including Senate Bill 677 in Oregon (1971) resolutely defend agribusiness.
} 
Organizers were also often victimized by their outspokenness and growing fame. After an assassination plot against Chávez was uncovered in 1971, bodyguards were hired to protect him. ${ }^{165}$ As the UFW developed into a well-organized network and umbrella union representing some 40,000 farmworkers with a well-developed annual budget of $\$ 1.5$ million, it increasingly became a player on the national stage. ${ }^{166}$ Chávez often resorted to radical tactics, most famously hunger strikes, to advance the movement: in 1988 he fasted to support a campaign against the use of pesticides, and throughout his career he toured extensively, never limiting himself to one location.

While field workers' voices were often subsumed by racism or judiciary powers to define justice, the confidence ascribed in movements of unity offered the downtrodden a sense of collective courage to speak against injustice. Speaking to a delegation of the National Farmworkers Union in Winnipeg in 1971, Jessica Govea, an assistant to Chávez, recounted the discrimination faced by one Manuel Rivara, who was run over on the picket line by a farmer driving a truck; after failed attempts to prosecute the farmer, Rivara was “told by a California judge that he was 'lucky' not to be prosecuted himself for obstructing a public roadway." ${ }^{167}$ Indeed, farmworkers still often face intermittent bouts of violence, especially when working with uncertain statuses. ${ }^{168}$ Rural labour conflict, shaped in part by differences in nationality and class, have come to intersect with diverse agribusiness climates across the globe.

\footnotetext{
165 Bardacke, Trampling out the Vintage, 395.

166 Ibid.

167 ““'Hope Pledged' to NFU Dispute,” Winnipeg Free Press, Thursday, Dec. 9, 1971.

168 This was the case in Greece where undocumented Bangladeshi strawberry harvest workers came under attack. See Helena Smith, “Greece's Migrant Fruit Pickers,” The Guardian, Sept. 1, 2014.
} 


\subsection{Connections with Home: Corridors of Survival and Exchange}

This final section explores how the labour emigration evolved for the Mexican migrant after the Bracero Program came to a close. After Bracero Program's formal termination, migrant farmworkers continued to receive second-class treatment, as American agribusiness remained reliant on a Mexican workforce. ${ }^{169}$ Kelly LytleHernández notes how, "by the mid-1970s, vigilantes were patrolling the border, and Congress was hosting explosive debates about how to solve the wetback problem. ${ }^{, 170}$ As Gabriel and Macdonald have highlighted,

The high proportion of undocumented migrants who come to the United States from Mexico make this a truly North American problem, and the bad will it has created between the two countries threatens to stall deeper integration. In this context, Canadian programs and the Canadian immigration model are sometimes held up as "best practices," particularly the longstanding, low-wage, sectorspecific, temporary Seasonal Agricultural Workers Program (SAWP). ${ }^{171}$

Toward the end of Bracero program, the U.S. government offered limited pathways toward citizenship for some braceros, allowing them to remain legally in the United States. In 1961, Immigration and Naturalization Services (INS) introduced a green card system for braceros enabling three-quarters of a million Mexicans to hold such cards by 1969. ${ }^{172}$ While the Bracero Program created corridors for temporary and permanent migration, the border control would resurface as a more highly mediated barrier that

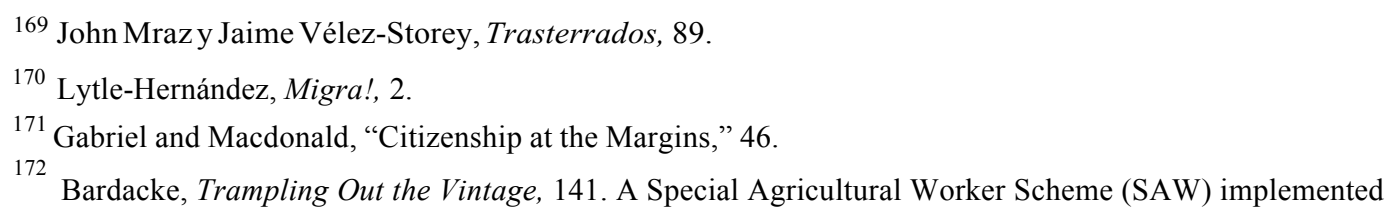
alongside the Immigration Reform and Control Act (IRCA) of 1986 continues to admit far fewer legal agricultural migrants than did the Bracero Program. The SAW effectively confused the profile of migrants in the United States. 
would come to define the post-Bracero era.

Rodolfo Acuña refers to corridors to describe how migration routes have come to function in a North-South relational context. Corridors functioned as avenues of survival and, psychologically, as avenues of opportunity. Acuña locates agency across borders and demystifies the assumption that Mexicans were "born apathetic and never attempted to organize." ${ }^{173}$ As managed migration routes failed to meet social needs, migration choices were instead made in light of stark realities. Migration corridors have also functioned in the context of transit routes through neighbouring countries, including routes connecting Guatemalan migrants with safe havens throughout Mexico. ${ }^{174}$ Air corridors now define contemporary seasonal agricultural migration to Canada, including for farmworkers who travel between Guatemala and Quebec.

Corridors of removal have also defined farm worker histories in North America. Mexican guest workers in Leamington staged a work stoppage in 2000 to contest a foreman's abuse, leading to the deportation of sixteen. ${ }^{175}$ Along the U.S. border, the criminalization of migrants has proven much more overt, since the initial

Philip Martin, "Good Intensions gone awry: IRCA and U.S. Agriculture," The Annals of the Academy of Political and Social Science 534 (July 1994): 44-57. See also Martin, Harvest of Confusion: Migrant Workers in U.S. Agriculture (Boulder: Westview Press, 1988); and P. Martin and J. Edward Taylor, Harvest of Confusion: SAWs, RAWs, and Farmworkers (Washington, D.C.: Urban Institute, 1988). While the SAW gave legal status to undocumented workers who performed at least 90 days of farm work over 1985-6, it was soon abused by those filing fraudulent claims. A Replenishment Agricultural Work Scheme (RAW) also allowed migration and naturalization after five years of farm labour and was terminated in 1993.

${ }^{173}$ Acuña, Corridors of Migration, ix. Geraldo Cadava's revisionist "transnational" history of the Arizona/Sonora region also makes use of the corridor concept and pays attention to the economic sectors in which migrants operated, providing a new borderlands approach to the modern history of the region. See Geraldo L. Cadava, Standing on Common Ground: The Making of a Sunbelt Borderland (Cambridge, MA: Harvard University Press, 2015).

${ }^{174}$ Economic hardship has driven out-migration from Guatemala and as many migrants undergo Mexicanization, learning Spanish and often claiming a Mexican identity in the United States. See Xóchitl Castañeda, Beatriz Manz and Allison Davenport, "Mexicanization: A Survival Strategy for Guatemalans in the San Francisco Bay Area," Migraciones Internationales 1.3 (July-December 2002): 102-123.

175 As David Bacon notes in Communities without Borders, labour unrest among guest workers was rarely viewed as welcome, as was the case with Jamaican sugar workers in 1980s Florida, who staged a work stoppage with the goal of improving piece rates, sparking a vicious grower response of intimidation with dogs, as disruptive workers were "loaded onto planes back home." (See 230). 
criminalization of "unsanctioned migration" in $1929 .{ }^{176}$ Migration remains a vehicle of survival for those who move to locate work and migration corridors often function in ways largely invisible to others. In contrast with a pervasive American climate of migrant illegality, state-endorsed farm work contracts in Canada, perhaps by no coincidence in timing with their onset in the 1970s, a time of emergent anti-wetback narratives in the United States, would serve to protect migrants from discrimination at the border. Another significant corridor involves the realm of the economic, which functioned in important ways as a connecting thread to migrants' families and loved ones. Margaret Gray's study of New York State documents farmworkers sending money to their families, generally through a wire transfer, just as farmworkers in Portage la Prairie and Oliver use wire transfers to send money home. ${ }^{177}$ Links between sending regions and migration destinations in the United States, between Jalisco and Boston, Puebla and New York, Michoacán and Chicago, Guerrero and Georgia, have not taken hold in a similar way in Canada. ${ }^{178}$ The diversification of migrant destinations accompanied the neo-liberal

\footnotetext{
${ }^{176}$ Lytle-Hernández notes that this early criminalization process "routed" emigrant workers away from "American worksites and communities and delivered them instead to U.S. jails and prisons prior to deportation." See Migra!, 93.

${ }^{177}$ Margaret Gray, "How Latin American Inequality becomes Latino Inequality: A Case Study of Hudson Valley Farmworkers" in Paul Gootenburg and Luis Reygadas, eds. Indelible Inequalities in Latin America: Insights from

History, Politics and Culture (Durham: Duke University Press, 2010), 180. On New York farms, illegal farmworkers continue to lack overtime pay, days of rest, or protections that that legalize collective activity. See Paul Brooks, “Migrants' needs not being met," Times Herald-Record, Nov. 11, 2007.

${ }^{178}$ Migrants from Jalisco would become known for their ability to generate remittances, and alongside Guanajuato and Michaocán, Jalisco traditionally provided the highest numbers of sending migrants.

Mexicans' ability to migrate as wage earners was also not dissimilar to patterns of regional economic emigration common to small Pacific states like Tonga and Samoa.

179 An interesting exception to this rule in Canada has had to do with the development of "niche" Latin American communities in urban centre, including, for instance, the migration of Colombians, to London, ON, now dubbed "Londombia."
} 
reshaping of export-oriented agriculture in Mexico. ${ }^{180}$

Despite often-positive economic results of migration, the potentially sinister cultural dislocations caused by migration were voiced early on by Mexican churchmen, who warned of the adverse effects migration might have on the vulnerable spiritual identities of migrants. Churchmen in Guadalajara were concerned in 1921 about the problem of migration and formulated a national church policy on migration at a conference attended by some five hundred clergymen. ${ }^{181}$ Emigration was described as perilous to Mexican identity and patriotism, allowing migrants to absorb American concepts and cultural habits while disrupting family integrities, and in the wake of the conference, many clergymen would follow migrants abroad as numerous priests traversed the border in the $1920 \mathrm{~s} .{ }^{182}$ Church and state also made efforts to contest outmigration on "nationalist grounds," seeing migration as unjustly serving American economic prowess. ${ }^{183}$ The Mexican Church would ultimately recognize the material benefits of migration, in spite of the cultural shifts required of workers crossing borders.

Migrant communities encountered new challenges in light of migration, and a final indicator of persisting connections with home was the migrant worker's ability to transfer his or her own cultural baggage to a host country, if temporarily. This cultural transfer often encompassed culinary or spiritual practices, languages spoken, or celebrations of identity abroad. While Canada has yet to see a phenomenon of rootedness resulting from seasonal migration as it occurred in American contexts,

\footnotetext{
${ }^{180}$ Barndt, Tangled Routes, 44.

${ }^{181}$ Fitzgerald, A Nation of Emigrants (2009), 76-77, 80, 193 n4.

182 Ibid., 89.

183 Ibid., 98.
} 
interest groups promoting migrant agricultural workers' rights in Canada have often claimed residency or citizenship rights as an indication of the freedoms migrants have yet to claim from a state that has continued to benefit from their labour power. The future of the permanency of circular farm labour migration to Canada in this respect remains to be seen.

\section{Conclusions}

As Peter Nyers and Michelle Lowry observe, migrant rights movements, (in addition to movements advocating for refugees' rights), “appear in various forms and take on a diverse set of tactics to suit their particular contexts and circumstances." 184 They ask, "What of the refugees and migrants themselves? Must they be "spoken for"? Or can they speak, advocate and, organize for themselves?"185 While the history of Mexican farm labour mobilization is complex and deeply defined by regional as well as temporal variation, one continuity was made manifest: that of the persistence of solidarity movements, from the initial, radical emphasis upon the resurgence the working man at the beginning of the twentieth century, to the reformist, populist movements of unity that characterized the civil rights period, and finally, to the era of the temporary, non-citizen worker or undocumented majority worker who would come to form an important economic backbone for national "progress" in the United States and Canada.

Another continuity in the story was the fact of labour repression in agriculture, and the mixed levels of support given by states to farmworker movements, as most evident in the mixed position taken towards the Bracero Program by the Kennedy administration.

\footnotetext{
${ }^{184}$ Michelle Lowry and Peter Nyers, eds., "Introduction: Global Movements for Refugee and Migrant Rights," in Lowry and Nyers, eds., Special issue of Refuge: Canada's Periodical on Refugees 21:3 (May 2003): 2.

${ }^{185}$ Ibid. Lowry and Nyers here further highlight the "the thorny political problems that arise when activists organize for rather than in solidarity with migrant and refugee communities.” (3)
} 
While independent farmworker organizations in the United States were often more resourceful than national umbrella unions that were initially designed to serve the interests of white labor, collaborations between ethnically specific labour movements, leftist political actors, and national union organizations like the AFL-CIO, would work to reshape the farm labor climate in the twentieth century with varying levels of success, just as the Canadian Labour Congress in Canada would ultimately form an important voice in articulating injustices experienced by seasonal farm workers. ${ }^{186}$ In seeking to chart out transitions in the American farm labour climate over the course of the twentieth century, diverse resources and archives were consulted, both primary and secondary. The Bracero History Archive, a join project associated with George Mason University, Brown University, the Smithsonian Museum of American History, and Institute of Oral History, University of Texas at El Paso, and the Roy Rosensweig Center for History and New Media, offered an expansive and diverse collection of photographs and recorded oral history interviews with Bracero workers and members of their family, while the Taylor archive offered a unique window into interwar America. American trends would find mirrors in Canada where migrants rights movements, churches, and unions would adopt differing levels of participation and engagement with the lives, causes and day-to-day realities of foreign migrant farmworkers. The next chapter turns to oral history to gain insights into the migrant experience to highlight findings from more than forty interviews carried out with SAWP workers in Manitoba and British Columbia between 2012 and 2015.

\footnotetext{
${ }^{186}$ Francisco Martin del Campo, in his paper, "Environment, Leadership and Union Building in California Agriculture during the Strike Wave of 1933," with whom I shared a panel at the 2016 American Society for Environmental History (ASEH) Conference, helped clarify the connections formed between Filipino labour organizations, Latino labour militants and their communist advocates who faced repression because of their militarism in support of farm workers during the 1933 strike wave that encompassed 50,000 workers.
} 


\section{4. "There Is Not Much Work that is Nice / No Hay Mucho Trabajo que está Bonito": Findings from Canadian Fields}

"Oral data has the great advantage of extending the range of persons about whom we can write."

This chapter will suggest that underrepresented groups work on the margins of Canadian society, yet does it not presuppose participants as "subalterns" without any sense of agency in their jobs; in this way, the margin is reset in the centre. It places worker accounts in the limelight to offer a series of snapshots of local rural landscapes as they have become implicated in modern-day migrants' worlds. As David Harvey and Mark Riley note, oral historians responded to positivist critiques of their practice in three critical ways: by revisiting oral history methodologies; by reappraising the subjectivity of memory and practicing oral history in a reflexive and critical way; and by more broadly challenging "traditional historical practice. ${ }^{2}$ While Harvey and Riley confirm oral history's "long and contested genealogy" they still look to its potential as an alternate means to read agricultural change over time; in doing so, they have suggested that the "toolkit" offered by oral history approaches to new culturally-inflected rural geography research (in their case, in Britain) might offer a means to subvert narratives that often suffer from a reliance upon the subjectivities of the privileged. ${ }^{3}$

\footnotetext{
"Jean Barman, "Writing Women into the History of the North American Wests, One Woman at a Time," in Elizabeth Jameson and Sheila McManus, eds. One Step Over the Line: Toward a History of Women in the North American Wests (Edmonton: University of Alberta Press, 2008), 100.

${ }^{2}$ Mark Riley and David Harvey, "Talking Geography: On Oral History and the Practice of Geography," Social and Cultural Geography 8.3 (2007): 346.

${ }^{3}$ Mark Riley and David Harvey, "Oral Histories, Farming Oractice, and Uncovering Meaning in the Countryside", Social and Cultural Geography 8.3 (2007): 392. Their approach, which encompassed a "move beyond previous qualitative research, which has mostly used the semi-structured interview (or interrogation), towards an approach which elicits more "conversational narratives"' is similar to that taken in my research, which began at the outset with a structured questionnaire and turned ultimately instead toward an approach that privileged dialogue over structure. See 393.
} 
In North America, oral history has gained currency as a mean to write about the contemporary world of Mexican migration. Judith Adler Hellman's work, for instance, adopts a personal interview strategy to uncover wider patterns. ${ }^{4}$ In reading worker accounts as "modern" texts or discourses, this chapter locates manifestations of modernity in a longer past to consider how Canadian life and culture became interwoven into farm workers' experiences. It offers a counterpoint to an existing official archive, an overdependence upon which, as Ravi Vaithees has suggested in his critique of the Cambridge school of South Asian historiography, may lead to politicized conclusions concerning vernacular movements and activities. ${ }^{5}$ An over-dependence on the colonial archive in the case of southern South Asia led to omissions of interpretation when it came to "language, culture, ideology... and what counted as politics." ${ }^{6}$ Other critics of colonial archives, such as Tony Ballantyne, have stressed how "the [colonial] archive is deeply problematic; the manuscript collections, parliamentary papers, court records, periodicals and newspapers we use are not simply documents that allow us to access the colonial past, but rather were constitutive of the inequalities of that past" or understood otherwise, the archive constitutes the "memory of the state."7

In pursuing oral research in Canada, I benefited from prior training in the field in Samoa and New Zealand, where I conducted a series of twenty-six oral history interviews with postwar Samoan labour migrants to New Zealand and Ni-Vanuatu agricultural guest workers in Central Otago in 2007-08. ${ }^{8}$ This work drew upon the field

\footnotetext{
${ }^{4}$ See Hellman, The World of Mexican Migrants. Her account of "Pedro P." for example recounts how agricultural harvest work was balanced with paid work in other sectors.

${ }^{5}$ See V. Ravi Vaithees, Religion, Caste and Nation in South India: Maraimalai Adigal, the Neo-Saivite Movement, and Tamil Nationalism (New Delhi: Oxford University Press India, 2015).

${ }^{6}$ Ibid., 5.

${ }^{7}$ Ballantyne, Orientalism and Race, 10.
} 
of South Pacific labour history, finding parallels between nineteenth century patterns of Melanesian island labour integration and indenture in colonial plantation zones of Fiji, (Britain), Queensland (Australia), and New Caledonia (France), and contemporary analyses of Pacific labour integration and emigration. ${ }^{8}$ In knitting together national with trans-national histories and locating them as precursors to contemporary labour migration paths and networks, my approach in this study is similar, giving attention to broader economic networks and patterns delineated by political and structural foundations, opportunities and limitations, and prior histories of economic emigration.

While the oral histories collected here are rooted in a labour history approach they also fit in with a broader nexus of Mexican oral history studies that have confronted more vulnerable groups but have also turned their gaze toward elite groups as well as middle classes. Among Latin American historians, archival and oral history approaches to the past are often used in dialogue with one another. ${ }^{9}$ My oral histories fit in with more recent trends in the social history of rural community and place, which take unassuming elements of the everyday more seriously as objects of inquiry. In this respect, Valerie Matsumoto's oral history study of a Japanese-American farming colony in Cortez, California, is particularly instructive. In Farming the Home Place, Matsumoto's oral histories highlight how everyday farm tasks, including the challenges and joys of work, as well as the barriers to and opportunities for cross-cultural integration shaped life in this farming colony from the 1920s through to the postwar decades. The substance

\footnotetext{
${ }^{8}$ See Naomi Alisa Calnitsky, "Colonized Pasts, Labour Circuits and Post-1945 Mobility to New Zealand: A Case Study of Samoa and Vanuatu," (M.A. Thesis, History, University of Otago, 2008). These two case studies followed modern labour integration in the regional context of the South Pacific involving the "metropolitan" (in this case, contemporary New Zealand) absorption of Pacific Island labour, one Polynesian and the other Melanesian. ${ }^{9}$ See, for e.g. Jaymie Patricia Heilman, Before the Shining Path: Politics in Rural Ayacucho, 1895 1980 (Stanford: Stanford University Press, 2010). For a Canadian regional study that combined archival with oral research, see Stacey Raeanna Zembrzycki, "Memory, Identity, and the Challenge of Community among Ukrainians in the Sudbury Region, 1901-1939” (Ph.D. Thesis, Carleton University, 2007).
} 
of Matsumoto's rural history interviews confirms how seemingly "small” events loomed large in the farming colony's past:

May and June were the months of strawberry harvest, followed by the eggplant harvest, as well as peaches and apricots, so the Nisei were kept busy making stacks of produce crates... all summer long, they nailed fifty-pound lug boxes in preparation for the grape harvest in the fall... ${ }^{10}$

In cases of oral history research where the past is more political, silences or omissions are often recognizable as historical indicators to be aware of, as evident in Kirsten Emiko McAllister's account of her research among Japanese-Canadian elders in New Denver, B.C. ${ }^{11}$ More specifically, in terms of approaching contemporary food systems and the workforces that support them, the participatory anthropological approach of Seth Holmes, the more visually-inflected documentary work of David Bacon, and the critical political science approaches of Margaret Gray, which all equally take migrants' lives seriously, serve as a guide. ${ }^{12}$

The set of oral histories I present here help locate new perspectives on and windows into migrant histories in Canada, and also intend to promote a rethinking of the ways in which migrant Latin American pasts have become increasingly interwoven

\footnotetext{
${ }^{10}$ See Valerie Matsumoto, Farming the Home Place: A Japanese American Community in California, 1919-1982 (Ithaca, NY: Cornell University Press, 1993), 66-7.

${ }^{11}$ See Kirsten Emiko McAllister, Terrain of Memory: A Japanese Canadian Memorial Project (Vancouver: UBC Press, 2010), 128-31.

${ }^{12}$ See Seth Holmes, Fresh Fruit, Broken Bodies: Migrant Farmworkers in the United States (Berkeley: University of California Press, 2013), Hellman, The World of Mexican Migrants, David Bacon, Communities without Borders: Images and Voices from the World of Migration (Ithaca: ILR Press, 2006), and Margaret Gray, Labor and the Locavore: The Making of a Comprehensive Food Ethic (Berkeley: University of California Press, 2013). In Gray's work, the shift from a Black to a Latino workforce in the Hudson Valley is charted, as are the housing conditions of undocumented farmworkers employed in the region.
} 
into Canadian history. The oral histories intervene in existing knowledge frameworks and discourses concerning agricultural workers' lived experiences, by presenting a series of case studies from the field that underscore worker perspectives and memories on labour in Canada. The field conversations featured here serve as a counterpoint to the existing literature which has for the most part failed to take an historical approach but has increasingly turned to oral history as a central method to locate the migrant voice; participatory approaches would also surface in Canada in Katie Marie Hinnencamp's study of farmworkers in Niagara-on-the-Lake, which highlighted their dependence on bicycles for transport. ${ }^{13}$ Workers in my study often refer to alternate trans-national experiences of work performed in the United States; in addition, they describe traditional occupations performed at home in Mexico, often in agricultural sectors but not exclusively, and on occasion discuss family or the nature of their home region. Workers often framed their familiarity with farm work by describing the agricultural industries in their native regions, including coffee estate work in Veracruz; avocado, lime, and other fruit work in Michaocán; work in orange groves in the state of San Luis Potosí; or ranching life in Sonora or Nayarit.

The telling of migrants' stories and contributions to Canada's economic life, via official discourses, may present a seemingly comprehensive picture of guest worker

\footnotetext{
${ }^{13}$ See, for example, Adriana Gabriela Paz Ramirez, "Embodying and Resisting Labour Apartheid: Racism and Mexican Farm Workers in Canada's Seasonal Agricultural Workers Program," (M.A. Thesis, Sociology, UBC, 2013). In Tortillas and Tomatoes, Basok's interviews in Leamington detailed emotional challenges faced by guest workers in the greenhouse industry. Hinnencamp sought a move away from "researcher-driven" studies and towards a more participatory approach. See Katie Marie Hinnenkamp, "Bicycles Travelling in the Rain: A Participatory, Arts-Informed Account of Mexican Farmworkers in Canada” (M.A., University of Toronto, 2007). Bicycles were used to purchase groceries or make phone-calls home, but were also dangerous in Ontario communities where vehicles failed to respect cyclists and agricultural workers riding them had no access to lights (140).
} 
pasts, yet insights into this labour history offered in individual accounts may better inform policy and the public about the effectiveness of managed agricultural migration programs. Informed field knowledge has the advantage of giving a human face to experience. The pursuit of social truth in the field of labour history has the benefit of allowing voices of workers to be played against economic narratives that tend to dominate discussions at the national level.

In offering a careful reading of migrant experiences that engages with cultural determinants in addition to political economy, we may expand our definition of migration history. As economic migrants, the group explored here offer glimpses into their own preferences in terms of the jobs made available in Canada and the sorts of jobs they have performed at home in the past. Judith Adler Hellman's work reminds scholars of the need to expand their research questions such that the questions asked do not prescribe any one story or attempt to determine preconceived answers. ${ }^{14}$ In a similar fashion, Vicki Ruiz, Mexican-American historian of Latina labour, in her influential monograph, Cannery Women, Cannery Lives (1987) critically did not view her subjects as victims. While I constructed an initial skeleton of questions to guide my interviews, I left space for participants to engage and reveal stories, responses, and explanations that sat outside the boundaries of my questionnaire. ${ }^{15}$

\footnotetext{
${ }^{14}$ Hellman's interview with "Marta" who, in order to escape the powerful domination of in-laws, relocated to America to join her husband instead of remaining in her home village. The propensity for male migrants to engage in affairs was another determining factor for women choosing to follow absent husbands and leave Mexico. This problem (of spousal separation) was developed to some extent in my own interviews. See Chapter 4 in Hellman, The World of Mexican Migrants.

${ }^{15}$ See Vicki L. Ruiz, Cannery Women, Cannery Lives: Mexican Women, Unionization and the California Food Processing Industry, 1930-1950 (Albuquerque: University of New Mexico Press, 1987).
} 
In the field, I adjusted my approach as necessary, given the range of terrain and local particularities of my chosen sites of research. In order to secure oral consent for interviews, I first always explained that I was pursuing a study relating to the experience of Mexican farm workers in Canada according my Research Ethics Board script, and then, before beginning any interview, made sure that this was understood by the participant and that they had agreed to take part in answering my questions about their working experience in Canada. I sometimes looked to alternate sources of information, including local residents or town dwellers, estate owners, and local migrant outreach workers, to help better define how local histories of seasonal farmworkers had played out in the chosen regions for research. I ultimately opted for a looser-format interview, drawn in part from the original questions I composed in my bilingual questionnaire and that I had first used in the field in 2012, but based more closely around the circumstances of each particular farmworker and the nature of their personal story. While all the interviews were carried out in Spanish, I transcribed interviews into English, recording some of the key Spanish phrases used, at times during and in some cases after each interview took place. In my first year I used handwritten notes to record interviews and then transcribed them into type; in the later years in the field, if the interview was of a shorter nature, I often skipped the handwritten method and recorded my field notes directly in type. I include a sample of my field notes in Oliver to detail the character of my field note process (See Appendix 4). The farmworkers' use of bicycles proved an advantage, as I was often able to wave workers down in the street to proceed with encounters that could lead to interviews. 
Judith Hellman's narrative of undocumented migrants living on the other side of the border, or otro lado, earning a living in the United States, painted a humanistic portrait of migration that sat outside of economistic interpretations. Informed by this approach, my oral histories sought to recover Mexican perspectives and re-situate these narratives within larger conversations surrounding migration, immigration, cosmopolitanism, and temporary foreign worker programs in Canada. To recover migrant narratives as truthfully as possible, an engagement with the concept of "lived histories" and "life histories" was additionally useful. This approach presumes that migrant histories are consistently evolving, yet are rooted in structures and tendencies of the past. Canada's contemporary agricultural migrants have continued to inhabit workspaces within and outside of the realm of inclusion within the nation; while tied to "modern" migration networks, their experiences remain locked within larger, politicized structures.

Following from the approaches taken by oral historians of farm labour and migration, my oral history methodology was also rooted in a cultural sensitivity and inclusive approach that recognized how different participants might offer unique and relevant information that might serve to complicate understandings of the SAWP and its past. This approach would therefore have to include female workers in a migration climate that was still dominated by men. Frank Bardacke's revisionist history of the United Farm Workers rereads farm labour narratives from a point of departure that refuses to assume the victimhood narrative that often predominates in the literature on Latino farm workers. Deborah Cohen's bracero testimonies uniquely offered a Mexicancentred approach that attended to bracero memory and emotion, and individualized conceptions of dignity and agency; Cohen addressed alternate themes 
that help constitute a social history of the Bracero period, including braceros' working and living environments, same-sex dynamics on farms, questions of masculinity, and other interrelated parameters of sexuality. ${ }^{16}$ In my first summer of field research in Manitoba, I met with the Agricultural Workers Alliance representative in Portage la Prairie, Gustavo Mejicanos, who introduced me to a number of workers employed in the area and pointed out the significant farm sites in the province that were in the practice of hiring Mexican workers; on return visits to Portage and Selkirk and excursions to Westwood in Winnipeg where workers consistently traveled on Friday evening, I was able to collect interviews and develop relationships of trust with individual farmworkers that could not have been achieved had I performed only one round of field work. Conveniently located only twenty minutes' drive from my home, the Good Will store in adjacent shopping area in Westwood, Winnipeg, was a key site to pursue interviews with farmworkers without having to make the longer driving trip to Portage la Prairie.

In British Columbia, I also benefited from connections made with the Agricultural Workers Alliance Surrey Office and was able to perform field visits to sites often frequented by migrants after work, including the town centres in Abbotsford, Pitt Meadows, and Oliver in the South Okanagan, as well as the Rutland area of Kelowna. During my first year of field research in British Columbia I found a temporary job picking cherries outside of Kelowna (a job that lasted not more than a week). While I did not pursue interviews on the cherry estate, which had a small Mexican workforce of about twenty, I was able to get a sense of their relationship with the employer, the

${ }^{16}$ See for e.g., Deborah Cohen, "From Peasant to Worker: Migration, Masculinity, and the Making of Mexican Workers in the US," International Labor and Working-Class History 69 (2006): 81-103. 
dynamic of their working rhythms, and the state of their onsite work accommodations. In the two subsequent years I based myself in Kelowna town centre and at a recreational camp site located north of the Kelowna airport; in this way I was able to access rural spaces more directly, take photographs of worker accommodation, and also make frequent trips into Lake Country and more distant regions employing migrant workers such as Vernon in the North Okanagan. In other cases, I made visits into the town centres in Winfield (in Lake Country) where I was able to make connections with farmworkers after their working day, as well as church workers based in the area. In Abbotsford, I found that commercial zones and the town center were the best location to converse with farmworkers and secure interviews, especially in the evenings once the harvest workday was done; this was also true in other Greater Vancouver regions like Ladner.

In Oliver, La Tienda Mexicana (or, the Mexican shop or store) was another key social site and space where migrants often gathered, allowing me to meet with farmworkers and pursue new connections and oral history interviews. More than this, $L a$ Tienda allowed migrants to recreate their traditional foodways and by extension, cultural lifeworlds in Canada. ${ }^{17}$ As Katarzyna Cwiertka, Megan Elias, and Jeffrey Pilcher have suggested, the discipline of food history "has been curiously slow to take a seat at the academic table."18 Despite this, the deep connections between food and food production

\footnotetext{
${ }^{17}$ On the intersections between food, memory and ethnic identity, see Jon Holtzmann, "Food and Memory" Annual Review of Anthropology 35.1 (2006): 361-78. See also Warren Bellasco and Philip Scranton, eds. Food Nations: Selling Taste in Consumer Societies (London: Routledge, 2002). There is now an expanding body of literature on food history and Mexican cuisine, intersections between taquerías and urban space, and the integration of regional cuisines into the cuisines of Mexico City. Mexican diasporic cuisine and the arrival of Mexican foods into the United States with early migration at the beginning of the twentieth century, is another element explored in this literature. See in particular, the work of Jeffrey Pilcher, Planet Taco: A Global History of Mexican Food (Oxford, New York: Oxford University Press, 2012) and :Que vivan los tamales! Food and the Making of Mexican Identity (Albuquerque: University of New Mexico Press, 1998).

${ }^{18}$ See Katarzyna J. Cwiertka, Megan J. Elias, and Jeffrey Pilcher, "Editorial Introduction: Writing Global Food History," in Global Food History, 1.1 (2015): 5.
} 
to histories of nationalism and nation-making, empire, global trade, consumption, and histories of capitalism are all now increasingly apparent in scholarship dealing with the history of food from a multitude of angles, including the production of food knowledge and the diverse regionalisms associated with cuisine.

My field visit to Covert Farms north of Oliver, after making contact with "Pablo" (whose interview is included later on in this chapter), while he was out shopping in the town centre, was one of the most beneficial, as I was able to join, meet, and interview a number of the workers on their lunch break after their morning hours of work on the vineyard. After making this initial contact, Pablo encouraged me to visit the farm during the workers' lunch hour. My visit to Covert, a fine winery and vineyard estate that also draws visitors from as far as the Yukon territory, gave me an additional window into the food culture of the workers that was mirrored in a different set of field visits that I made to East Selkirk, Manitoba.

Still, due to many workers' precarious positioning and long workweeks, extensive and lengthy interviews were not always realistic in the field, so in light of these practical barriers and working within an uneven, yet often predictable architecture of the workers' schedules, I was able to construct a wider set of oral histories of a shorter nature that nonetheless made efforts to excavate numerous often-veiled worlds, to uncover improved, qualitative understandings of the program from a Mexican point of view. Before presenting the interviews that constitute the centerpiece of the chapter, I first consider early interviews performed by news reporters with farmworkers in Manitoba, to highlight a number of key themes and discourses presented in the 1970s that mirror, as well as depart from the more recent discourses and experiences gathered in my work. 


\subsection{Manitoba-Mexico Connections: Early Interviews with Farm Workers}

Oral accounts of farmworkers were recorded in Manitoba in a series of news articles printed in the late 1980s and early 1990s, and these articles help shed light on family relations, emotion, and the emerging theme of trans-national separation for work and wage earning opportunities in Canada. In the summer of 1988, some forty men from Mexico were hired in Manitoba, and that year Winnipeg Free Press sent reporter Maria Bohuslawsky to Mexico to document how the lives of three Mexican families were transformed as a result of the Canadian farm labour contracts secured by their migrant male breadwinners. One account documented the story of the Rodriguez family of nine children between 6 months and 18 years of age, for whom the father's farm labour contract in Canada was

a matter of survival...In a house on a hilltop in a remote corner of this village 70 $\mathrm{km}$ south of Mexico City, Manitoba is part of the daily vocabulary. It means food on the table and the courage to dream of professional careers for the children. ${ }^{19}$ Critical wage differences between Canada and Mexico were also evident. In 1988, migrant farm workers in Manitoba earned five dollars an hour, compared to a full day's wage of three dollars at home, and in 1991, another article reported a slight increase in Manitoba farmworkers' wages. ${ }^{20}$ Emotional stories shaped journalistic narratives of migrant farmworkers from this time; Jesús Rodriguez had worked in Portage la Prairie eight consecutive summers and his wife Isavel experienced emotional challenges during their time of separation: "Every time he leaves it's like he's leaving for the first

\footnotetext{
${ }^{19}$ Maria Bohuslawsky, "Source of Hope: Harvest Work in Manitoba Fields lets Mexicans Clothe, Feed their Families," Winnipeg Free Press, Saturday, June 11, 1988, 53. Winnipeg Free Press Archive.

${ }^{20}$ Ibid., and Mary Ann Fitzgerald, "Same People take Same Stand on Mexican Deal," Winnipeg Free Press, Thursday, January 31, 1991.
} 
time...That's why I'm so worn out...The children cry when he leaves." ${ }^{21}$ The Canadian program, as depicted in 1988, also saw shifts in housing patterns in Mexico as fostered by seasonal migration to Canada:

Before Canada they lived in a one-room stone hut on a hillside. Now they have a five-room cement house in town...Everything we own is from Canada... What I hope is to be able to send the children to school. They have a better future because of Canada. ${ }^{22}$ (Italics mine.)

Farm work contracts could result in new material acquisitions and gifts taken across borders, a sort of “development aid” derived from Canadian contracts. This pattern continues to shape farmworkers' spending habits today; one "Arturo," described later on, during his time off work bought a pair of heels for his daughter at a thrift store in Westwood, Winnipeg, on a Friday evening out. ${ }^{23}$ Bohuslawsky's account echoed this phenomenon; she described how the "husband-farmworker" would return, "bearing gifts —boxes of clothes, zucchini seeds, pots and pans, a sewing machine, radio, a record player." ${ }^{24}$ Additionally in 1988, corridors of mobility to other seasonal jobs in the U.S. were prevalent among the Manitoba group: one Pedro Bello Castro was employed three years in Manitoba, then followed this contract with a number of years of work in Texas.

Mexican views of Canadian rural landscapes as orderly, in comparison with patterns of disorder at home, also came through in Bohusklawsky's account. According

${ }^{21}$ Bohuslawsky, "Source of Hope," 53. In some cases work contracts disrupted relationships at home while in others, family remained intact yet fathers left chilrden behind for six to eight months at a time.

22 Ibid.

${ }^{23}$ Field findings, Winnipeg, Aug, 2014.

${ }^{24}$ Bohuslawsky, "Source of Hope," 53. 
to Sotero Rodriguez Dominguez, Portage la Prairie was described as a "prosperous place with well-organized farms and trusting people," an indication of the diverse and perhaps disorganized rural settings from which many migrants had come. ${ }^{25}$ Other cultural differences were evident, as Sotero indicated: "Here [in Mexico] if someone sees a bird they get a slingshot...I've told my children, in Canada the birds are not afraid of people. They come very close." ${ }^{26}$ Sotero's wife Rutila forwarded the argument that many people in Mexico "really need[ed] the work in Canada." ${ }^{, 27}$ Superimposed against these narratives from the Seasonal Agricultural Worker Program's early years, more recent discourses have diverged from accounts of the past, especially in their emphasis upon asymmetries of power caused by migration, despite the fact that early accounts still presented a variegated and rarely simple picture of migrant realities.

\subsection{Field Findings I: Manitoba}

\section{Antonio}

"Antonio" was riding his bicycle on a Monday evening in late June, on his way to his lodging at the greenhouse where he worked in East Selkirk, Manitoba along with four other workers from Mexico. ${ }^{28}$ Eager to chat after work, Antonio described his origins: he was originally from Oaxaca and currently resides in Mexico City with his wife and three children. ${ }^{29}$ His opinion on work in Canada was that the work was good, but he could not easily make new friends among Canadians. In Mexico, he worked mainly in construction, and in Canada his greenhouse employer spoke only a small amount of Spanish. His job involved cultivating a variety of vegetable and ornamental plants, as

\footnotetext{
25 Ibid.

${ }_{27}^{26}$ Ibid.
} 183 
well as berries and shrubs for the greenhouse's local store and for retail outlets throughout the province (Fig. 10). Antonio was also able to engage in a return trip to Mexico mid-way through his contract in Canada. He had arrived to work in Canada in February of 2012. After work, he often frequented the Extra Foods marketplace for shopping, in the town centre of Selkirk, which connects to East Selkirk via a bridge commonly used by the migrant workers employed in the area (see Fig. 9). While most Canadian residents in town rarely made use of bicycles for transport, the bicycle was one of his most important means of travel.

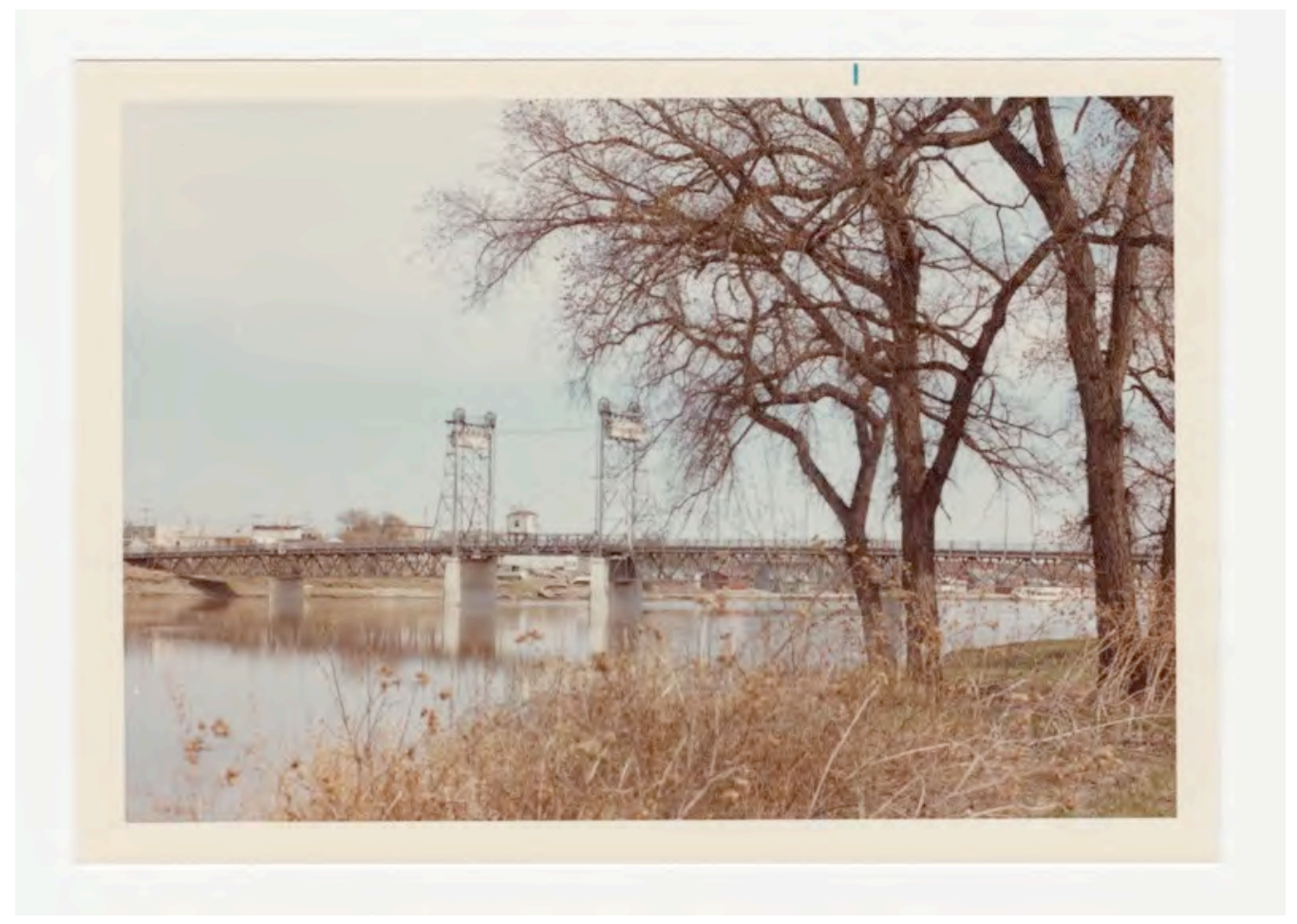

Fig. 9 "View of Selkirk, Manitoba, 1972."

(INTERLAKE COMMUNITIES - Selkirk - Farm near Selkirk, [1972]. Digital Image GR13-001997.JPG, Archives of Manitoba) For Selkirk-area SAWP workers, free time was often spent fishing or riding bicycles to the town centre.

\footnotetext{
${ }^{28}$ Pseudonyms were created for all participants in this study.

${ }^{29}$ Interview with “Antonio," Aug. 2012, Selkirk, Manitoba. A return visit to East Selkirk in 2014 found that most contracts were limited to four months (February through June). Still, a small number of workers stayed on to work in the fall. Most would return home in June, as greenhouse contracts in Manitoba could prove
} 


\section{Mariano}

"Mariano," from Temoac Morelos in the state of Morelos, an indigenous village that produces mainly tomatoes or jitomates, was also employed at the invernadero in East Selkirk. In Morelos, during the daytime he works in a tomato greenhouse (see Fig. 10) where he is the owner/employer and in the afternoon he spends time hunting doves, voy de caseria de palomas torcases. ${ }^{30}$ He was the father of three children, all boys. ${ }^{31}$ Mariano spent five full seasons as a temporary agricultural worker in Canada and, as a result, developed quite a bit of work experience from his time in Canada as a seasonal worker. One of his previous contracts was at cucumber greenhouse, Albuna Farms, in Leamington, Ontario. For Mariano, the greenhouse work in Ontario was preferable to floricultural work in Manitoba since there was "more work" available (i.e. more hours of work and a longer working contract), and additionally, it was easier to access Mexican foods in the town of Leamington, including hierbas or herbs from Mexico for cooking, whereas in Selkirk there was nothing.

In Leamington, Mariano had worked and spoken with a number of other workers who had previously worked in tobacco fields in Southern Ontario, however he had no personal experience working in tobacco in Canada. From what he had learned through conversations with other workers, tobacco-farm jobs involved experiences of high heat in the kilns and also heavy use of machinery. The Leamington contract was described as good, but the greenhouse owners were either Italian or Chinese and less

\footnotetext{
short and potentially less desirable for wage-earning migrants. A small group of workers performed, since the cold month of February, much of the behind-the-scenes work required for sprouting and developing a large selection of greenhouse-grown flowers and vegetables. In 2014, a group of eighteen Mexican migrant workers shared three trailer houses equipped with televisions, while adjacent sheds stored the workers' bicycles.

${ }_{31}^{30}$ Follow Up Interview with "Mariano," Aug. 29, 2014, Winnipeg-Selkirk correspondence.

${ }^{31}$ Interview with "Mariano," June 11 and 12, 2014, East Selkirk, Manitoba.
} 
agreeable than Manitoba employers; Canadian employers were nicer, más contento, in Manitoba than in Ontario. Mariano's Manitoba employers treated him and workmates very well: Mis patrones son muy buenos con nosotros Mexicanos. ${ }^{32}$ In August 2014, in a follow up interview, Mariano was still employed at the greenhouse, and his winter plans involved taking some days of vacation at home.

Comparing food between the two countries, Mariano described Canadian food as sweeter and more artificial, whereas in Mexico, food had more taste: "En Mex tienen mas sabor la comida;" still, he enjoyed some Canadian foods (Algunas comidas Canadiense me gustan). Mariano planned to return to Mexico in early September once his Manitoba season expired. He personally enjoyed the work in Canada and hoped to return the following year. Mariano also took photographs of his workplace using his cell phone, providing a proud description of the flowering goods grown in Manitoba, "Everything is Flowering," (see Fig. 10) and agreed to share them for this project.

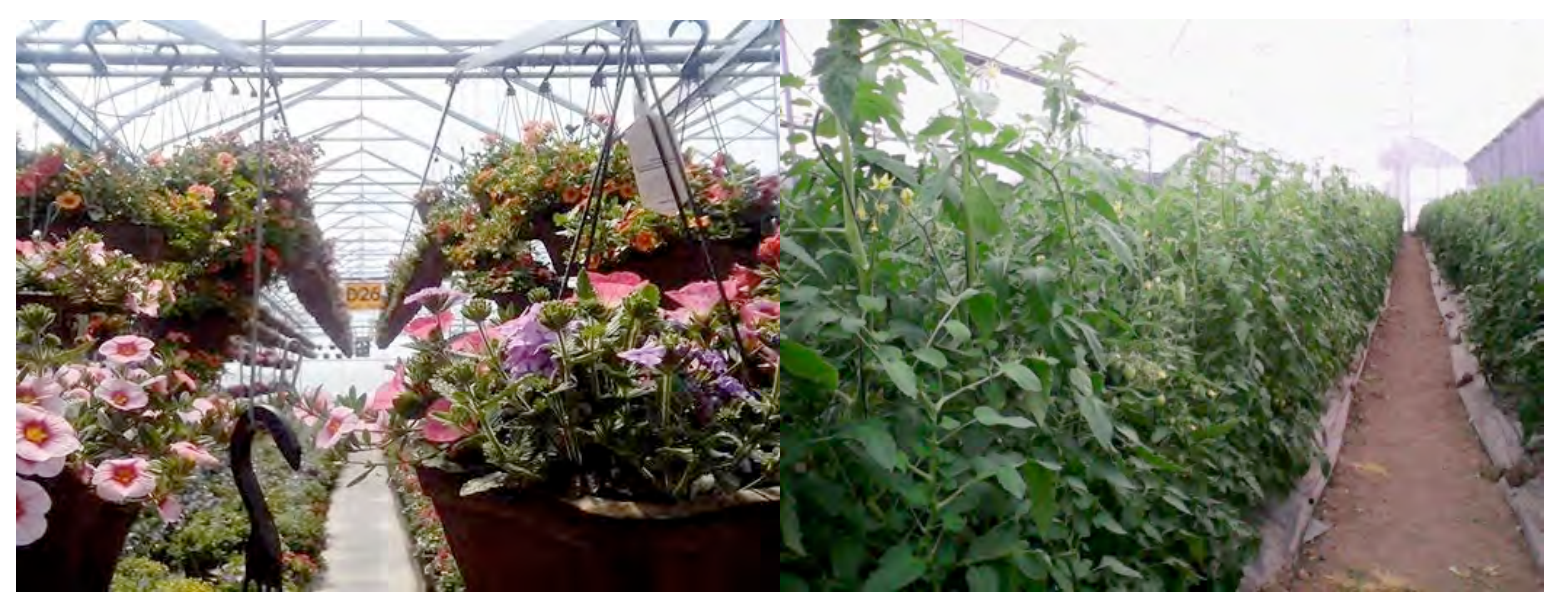

Fig. 10 Greenhouse Landscapes: Canada and Mexico

(Photographs Courtesy of Mariano)

Note the hanging flower baskets geared for Canadian home-owner consumption.

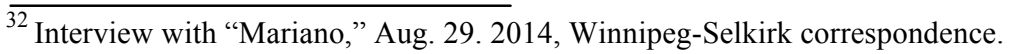


In March 2015, Mariano would return to work in Selkirk for another season, and made comment that, now that se acabo la nieve (the snow was gone), el tiempo es agradable (the weather was pleasant). ${ }^{33}$ At the end of his 2015 season he returned home to Morelos where the weather was good, esta el clima muy bien, and planned to return once again to Canada in late February $2016 .^{34}$

\section{Segundo}

I first encountered "Segundo" when he was cycling across the bridge from the town centre back toward his accommodation site in East Selkirk in the early evening. He was from Tenancingo, Estado de Mexico, and had worked in Canada for a total of nine

consecutive years. ${ }^{35}$ However, 2014 was his first time working in Manitoba. His contract was “muy corto," extremely short, lasting just over four months, from February through June. At home in Mexico, he had a wife and three small children and he was looking forward to returning home in late June. In the past, Segundo had experience working seasonally in Quebec, Ontario, and British Columbia; he had harvested strawberries in Quebec, apples in Osoyoos, and had also worked at a greenhouse in Ontario. On the 21st of June, Segundo's contract at the greenhouse would be completed.

\section{Alejandro}

For "Alejandro," from the central part of the state of Veracruz, fishing in the river was easy, cheap, and convenient, and he, along with some co-workers, interested in fishing were able to buy fishing rods in town. ${ }^{36}$ All of the fish caught locally by the workers were caught in the Red River, which divides the town of Selkirk from the East

\footnotetext{
${ }^{33}$ Interview with "Mariano," East Selkirk, Manitoba, April 12, 2015.

${ }^{34}$ Follow-up with "Mariano," Winnipeg-Morelos Correspondence, December 22, 2015.

${ }^{35}$ Interview with "Segundo," East Selkirk, Manitoba, June 11, 2014.

${ }^{36}$ Interview with “Alejandro,” East Selkirk, Manitoba, June 11, 2014.
} 
Selkirk area. The town is in fact an important fishing area, offering plentiful opportunities for catching catfish and walleye varieties, and an oversized catfish statue still welcomes visitors to the town. The large fish caught by the workers on one day in June would be chopped up and set in a pot of boiling water with onions and used to make fish tacos for dinner, with cilantro and limes. These worker habits allowed the Selkirk group to forge a niche in the local environment, allowing a merging of recreation with consumption in a way that was specifically inscribed by local Canadian conditions.

\section{Bernardo and Jorge}

On the way back from the town centre, "Bernardo" was cycling toward the greenhouse, over the bridge that divides the town from East Selkirk. Compared with his Manitoba experience he in fact much preferred the job that he had worked in previous years at Niagara-on-the-Lake, Ontario. ${ }^{37}$ The physical environment at his Ontario job was much nicer, and more preferable to the conditions in Selkirk. "Jorge," also cycling back from the town centre, had had somewhat of a different employment history compared with the rest of the group: Jorge had worked in Manitoba for a total of thirty years as a temporary jornalero or day labourer. ${ }^{38} \mathrm{He}$ had a wife and five children in Mexico, three of whom were grown up daughters, all married, while the other two were much younger, just boys, aged twelve and five. Jorge was fifty-six, while his wife in Mexico was forty-eight. A seasoned migrant farmworker, Jorge's longer tradition of migration set him apart and imbued him with a sense of experience and familiarity with seasonal migration to Canada.

\footnotetext{
${ }^{37}$ Interview with "Bernardo," June 11, 2014, East Selkirk, Manitoba.

${ }^{38}$ Interview with “Jorge,” June 11, 2014, East Selkirk, Manitoba.
} 


\section{Carlos}

The Selkirk-area greenhouse worker "Carlos," was considerably younger, and hailed from Hueyapan de Ocampo in the Southern part of the state of Veracruz, not far from the very beautiful town of Catemaco. ${ }^{39}$ Carlos noted that the region he was from was highly agricultural and grew a lot of coffee. ${ }^{40}$ In his hometown, he had a small sugar cane field- "tengo terreno de cañas de azúcar" and he also owned a taxi. ${ }^{41}$ Carlos described his home state of Veracruz as bonito — very nice, with many lakes, beaches, and forests. Ideally he desired to work another term in Canada in the following year, and enjoyed travelling to Canada for work- “A mi me gusta Canada para trabajar.” As for Manitoba, Carlos' impressions of the province were not that favourable. He much preferred his time spent working in Quebec, where he had experience having worked six previous seasons. In Quebec, Carlos recalled that there were many more Mexican workers than in Manitoba, and his work involved transporting potatoes from the field to the company storehouse in a big truck: "yo transporte papas del campo a la empresa en un grande camión." During this time, Carlos worked and lived approximately thirty minutes from the city of Montreal, in the town of Joliette.

Carlos enjoyed eating fish and described feeling lucky that Selkirk's river had plenty of fish and offered good opportunities for fishing. In describing his eating routine, he noted that he did not work on Saturdays or Sundays and so planned to have mole in the morning the next day for breakfast, and for dinner that night he was preparing carnitas, a Mexican dish made with pork, in the shared kitchen in the workers' trailer. While Carlos has never before worked in the United States, preferring not to work there,

\footnotetext{
${ }^{39}$ Interview with "Carlos," Winnipeg-Veracruz Correspondence, Dec. 22, 2015.
} 
he still had many family members who lived there including cousins and uncles in North and South Carolina, Southern California, Las Vegas, Texas and elsewhere. Interestingly, Carlos indicated that all the women in his family still resided Mexico while the majority of his family members living abroad in the United States were men, another indication of gendered trends in labour emigration within his own family network.

The temporary loss of integrity of nuclear family units posed challenges for guest workers like Carlos, who says: "In Mexico, I am married, but here, I am not," indicating the stark new social milieu created for him by labour migration. ${ }^{42}$ By time August arrived, Carlos was back home in Veracruz. Carlos did, however, anticipate returning to Canada the following year, expecting to work in Ontario. ${ }^{43}$ In April 2015, Carlos informed me of his return to Canada where he had been placed at a floriculture job in the London, Ontario area in a small town called Wyoming, while he was accommodated in nearby Sarnia, where it was still un poco de frio, a little bid cold. ${ }^{44}$ Carlos returned to his native Veracruz after his term of floricultural work ended in November, and described his home state as very beautiful, having beaches, lakes, and forests. ${ }^{45}$

\section{Jesús, Arturo and Ángel}

"Jesús" from Acapúlco was enjoying his free time after the workday watching

\footnotetext{
${ }^{40}$ Interview with "Carlos," East Selkirk, Manitoba, June 11, 2014.

${ }^{41}$ Interview with "Carlos," Winnipeg-Selkirk correspondence, June 22, 2014.

42 Interview with "Carlos," East Selkirk, Manitoba, June 2014.

${ }^{43}$ Interview with "Carlos," Winnipeg-Selkirk correspondence, August 12, 2014.

${ }^{44}$ Communication with "Carlos," Apr. 23, 2015.

${ }^{45}$ Interview with "Carlos,” Winnipeg-Veracruz Correspondence, Dec. 22-3, 2015.
} 
television; Jesús also spent free time communicating with friends on his cell phone, fishing in the nearby river, and relaxing in between workdays. ${ }^{46}$ While East Selkirk has employed comparatively small numbers of offshore workers, farms located west of Winnipeg, especially those in Portage la Prairie consistently employed greater numbers, leading to a reshaping of the social landscapes of rural towns and surrounding areas, including Elie, Marquette, St. Eustache, and Macdonald and larger centres like Portage. "Arturo," from Guadalajara was employed just west of Winnipeg at Itzke River Farms in Marquette, which in 2012 contracted him to work alongside twenty-seven other men from Mexico. ${ }^{47}$ Arturo was the father of three children - two of them señoritas-and had worked in Canada for four consecutive years. Arturo complained that he did not enjoy working in Canada in the months of October and November when the weather got quite cold.

Marquette is located sixty kilometers from Winnipeg, and each Friday evening, consistently throughout the farm season, the farm workers were driven in a large school bus between Marquette and Westwood where they were given a free evening to perform grocery shopping and have a bite to eat. While personal mobility to travel off the farm after a typical workday remained limited for farmworkers at Marquette, the weekly trip to Winnipeg allowed a relaxation of this rule. Nicole Guidotti-Hernandez details a similar phenomenon of the free day out for bracero workers, who, in their "limited" hours of leisure, experienced "moments in town" and played new roles as local consumers:

\footnotetext{
${ }^{46}$ Interview with Jesús, East Selkirk, Manitoba, June 2014.

${ }^{47}$ Interview with “Arturo," Winnipeg, June 2012. Itzke River is a modern 1,200 acre vegetable farm that grows corn, celery, lettuce, broccoli, cabb age and cauliflower and markets produce throughout Manitoba, Saskatchewan, Quebec, B.C., Alberta, and Ontario. The farm's labour needs often reach 140 workers in peak harvest months when most of the farm workforce is sourced from Mexico.
} 
When Braceros were taken to town from the labor camps, it was often on Sunday mornings when people were in church. They were tasked with doing their grocery shopping, getting haircuts and if lucky, seeing a matinee movie in a segregated theatre. The main reason Sunday mornings were apt for bracero leisure in public was because most good Americans were in church on that day and would not see the workers. They also had to work 6 days a week, so Sunday was the only free day. $^{48}$

Similar systems were put in place for farmworkers in Portage who often took trips to Winnipeg, coordinated on some Sundays for a free afternoon at the mall. ${ }^{49}$

In the 2014 season, about one hundred Mexican farmworkers were employed seasonally at Marquette, alongside a mere five Canadian workers. ${ }^{50}$ Every Friday, Arturo met a friend "Ángel" in Westwood, who was originally from Mexico City but now resides in Winnipeg and was not a farmworker. "51 “Ángel” often took time to meet Arturo at the Good Will store and catch up with him at the end of his workweek. In Mexico, Arturo lives approximately one hour from Mexico City, his house located very close to the volcanic "Mount Popo," or Popocatépetl. Arturo was married with three daughters, two who were "grown up," (20 and 25), while the third was sixteen,

${ }^{48}$ Guidotti-Hernández, "Bracero Lives," 282. Guidotti-Hernández also points to the historical context in which Nadel photographed Bracero workers frequenting the streets of Watsonville, California in 1956, and to the fact that braceros more commonly patronized Mexican owned businesses such as "Zacatecana Café" and "Monterrey House," just as Mexican farmworkers in British Columbia would patronize La Tienda Mexicana and Mexico Sabroso in Abbotsford town centre (See 283).

${ }^{49}$ In Marquette, the all-male farm workforce was housed in a large dorm-style accommodation onsite, and the farm's remote location meant migrants had only limited access to a part of Winnipeg, enjoying few chances for integration with Canadian urban life. I first learned of the Friday evening excursions from Gustavo Mejicanos, who accompanied me on an initial visit to Westwood to meet the group from Itzke. These circumstances would contrast with conditions in Oliver and Pitt Meadows, where Mexican seasonal farm workers often drove company vans with small groups of workers travelling together in a vehicle driven by a designated worker, and with the urban terrain of Kelowna where many farmworkers made frequent use of public transit to travel between their worksite and the town. Still others in Kelowna had limited access to busses and often had to hike forty-five minutes between their farm-site and the town.

${ }^{50}$ Field Findings, Westwood, Winnipeg, Aug. 2014.

${ }^{51}$ Interview with “Arturo,” Aug. 22, 2014. 
and he often bought gifts for daughters at this store. After a number of years working in Canada, Arturo's English language skills had improved tremendously. He had gained many years of farm work experience in Manitoba, and his job was related primarily to tasks involving the harvesting of cauliflower and broccoli.

\section{José, Diego, Rodrigo, and Armando}

Four workers, "José," "Diego," "Rodrigo," and “Armando," were walking together along a west Winnipeg sidewalk on an evening in August 2014, after stepping out of their school bus transport. A typical farm workday for this group involved rising

at $5 \mathrm{AM}$ to begin work. "Armando,' from the northern state of Sinaloa, had in total worked eight years in Canada, including previous contracts in Ontario and Quebec. In Sinaloa, he lived in a small town with his wife and three children, and worked con las vacas (with the cows). ${ }^{53}$ His co-worker, "José," came from a town in Estado de San Luis Potosí and worked in agriculture - mainly con las naranjas or in the orange groves. ${ }^{54}$ José had worked a total of seven years in Canada, and he was also the father of five children. Another worker in this group, "Diego" lived in the state of Morelos, and had worked a total of thirteen years in Canada, including prior work in Ontario. ${ }^{55}$ Diego admitted that he much preferred the work available in Ontario to that in Manitoba, since Ontario's working season was longer. In Mexico he worked mainly as a taxi driver, and was married with three children. The final worker in this group, "Rodrigo," was from Tlaxcala, and he had had five years' experience working in Canada, where the money earned was much better than what it was possible to earn in his home

\footnotetext{
${ }^{52}$ Field Findings, Westwood, Winnipeg, Aug. 2014.

${ }^{53}$ Interview with “Armando," Winnipeg, Aug. 2014.

${ }^{54}$ Interview with "José," Winnipeg, Aug. 2014.

${ }^{55}$ Interview with “Diego,” Winnipeg, Aug. 2014.
} 
state. ${ }^{56}$ At home, Rodrigo worked primarily in construction, and also had a wife and three children.

Portage-area workers no longer have the luxury of visiting the Agricultural Workers' Alliance office after its closure in 2012 (see Fig. 11). While in operation, however, AWA representatives made efforts to visit farm sites and developed a rapport with workers employed in the area. The AWA opened its first centre in Canada 1992.

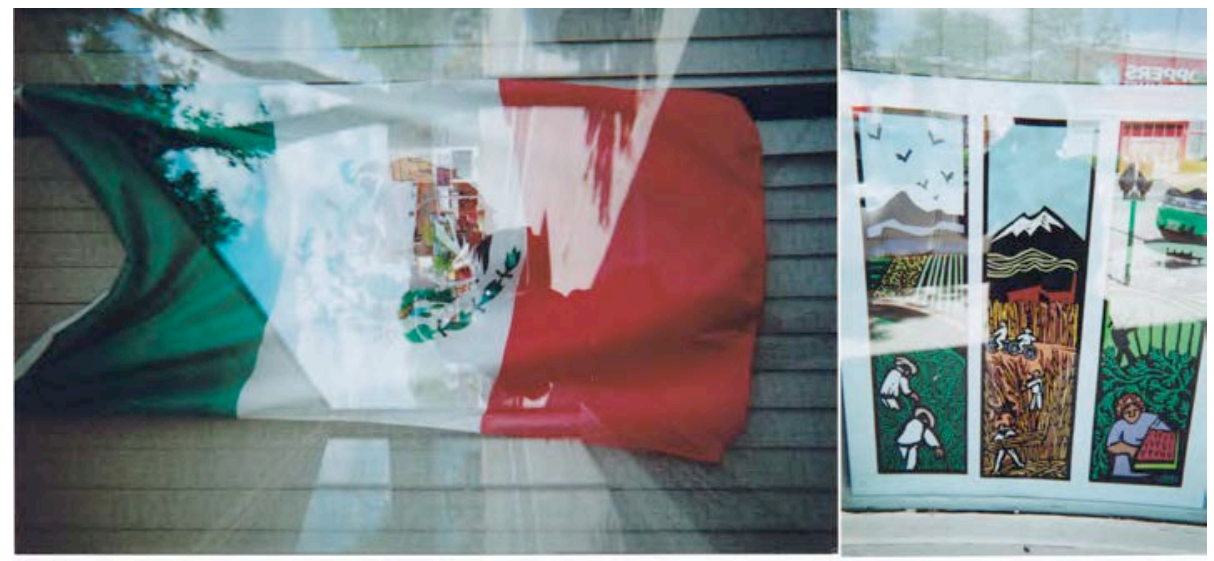

Fig. 11 Window Display, Agricultural Workers Alliance Portage la Prairie (Photo: Naomi Alisa Calnitsky, Portage la Prairie, 2012)

In Portage on a Friday evening it is common to see all-male Mexican farmworkers performing grocery shopping, visiting the post office, and spending time in and around the main street of the town; over time, this migrant worker presence has indeed become embedded into the locality, as it similarly has in small towns like Oliver in British Columbia. Workers return to work six, seven, or eight consecutive years at the same farm, some being fresh recruits, and still others have worked in Manitoba for a more extensive portion of their lives, in some cases up to thirty years or more. Many returning 
workers have familiarized themselves with Canadian surroundings and in some cases have developed fairly good English language skills and horizontal relationships with one another.

By late July of 2013, the Portage-area strawberry harvest had passed and the Portage-area workers at Mayfair farms were moving on to harvest of other vegetables like broccoli and cauliflower. ${ }^{57}$ Manitoba's seasonal farmworkers have also benefitted from church services held during harvest months, one in the small prairie town of St. Eustache and the other in Portage, which was performed in Spanish. ${ }^{58}$ Portage has consistently drawn in high numbers of offshore workers, alongside the farms closer to Winnipeg. ${ }^{59}$ The size of the imported workforce largely depended on the extent of production. In Portage, conflicts over agricultural working hours among guest workers who had joined a union local in 2006 came to the fore three years later when an employer capped their weekly working hours at 70 per week to evade having to pay overtime wages. ${ }^{60}$ This case is discussed in more detail in Chapter Five.

\section{Luis, Gerardo, and Manuel}

One older farmworker, "Luis," was travelling in to Winnipeg for the day from Portage la Prairie from Mayfair farms in August 2012. Sporting a wide-brimmed Mexican sunhat inside of the Polo Park Shopping Centre, Luis admitted he and most of his fellow workmates could not speak English well, but optimistically expressed

\footnotetext{
$\overline{56}$ Interview with "Rodrigo," Winnipeg, Aug. 2014.

${ }^{57}$ Field Findings, Portage La Prairie, Manitoba, July 2013.

${ }^{58}$ Field Findings, Manitoba, Aug. 2012.

${ }^{59}$ At individual worksites, numbers ranged from ten offshore workers (as was the case with one Portagearea nursery), to forty (as at a Portage-area vegetable farm and berry estate), to eighty (as at a larger vegetable farm in the Portage vicinity).

${ }^{60}$ The Canadian Press, "Manitoba Workers Vote to Decertify Two Years after Joining Union," The News (New Glasgow), Aug. 08, 2009.
} 
interest in learning English, suggesting he might benefit greatly from taking an English language class. ${ }^{61}$ During an earlier field visit to Mayfair, an older farmworker from Monterrey, "Gerardo," recounted how as a result of his migration to Manitoba, he had become economically capable of sending his son to a technical school at home. ${ }^{62}$ Gerardo had been returning to work in Manitoba for many years. Another set of workers, a pair of brothers, worked together at Mayfair in 2013; they were fortunate to have secured a work contract together on the same host farm. ${ }^{63}$ One other worker at Mayfair who was on his first contract in Canada had formerly worked outside Mexico in Chicago, likely as an undocumented migrant.

"Manuel" was employed at Connery's vegetable farm in the Portage area. Manuel reported leaving his wife and children in the town of Axtla de Terrazas in the state of San Luis Potosí to come work in Canada, for a total of nine months in Manitoba during the 2013 season. ${ }^{64}$ During a Sunday outing in Winnipeg, Manuel found time for a temporary distraction from his regular farm work routine by strolling the shopping mall to buy some clothes and enjoy Chinese food at the cafeteria. In Mexico, he worked mainly in the orange harvest and had by 2013 worked a total of eight seasons in Canada, seven in Manitoba and one in Quebec. ${ }^{65}$ Manuel had never had any experience working in the United States. There were also variations in his own past as a farmworker in Manitoba: a previous boss in Manitoba had given many hours of work yet his current employer did not demand as much labour. In Quebec as a temporary agricultural worker, he had been employed at a tree nursery.

\footnotetext{
${ }^{61}$ Interview with "Luis,” Winnipeg, Aug. 2012.

${ }^{62}$ Interview with "Gerardo," Portage la Prairie, July 2012.

${ }^{63}$ Field Findings, Portage la Prairie, June 2013.

${ }^{64}$ Interview with "Manuel," Portage La Prairie, Aug. 2013.
} 
In Manitoba, upon arrival to the farm, Manuel's main preoccupation was with the asparagus harvest. The job then transitioned to strawberries, and at the time of interview, Manuel was working the broccoli harvest. Manuel described how he considered not returning to Manitoba in the coming season, since there was not much work that was nice —_"no hay mucho trabajo que está bonito," and he had much preferred the work available to him in a past season in Montreal. This view would shift mid-October when Manuel set out to return home to his family; at that time, Manuel indicated a hope and expectation to return to Manitoba the next season. ${ }^{66}$ As for his flight to Canada, he was initially very much afraid on his first flight but soon lost his fear of flying.

Manuel had been looking forward to returning home since he missed the food, his family and especially his children, but Canada still gave him everything he needed to live better-“para vivir mejor"-while Mexico offered him few good economic opportunities. His three sons were in their late teens and early twenties. In 2014, Manual arrived in Manitoba much later in the year-in May—due to a lengthy winter cold spell in the province, whereas in former years he had typically arrived in February. ${ }^{67}$ Manuel's account indicates a deeply ambivalent relationship that many workers have in migrating to Canada, wherein the jobs that were made available often operated imperfectly with their own ideals.

\footnotetext{
${ }^{65}$ Ibid.

${ }^{66}$ Interview with "Manuel," Winnipeg, October 17, 2013.

${ }^{67}$ Interview with "Manuel," Winnipeg, June 22, 2014.
} 


\subsection{Field Findings II: British Columbia}

\section{Manuel Alejandro}

Despite the newness of the Mexican worker in the British Columbian agricultural landscape, the addition has proven significant, as the onset of the BCSAWP in 2004 allowed non-Canadian migrant workers to quickly saturate a diverse array of agricultural sectors and seasonal labour markets. Rural zones of production near Vancouver are often intimately interlinked with urban consumer markets and demands, and Mexican migrants often traversed the networks connecting farms with the city. In one case, a Mexican SAWP worker was taken along to an East Vancouver farmers' market to perform support work (transporting and unloading of fresh produce, in this case blueberries and strawberries) in August 2012. The Indo-Canadian farm owner, based in Abbotsford, had asked her hired worker to accompany her to unpack fruits for sale at her market kiosk. It was here that "Manuel Alejandro" reported he had some prior experience working in Canada but outside of British Columbia, and had worked an Abbotsford contract for three consecutive years after working initially in Simcoe, Ontario, in a floricultural job. Originally from Puebla, he had left behind a wife and three children to perform farm work with berries in British Columbia. ${ }^{68}$ While he did not deal directly with customers, he spent the entire day at the market, unloading and re-loading the boxes of berries for sale to local passers-by.

\section{Gonzalo, Felipe, Epifanio, Patricio, and Hernando}

The sight of Mexican harvest workers has become common currency in

\footnotetext{
${ }^{68}$ Interview with “Manuel Alejandro,” East Vancouver, August 3, 2013.
} 
Abbotsford's town centre in the Fraser Valley where vast blueberry fields surround the town. This productive landscape is not dissimilar to that of Ladner, whose local economy is also underpinned by agricultural production. The migrant workers located in the Abbotsford area often cycle to town after the workday to frequent shopping trips and eat at local restaurants. I returned to Abbotsford in September of 2014 and encountered "Gonzalo," riding his bicycle through the town centre on his way toward a small local Mexican restaurant, “Mexico Sabroso.” As described in Hinnencamp’s study, bicycles allowed Canadian communities to only "fleetingly" see foreign farmworkers in a broader context of their invisibility. ${ }^{69}$ Gonzalo had travelled to the restaurant to meet three other workers for dinner after his workday. Originally from Tlaxcala, he described not having a very big family. ${ }^{70}$ While Gonzalo had no positive or negative opinions of his job in Canada, the work was simply viewed and understood as a job that he was able to access, and the prospect of traveling to Canada for work was considered appealing.

Four blueberry pickers, of a group of forty Mexicans working at a local farm arrived in Abbotsford for the berry harvest season in July of $2014 .^{71}$ The relatively late schedule for berry harvesting meant these contracts were timed differently than those prevalent in Ontario or the Prairies as blueberry work followed seasonal needs. While out shopping one evening, the group was waiting outside while another, "Felipe," was purchasing beer. For these workers, a workday typically involved waking up at five in the morning to commence work, a morning work schedule similar to that described in Manitoba. "Epifanio," who had come from Tepic, near Puerto Vallarta, worked the remainder of his year in Mexico on a tomato farm. ${ }^{72}$ Epifanio, employed not far from the

\footnotetext{
${ }^{69}$ Hinnenkamp, "Bicycles Travelling in the Rain," 77.

${ }^{70}$ Interview with "Gonzalo," Abbotsford Town Centre, September 2014.
} 
town centre, acknowledged that the Canadian dollar was stronger than the Mexican peso and he could therefore earn más dinero or "more money" in Canada than at his tomatoharvesting job in Mexico. ${ }^{73}$ Epifanio's rural background made him a strong candidate for seasonal migration to Canada. Each month, he sent a portion of his earnings home to his family in Tepic, where he has two small children. In Canada, Epifanio never once rode a bicycle, in contrast to a number of other workers in the Abbotsford area. In addition, the dynamic of the town layout and consumer landscape differed dramatically from that of Portage, which is home to a number of large supermarkets but fewer box stores and shopping malls than are prevalent in Abbotsford. Epifanio conceded that his Canadian employers were not able to communicate with him or with his fellow workers in Spanish at all, constituting one drawback in his Canadian job. Although Epifanio's English language skills were quite good, those of his fellow workers were not very strong. His co-worker, "Patricio," also from Tepic, was similarly employed on a tomato farm in his hometown. ${ }^{74}$ Patricio was also the father of two children, and had previous experience with work outside of Mexico as a dishwasher at a restaurant in San Francisco, a city that had a significant Mexican expatriate presence.

A third blueberry worker, "Hernando," came from Michoacán where he harvested fruits typical to his region: avocados, mangos, limes, lemons, and other fruits. ${ }^{75}$ Hernando had a son in Mexico, who shared his first name. As a temporary farmworker he had performed a total of seven years of greenhouse and nursery work in Surrey and additionally spent a full season working an agricultural contract in St. Remi, Quebec, close to Montreal, on a farm that grew mainly lettuces and other vegetables. Hernando,

${ }^{71}$ Field Findings, Abbotsford, September 2014.

${ }^{72}$ Interview with "Epifanio," Abbotsford, September 2014.

${ }^{73}$ Ibid. 
however, much preferred his current contract and previous seasons working in British Columbia to his recollections of working in Quebec, a contract that he did not particularly enjoy. Originally from the state of Nayarit, Felipe noted that it was quite possible he would return to work in Canada, but he was not entirely sure. ${ }^{76}$ According to Felipe, earnings from blueberry harvesting work in Canada were not great, but they were certainly better than those available to him at home as a farm worker in Nayarit.

The Latinization of farm labour in the Greater Vancouver region benefited from the outreach work of the Surrey-based Agricultural Workers' Alliance centre which often performed visits to farms, organized recreational activities for workers in the Greater Vancouver area, and created welcome events and cultural activities for migrant workers employed in the region. This area, in addition to the Fraser Valley, witnessed an expansion of an offshore farmworker presence after the BCSAWP began; the municipality of Ladner to the south of Vancouver joined a number of other Vancouver-vicinity regions including Pitt Meadows, that have hired on temporary Mexican migrant farm hands. ${ }^{77}$ In the outskirts of Ladner, Mexican migrant workers could be seen cycling down rural roads to attend services at a local Augustinian Church. ${ }^{78}$ In Ladner, I met workers from Cuernavaca, Morelos, and Toluca, who were put to work trimming tall trees on local church grounds. Named after settler brothers William Henry and Thomas Ellis Ladner, the town is situated twelve miles south of Vancouver in proximity to the municipality of Delta, another destination for migrant farm hands. The

\footnotetext{
74 Interview with "Patricio," Abbotsford, September 2014.

75 Interview with "Hernando," Abbotsford, September 2014.

76 Interview with “Felipe,” Abbotsford, September 2014.

${ }^{77}$ AWA members and volunteers played a key role in organizing solidarity events such as a Oaxacan chocolatewrapping event in Greater Vancouver in June of 2012, to which the workers employed in the region were invited.
} 
region is dotted with cultivated blueberries and other farms, including flower farms, organic vegetable farms, nurseries, and greenhouses. In addition to family help, many farms and greenhouses in this region opted to hire SAWP workers as an addition to their rural labour equation.

In Lake Country, north of Kelowna, sometimes referred to as the Apple Capital of Canada, increasing numbers of migrant workers have been accommodated in agriculture, and this area continues to grow an estimated one third of all apples grown in Canada. Home to the towns of Winfield and Okanagan Centre and nearby Oyama, Lake Country mainly produces apple juice. ${ }^{79}$ The local history of fruit production in this region is intimately bound up with itinerant and internal migration routes, with SAWP workers constituting the latest addition to a longer past shaped by seasonal work and mobility. Mexican migration in the North Okanagan was not, however, limited to Lake Country; it also included sites further north including Vernon, and, in July 2012, recently arrived Mexican workers departed the Kelowna airport to work at Penticton in the South Okanagan but also as far north as Kamloops. ${ }^{80}$ New nodes of production have incorporated seasonal workers into working landscapes that were for decades traditionally reliant solely upon Canadian labour.

\footnotetext{
${ }^{78}$ Field findings, Ladner, British Columbia, August 10, 2013.

${ }^{79}$ In Winfield, a Jehovah's Witness Church offered Spanish-language services, which a number of returning workers from Mexico often attended. It was there I spoke with one church worker involved in outreach initiatives with the Spanish-speaking migrant workers in the Lake Country area; originally from Costa Rica, she recounted a story of a Mexican agricultural worker who fell off his ladder at an apple orchard to find that the employer was unwilling to provide care for his injury. The worker benefitted instead from the aid of local Jehovah's Witness volunteers who helped him through his broken leg injury and advocated on his behalf. Interpersonal support networks were here forged through church worker relationships with seasonal workers in local contexts. Field Findings, Winfield, July 2012.

${ }^{80}$ Field Findings, Kelowna, July 2012.
} 
Employers of guest workers had to carve out niches for migrants, offering onsite accommodation and seasonal jobs. The spectrum of worker "captivity" in Canada was often dependent on local geographies or specific modes of transport and accommodation offered by employers; at Valley Orchards, Kelowna, a cherry and apple estate, a fortyfive minute hike between the orchard and nearest corner store made it difficult for the twenty-odd Mexican workers employed to travel to and from the town site. This particular group had no access to bicycles while the elevation of the area made the return hike more challenging, as workers could not easily procure rides to town from Canadians with access to vehicles. This group also often worked night shifts in fruit packing warehouses and had to purchase groceries strategically on days off. Conversely, Mexican farm workers in Lake Country learned to navigate urban transit systems to access the downtown core.

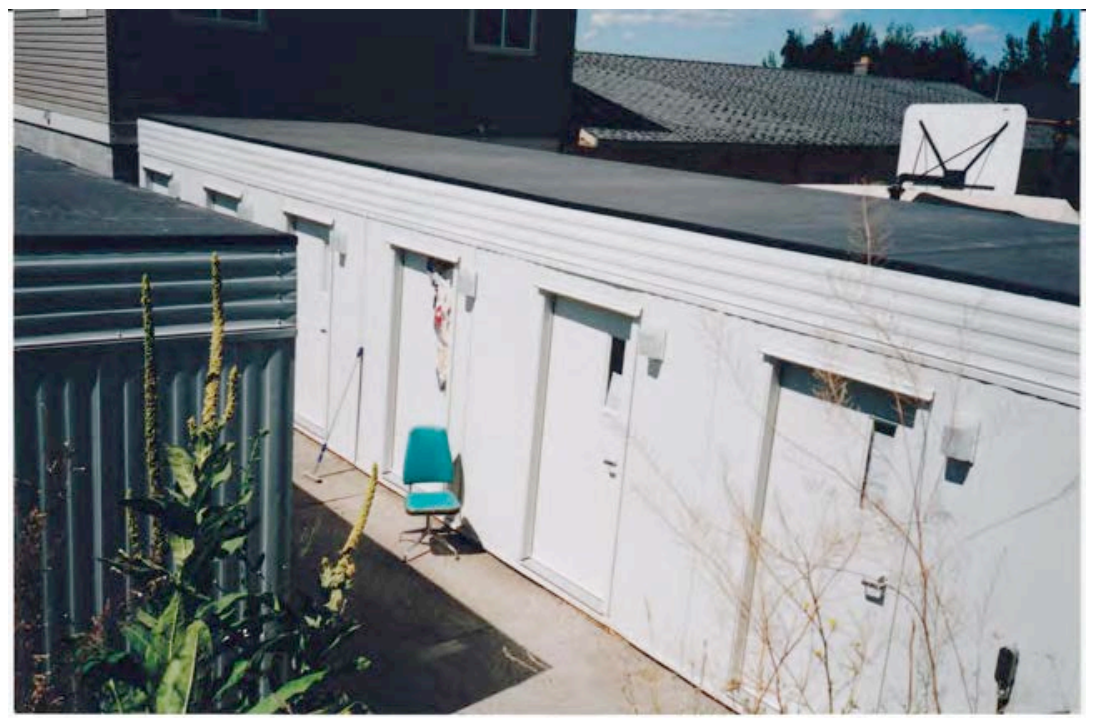

Fig. 12 Mexican Migrant Worker Housing, Kelowna

(Photo: Naomi Alisa Calnitsky, August 2012)

Note the uniformity of worker housing as in the Bracero period (See Fig. 21) 


\section{Chico, Francisco, and Lazaro}

Of three workers at the UBC Okanagan bus interchange in Kelowna in August 2012, all were fathers with children in Mexico. "Chico," from Tlaxcala, a father of four, was previously employed in fresas or strawberries in Ontario, prior to working in British Columbia at a cherry orchard. " 81 "Francisco," from Veracruz had worked previously in Canada on eight other occasions, having worked four years in Quebec and another four in Alberta. ${ }^{82}$ The 2012 season was his ninth time working seasonally in Canada and his first time in British Columbia. "Lazaro," from Puebla, had previously worked on a farm in Quebec with verduras or green vegetables, and had seven little ones. $^{83}$ As of July 2012, Chico, Francisco, and Lazaro had worked in Canada a total of five months, having arrived to British Columbia in early March.

A more substantial Mexican presence is now found in the outskirts of Kelowna on the higher-elevation orchard estates in hillsides surrounding the city. Within the city proper there exist only subtle hints of a Mexican presence. Kelowna's city buses began to advertise Western Union's “next day service to Mexico," offering a Spanish hotline or Línea en español to encourage Mexicans riding the bus system to make use of its international money transfer services; targeting the locally situated seasonal Mexican presence, the ad featured a photograph of a smiling Mexican farm worker. In Rutland, a neighbourhood adjacent to Kelowna, where another workers' alliance centre also recently closed down, Mexican migrants often walk the neighbourhood and frequent the Salvation Army thrift store, where cheap clothing and goods could be easily acquired.

\footnotetext{
${ }^{81}$ Interview with "Chico," August 2012. Migrant farmworkers from Mexico often used the city transit system to move between the orchards and the city, and many were hired in the cherry orchards in and around Winfield, British Columbia. One such orchard, Tangaro, located in upper Lake Country, employed as many as fifty migrants from Mexico in 2012.

${ }^{82}$ Interview with "Francisco," August 2012.

${ }^{83}$ Interview with “Lazaro," August 2012. 


\section{Alfredo}

En route to Lake Country, two workers at the UBC Okanagan bus exchange indicated they had only been in British Columbia two weeks, the first week without any work at all. The work "Alfredo" and his friend had secured would last only until midSeptember, providing about a month and a half of work. ${ }^{84}$ Alfredo's employer was female and he had no complaints about her. Working with cherries and apples was good work and he had travelled to Canada six consecutive years as a harvest worker. He also had two years' of prior experience working in fresas (strawberries) on Prince Edward Island, and performed eight months of work in Pitt Meadows in blueberries. At the time of interview he was harvesting fruit and doing other orchard work among a group of sixty others from Mexico, earning $\$ 9.28$ per hour. The pay for Alfredo was fairly good. He was lugging food supplies he had bought in town onto the bus, including Coca-Cola and other groceries. Describing his family situation in Zacatecas, his home town, Alfredo spoke of a small ranch where he lived, with cows, as well as five children, three of whom were daughters, the oldest being 20 years old, and the second oldest aged 17. He was happy to converse in Spanish with a Canadian since it was a rare experience for him in Kelowna, where few in the local community could speak his language.

\section{Victor}

In the McCullough Road region in the hills outside of Kelowna in August 2012, five orchard workers from Zacatecas, Coahuila, Tlaxcala, and Veracruz, gathered in the evening outside of the East Kelowna Community Hall. ${ }^{85}$ One of the older workers

\footnotetext{
${ }^{84}$ Interview with “Alfredo,” Kelowna, August 2012.

${ }^{85}$ Field Findings, Kelowna, British Columbia, August 2012.
} 
described his family in Mexico: he was the father of four children, while another was the father of two children. He was not planning to return home until October and had already been working in the orchards, pruning fruit trees and harvesting fruits for a full six months. Having flown through Vancouver to Kelowna from Mexico, he had not had any time to visit Vancouver. In Winfield at that time some 150 Mexican women were also employed in the orchards. Further down the road along the hillsides, a Oaxacan, "Victor" described having worked seven years in B.C. and four full seasons in Ontario, making 2012 his twelfth season working in Canada. ${ }^{86}$ Along with numerous other British Columbian workers, Victor had had prior experience working in Eastern Canada. In Mexico his home was a town on the Pacific coast in the state of Oaxaca, where he had a small family with three young children. The town operated an oil refinery for Petroleos Mexicanos or PEMEX, likely the coastal town of Salina Cruz, and his job there was connected with the oil industry.

\section{Pedro, Maria, and Fernando}

In August 2013, in the outskirts of Winfield, two orchard workers "Pedro" and "Maria" described the nature of their working and living conditions in nearby Vernon, where they worked among a group of sixty accommodated in three barrios or dorm houses, which housed twenty workers each. ${ }^{87}$ Pedro was relatively young and hailed from the capital city region of the Federal District, residing one hour to the south of the city, and he had left behind a family to come work for his ninth year in British Columbia. Pedro had worked most commonly with cherries, and confessed that while

\footnotetext{
${ }^{86}$ Interview with "Victor," Kelowna, August 2012.

${ }^{87}$ Interview with "Pedro," Winfield, British Columbia, August 6, 2013.
} 
working and picking fruit, he could eat a lot of fruit off the trees while also picking fruits for market, a perk of his job. Pedro was fond of his Vernon contract and, unlike many other SAWP workers, had had prior experience as a migrant worker in the United States, where he had spent three years in Virginia working on a tobacco estate. Pedro had no complaints with his Vernon farm, but was not happy with the regulations given him and his coworkers such that they were not permitted to drink alcohol on the farm site. ${ }^{88}$ Pedro also observed that government had the power to choose where to send each worker and that as an applicant for a Canadian farm work contract, he was not able to determine his working location. Despite this, Pedro was keen to apply to work again in Canada the following year. That year he worked a Vernon orchard job from February through September. Compared to his memories of Virginia the work in Canada was "much better." According to Pedro, the Mexican women employed in the area were more likely to work in packinghouses since they were better at sorting fruits and more delicate with selecting and handling the fruits that would end up in markets.

"Maria" hailed from Michoacán and worked in the Winfield area in the orchards after having previously worked one year in floriculture in Ontario. ${ }^{89}$ She left behind two daughters in the care of her mother, and her children were not attending school at the time since it was the summer holidays in Mexico. Maria much preferred her previous season in Canada working in a flower greenhouse to her current job in fruit work in Winfield, which involved heavy physical labour and more exacting demands on her body. Since her time in Ontario, Maria had also worked four consecutive seasonal jobs

\footnotetext{
${ }^{88}$ Similarly, in New Zealand, Pacific Island guest workers in agriculture faced prohibitions surrounding the consumption of alcohol.

${ }^{89}$ Interview with "Maria," Winfield, British Columbia, August 6, 2013.
} 
in B.C. including a short-lived 2013 fruit-picking contract that lasted two months only, commencing in July and ending in September. She was not especially enthralled with her orchard job, and noted that she was one of about 120 Mexican women employed in the area. According to Maria, the farm owner had initially paid for her flight to Canada. Despite her distaste for the job, Maria considered returning to work in Canada again the following year. For Maria, English was difficult to learn and converse in and she was more comfortable speaking in her native language, Spanish. I was fortunate to have encountered Maria in the evening, at which time, her workday had expired and was able to join her for a hot chocolate out at the nearby Tim Horton's in Okanagan Centre.

Like Pedro, "Fernando" was also employed on a Vernon orchard and had worked in British Columbia a total of seven years. ${ }^{90}$ Tired at the end of his workday, Fernando noted that he and his fellow workers enjoyed only one day off per week from the orchard on Sundays. Fernando described being housed temporarily with sixty other Mexican workers in shared bunkhouses comprised of twenty workers each; in Canada, both he and Pedro had gained new experience operating orchard machinery. The money in Canada was also described as good. Originally from Nayarit and with a rural background, Fernando and his family had a rancho with a small amount of farmland. ${ }^{91}$ Fernando indicated that there was a strong likelihood he would return to Canada in the coming year. The next section turns to the South Okanagan, where a final set of field interviews was conducted, primarily in the Oliver area, between 2012 and 2014.

\footnotetext{
${ }^{90}$ Interview with "Fernando," Winfield, British Columbia, August 6, 2013.

${ }^{91}$ The lifestyle of the Mexican rancho is distinguishable from that of the ejido or communal farm put in place by the post-Revolutionary government. See Sam Quinones (Interview), Los Angeles Review of Books, May 8, 2015.
} 
In Oliver, the social landscape in the spring, summer, and autumn months was consistently transformed by the SAWP worker presence drawn from Mexico. Workers often frequented the local Mexican food store, worked with headphones on, organized to play after-work soccer matches, and developed horizontal friendships with one another that persisted beyond the workday. A local institution for the migrant community and Mexican outpost, La Tienda Mexicana emerged as a centre of sociability among Oliver's migrant farmworker community. One worker at La Tienda described working primarily with $u v a$ or wine grapes. Workers often carried small backpacks into town, frequented parks and shops in the evenings and on weekends, and found short-term mobility in bicycles, on foot, or through organized travel in company vans and school buses.

Prior to the rise of Oliver's orchard and, much later, modern vineyard industry, gold mining drew settlers to an area originally inhabited by the Nk'mip First Nation. By 1927, agricultural settlers in Oliver had planted varieties of Turkish tobacco, and many local orchardists often turned to the planting of ground crops, interspersed between rows of fruit trees, to provide supplementary income until their trees had fruited. ${ }^{92}$ Known for their melon crop in the 1920s, farmers in the Oliver and Osoyoos diversified their rural output with each passing decade. The Zucca melon was grown in the South Okanagan as early as 1933 and until 1965, its candied peel was an important consumable commodity whose demand diminished after the Second World War (See Fig. 13). ${ }^{93}$

\footnotetext{
92 City of Oliver Archives Heritage Display, Oliver, British Columbia. In nearby Keremeos, between 1900 and 1930 a small Chinatown arose with Chinese often entering the local orchard industry; a tomato cannery was also worked by thirty-five Chinese during World War One.

${ }^{93}$ Osoyoos and District Museum and Archives, "The Zucca Melon," excerpted from Hermann Gummell, 45 Report of the Okanagan Historical Society, 1981, pp. 137-38.
} 


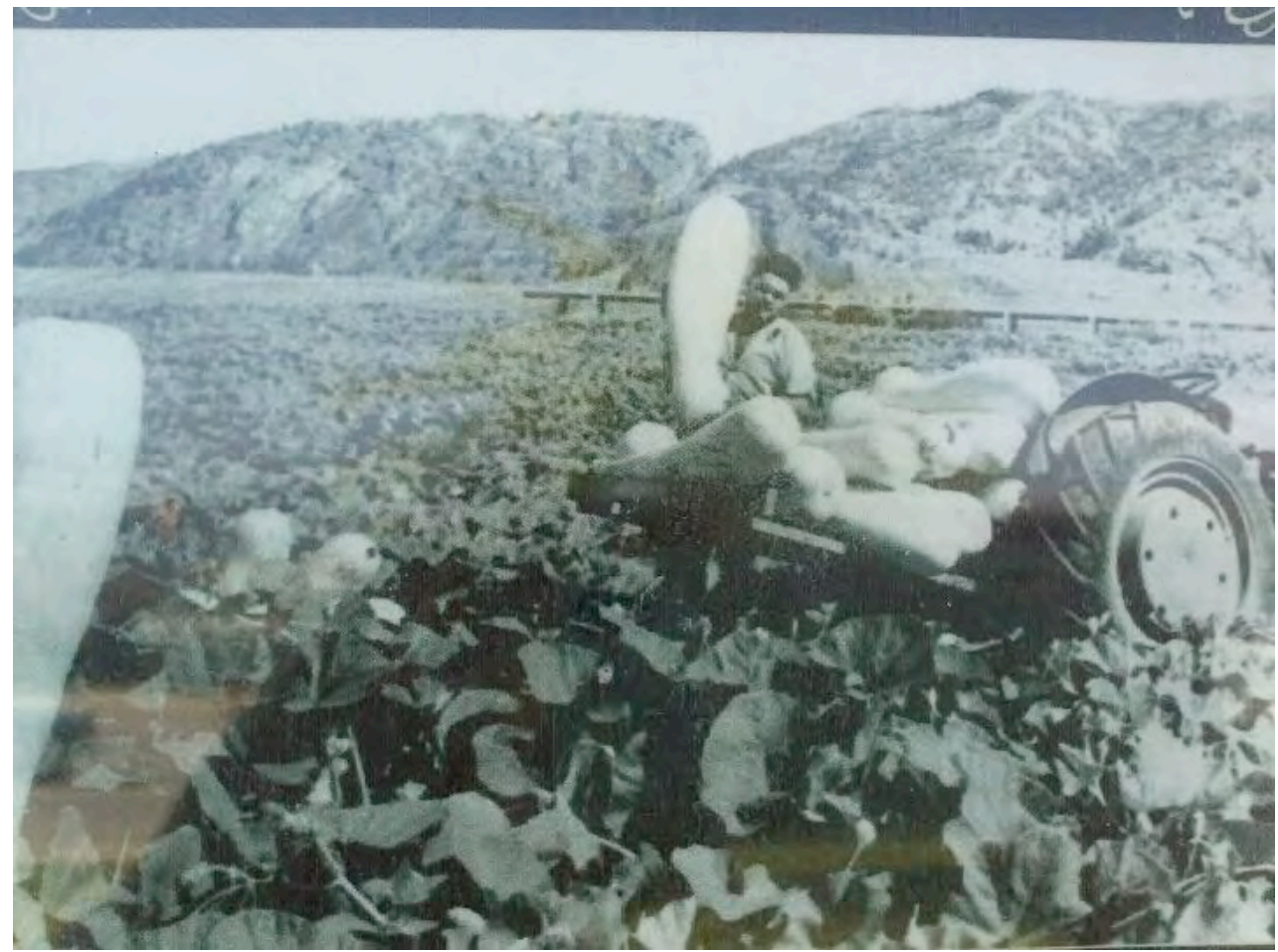

Fig. 13 The Zucca Melon Harvest, Oliver

(Photo: Naomi Calnitsky, Oliver Outdoor Heritage Display, Oliver Archives)

The largest Zuccas weighed a remarkable 127 pounds, and the skin was so tough it often had to be cut with a saw.

\section{Magdalena and Gabriela}

"Magdalena," a fruit picker in Oliver in 2012, left behind four children to work a British Columbia contract. ${ }^{94}$ Originally from San Luis Potosí, Magdalena was shopping after her workday with two male co-workers and another female co-worker "Gabriela," also a mother of two very young girls who migrated to Canada for eight months to work in an Oliver-area fruit orchard. ${ }^{95}$ According to Magdalena, there were about twenty-five women workers based in Oliver that year and their contracts in

94 Interview with "Magdalena," Oliver, August, 2012.

95 Interview with “Gabriela," Oliver, August, 2012. 
Canada would last until December. While Magdalena appeared quite happy to be working in Canada, Gabriela's visceral connection to her children made it more emotionally difficult to depart Mexico for work. ${ }^{96}$

\section{Miguel Ángel}

In late July, one Oliver-area farmworker employed seasonally on a cucumber estate, "Miguel Ángel," was taking a rest on the grass near the town centre. Miguel Ángel described working mainly with pepinos in Oliver and earning seven hundred dollars per week. ${ }^{97}$ He had three daughters or hijas and also three sisters, and had travelled all the way to Canada from Chiapas in southern Mexico. His work in Canada was admittedly difficult and included very long days of work, sometimes twelve or fourteen hours per day. Sometimes, after a day of work in the field, Miguel Ángel was extremely tired; he confessed he "did not enjoy as much freedom in Canada as in Mexico," yet the money he was able to earn was good. Mexico was here depicted as a space defined by more freedom, in contrast to the Canadian working experience. Also, his Canadian employers could not converse well in Spanish. It was his third year working in British Columbia, and in previous seasons he had worked in Oliver. Miguel Ángel did not have any experience working contracts in other provinces, so British Columbia was his first exposure to Canada. He also had not had any experience working in the United States, with Canada constituting his first experience working abroad. Later that evening he was planning to join a group of other workers to play fútbol (soccer).

\footnotetext{
${ }^{96}$ Instances of men experiencing homesickness for children were also evident in Min Sook Lee's National Film Board film, El Contrato. Lee's new film, Migrant Dreams, is a continuance of her earlier film project that highlights the experiences of migrant workers from other parts of the world, including Indonesia, in Leamington.

${ }^{97}$ Interview with “Miguel Ángel,” Oliver, July 2012.
} 


\section{Pablo and César}

A returning migrant farmworker to Oliver, "Pablo," had formerly worked as a plumber in Mexico. ${ }^{98}$ Originally from Toluca, Pablo was six months into his working contract in August 2012 was planning to work in Oliver until November. Pablo had developed a longstanding connection with an organic host farm and vineyard in the hills north of the town centre, where he had been based seasonally for seven consecutive years. Pablo lived and worked alongside eight other men, and his workday began just after $4 \mathrm{AM}$ and ended at 4.30 PM. The shared trailer housing sat behind the farm shop and wine store (See Fig. 14). ${ }^{99}$ The trailer had six rooms: while three workers were given private rooms, the others had to share sleeping quarters, and altogether nine men shared six fridges. The small group of Mexican workers employed on the estate always took their lunch breaks together. Some ate tortilla soup with cold coca-colas from their in-trailer fridge, with Spanish TV broadcast into their communal living room. Of nine vineyard workers employed that year, three were "fresh;" they had never before worked in Canada. Two were from San Luis Potosí, another from Coahuila, and another from Chiapas. "César" had formerly worked on a coffee plantation in the state of Veracruz. ${ }^{100}$ The money he earned in Canada was good and he often transferred funds home to Mexico, while another worker in this group had previous experience working in a tomato greenhouse in Delta, B.C.

While small-scale cultural commerce in imported Mexican food and goods offered a cultural web of support for Oliver area workers, the level of organizational

\footnotetext{
98 Interview with "Pablo," Covert Farms, Oliver, August, 2012.

${ }^{99}$ At a high elevation, the vineyard estate and farm offered fine wine tastings for visitors as well as crafted gourmet foods for sale directly off the farm site.

${ }^{100}$ Interview with “Cesar”, Oliver, August 2012.
} 


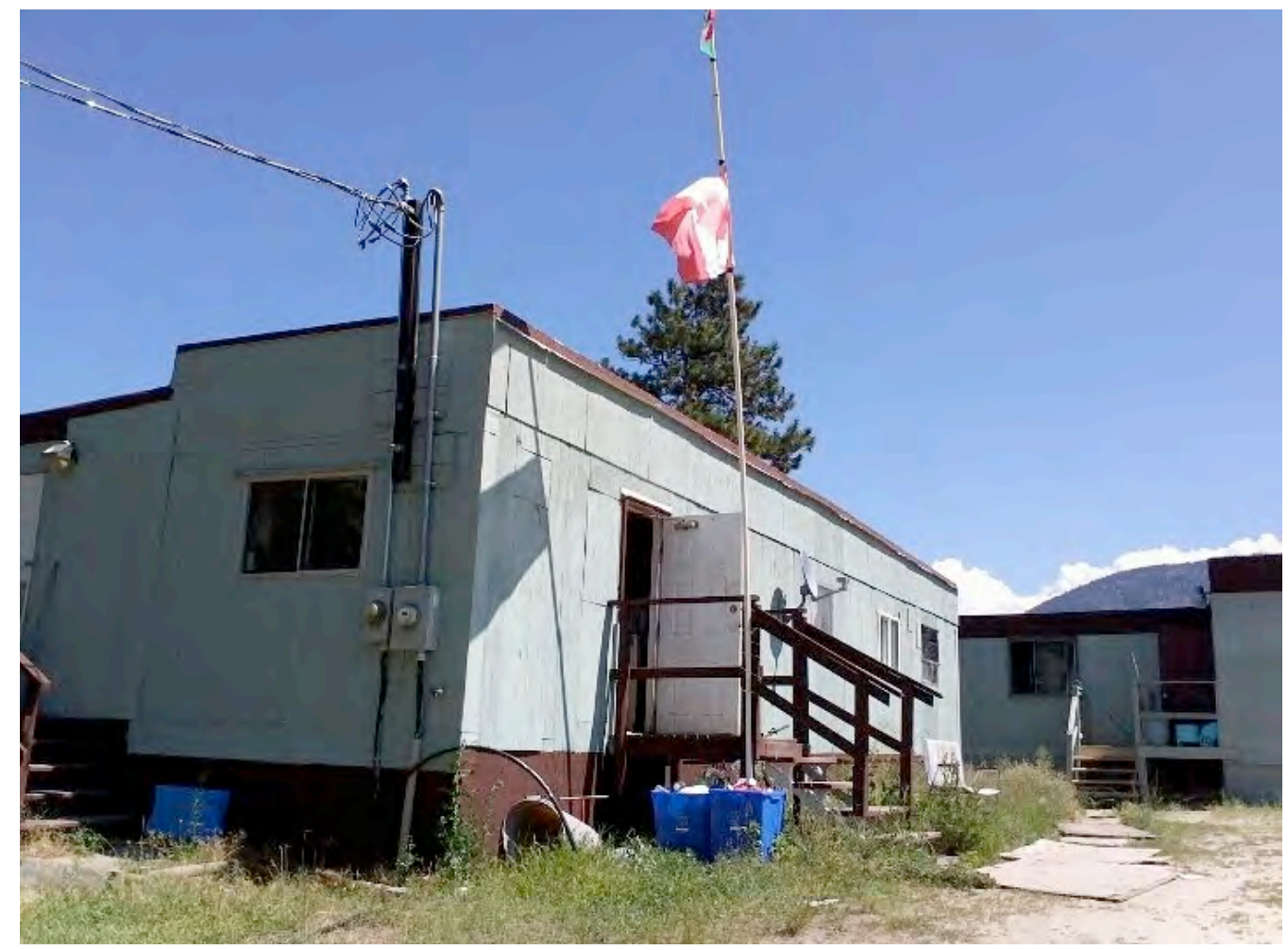

Fig. 14 Mexican Migrant Worker Housing, Oliver

(Photo: Naomi Alisa Calnitsky, 2012

Note the onsite trailer accommodation and small living quarters.

This housing is not directly seen from the common public entrance, where visitors can shop and perform wine tastings.

outreach for migrant farmworkers in the South Okanagan was limited. ${ }^{101}$ For one Oliverbased farmworker, Vancouver was viewed as a stopping point on the journey to Oliver, and class, culture and language made Canadian community life somewhat detached from worker experiences. In some cases locals had little knowledge about the nature of the SAWP: a vineyard owner who hired only Canadians was unaware that Mexican workers were hired in other provinces; he thought the phenomenon was purely a local one.

\footnotetext{
${ }^{101}$ Field Findings, Oliver, August 2012. The Agricultural Workers Alliance expanded its presence to Kelowna, and every so often sent representatives to Oliver to "make rounds" and visit the workers.
} 
Numerous Oliver-based workers from Mexico had had diverse agricultural employment backgrounds. One worker, sporting a white, wide-brimmed hat outside a gas station in the town centre recalled performing tobacco work in Ontario, while his coworker had worked in Atlantic Canada, harvesting berries near Halifax. British Columbia contracts rarely had consistent lengths and in some cases Canadian workers constituted a part of the workforce. One Romanian viticulturalist in Oliver took his two hired Mexican workers to town so they could visit their banks and described being given the option to hire from Mexico for shorter contracts that fit with his seasonal needs, typically in the range of three to six months. In another case, an Oliver-based landowner leased orchard land to a family member, who began the practice of hiring four Mexican farm hands alongside seasonal workers from Quebec. ${ }^{102}$ In this and other cases in the Okanagan Valley and elsewhere in British Columbia, full, eight-month seasons of work were not available, this fact rendering British Columbia contracts somewhat more irregular than those experienced on vegetable farms in Manitoba.

\section{Miguel, Juan, Enrique: Sinaloa, Chiapas, Mexico City}

"Miguel" was hired as an orchard worker in Oliver after having worked some years in construction labour in Sacramento, California, without any prior experience as a seasonal worker in Canada. ${ }^{103}$ In Sinaloa, Miguel had his own rancho with a horse and some farming implements. In Oliver, Miguel made use of a bicycle to reach the town after work. He was looking forward to applying to return as a farmworker in the coming year and was extremely happy to be working in Canada, reporting satisfaction with his

\footnotetext{
${ }^{102}$ Field Findings, Oliver, August 2012.

${ }^{103}$ Interview with "Miguel," Oliver, August 2013.
} 
Canadian contract. "Enrique," from the Federal District, had worked a total of seven years in Oliver, primarily in the fruit orchards, while "Juan" travelled from his native Chiapas to work in Canada and was placed on a local vineyard. ${ }^{104}$ Miguel, Juan, and Enrique were only three of the estimated six hundred Mexican workers employed seasonally in Oliver in 2013. ${ }^{105}$ Of this number, an estimated one hundred were women.

\section{Pepe, Orlando, Feliciano, Vicente}

At la Tienda Mexicana in October of 2014, five workers from diverse regions including Veracruz, Oaxaca, Chiapas, and Tabasco, were congregated outside the Mexican food store on a Friday evening after a day of vineyard work that had begun at five in the morning. The Tienda offered a resting spot in the town for farmworkers in the area. One of worker from Veracruz described his region as producing a lot of cane sugar or cañas de azúcar. "Pepe," from Oaxaca, was a younger, newer migrant working the grape harvest and enjoyed his job in Canada. ${ }^{106}$ The money he earned as a temporary worker in British Columbia was much better than that in Mexico. On Friday evenings, he spent his free hours shopping at the nearby Superstore, Dollar Store, and the small Mexican store to purchase food. As a vineyard worker, he had one full day off per week on Sundays, when he was able to take a rest. His employer was Canadian and could not converse in Spanish.

"Orlando" from Guadalajara, had worked in Canada eight years as a

temporary farmworker with all contracts having taken place in British Columbia. ${ }^{107}$

\footnotetext{
${ }^{104}$ Interviews with "Enrique” and "Juan," Oliver, August 2013.

105 Ibid.

${ }^{106}$ Interview with "Pepe," Oliver, October 10, 2014.

${ }^{107}$ Interview with “Orlando,” Oliver, October 10, 2014.
} 
Sporting a T-shirt from Morelia, capital of Michoacán, Orlando offered a nuanced and opinion-filled account of his current contract and prior experience as a seasonal agricultural worker; the work and pay available to him in previous years at a flower nursery in Abbotsford were much superior to his most recent vineyard contract that had commenced in April and would end in October. Vineyard pay was not as good as in floriculture. In Mexico he had five children, with three full-grown daughters and two younger daughters. Orlando expressed interest in locating work in British Columbia that was potentially different from his vineyard job, indicating a sense of dissatisfaction with his current contract.

A small group of Mexican vineyard workers out after work on their way to a small local restaurant in Oliver's town centre was comprised of men drawn from Queretaro, Aguascalientes, and Tlaxcala. "Feliciano,” from Tlaxcala, had worked seasonally in Oliver in wine grape harvesting. This was his first season in British Columbia and in Canada. ${ }^{108}$ Feliciano was not inexperienced as a migrant farm worker; he had extensive experience working in the United States, including in Miami, North Carolina, South Carolina, and Kentucky. In North Carolina, he was employed in general field labour. According to Feliciano, the work in Canada was okay and the money from vineyard work was good, and his pay was much better than what he could earn at home in Tlaxcala. According to Feliciano there were fewer women workers employed in Oliver area that year, compared with the numbers present in the previous year. "Vicente," from Aguascalientes described how, once he had gained access to Canada's temporary work program, it was not difficult to "find work" in Canada. ${ }^{109}$ The

${ }^{108}$ Interview with "Feliciano," Oliver, October 2014. 
job was coordinated for him, and once recruited, it was easy to work within its parameters, which offered him some measure of stability. The next section briefly considers the emergence of industrial wine production in Canada and its intersection with the Seasonal Agricultural Workers Program.

\subsection{Canadian Viticulture and the New Migrant Presence}

The strong role migrant agricultural workers have played in industries such as tomatoes or tobacco often overshadows, in much of the scholarship on the SAWP, their emergent presence in other sectors such as Canadian viticulture. The Okanagan Valley along with its eastern neighbor, the Similkameen, emerged from the late twentieth century with a well-deserved reputation for its fine wines and wine tourism. Pioneering efforts led to wine production's onset in Canada and its eventual development into a viable economic enterprise. ${ }^{110}$ Wine growing in Canada was in its earliest stages an amateur pursuit, and Canada's contemporary winemakers built their efforts on founding practices of settlers intent on cultivating wine in the New World with the knowledge and techniques of Old World wine makers. ${ }^{111}$ Since the 1990s a shift toward New World dominance in global wine growing took place in regions like Australia, California, and Chile. ${ }^{112}$ These changes were reflected to an extent in Canada as well.

\footnotetext{
${ }^{110}$ Seventeenth century French priests in Quebec engaged in short-lived experiments to ferment existing labrusca grapes to make sacramental wines. See Rod Phillips, Ontario Wine Country (North Vancouver: Whitecap Books, 2006), 13. 
Climatic and soil conditions suitable for wine growing played a key role in setting the stage for wine growers to succeed in the way they have in Canada. Geographically part of the Sonoran desert that extends to Mexico, the South Okanagan's dry heat and lack of rain offered British Columbian pioneers ideal conditions to cultivate wine. The soils and climatic conditions of the Okanagan are diverse and have long depended on shifting soil characteristics within the region: while the Southern Valley is characterized by hotter and sandier soils, vineyards in the north face cooler conditions and benefit from deeper topsoil and clay. The Okanagan today counts among the top wine regions in Canada. As global market forces reshaped economic opportunities for the Canadian wine industry, they also worked against the interests of growers: a 1988 trade agreement between Canada and the United States introduced greater competition from global wine markets, leading to a dramatic reduction in Ontarian and British Columbian vineyard acreage, with some 7,000 acres in Ontario and over two-thirds of vineyard acreage plantings "pulled out" in British Columbia. ${ }^{113}$

The "offshore" presence in the vineyard sector was not limited to the South Okanagan; some eight Mexican workers were hired to work at Cedar Creek Vineyards in Southeast Kelowna for a six-month contract, while others were employed by Mission Hill winery in West Kelowna. In October 2011, the Globe and Mail reported a rise in numbers of Mexican seasonal workers in British Columbia since 2005, with a feature article about the presence of workers on vineyards. Jany Lopez's street stand, which for a number of seasons had "cater[ed] to Mexican palates" was later expanded into her

\footnotetext{
113 Tony Aspler, The Wine Atlas of Canada (Singapore: Angel Edition for Random House Canada, 2008), 23. Since its pioneering days, B.C. has made great strides in wine and today generates some 14 million liters of wine annually. (Canadian Vintners Association / Association Des Vignerons Du Canada. "Canadian Wine and Grape Industry Contributes \$6.8 Billion.” http://www.canadianvintners.com/?p=294, Accessed Nov. 18,2013)
} 
store, La Tienda Mexicana. ${ }^{114}$ As described in the article, Blue Mountain Vineyard and Cellars in Okanagan Falls took on Mexican hired hands, the vineyard generating 12,000 cases of wine annually, including sparkling wines. ${ }^{115}$ The Mexican group was provided housing in a "new, purpose-built accommodation with a fully equipped kitchen and a washer and dryer." ${ }^{116}$ At another vineyard, Hidden Terrace, Mexican workers offered a measure of stability for the harvest season:

Steve McDonald, the manager at Hidden Terrace vineyards, advertised locally for 18 vineyard workers. Nine people applied. He hired all of them but only two are still working at the vineyard. The Mexicans, meanwhile, stay and have only to walk out the front door to be at work. ${ }^{117}$

This message of "convenience" eclipses the long travel and extensive management necessary for an international transfer of labour, and also mirrors the discourses that defined employer conceptions of what constituted a labour shortage, as detailed in earlier chapters. The consistency of service offered by migrants proved durable, as many vineyards in the valley have increasingly chosen tap into the opportunities available in hiring "offshore" through the SAWP.

\footnotetext{
${ }^{114}$ Wendy Stueck, "Mexican Labourers Keep B.C. Wine Flowing," Globe and Mail, October 14, 2011.

${ }^{115}$ In 1991, Blue Mountain crafted its own label, and the winery produces varietal wines including Pinot Blanc, Pinot Gris, Pinot Noir, Sauvignon Blanc, and Chardonnay grapes. "Blue Mountain Vineyard \& Cellars" in John Schreiner, The Wineries of British Columbia (Rev. ed. (North Vancouver: Whitecap Books, 2009, 46. ${ }^{116}$ Stueck, "Mexican Labourers."

${ }^{117}$ Ibid.
} 


\subsection{Histories from "Below": Some Reflections}

The human archive of shared and individual experiences presented here is shaped by themes of mobility, resilience, and interdependence, and taken together, these worker accounts offer what I can discern as only small glimpses into the vast world of migrant labour that Canadian agriculture has increasingly become interlinked with. Tony Ballantyne has put forward the idea of "entanglement" as a central means through which to understand colonial histories, and I suggest the notion of entangled history is particularly useful when evaluating migrant pasts, especially those enmeshed within Canadian history but without full integration into the life of the nation. ${ }^{118}$ Economic opportunity and satisfaction with work available often contrasted with structural limitations facing individuals whose ideals in their workplaces often clashed with concrete realities; Pedro's dissatisfaction with the terms of his "freedoms" in Canada give a window into the ways in which workers perceived their Canadian contracts, while Luis' expression of interest in learning English pointed to certain cultural deficiencies that made integration into Canadian life more difficult while on contract. Maria, moreover, despite not feeling fully comfortable or satisfied with the orchard job available in British Columbia and preferring her memories of floriculture work in Ontario nevertheless expressed interest in continuing on in the program while Vicente was content with the employment stability offered him by the SAWP structure.

In Mexico, alternate networks of employment often supplemented seasonal contracts in Canada; off-season jobs included taxi driving, farm and greenhouse jobs in sending regions, including in oranges, tomatoes, coffee, and sugarcane (for a list of

\footnotetext{
${ }^{118}$ See Ballantyne, Entanglements of Empire.
} 
occupation range among migrants, see Appendix 6). Alternate occupations shaped migrant depictions of their own lives outside of Canada and in many instances, harvest work and other jobs in the United States constituted a critical part of migrants' lived histories and identities.

As Kristina Llewellyn, Alexander Freund, and Nolan Reilly suggest, oral histories can help fill the silences of the archive. ${ }^{119}$ Many of the men interviewed here evidently had large families to support at home. In addition, many of my interviewees reported affection for work in Canada, as well as instances of distaste for certain jobs or conditions, along with past experiences of satisfaction or memories of dissatisfaction with previous work contracts. In certain cases these accounts reveal inconsistencies in a program that promotes mobility without citizenship, and these nuances, while subtle, continue to shape migrant lives in ways rarely discussed actively by policymakers. The presence of these voices is, in addition, an indication of the absence of those that have continued to go unrecorded, suggesting a scope of stories and lived lives on the fringes that continues to evade historiographical inclusion.

Farm workers' itinerant nature and lower levels of education among most migrants rendered their lives illustrative of the silences that often accompany history and this often irreconcilable fact presented this study with unique challenges. The stories collected here speak to lives lived within and outside the boundaries of the nation, between two worlds, in radical rural spaces often removed from Canadian society at large. At the same these stories are intrinsically embedded in Canadian economic history and metabolic history, as well as Canada's contemporary social history of migration.

\footnotetext{
${ }^{119}$ Kristina Llewellyn, Alexander Freund, and Nolan Reilly, The Canadian Oral History Reader (Montreal Kingston: McGill-Queens University Press, 2015), 9.
} 
As Judith Adler Hellman's study, The World of Mexican Migrants: Between a Rock and Hard Place (2008) described, one undocumented migrant Luis'strategy of "keeping [his] head down" left him for the most part free to live and work in the migrant-rich climate of New York City, where a "safety in numbers" would come to define his very existence. ${ }^{120}$ As migrants' lives often continue to go unnoticed, a multilayered and complex human world subsists in the national margins. Insofar as geography has inflected migrant experiences, so too has technology, and migrants' capacities to evolve in step with new developments often played a key role in their ability to survive shifting economic contexts at home and abroad.

Evidence of cultural resiliency, as well as flexibility, were found in my research, as migrants made use of varying forms of transport, including the bicycle, which allowed them to access new "freedoms" in Canadian landscapes outside the boundaries of their daily work contracts. Jon Holtzman asks, "how...does real or perceived resilience in foodways speak to understandings of the present and imaginings of the future through reference to a mythic or historicized conception of past eating?"121 In this respect, the workers discussed in this chapter reveal resiliencies not only in foodways but other spheres of life: in their use of modern technologies to maintain concrete connections, both social and economic, with home, in their capacity to navigate new urban and rural landscapes, and in their capacity to render their own social worlds flexible to better their own experiences in the wake of transnational dislocation. When detached from migrant justice narratives, oral histories collected here equally present angles of satisfaction and dissatisfaction with work in Canada.

\footnotetext{
${ }^{120}$ Judith Adler Hellman, The World of Mexican Migrants, Prologue.

${ }^{121}$ Holtzmann, "Food and Memory," 361.
} 


\section{Migration and the Mexican Body: Cultural Crossings}

"It's that transformative power of looking at agriculture through a cultural lens, as opposed to only looking at agriculture through an economic lens...It's time we put culture back into agriculture."-David Mas Matsumoto ${ }^{1}$

"Christianity, with is emotion, its blood sacrifice and ritual, becomes a natural and novel extension of the native religion. The qualities of charity, love, and turn-the-other-cheek, however, are rejected...that's what Mexico is all about: you have to kill a man in order to believe in him."-Carlos Fuentes, Burnt Water ${ }^{2}$

This chapter considers the malleability of migrant identities as shaped by seasonal migration to Canada for farm labour in a context of Mexican migration and diaspora culture more broadly. It considers how the people behind the headlines have been portrayed in Canadian print culture, and how their laboring culture, embedded in Canadian production patterns and regimes, has intersected with Canadian legal frameworks and structures that should, in theory, universally offer protections, labour rights standards, and regimes of equality for all working actors under the state's domain. In addressing the cultural questions that have intersected with foreign seasonal farmworker pasts in Canada, this chapter asks, how were identities shifted or remade, or implicated in new regimes of economic globalization and mobility? Why do migrants take Canadian goods across borders? What social contexts allow for a reshaping of

\footnotetext{
1 David Mas Matsumoto, "Mas Matsumoto Keynote," 10th Annual OSU Oregon State University Small Farms Program, https://vimeo.com/73247928 Accessed December 12, 2015.

${ }^{2}$ Carlos Fuentes; Margaret Sayers Peden (trans. and selected), "Chac-Mool,” Burnt Water (Short Stories) (Farrar, Straus and Giroux, 1980).
} 
seasonal workers' sense of their own "Canadianness"? To what extent were migrant workers framed as foreigners in Canadian print media? To what extent did migrant justice groups instead frame this "temporary" working group with narratives of inclusivity and rights-based demands? How did Mexican "culture," including foodways, language and behavioral patterns, "fare" in Canadian working climates and in other parallel or divergent contexts of migration to the United States?

In interwar United States, Mexican migrants penned new corridos (ballads), boasting about the Anglo-American women they had encountered through intercultural sexual unions, or new American pants they sported as a mark of a transformed identity, differentiating themselves from the "nakedness" of Mexican citizens or norteños of the north. ${ }^{3}$ How have such cultural dynamics operated in Canada, to what extent has modern Canadian culture offered opportunities for identity evolution, and which specific barriers to cultural change have played in to migrants' worlds? This chapter will explore Canadian and other contexts to reevaluate the contemporary migration patterns of seasonal farmworkers within a broader temporal and geographical view that sees cultural questions as in many ways concrete extensions or continuities of the textures of the past that include evolution, hybridity, and exchange. As John Van Maanen observes, ethnographies are "portraits of diversity" in an "increasingly homogeneous world.", Did regional variations in work and landscape chalk up to a diversity of productive experiences in Canada, or did homogeneity and assimilative tendencies reduce the chances for "culture" to flourish and reproduce itself abroad? How were new spaces of

\footnotetext{
${ }^{3}$ Monique Flores Ulysses, “'Despedida de un norteño': American Empire and the Corridos of Mexican Migration, 1917-1932," Graduate History Symposium, University of Toronto, May 7-8, 2015.

${ }^{4}$ John Van Maanen, Tales of the Field: On Writing Ethnography (2nd ed.) (London and Chicago: University of Chicago Press, 1988; 2011), xvii-xviii.
} 
intimacy or friendship constructed in the wake of trans-national migration?

In the previous chapter, migration's intrinsic linkage to hope for change was reflected in field findings, where chances for sustained employment in Canada were superimposed against economic and social ideals and aspirations. As Forrest Colburn contends, Latin American migration has often been defined by "individual 'exit strategies'... a common solution to grave problems [which] serve as a political and economic 'safety valve' for regimes that might otherwise be overwhelmed by demands for radical change," and along similar lines, Rodolfo Acuña's work has contextualized Mexican migration in terms of "corridors." Migration's intersection with shifting trends in the material wellbeing of migrants is viewed alongside specifically cultural factors that continue to shape migrants' conceptions about breadwinning as constitutive of masculine ideals. In studying the interstices of modernism and tradition, or what might be defined as culture, Ian Mackay has pointed to the ambiguous and, at times, constructed or actively reconstituted nature of culture. ${ }^{6}$ Along these lines, the chapter effectively extends the scope of the dissertation to address such interstices by giving them focused and serious attention.

In addressing rights discourses as they have interacted with offshore farm labour migration in Canada, the chapter considers the evolving relationship between temporary workers and the Canadian state and Canada's legal framework of rights protections, or lack thereof, with respect to its shifting foreign seasonal workforce. Finally, the chapter explores how Canadian and Mexican "modernities" have interacted with the conditions attached to modern migration schemes, which moderate migrants'

${ }^{5}$ Forrest Colburn, Latin America at the End of Politics (Princeton: Princeton University Press, 2002), 125 and Acuña, Corridors of Migration.

${ }^{6}$ See Ian Mackay, The Quest of the Folk: Antimodernism and Cultural Selection in Twentieth Century Nova Scotia (Montreal and Kingston: McGill-Queens University Press, 1994). 
lives while shaping and effecting webs of mobility, interconnectivity, and control.

As the Seasonal Agricultural Worker Program snowballed and grew, so too did the web of support and activism among Canadians who performed outreach, advocacy, and support work to address guest workers' lives and struggles. As a result, the interpersonal sphere was often bound up with economic, political, and cultural questions. Migration's connection with human rights concerns has gained traction and interest from a wide array of actors including international organizations, most often in overt cases of injustices linked to labour problems. ${ }^{7}$ While Canada enabled a certain number of protections for temporary workers' basic rights - the right to be paid for one's work, to access to safe work, and to retain documents_limited migrants' rights have raised questions over the extent to which the Canadian state extended sufficient protections over guest workers employed under its domain. ${ }^{8}$ Seasonal workers' confluence and collision with the law in Canada, and their standing in the media, especially in terms of inclusion in or exclusion from contemporary definitions of the nation, are revisited in this chapter. In addressing culture, the chapter moves toward an exploration of masculinities, gender, and cultural resilience, as well as the construction of a "third space" that allows trans-national cultures to retain their integrity abroad. The first three sections take Mexican trans-national and diasporic culture as their subject, while the last three sections deal with I term "structural culture," or Canadian print, legal, and labour rights cultures that have impacted the migrant farmworker experience.

\footnotetext{
${ }^{7}$ Raúl Delgado Wise, "The Migration and Labor Question Today: Imperialism, Unequal Development, and Forced Migration,” Monthly Review Vol. 64 No. 9 (February 2013): 32. On human rights in international history see for example Jenny S. Martinez, The Slave Trade and the Origins of International Human Rights Law (New York: Oxford University Press, 2014).

${ }^{8}$ See Government of Canada; Citizenship and Immigration Canada. "Understand your Rights-Temporary Foreign Workers.” http://www.cic.gc.ca/english/work/tfw-rights.asp, Accessed July 1, 2014.
} 


\subsection{Mexican Identity and Cultural Resiliency in the Modern World}

Historical and multi-disciplinary scholarship concerned with Mexican culture has revolved primarily around the meaning and symbols of the nation; around language and Spanish colonial culture and architecture; around histories of gender and sexuality; foodways and culinary cultures; revolutionary ideas and ideals, political cultures, and poverty; indigeneity, folk and artisanal cultures, and pre-colonial civilizations. It has also explored urban geographies, rural community formations, and the interplay between the cities and the countryside. Inga Clendinnen's work has done much to decode pre-colonial culture in the Central Valley of Mexico and to explore the early period of religious contact in the Yucatan. ${ }^{9}$ Alan Knight, in an essay on Mexican national identity and how it might be defined, distinguishes between those symbolic characteristics of Mexican national identity (such as tequila) and the more qualitative characteristics pertaining to religion or behavior (for example, "Mexicans are prone to violence"). ${ }^{10}$

Migrant identities, while also personal, were often inflected by broader indicators, including language, religion, nationality, regional affiliation, and past occupations. While migrant identities remained culturally static or constant in some ways, in other ways they evolved as a result of increased exposure to Canada and time spent working abroad. Still, cultural identities often proved resilient among farmworkers in Canada. In Canada, new markets seeking to cater to the "critical

\footnotetext{
${ }^{9}$ See Inga Clendinnen, Aztecs: An Interpretation (Cambridge: Cambridge University Press, 1991) and Ambivalent Conquests: Maya and Spaniard in Yucatan Peninsula, 1517-1570 (Cambridge: Cambridge University Press, 2003).

${ }^{10}$ See Alan Knight, "Mexican National Identity," in Mexican Soundings: Essays in Honour of David A. Brading, edited by Susan Deans-Smith and Eric Van Young (London: Institute for the Study of the Americas, 2007), 192-214. Others, like Linda Newson and John King, have considered Mexico City through the lens of its culture, exploring the city through its pre-Columbian, colonial, and modern stages. See Linda Newson and John King, eds. Mexico City Through History and Culture (New York and Oxford: British Academy and Oxford University Press, 2009).
} 
mass" of migrant farmworkers emerged in some cases. ${ }^{11}$ In small towns like Oliver, farmworker migrations were accompanied by shifts in consumer landscapes; consumable goods like imported dried beans, chiles, hand-held lime juicers, sauces, condiments entered the consumer landscape, including Oaxacan string cheese stocked at IndoCanadian owned groceries to serve seasonal workers' tastes.

For Mexican communities in the United States, urban spaces have provided niche environments for the persistence of cultural enclaves abroad, and more densely Latino neighborhoods often became marked by muralism and small businesses that were directly reflective of the culture of Mexico, from Mexican taquerias in New York City to bakeries crowned by the Virgin of Guadalupe in San Francisco’s Mission District. The Catholic faith continues to shape identity and experience within and outside of Mexico. Roberto González Echevarría points to Catholicism's embeddedness in Mexico and Peru since in these colonial centres, Spaniards had to compete with and pacify already established and well-organized civilizations. ${ }^{12}$ The imposition of Catholicism in Mexico had a lasting effect, but it first to be "cast," as Kathryn Burns suggests, into indigenous linguistic understandings of its core messages. ${ }^{13}$ As Carlos Fuentes intuited, Catholicism's indigenization in Mexico was cemented primarily by its defining characteristics of emotion, blood sacrifice and ritual, traits that proved broadly appealing to a Mexican sensibility.

\footnotetext{
${ }^{11}$ Pietropaolo, Harvest Pilgrims, 23.

${ }^{12}$ Roberto González Echevarría, Cuban Fiestas (New Haven and London: Yale University Press, 2010), 32. In the more peripheral colonies of the Caribbean, the religious identity of the Taínos was initially less concrete and so a Catholic imprint demanded less cultural change; another reason for this trend, as suggested by Alejandro de la Fuente, had to do with Cuba's positioning less as a colony for Spanish settlement and more as a fortification and transatlantic node of trade and Alejandro de la Fuente, Havana and the Atlantic in the Sixteenth Century (Chapel Hill, University of North Carolina Press, 2011).

${ }^{13}$ See Kathryn Burns, "Introduction," Into the Archive: Writing and Power in Colonial Peru (Durham and London: Duke University Press).
} 
As Timothy Anna has suggested in Forging Mexico, an emergent regionalism became a driving force in post-colonial Mexican nationhood, one that continued to maintain tensions with the centre, as Anna suggests: "The tensions between the forces of centralism and regionalism and between control of the few and a voice for the many are the dominant themes of Mexican history."14 Local identities would define and shape how migrants viewed their positioning in the world, and often intersected with diverse indigenous backgrounds. Indigeneity in Mexico, as much as it became bound up with identity politics, has often had attendant economic and social implications in different regional contexts. Indigenous Oaxacans including Mixtec and Zapotec communities entered a new economic climate after NAFTA as internal migrants in support of exportoriented agribusiness in Mexico's northwest. As trans-national agricultural migrants, indigenous Oaxacans also performed agricultural work in the United States, including in the Pacific Northwest. ${ }^{15}$ In twentieth century Mexico, indigeneity often came to symbolize poverty, social exclusion, and racialized oppression.

Portrayals of indigenous life in Mexican visual art, as in Diego Rivera's mural depiction of "The Indigenous World," reinforced conceptions of indigenous Mexico as a world tied to the daily toil of agricultural production. Indigenous migrants have become involved in collective action in the United States, participating in the Northwest Treeplanters and Farmworkers United of Oregon, in the Asociación Tepayac in New York and the Coalition of Immokalee Workers (CIW) in Florida. A revival of interest in

\footnotetext{
${ }^{14}$ Timothy Anna, Forging Mexico, 1821-1835 (Lincoln: University of Nebraska Press, 1998), xii.

${ }^{15}$ See, for example, Erlinda Gonzales-Berry and Marcela Mendoza, Mexicanos in Oregon: Their Stories, Their Lives (Corvallis: Oregon State University Press, 2010). For a more focused study of the role of race and "racial geography" in a comparative colonial United States/colonial Mexico approach see María Josefina SaldañaPortillo, Indian Given: Racial Geographies Across Mexico and the United States (Durham and London: Duke University Press, 2016).
} 
pre-colonial indigenous poetry, language, culture, and society, promoted by James Lockhart, has seen a text-based resurgence in the study of Nahuátl and the early colonial and pre-colonial eras through Náhuatl sources. ${ }^{16}$ While popular conceptions of the precontact period often imbued indigeneity with nostalgia, indigenous modernity often faced moral degradation and a reduced status. ${ }^{17}$ Indigenous identities in contemporary Mexico often conflicted with state authorities, while the idealized mestizo of mixed Spanish and Indian descent became the ultimate expression of La Raza Cósmica or “Cosmic Race,” a term coined originally by José Vasconcelos in 1925 to indicate a universalist vision of racial and national coherence.

In the world of migrant farm labour, indigenous workers from rural backgrounds often participated in disproportionate numbers. Indigenous participation in farm labour migration would encompass the Bracero period, and in addition to Mixtec and Zapotec from Oaxaca, Nahuas from Central Mexico and indigenous people from Michaocán would become engaged in migrant farm work. ${ }^{18}$ In fact, Náhuatl-speaking braceros used their native language as way to covertly coordinate strikes for fair wages, the language allowing workers to communicate horizontally in a native language. ${ }^{19}$ Indigeneity continues to fuel inter-cultural conflict in Mexico and the United States, with indigenous groups experiencing exclusions in a number of areas, employed in "ethnically segmented" labour streams and often facing racist prejudice from fellow Mexicans. ${ }^{20}$ While Canadian depictions of foreign farm workers often risk reducing worker

\footnotetext{
${ }^{16}$ See, for example, James Lockhart, We People Here: Nahuatl Accounts of the Conquest of Mexico (Berkeley: University of California Press, 1994).

${ }^{17}$ José Rabasa, Without History: Subaltern Studies, The Zapatista Insurgency, and the Specter of History (Pittsburgh: University of Pittsburgh Press, 2010).

18 Jonathan Fox and Gaspar Rivera-Salgado eds., Indigenous Mexican Migrants in the United States (La Jolla: UC San Diego, Center for Comparative Immigration Studies, 2004) 2.

19 Ibid.

${ }^{20}$ Ibid., 4. 
identities to the parameters of nationality or sex alone personal and regional identities inflected migrant identities in more ways than one.

Mexico's heterogeneous and regional nature has helped to render any singular concept of Mexican identity imagined at best. Afro-Mexican identities, for instance, have their own histories that have been well documented by historian Herman Bennett. ${ }^{21}$ While Spanish remains a key definer of modern Mexico, many indigenous languages continue to thrive, and Náhuatl words continue to pervade Mexico's demographic and urban geography. American corporate spaces of consumption and tourism have also dramatically reshaped many coastal as well as urban regions, and their associated economic zones. ${ }^{22}$ With the rise of Benito Juárez, indigenous identity emerged prominently in Mexican politics, paving the way for what Florencia Mallon refers to as the inclusion of the popular in the political framework of the nation. ${ }^{23}$ This theme found continuity after the revolution when a new agrarian politics reshaped Mexico, producing a historical literature that increasingly focused on rural life and transformation. ${ }^{24}$

With the twentieth century witnessing the rise of Mexican emigration, Catholicism's embedded place in Mexican identity would also cross borders. The Virgin of Guadalupe came to define Mexican spirituality and ideal sacrificial motherhood within and without Mexico. ${ }^{25}$ The Virgin was heralded in UFW marches as a

\footnotetext{
${ }^{21}$ See Herman L. Bennett, Africans in Colonial Mexico: Absolutism, Christianity and Afro-Creole Consciousness, 1750-1640 (Bloomington: Indiana University Press, 2003).

${ }^{22}$ A telling example of this trend was the recent building of a Wal-Mart in 2004 "barely a mile" from the ancient pyramid site of Teotihuacán, inciting protests, hunger strikes, and blockades of the construction site. See "WalMart and the Pyramids," The New York Times, December 8, 2012.

${ }^{23}$ Florencia E. Mallon, Peasant and Nation: The Making of Postcolonial Mexico and Peru (Berkeley: University of California Press, 1995), xv-xvi.

${ }^{24}$ See for example, Christopher R. Boyer, Becoming Campesinos: Politics, Identity, and Agrarian Struggle in Postrevolutionary Michoacán, 1920-1935 (Stanford, CA: Stanford University Press, 2003). On peasant politics in twentieth century rural Mexico see Tanalís Padilla, Rural Resistance in the Land of Zapata: The Jaramillista Movement and the Myth of the Pax Priista (Durham: Duke University Press, 2008).
} 
symbol of her protection over the Mexican people, a sign of resistance to assimilation, and as a safe haven symbol for Mexican peoples abroad. While class concerns loom large and tend to dominate many analyses of migration, alternate approaches began to rethink migration on cultural terms. ${ }^{26}$ Still other work has focused on the dangers and perils of migration, including racialized violence at the border and in the border region. $^{27}$

Church culture also impacted the lives of migrants and established communities in both Canada and the United States. In Canada, Christian outreach and organizational efforts surfaced in Ontario, with Diocese of London playing an outspoken role in aid work with agricultural workers employed in their vicinity. ${ }^{28}$ For farmworkers, religion could often serve as an inter-cultural unifier, linking them more intimately with community members in host regions, on specifically spiritual terms. A trend of community church outreach was similarly found to exist among seasonal Pacific Island orchard and vineyard workers in the Central Otago towns of Cromwell, Roxburgh, and Alexandra, New Zealand. ${ }^{29}$ An additional complicating element linked to the question of modernity was the increased place of cosmopolitanism in migrants' lives. Individual migration paths could deeply shape personal life histories, as witnessed in Pedro's account of farm labour in Virginia or Miguel's experience in urban Sacramento. Many migrant farmworkers in Canada were "seasoned" with prior experience abroad. Pedro's

\footnotetext{
${ }^{25}$ On the role of faith for Mexican-American women, see Jeanette Rodriguez, Our Lady of Guadalupe: Faith and Empowerment among Mexican-American Women (Austin: University of Texas Press, 1994).

${ }^{26}$ See, for example, Gabriela F. Arredondo, Mexican Chicago: Race, Identity, and Nation, 1916-1939 (Champaign: University of Illinois Press, 2008).

${ }^{27}$ See, for example Oscar Martinez, Troublesome Border (Tucson: University of Arizona Press, 1988) and Oscar J. Martinez, "Border People: Life and Society in the U.S.-Mexico Borderlands," The Oral History Reader 24.1 (1997): 132-6.

${ }^{28}$ Diocese of London, "Migrant Workers," and "Migrant Workers in London Diocese” (Migrant Workers Ministry), A Snapshot in Time.

${ }^{29}$ See Calnitsky, "Colonized Pasts."
} 
contract in Virginia on a tobacco estate was something to be proud of, a novelty in his working career. With increased time spent in Canada, identities evolved as familiarity with Canada and its consumer spaces allowed temporary workers to quickly form new connections with place.

\subsection{Secret Histories of Gender: Migration and Machismo}

Describing the Mexican male in his 1950 essays on the Mexican psyche, The Labyrinth of Solitude, Octavio Paz wrote of the "the Mexican macho" as a "hermetic being, closed up in himself, capable of guarding [...] himself." ${ }^{30}$ The work of Paz in theorizing machismo in relation to the Mexican sensibility newly placed it in a penetrating poetic format. In Mexican society, for Paz, "fortitude in the face of adversity" was "admir[ed]...more than the most brilliant triumph." 31 This culture of the macho or privileging of fortitude in the face of adversity intersected with histories of Mexican performances of farm work in highly complicated ways. In the contemporary forestry sector of the Pacific Northwest, foreman abuses were often compounded by challenges faced by unions unable to achieve sufficient representation for workers in this sector, while the machismo associated with work led many to reduce their tendency to express grievances over adverse conditions.

Connected with the problem of endurance and the physicality of farm labour was the question of health care, and in Canada, migrant farmworkers often faced numerous difficulties in readily accessing health services. By extension, health services were not always campaigned for by workers, while it was often external bodies, including women advocates, who made efforts on behalf of migrants so they

\footnotetext{
${ }^{30}$ Octavio Paz, The Labyrynth of Solitude / El Laberinto de la Solidad (New York: Grove Press, 1985), 31. ${ }^{31}$ Ibid.
} 
might more readily access those rights. When in May 2013 the province of Manitoba extended health coverage to the 400 seasonal workers in the province, one farmer who employed them commented: "I'm not sure why they did that... They always get taken care of...It's never an issue"; his hired workers formerly paid into private health insurance through the Royal Bank of Canada and cost only a "few cents a day.",32

The question of masculinity surfaces somewhat prominently in migration scholarship, the historiography of farm work, and in Mexican labour history more generally. Masculinity in Mexican historiography is now a well-developed area of study. ${ }^{33}$ Robert Buffington describes working-class Mexican men as having "had hard lives. On that point at least, most everyone agrees. ${ }^{\text {"34 }}$ Buffington frames machismo as a "nearly universal term" often used to denote "aggressively masculine behaviour" that, while often "applied to male culture," found its most "notorious practitioners" in the Mexican male working-class. ${ }^{35}$ The Porfiriato reconstituted Mexican masculinity in its pursuit of order, resulting in new working class formations and an emergent working class consciousness in a modern sense; Mexican machismo also became inflected by urban-rural discrepancies, with machismo viewed as backward and more prevalent among rural men who faced obstacles to modern education. ${ }^{36}$

\footnotetext{
${ }^{32}$ Carol Sanders, "Rally Prompts Province to Cover Health Benefits," Winnipeg Free Press, May 16, 2003.

${ }^{33}$ See Matthew C. Gutmann, The Meanings of Macho: Being a Man in Mexico City (Berkeley: University of California Press, 2007) for an ethnography of machismo; Sergio De la Mora, Cinemachismo: Masculinities and Sexuality in Mexican Film (Austin: University of Texas Press, 2006) on film; and Victor Macías-Gonzáles and Anne Rubenstein, eds., Masculinity and Sexuality in Modern Mexico (Albuquerque: University of New Mexico Press, 2012). For a study of masculinity beyond the boundaries of Mexico see Alfredo Mirandé, Hombres $y$ Machos: Masculinity and Latino Culture (Boulder, CO: Westview, 1997).

${ }^{34}$ Robert M. Buffington, A Sentimental Education for the Working Man: The Mexico City Penny Press, 19001910 (Durham and London: Duke University Press, 2015), 1.

${ }^{35}$ Ibid., 6.

${ }^{36}$ Ibid., 7-8 and Josue Ramirez, Against Machismo: Young Adult Voices in Mexico City (New York: Berghahn Books, 2008).
} 
While the historiography of Latino farm work is dominated by literature on male workers, an emphasis upon women workers, promoted in feminist anthropology in a range of studies focusing on trends in the feminization of the Mexican industrial workforce in the second half of the twentieth century dramatically reoriented the scholarly gaze. In José Alamillo's history of Mexican farm labour and leisure, Making Lemonades out of Lemons (2006), the focus is on male masculinities and perceived male superiority, which often proved disruptive to family integrity, while pool halls and saloons in rural outposts served as male-only spaces conductive to the plotting of farmworker strikes. ${ }^{37}$ The first Mexican female agricultural migrants hired in Canada entered the program through corridors of temporary work offered in Ontario. In 1997, Mexico sent fifty-seven female workers of a total of 5,000 to Ontario. ${ }^{38}$ The Canadian program prioritized hiring "single mothers, widows, and divorcees," leaving married and single women out of its criteria for the ideal female migrant. ${ }^{39}$ While most depictions of the SAWP have correctly described it as dominated by men, female workers were also rendered flexible to serve Canada's often-unstable agricultural export sector. ${ }^{40}$ Women migrants adapted to new parameters of guest work, with single mothers often leaving children with extended family and at times, on their own.

\footnotetext{
${ }^{37}$ See José M. Alamillo, Making Lemonade out of Lemons: Mexican American Labour and Leisure in a California Town, 1880-1960 (University of Illinois Press: Urbana, 2006). In the broader Euro-American context, the twentieth century also witnessed a new "veneration" of manly strength and fitness. See Jennifer Evans, "Queer Beauty: Image and Acceptance in the Public Sphere," Chapter Five in Globalizing Beauty: Consumerism and Body Aesthetics in the Twentieth Century, Edited by Thomas Kühne and Hartmut Berghoff, (Basingstoke: Palgrave Macmillan, 2013), 96. Julia Roberts similarly explores masculinity in the context of the eighteenth and early nineteenth century Upper Canada tavern and its positioning in counterpoint to colonial social ideals and shifting attitudes toward alcohol. See Julia Roberts, In Mixed Company: Taverns and Public Life in Upper Canada (Vancouver: UBC Press, 2009).

${ }^{38}$ Barndt, "Fruits of Injustice," in Women Working the NAFTA Food Chain: Women, Food and Globalization,Edited by Deborah Barndt (Toronto: Sumach, 1999), 47.

${ }^{39}$ Ibid. One "Irena" in Women Working the NAFTA Food Chain preferred the work available in Canada too that at home and related how she could purchase goods such as sewing machine she took home to Morelos.

${ }^{40}$ Ibid., 38-9. 
Interconnected with the newer emphasis in multidisciplinary scholarship on women workers are questions relating to the treatment of women and their bodies. In cases of sexual harassment and the mistreatment of women, questions relating to gender and power in the workplace often took center stage. A Canadian Labour Congress (CLC) report documented the case of one Teresa from Mexico who, while working on an Ontario apple orchard, "fell off a tractor, which then ran over her legs;" she underwent surgery twice, faced reprimands from a Mexican Consular official who "blamed her for being clumsy" and "demanded... she sign a document confirming his version of the accident, and said she would be returned to her family in Mexico" while the farm owner "paced the hallway... angry and anxious to have Teresa sign the document." ${ }^{\text {In }}$ In th case, the female migrant's vulnerability was overt, while the employer was concerned only about his own wellbeing. Two police officers later found her belongings "carelessly stuffed into a plastic bag and tossed near the ditch." ${ }^{42}$ Mexican women who took SAWP contracts operated as breadwinners for their families and were often "stigmatized as sexually available by their own countrymen," while another shocking case of the differential treatment of women occurred when one farmer "forbade his female workers to leave the farm, while the men were free to come and go." 43

In Mexican trans-national migration studies, the category of sexuality has gained more sustained consideration with a growing number of studies focusing specifically on sexualities across borders. Like masculinity, emotion, and affect, sex, love, and

\footnotetext{
${ }^{41}$ Flecker; C.L.C., Canada's Temporary Foreign Worker Program (TFWP), 1-2. 42 Ibid.

${ }^{43}$ Kerry Preibisch and Evelyn Encalada, Migrant Women Farm Workers in Canada-Information Guide (Guelph: Rural Women Making Change, University of Guelph, July 2008), 3-4. Ontario took in 393 seasonal women workers in 2006, three-quarters migrating from Mexico and one-quarter from the Caribbean. The sociological scholarship of the late Dr. Preibisch on the experiences of female SAWP workers did much to improve the literature on this topic in Canada. See also Deborah Barndt, Tangled Routes: Women, Work and Globalization on the Tomato Trail (Lanham, Maryland: Rowman \& Littlefield and Aurora, ON: Garamond Press, 2002).
} 
homosexuality are now well developed in scholarship on the history of Mexico and Latin America, developed in part by Pete Sigal, Serge Gruzinski, William French, Katherine Bliss, Noemí Quezada, Asunción Lavrin, and Donna Guy. ${ }^{44}$ While fewer studies document farmworkers' sexualities, Jennifer Hirsch and the late Lionel Cantú have studied the varying patterns of sexuality among migrants in the United States, with Cantú's work charting patterns relating to sexuality and expression among farm workers in Guadalajara and Southern California. ${ }^{45}$ Alternate sexualities in Mexico date to preHispanic times, with the phenomenon of homosexuality severely punished in New Spain, and spanning social and racial divisions. ${ }^{46}$ As queer communities have surfaced as a growing component of Mexican culture and modernity, despite persecution, queer identity is often celebrated through art and manifested in small town environments and urban culture.

An additional approach to the problem of gender is through the question of the body. In the realm of farm work, employers often imagine an ideal, contributing physical body that is "disembodied" from the real identity of the worker as a person or

\footnotetext{
${ }^{44}$ French historians of Mexico like Serge Gruzinski, have contributed to this development. A number of thematic and regional studies have also been produced. See Daniel Balderstron and Donna J. Guy, Sex and Sexuality in Latin America (New York: New York University Press, 1997). Sexuality studies of the preHispanic period include Noemí Quezada, Sexualidad, Amor y Erotismo. Mexico Prehispánico y Mexico Colonial (México: UNAM, Instituo de Investigaciones Antropológicas, Primera reimpresion, 2002). On the colonial period see Pete Sigal, Infamous Desire: Male Homosexuality in Colonial Latin America (Chicago: University of Chicago Press, 2003). On letters of affection see William E. French, The Heart in the Glass Jar, and for a survey see William French and Katherine Elaine Bliss, Gender, Sexuality and Power in Latin America Since Independence (Lanham, MD: Rowman and Littlefield, 2007). On chastity and challenges to sexuality among nuns in colonial Mexico see Asunción Lavrin, Brides of Christ: Conventual Life in Colonial Mexico (Stanford: Stanford University Press, 2008).

45 See Lionel Cantú Jr., The Sexuality of Migration: Border Crossings and Mexican Immigrant Men, Edited by Nancy Naples and Salvador Vidal-Ortiz (New York and London: New York University Press, 2009), Jennifer S. Hirsch, A Courtship after Marriage: Sexuality and Love in Mexican Transnational Families (Los Angeles: University of California Press, 2003) and Lionel Cantú and Eithne Lubhéid, eds., Queer Migrations: Sexuality, U.S. citizenship, and Border Crossings (Minneapolis: University of Minnesota Press, 2005).

${ }^{46}$ See Pete Sigal, "To Cross the Sexual Borderlands: The History of Sexuality in the Americas," Radical History Review 82 (2002): 171-85 and Serge Gruzinski, "The Ashes of Desire: Homosexuality in Mid-

Seventeenth Century New Spain,” in Pete Sigal, Infamous Desire, 204-5.
} 
human on the one hand, and an idealized body or machine on the other. ${ }^{47}$ Recent work on Indigenous Canadian masculinities foregrounds the intersections between indigenous lives and bodies with colonialism and the residential school experience. ${ }^{48}$ The toil and the "broken body's" associated with farm labour was emphasized in recent work involving extensive field research in Mexico and the United States from anthropologist Seth Holmes. $^{49}$

Notwithstanding the paternal compulsion and perceived responsibility to provide, economic realities have long impelled Mexican women to participate in history as economic agents. Silvia Arrom's work has mined the diverse roles of Mexican women in breadwinning in late colonial and early Independent Mexico. ${ }^{50}$ Others, like Sarah Chambers, have examined how legal structures intersected with gendered economic behavior through paternal discourses of providing for offspring in the colonial Americas, which in fact had roots in early modern Europe wherein the Siete Partidas, codified in Castile in the thirteenth century, enshrined parental (and paternal requirements to provide for their offspring. ${ }^{51}$ In other Latin American contexts of migration, fatherhood played a central role; Eileen Suárez Findlay’s We are Left without a Father Here considers how cultural tools such as the concept of bregar (to negotiate, or "extract favourable possibilities" from limited options shaped Puerto

\footnotetext{
${ }^{47}$ Tomás Summers Sandoval, "Disobedient Bodies: Racialization, Resistance and the Mass (Re)Articulation of the Mexican Immigrant Body," American Behavioral Scientist 52.4 (December 2008): 587, citation from Adela de la Torre. For other studies emphasizing the role of the body in history see Ballantyne, Entanglements of Empire and Axel, The Nation's Tortured Body: Violence, Representation and the Formation of a Sikh "Diaspora."

${ }^{48}$ See Robert Innes, ed. Indigenous Men and Masculinities: Legacies, Identities, Regeneration(Winnipeg: University of Manitoba Press, 2015).

${ }^{49}$ See Seth Holmes, Fresh Fruit, Broken Bodies: Migrant Farmworkers in the United States (Berkeley: University of California Press, 2013).

${ }^{50}$ See Silvia Marina Arrom, The Women of Mexico City, 1790-1857 (Stanford: Stanford University Press, 1985) and Arrom, "Mexican Women: Historical Perspectives," ReVista (Winter 1998).

${ }^{51}$ Sarah Chambers, "The Paternal Obligation to Provide: Political Familialism in Early-Nineteenth Century Castile," American Historical Review 117.4 (2012): 1128.
} 
Rican agricultural migrants' survival mechanisms in the United States. ${ }^{52}$ While many studies like Suárez Findlay's continue to focus on male migration, Tamar Diana Wilson has contested the "myth" of male migration, noting how almost half of Mexican arrivals into the United States between 2000 and 2005 were female. ${ }^{53}$ While a small percentage of seasonal agricultural workers were female in Canada in the early 1990s, the growing involvement of women in the program has sparked renewed attention to the "double oppression" of women migrants in contemporary agricultural labour markets.

\subsection{Carving A “Third Space": Alternate Models of Community and Diaspora}

\section{Formation}

The historical literature on Mexican community formation in the United States is often defined by regional emphases. The work of Michael Innis-Jimenez, for instance, builds on the work of Gabriela Arredondo, to look at the ways in which community life and social space functioned in interwar Mexican South Chicago. Just as Mexican migrants entered the steel mill industry when mills were in dire need of labour, Canada's migrant agricultural workers were courted according to discourses of need, but also, of labour preference and flexibility in policy. While the Bracero Program allowed cross-border migration for the Mexican worker, other forms of labour provided alternate occupational niches for Mexican workers both before and after the Second World War. Urban gardening work, as performed by Mexican jardineros or maintenance gardeners and their ayudantes (helpers), also has roots in the interwar

\footnotetext{
${ }^{52}$ Suárez Findlay, We are left without a Father Here, 11. In this study, fatherhood and family separation were historical agents in shaping the social history of postwar Puerto Rican migration to sugar beet fields in Michigan.

${ }^{53}$ Wilson, Women's Migration Networks in Mexico and Beyond, 24.
} 
period, when as early as the 1930s Japanese gardeners hired on Mexican help. The Mexican worker has since come to dominate this industry in Los Angeles, a niche first made formal in the 1940 s by migrant Japanese men. ${ }^{54}$ Hospitality and other industries also came to depend largely on migrants with diverse occupational niches coming to define "Mexican lives" in a diaspora setting that often promoted assimilation.

Chicago's urban history of migration offers a telling example of how migration schemes often went awry and rarely led to intended results. Braceros often skipped out of agricultural or railroad work contracts in the Midwest and ended up in urban Chicago (now home to at least one million Mexican residents) in need of new work and housing. Managed schemes like the Bracero Program often proved imperfect in controlling all aspects of the migration process. Bracero migrations leading to permanent Mexican settlement in Chicago stemmed from the Railroad Bracero Program, which saw 15,000 braceros work on railway lines between 1943 and 1945 and further patterns of permanent settlement in the city. ${ }^{55}$ Churches, such as the Mexican Baptist Mission (formed in South Chicago in 1928) were safe havens that promoted the welfare of the Mexican community. ${ }^{56}$ When braceros arrived in the city facing difficulties, many were taken in under the protective wing of the city's already-established Mexican American

\footnotetext{
${ }^{54}$ Hernan Ramirez and Pierette Hondagneu-Sotelo, "Mexican Gardeners in the USA," in Majella Kilkey, Diane Perrons, and Ania Plomien eds., Gender, Migration and Domestic Work: Masculinities, Male Labour and Fathering in the UK and USA (New York: Palgrave Macmillan, 2013), 16; 122. Part of the entrance of Japanese into the gardening trade was a reflection of the group's own history of discrimination in the State of California; Japanese farmers in California faced legal challenges including a 1913 Alien Land Law that sought to reduce competition between Japanese agriculturalists and white farmers. Suburban gardening diverged from harvest work as a highly privatized service in which freedom and flexibility to manage and control gardening routes was achieved, as jardineros retained a measure of independence in their occupations while the ayudantes came to typify the wage-dependent and undocumented worker. Mexican and other Latino jardineros evolved into private entrepreneurs, with labour autonomy and agency attained through the hiring of their own waged employees or ayudantes.

${ }^{55}$ Lilia Fernández, "Of Immigrants and Migrants: Mexican and Puerto Rican Labor Migration in Comparative Perspective, 1942-1964,” Journal of American Ethnic History 29.1 (Spring 2010), 17.

56“"Mexican Baptist Mission, South Chicago, 1 July 1929," Mexican Labor in U.S. Field Notes Series C Set-I, 60. Paul S. Taylor Papers, Bancroft Library Manuscripts Collection.
} 
community. ${ }^{57}$ The earliest Mexican migrants in Chicago were male, and their arrival generated inter-ethnic commingling including with Irish and Polish women.

Mexican cultural identity has been depicted as malleable in the wake of dislocation, but also resilient in the face of shifts wrought by migration. Owing to Mexicans' failure to assimilate in Anglo-American urban culture, in 1920s Chicago the problem of classifying Mexican residents collided with debates over urban policies intent on segregating communities according to nationality or race:

The objections to Mexicans are because of race, economic competition, and lower standards of living. People would like to segregate the Mexicans as well as the Negroes, but we probably will not go ahead with the segregation for two reasons: [1] The legal case for such separation is not so clear as for separation of the Negroes. We understand that the Mexicans are legally classed as white.

[2] The Mexicans do no present a general problem throughout the entire Chicago community as does the Negro... The Steel Company brought the Mexicans in to cut the wages. So all the other nationalities resent them... The Mexicans are lower than the European peasant. They are not white and not Negro. They are Mexican. ${ }^{58}$

These kinds of American debates, inflected by discourses of inter-ethnic labour competition and overt racism, were also impacted by the historical climate in which they were set, in this case a diversification of the urban cultural geography of the American Midwest. Narratives like these also had earlier manifestations, when in the

\footnotetext{
${ }^{57}$ In South Chicago, Mexican workers were prominent participants in the United Steel Workers union in the 1940s. 58 “Secretary, Chamber of Commerce, South Chicago," Mexican Labor in U.S. Field Notes Series-C, Set-I, 62-3, Paul S. Taylor Papers, Bancroft Library. 
nineteenth century Lone Star Republic "Texians" had "casually labeled Mexicans a 'a mongrel race, inferior even to negroes."

In Canada, Caribbean diaspora formations would precede the arrival of seasonal workers. The more formal West Indian Domestic Scheme of 1955-60 saw female managed migration from the Caribbean begin. ${ }^{60}$ Managed migration from the Caribbean in the 1950s paved the way for the ensuing managed scheme devoted to Caribbean agricultural labour in the 1960s. In describing the West Indian Domestic Scheme, Frances Henry observed:

The Ministry of Labour in each island selects the women, puts them through a two-week indoctrination course and sees that they fulfill immigration requirements...On arrival in Canada the women are granted landed immigrant status and are placed in a home for a period of one year. The majority of them are in Montreal and Toronto. ${ }^{61}$

Due to the non-seasonal nature of this scheme, Caribbean women entering Canada were offered pathways toward naturalization. The era of more liberalized immigration policies after 1960 would see many thousands more enter Canada as regular immigrants, and the onset of Canada's "Offshore Program" can be viewed against these developments.

\footnotetext{
${ }^{59}$ Hämäläinen, The Comanche Empire, 213.

${ }^{60}$ The scheme involved Jamaica and Barbados. See Ruth Lynnette Harris, “The Transformation of Canadian Policies and Programs to Recruit Foreign Labor: the Case of Caribbean Female Domestic Workers, 1950s1980s," Ph.D. Thesis, Sociology, Michigan State University, 1988. See also Abigail Bakan and Daiva Stasiulis, eds., Not One of the Family: Foreign Domestic Workers in Canada (Toronto: University of Toronto Press, 1997). The late eighteenth century saw the initial arrival of some five hundred Jamaicans to Canada and in the nineteenth century, mining migrations between the Caribbean and Cape Breton would occur until 1920.

${ }^{61}$ Frances Henry, "The West Indian Domestic Scheme in Canada," Social and Economic Studies 17.1 (1968): 83. Caribbean women entering through this scheme were also free to pursue alternate lines of work in Canada once the year had expired.
} 


\section{4 "Excluding Agricultural Workers from a Protective Regime Contributes}

\section{Substantially to the Violation of Protected Freedoms": Migrants vs. the Law}

This section turns to Canadian legal culture to explores the ways in which temporary foreign workers have been framed in Canadian legal discourses, and the ways in which Canadian governance models over non-citizen workforces were pitted against international labour standards and ideals. While Canada has signed numerous international treaties relating to migrants' rights, these rights were rarely practiced in law. Despite fluctuations, federal labour legislation in Canada from the mid-1980s on often ran counter-current to International Labour Organization (ILO) principles and ideals. Despite Canada's participation as a founding member of the ILO in 1919, legislation at our highest judicial level set limits on Canada's constitutional capacity to protect all workers' freedoms of association. In 1987, our Supreme Court failed to protect the worker's rights to strike in a series of cases known as the "Labour Trilogy."62 The ILO supervisory body, the Committee on Freedom of Association (CFA) received 77 complaints from unions against Canada relating to "infringements" on rights of association. ${ }^{63}$ When Canada failed to comply with CFA recommendations the CFA "hardened its tone" toward Canada, since a number of its core principles were demonstrably in conflict with Canadian constitutional law. ${ }^{64}$ Given this new labour climate and legal paradigm, employer rights were privileged and protected above all, rendering seasonal labour eruptions rare and unlawful in a Canadian context.

\footnotetext{
${ }^{62}$ Maude Choko, "The Dialogue between Canada and the ILO on Freedom of Association: What Remains after Fraser," International Journal of Comparative Labour Law and Industrial Relations 28.4 (2012): 400.

${ }^{63}$ Ibid., 401.

${ }^{64}$ Ibid., 402. The right of one greenhouse worker to wear protection over his face when working in a chemically-dense environment in Southern Ontario was denied when one worker, Carlos, was fired for purchasing his own face mask at a local dollar store. See Anna Maria Tremonti, “'Migrant Dreams' Broken as Workers Face Exploitation on Ontario farms." The Current CBC. April 28, 2016.
} 
Social unionism is a brand of unionism that seeks to extend inclusion to minority and under-represented groups without the barriers of sex or nationality. In Canada, it was of benefit to the foreign migrant worker base since it allowed an extension of representation to more marginal groups such as temporary workers. ${ }^{65}$ In addition to operating with increased social and "multi-national" inclusivity, North American unions have increasingly operated trans-nationally. In the United States, the AFL-CIO recently made efforts to protect farmworkers across the border in Baja, California, when it advocated on behalf of workers who experienced "rights violations" in the San Quintin Valley. ${ }^{66}$ The UFW Organizing Committee affiliated with the AFLCIO umbrella union in 1966, and under governor Edmund Brown in California worked to enact milestone labour legislation in 1975, with the Agricultural Labor Relations Board making collective bargaining rights for farmworkers a reality. ${ }^{67}$ In May of 2011 , a SAWP worker was relocated from British Columbia to Quebec for alleged interest in participating in a Canadian union, participated in a press conference at the Mexican Senate accompanied by representatives of the Canadian UFCW Union to denounce blacklisting practices facing union activists from the SAWP. Although Robles never actively sought his transfer to Quebec, hoping to return to Mission, he was instead sent to Richard Legault Farm. The UFCW's position as a trans-national agent operating in favour of the rights of labour revealed its bi-national presence and beyond-the-border impact through its promotion of migrant concerns in both Canada and Mexico. In addition to the role played by activist unions, independent organizations and NGOs such as No One is Illegal, Okanagan-based Radical Action with Migrants in

\footnotetext{
65 Jason Foster, "From 'Canadians First' to 'Workers Unite': Evolving Union Narratives of Migrant Workers,” Relations Industrielles / Industrial Relations 69.2 (Spring 2014): 258.

${ }^{66}$ Mike Hall, “AFL-CIO Backs Baja Farm Workers’ Rights,” AFL-CIO, April 1, 2015.

67 “Mexican Farm Workers Collection: A Guide," University of Texas Arlington Special Collections, Historical Note to Mexican American Farm Workers Collection, [1969-87].
} 
Agriculture (RAMA), and Justicia 4 MigrantWorkers, have stepped in to advocate on workers' behalf in the wake of Canadian legal shortcomings with respect to migrants' rights.

As Ontario developed it postwar labour legislation, agricultural workers were largely excluded from its parameters, with the exception of an Agricultural Labour Relations Act (ALRA, 1994) that gave agricultural labour rights to join unions and engage in collective bargaining. Repealed in its entirety the following year by Progressive Conservative Mike Harris' Labour Relations and Employment Statute Law Amendment Act (LRESLAA), farmworkers in the province were now subjected to section 3(b) of the Labour Relations Act (1995) excluding them from the labour rights regime. ${ }^{68}$ Employers increasingly choose to hire foreign workers less prone to unionize to procure a cheaper and more docile workforce, as was the case with B.C. construction companies sourcing workers from Mexico in 2008, and in many Ontario greenhouses today, workers from Thailand and Indonesia, many of whom had to pay exorbitant recruitment fees to access work in Canada, serve as a supplemental agricultural workforce. ${ }^{69}$ In Mexico the political climate in relation to migrants constituted a mixture of efforts to extend state protections to migrants abroad in theory through the consular visits to farms, and in practice, through consular officials' efforts to limit labour militancy among migrant farmworkers in Canada. The key concerns of Mexico in its relationship with migrants abroad has had to do with twin realms of the political, in which the status quo of bilateral labour schemes are maintained, and the economic, in ${ }^{68}$ Choko, "The Dialogue," 402-3 and Dunmore v. Ontario (Attorney General), [2001] 3 S.C.R. 1016, 2001, SCC 94, Judgments of the Supreme Court of Canada, Lexum Collection.

${ }^{69}$ See Richard Gilbert, "British Columbia construction companies find skilled workers in Mexico," Journal of Commerce, January 16, 2008 and Tremonti, "Migrant Dreams." 
which remittances may form key components of the national economy, while social questions were largely ignored.

\section{In September of 2006, United Food and Commercial Workers Union (UFCW)}

Local 832 submitted an application to certify a bargaining unit among Mexican seasonal farmworkers employed in Manitoba at Mayfair Farms, Portage la Prairie, which in its first year had hired on only four SAWP workers and today employs higher numbers. The application was submitted to the Manitoba Labour Board. ${ }^{70}$ Certification for the local to represent sixty-five farmworkers was granted the following year in June 2007. In Manitoba, seasonal farmworkers' rights to organize while on the job were until this point not clear-cut and the proposed bargaining unit included fifty-nine seasonal agricultural workers from Mexico. A hearing held over four days in January 2007 saw the host farm present a witness from the family farm who testified to his family's thirty-five year involvement in vegetable production, growing of wheat, oats, and strawberries on 1,250 acres and an array of vegetables. ${ }^{71}$ The members of the proposed unit were engaged in manual farm tasks of planting, weeding, irrigating, harvesting, and packaging produce, with the SAWP facilitating their "organized entry" into Canada. ${ }^{40}$ The workers were moreover not "naturalized citizens of Canada" and their employment limited to eight consecutive months each year. ${ }^{72}$ Campaigning for its claim as a "non-employer," the

\footnotetext{
${ }^{70}$ Manitoba Labour Board, Government of Manitoba, "Case No. 595/06/LRA IN THE MATTER OF: The Labour Relations Act-and-IN THE MATTER OF: An Application by United Food and Commercial Workers Union, Local No. 832, Applicant,--and MAYFAIR FARMS (PORTAGE) LTD., Employer/

Respondent" (Winnipeg, MB, 26 June 2007), 1-3. The original application was opposed by the Counsel for Mayfair Farms, which wrote to the Labour Board to argue that the migrant workers were, in effect, not employees of the host farm; the provincial Labour Relations Act was by extension, it was argued, not applicable to foreign workers since the Governments of Canada and Mexico were in fact the "associated, related or common employers" of the offshore workforce, rather than the farm owners.

${ }^{71}$ Ibid., 4. The farm, which accommodated workers onsite, directed a majority of its produce to Peak of the Market.

72 Ibid., 5.
} 
farm suggested it did not have full control over the recruiting process, not always receiving requested individuals from Mexico, failing to obtain fourteen workers it had requested in 2006 while "other workers were selected by Mexico and sent instead." 73

In the case, social incidents involving farm workers were also discussed; one infraction of a clause in the farm's rules of conduct for foreign workers specifying that they "may not fraternize with women at the farm" had occurred. ${ }^{74}$ Despite such ambiguities the board ruled in 2007 that foreign seasonal workers were in fact employees of the farm leading, in an accompanying Certificate, to an order allowing "certification to issue. ${ }^{, 75}$ After improved overtime wages were negotiated by local 832 of the UFCW, the employer responded by refusing to offer any overtime hours of work beyond 70 hours per week, thus reducing chances for higher earnings among unionized workers at the farm. ${ }^{76}$ Despite a legal victory, Mayfair's seasonal workers ultimately opted to decertify two years later, preferring the prospect of more hours and avoiding the complications and tensions associated with union membership. In observing this case, Dave Hall concluded that Mayfair workers were "under a lot of pressure to drop the union."77 They had been discouraged from participation in the UFCW local for several reasons, including pressures from the Mexican government not to unionize in Canada, and from farmers and other employers who believed representation through a Canadian union might result in certifications elsewhere. 
Canadian unionism dually served as an enlightened advocate for migrant farm workers' rights and a thorn in the side of Canadian employers. Activism in the pursuit of migrant freedoms encompassed activism from within, as pursued by workers themselves, and activism from without, pursued by church workers, unions, and others in solidarity with the cause. The Agricultural Workers Alliance, for instance, in 2011 highlighted how the Vancouver Mexican Consulate was in the practice of "giving the workers 'workshops' when they arrive to Canada" designed to intimidate and preclude them from creating problems for their employers and to limit contact with the wider community; those who stepped beyond such terms in B.C. faced the prospect of exclusion from the program. ${ }^{78}$ In addition this, female migrant agricultural workers often faced sometimesobjectionable circumstances that were entrapping, including situations from which it was "seemingly impossible...to escape." ${ }^{, 79}$ At a fish plant in Wheatly, Ontario, in Essex County that hired women from Mexico and Thailand, an employer assaulted nine women in 2008, leading to an ongoing court case surrounding female migrant vulnerability in the Canadian workplace. ${ }^{80}$ The government's "blind eye" to migrant exploitation set women in precarious positions that were oftentimes "unsafe...with few, if any protections." rural California, risk for female workers was detailed in Xóchitl Castañeda’s study of horizontal assault from male workmates. ${ }^{82}$ Notwithstanding multiple vulnerabilities,

\footnotetext{
${ }^{78}$ In December 2011 the UFCW/AWA with support from the Coalition for Migrant Worker Justice organized in Vancouver to stage a "Christmas demo" in support of migrant agricultural workers and against the Mexican Consulate's practice of blacklisting." “Join the Community Trial,” May 18, 2012, Courtesy of AWA Surrey.

${ }^{79}$ Holly Gibbs et. al., Negotiating Risk, Seeking Security, Eroding Solidarity (Halifax: Fernwood, 2012 ), 7.

${ }^{80}$ On the Immigration Minister's efforts to monitor employer accountability see Rachel Mendleson,

"Temporary Foreign Workers Canada Blacklist: Jason Kenney Wants Permanent Ban on Employers Who Abuse Migrant Workers," Huffington Post, April 20, 2012.

${ }^{81}$ The case saw a 69-year old employer Jose Pratas accused of assault; see Erica Bajer, "Pratas Pleads to Simple Assault," Chatham Daily News, March 1, 2013; Ricardo Veneza, "Migrant Workers Still Fighting Pratas,"

Blackburn News, July 17, 2013; and "Migrant Worker Abuse Case Drags," The Windsor Star, July 16, 2013. A

later verdict saw two Mexican female claimants win $\$ 150,000$ and \$50,000 in compensation for varying levels of sexual harassment in and out of their workplace.

${ }^{82}$ See Xóchitl Castañeda "Changing Constructions of Sexuality and Risk: Migrant Mexican Women Farmworkers in California," The Journal of Latin American Anthropology 8(2) (2003): 126-51.
} 
Canadian policy and legislation still often prioritized employer rights over those of seasonal workers.

In 2001, Canada's Supreme Court gave temporary agricultural workers the right to join employee associations while in Ontario their freedom to strike was withheld. The Court's position on foreign farm labour shifted when Dunmore v. Ontario revisited agricultural workers rights in legal discourse ${ }^{83}$ Judicial wavering was a hallmark of Canadian reasoning on the rights of foreign farm workers, which have continued to sit on ambivalent legal terrain in Canadian courts. In Dunmore it was argued that "the distinction between positive and negative state obligations ought to be nuanced in the context of labour relations, in the sense that excluding agricultural workers from a protective regime contributes substantially to the violation of protected freedoms. ${ }^{, 84} \mathrm{In}$ response to the Dunmore verdict, Ontario passed its Agricultural Employees Protection Act (AEPA), weakening the rights of the foreign farmworker from his prior status under the Ontario Labour Relations Act. ${ }^{85}$ Since the 2011 Fraser case which concerned farmworkers' rights to engage in collective bargaining, the "legal landscape" of section 2(d) specifying freedom of association has lacked clarity and was "fraught with legal uncertainty...qualified...by restrictive thresholds. ${ }^{״ 86}$ Foreign farm labour’s ambivalent legal status in Canada emerged, I suggest, as a result of coded and ambivalent Canadian

\footnotetext{
${ }^{83}$ Prior to the case, the Court maintained a "legalistic and individualistic" pattern, whereas in 2001, farmworkers' freedoms to associate were upheld. See Paul Cavalluzzo and Adrienne Telford, "Freedom of Association, the Right to Bargain Collectively and the Right to Organize" (Ottawa: Canadian Foundation for Labour Rights, March 2013), 4, and Kirk Makin, "Farm Workers have No Right to Unionize, Top Court Rules," Globe and Mail, April 9, 2001.

${ }^{84}$ Dunmore v. Ontario. Dunmore also signaled that section 2(d) of the Canadian Charter of Rights and Freedoms concerned with labour rights might be "broadened" to take on a "collective dimension," allowing workers to engage in representation in a collective manner, a format that could not be achieved through the singular actions of any one worker (Cavalluzzo and Telford, "Freedom of Association," 5).

85 Ibid, 6.

86 Ibid., 10.
} 
judicial reasoning on the one hand and Ontario's specific action to limit temporary workers' rights on the other.

Labour migration resulted in new legal entanglements in Canada. This fact, alongside persisting racisms on many farms, has caused innumerable problems for Canadian courts and for migrant workers. In Windsor, migrants faced dismal conditions at a farm where some 300 harvest workers were "referred to by numbers, and banned from speaking any language but English." ${ }^{87}$ The Mexican government has also been viewed as a new actor in violation of Canadian labour codes, as Tom Sandborn observed:

the government of Mexico, through its Ministry of Labour, violated sections 6(1) and 9 of the provincial labour relations code when it instructed Honorio Corona Martinez...to initiate a union decertification campaign...The Mexican government...threatened Mr. Corona that if he did not advance the decertification campaign, he would not be allowed to return to Canada to work. ${ }^{88}$ Questions remain as to whether or not union affiliation is positive or negative, yet the storefront-style, UFCW-affiliated worker alliance centres across Canada received over forty thousand complaints from farm workers in $2010 .{ }^{89}$ Success stories on the collective bargaining front occurred outside Ontario, when in 2013 migrant employees of Productions Horticoles Demers in Quebec, which hires Guatemalans and Mexicans to harvest tomatoes, strawberries, raspberries, peppers, cucumbers, and eggplants for markets in eastern Canada and New England, joined UFCW Local 501, a victory for a

${ }^{87}$ Makin, "Farm Workers have no right to unionize," 2.

${ }^{88}$ Tom Sandborn, "Mexican Government Union Busting in BC, Charges Union: Guest Workers pressured by Mexican officials to decertify unions, says UFCW," The Tyee, May 11, 2011. ${ }^{89}$ Ibid. 
union that has adamantly sought to incorporate farm workers under its wing. ${ }^{90}$

A final case for considering how legal entanglements have arisen involving migrant agricultural workers in Canada was that of Victor Robles, a Mexican migrant agricultural worker employed at an Indo-Canadian owned nursery in Mission, British Columbia, between 2006 to 2010. This case demonstrates defects inherent to how the SAWP came to operate in British Columbia. A victim of Mexico's micro-management over the farmworkers it sends to Canada each year, after working at a nursery job in Mission four consecutive years, Robles was transferred to a farm in Quebec ostensibly on his own request. In February 2011 when Robles was supposed to return to B.C. for a seasonal contract and faced complications obtaining his visa, Robles was informed by a Mexican government official that "the real reason Robles was blocked from travel was because he had participated in a union." ${ }^{.91}$ Robles' legal declaration reveals how SAWP workers were rendered vulnerable to anti-union instruction, intimidation, and re-routing within Canada. Deliberations in the Mexican Parliament in June 2012 called upon the state to respect worker rights to associate inside Mexico as well as abroad. ${ }^{92}$ In the proceedings, Robles' case was cited and it was noted that the workers at the nursery involved had filed for the decertification of their union affiliation with the UFCW some months prior to the incident. ${ }^{93}$ The next section turns to the question of human rights discourses as they became intertwined with migrant farmworker struggles in Canada.

\footnotetext{
${ }^{90}$ UFCW Canada, “UFCW Canada Local 501 Campaign Gains New Quebec Agriculture Unit,” Montreal, October 2, 2013.

${ }^{91}$ Another official would later scold the first official for revealing to Robles the complications associated with his file. Brett Matthews, "Victor Robles' Declaration,” Labour Relations Board, Monday, December 5, 2011 (Point 8): 2.

92 Government of Mexico Chamber of Deputies / Cámara de Diputados, "Response to Point Resolution Passed by the House of Representatives,” Parliamentary Gazette XV.3542, June 27, 2012.

${ }^{93}$ Ibid. Mexico maintained a bureaucratic discourse of supervision and protection over migrants, placing its officials on a much higher plane of power in relation to workers abroad.
} 


\subsection{Reconciling Human Rights Discourses with Migrant Realities}

International human rights provisions have undergone a number of critical transformations since the Second World War and by necessity encompassed questions concerning the rights of migrants. The International Convention on the Protection of the Rights of All Migrant Workers and Members of Their Families was adopted in December 1990 by the United Nations General Assembly as Resolution 45/158; its third part is concerned with the human rights of migrant workers and its fourth with "other rights of migrant workers" who are either documented or "in a documented situation."94 Article 16 of the convention ensures state protections over migrants from "violence, physical injury, threats and intimidation, whether by public officials or by private individuals, groups or institutions." 95 While international human rights conventions have addressed rights issues, international standards were not always played out in practice. ${ }^{96}$ In placing the question of migrant rights within a longer historical vista, we can better comprehend how nation states and the borders they patrol worked to redefine the rights and statuses of citizens, non-citizens and all other moving bodies that navigate state boundaries.

Connected with the question of human rights among workers in Canada is the question of the human rights climate in sending countries. Citizenship in the West continues to offer a key framework for social, political, and economic parameters of inclusivity in a nation state. While the origins of the idea of alienage have precedents in the political life of Greek city-states, which marked out explicit designations between

\footnotetext{
${ }^{94}$ Office of the United Nations High Commissioner for Human Rights, "International Convention on the Protection of the Rights of All Migrant Workers and their Families," Adopted by General Assembly resolution 45/158 of December 18, 1990.

${ }^{95}$ Ibid., Article 16, Point 2.

${ }^{96}$ On human rights in Canada, see Janet Miron, A History of Human Rights in Canada: Essential Issues (Toronto: Canadian Scholars' Press, 2009).
} 
citizen and alien, Roman law made civil law or jus civile applicable to its citizens alone.

This dynamic would set a foundation for how civil law came to operate through to modern-day contexts and rights-based privileges given to citizens in North American nation states, and by extension, would help define how non-citizens and undocumented migrants and workers would receive treatment by those states. Agricultural work schemes made few provisions for temporary workers to access citizenship and continue to create circumstances that allow participants to straddle the citizen/non-citizen boundary, offering temporary work and annual income for non-nationals. It is against this backdrop that migrants' rights were defined by subjective choices (and desires) of host states vis-à-vis their guest workforces. ${ }^{97}$

With migrant work's traversing of the legal/illegal binary, the Canadian SAWP is sometimes depicted as a model program. However, while offering a legal framework for migration, Canada has not allowed guest workers in agriculture to circulate freely on the Canadian labour market. ${ }^{98}$ Its participants in certain cases suffered exclusion from certain definable human rights, including the ostensible human right to engage in collective activity, but also other rights connected with housing and mobility. International measures set forth by the ILO and United Nations set concrete and agreed-upon ideals for all nations to strive toward, including equality of opportunity and treatment between nationals and migrant workers. ${ }^{99}$ Under the umbrella of international human rights

\footnotetext{
${ }^{97}$ Ryszard Cholewinski, Migrant Workers in International Human Rights Law: Their Protection in Countries of Employment (Oxford: Clarendon Press, 1997), 41. On human rights issues for migrants in Canada see also Tanya Basok and Emily Carasco,"Advancing the Rights of Non-Citizens in Canada: A Human Rights Approach to Migrant Rights," Human Rights Quarterly 32.2 (2010): 342-66 and Tanya Basok, "Human Rights and Citizenship: The Case of Mexican Migrants in Canada," (University of California, San Diego; the Center for Comparative Immigration Studies, Working Paper 72, April 2003). On human rights as it intersects with free trade regimes see Ariadna Estévez, Human Rights and Free Trade in Mexico: A Discursive and Socio-political Perspective (New York: Palgrave Macmillan, 2008).

98 Knowles, "The Seasonal Agricultural Workers Program," 1.

${ }^{99}$ Cholewinski, Migrant Workers, 106. Formed at Versailles in 1919, the ILO's mandate included management over international labour concerns, and it con sistently placed human rights at the center of its mandate: it set freedoms of
} 
mandates, international organizations came together to implement rights standards for migrant workers at international labour conferences in 1949 and 1975, to promote rights and protections for migrants, with measures adopted in 1975 focusing on the problem of clandestine migration. As international laws began to generate ideal standards for the protection of migrants worldwide, solidarity groups did much of the onthe-ground work of putting migrant farmworkers' rights into practice. ${ }^{100}$

Among many other intersecting issues facing migrant workers, the UN has recognized housing as a central challenge. Miriam Pawell has drawn attention to persisting substandard housing issues facing farmworkers in the San Diego area, citing one case in which farmworkers were living in shacks they had had to build themselves. ${ }^{101}$ Housing issues, by extension, remain high on the list of concerns for migrant workers in Canada today. With increased mobility has also come the increased need to implement human rights protections. Under Vicente Fox, Mexico extended efforts to protect migrants, creating an Office for Attention to Mexican Migrants Abroad with branches in eighteen states. ${ }^{102}$ Despite these measures, migrating workers are in many cases still not guaranteed access to rights and protections promoted by international laws. ${ }^{103}$ Injustices facing migrants, including corruption and extortion,

association at the heart of its founding principles, and this right was in 1946 incorporated into its constitution (Choko, "The Dialogue," 398-9). In a series of resolutions in the 1970s the United Nations underlined the varying levels of discrimination experienced by migrant workers, especially in Europe, in 1977 introducing a principle that migrant workers should receive equal treatment with nationals in a number of areas including individual and collective freedoms. Cholewinski, Migrant Workers in International Human Rights Law, 106.

${ }^{100}$ International migration and human rights issues are often studied together; work from Samuel Martinez, for example, has considered the problems that have accompanied the movement of people across borders in an American context. See for example, Samuel Martinez, ed. International Migration and Human Rights: The Global Repercussions of U.S. Policy (Oakland: University of California Press, 2009).

${ }^{101}$ Miriam Pawell, “The Crusades of César Chávez,” New Books in History Interview, May 29, 2015.

${ }^{102}$ Patricia Zamudio, "Mexican International Migration” in Toro-Morn Maura and Marixsa Alicia, Migration and Immigration: A Global View (Westport, CT: Greenwood, 2004), 142.

${ }^{103}$ In December 2012 Canada's federal government announced its decision to render seasonal agricultural 
sprang from deficiencies in the Mexican political system. ${ }^{104}$ While a label of legality was often applied to guest work schemes, inconsistencies in participating sending countries often permeated official methods through which migrants were recruited, reducing the legitimacy of official guest worker programs.

Based on her extensive field research among farmworkers in New York State, Margaret Gray has made the case for the necessity of labour laws for "all farmworkerscitizen or not," suggesting an expansion of the parameters of legal protection to legal and illegal migrants as a prerequisite for fair labour practices and standards. ${ }^{105}$ With unauthorized migrant numbers estimated 11 million in the United States, three-fifths of Mexican origin, recent efforts by President Obama to offer amnesty to undocumented workers and mitigate deportation practices point to the scale and extent of the issue. ${ }^{106}$ The movement of people across borders has become a contentious security issue in the eyes of many host nations, while legal and illegal migrants continue to fill many unwanted agricultural, industrial and service industry positions. Other international settings like Southern Italy have seen migrant citrus and tomato harvest workers from North Africa arrive via sea to work in Calabrian agriculture via legal and non-legal avenues. ${ }^{107}$ These European trends in farm work, often moulded by xenophobic anxiety and limited legal framework of legality, by default promoted more dangerous avenues

workers no longer eligible to apply for Employment Insurance (E.I.), and the ruling was decried by migrant worker advocates who claimed that Conservative policy worked against the interests of non-Canadian workers, as the Tories often dealt them "injustices." Sebastian Salamanca, "Advocate Decries Loss of EI for Seasonal Migrants," The Tyee, January 23, 2013.

104 “Piden renegociar Programa de Trabajadores Temporales con Canadá,” Provincia (Michoacán), February 25, 2013.

${ }^{105}$ Margaret Gray and Emma Kreyche, “The Hudson Valley Farmworkers’ Report: Understanding the Needs and Aspirations of a Voiceless Population," and "Executive Summary,” Bard College Migrant Labor Project.

${ }^{106}$ Amanda Holphuch, "Mexican Migrants not deterred by threat of arrest immigration study shows," The Guardian, August 1, 2013. On undocumented workers in the dairy sector see Roy Germano, "Immigrant

America: They Steal our Jobs?” (Documentary Film, Vice Media, 2014).

${ }^{107}$ ITUC; Anti-Slavery International, ITUC International Trade Union Confederation Guide (Brusssels: ITUC; London: Anti-Slavery International, 2011), 30. Calabria's citrus industries rely on tens of thousands of immigrant 
of mobility for migrants. Shifting migrant farm workforces support horticulture in the United Kingdom, where Polish and Bulgarians encountered "dreadful" conditions with inadequate housing and few provisions of health or safety. ${ }^{108}$ In Chile, poorer Bolivian migrants often fill harvesting jobs on vineyards. Global agriculture has suffered from extreme exceptionalism in its relationship to labour rights, the often-illegal status of its workforce, and the requirement of migration to serve its needs. Such a set of conditions has made human rights problems in farm work a persisting challenge for policy makers seeking to coordinate limited patterns of entry for workers from afar, as well as for those countries that continue to face high levels of clandestine migration.

\subsection{The Elephant in the Room: Media Performances and Farm Workers}

In this final section, I turn to the question of print culture to interrogate how and why seasonal workers have been depicted, imagined, and understood in Canadian media portrayals. While I do not perform a media study, I draw on the work of scholars like the geographer Harald Bauder who have devoted work to this task. While media accounts have framed offshore workers as critical economic agents and managed migration as a form of foreign aid, media also served to legitimate and reinforce existing programs while maintaining a sense of cultural exclusion that served to other farmworkers in print. ${ }^{109}$

workers, with a mere one-quarter holding regular working permits. Andrew Wasley noted a hierarchy of command in southern Italy in which a capo bianco ("white chief" or Italian gangmaster) and capo nero (or "black chief") drawn from the workers performed various levels of recruiting and managing the affairs of farmworkers. See Andrew Wasley, "Scandal of the 'Tomato Slaves' Harvesting Crop Exported to UK,"

Ecologist, September 1, 2011. In Puglia, Sub-Saharan Africans had inadequate housing conditions while Doctors Without Borders/Médecins Sans Frontières provided them healthcare for six consecutive years. See Laura Agustín, “Migrant Farm Workers in Italy: Any Identity But Victims?” The Naked Anthropologist, Jan. 21, 2010.

${ }^{108}$ Andrew Wasley, "Bitter Harvest: How Exploitation and Abuse Stalks Migrant Workers on UK farms," Ecologist, October 10, 2011.

${ }^{109}$ Harald Bauder, "Foreign Farm Workers in Ontario (Canada): Exclusionary Discourse in the Newsprint Media," Journal of Peasant Studies 35.1 (2008), Abstract. 
In local Ontario newspapers, sympathy toward farmers sprang from nativist ideas that often reinforced an "anti-immigrant" position; moreover, critics such as Bauder described "offshore" labour practices as having "semi-feudal" connotations while Canadian media makers concurrently fulfilled a role of reinforcing public consent for the program. ${ }^{110}$ On the other hand, Canadian media workers often performed the opposite function of muckraking, printing exposés of injustice, or expressing outrage toward the mistreatment or neglect of guest workers in agriculture. ${ }^{111}$ In such cases, journalistic discourse echoed critical academic accounts of the SAWP, to highlight themes of worker vulnerability, and problems that have arisen as a result of workers being tied to single employers.

In Manitoba, the collision of environmental forces with worker precarity also received attention when rural floods in 2011 impacted seasonal workers in the Southwestern part of the province:

Seasonal farm workers in the flood zone's vegetable patch might not be sent back to Mexico. Initially, the deliberate breach of the Assiniboine River dike near Hoop and Holler Bend on Saturday was expected to wipe out the crops. Now, things are looking up...Up to now, the farm [Connery's] has paid some of the workers to sandbag homes as well as cut asparagus. Connery isn't sure how other vegetable farms in the flood zone are faring... Not good, says the organization representing seasonal agricultural workers. It's trying to make sure the workers get paid while they're here, even if crops are

${ }^{111}$ A harassment scandal at Presteve Foods made the tribulations of guest workers known in the news. See, for example, Joe Friesen, “Temporary Foreign Workers win Sexual Harassment Case," The Globe and Mail, May 27, 2015.
} 
ruined and they don't have work.... ${ }^{112}$

The group was supposed to receive 40 hours per week but because of the floods often received "zero" hours; an AWA representative was seeking to "at least get for them the minimum compensation for being in Canada," insisted they had "arrived to Canada in good faith, giving up seasonal work opportunities elsewhere... They depend on the savings from what they make during their season here." ${ }^{\prime 29}$ The 2011 Winnipeg Free Press article highlighted precarity in its connection with the forces of nature: flooded fields made precarious seasonal work more precarious as many faced the prospect of having to return home without pay, when a regular working season brought $\$ 15,000$ to $\$ 20,000$ to each worker. ${ }^{130}$ While some reports focusing on harvest or processing workers featured interviews, more commonly, journalists consulted farmers or migrant worker advocates for information about foreign farmworkers.

Other media narratives included those that highlighted the program's potential to offer social mobility or material progress. Winnipeg Free Press articles about the first Mexican farm workers in Manitoba tended to work along these lines. One National Post article framed a migrant worker from Apan in Hidalgo as now better equipped to provide a chance for his children to attain mobility from "working class farmers" to private students, highlighting stories of children's careers: "one is a pilot and another is studying law." ${ }^{\prime 31}$ This reporting paradigm, typical to the Post's pro-business orientation, denoted economic progress and optimism. Other reports described the character of the temporary workforce; Denise Ryan's Vancouver Sun report in 2013 described agricultural workers

\footnotetext{
${ }^{128}$ Carol Sanders, "Vegetable Pickers Might Not have to Go Home," Winnipeg Free Press, May 182011 , A3.

129 Ibid.

${ }^{130}$ Ibid.

${ }^{131}$ Bauder, "Foreign Farmworkers," 113. Bauder refers here to Marina Jimenez, "Mexican Guest Workers May Complain About the Reserved Cultured North, But the Money they Make Picking Tomatoes Makes All the Difference to their Families Back Home," The National Post, September 6, 2001, A14.
} 
in British Columbia as flexible and impermanent. ${ }^{132} \mathrm{~A}$ "fruits of their labour" framing in Canadian accounts was also common wherein migrants were portrayed as consumers newly equipped to purchase goods as a result of wages earned in Canada. ${ }^{133}$

Media also shone a light on extreme stories involving trauma when farmworkers were involved in accidents or fatalities. A deadly van accident in Hampstead, Ontario, involving the deaths of ten Peruvian chicken workers received much media attention across the country, especially because of its highly tragic nature. ${ }^{134}$ The Toronto Sun described 2012 as a "deadly year" for migrant farmworkers in southwestern Ontario, citing the death of Ezequiel Cervantes-Nava by lightning in a ginseng field in Norfolk County and a number of other road accident fatalities. ${ }^{135}$ The article pointed to the "small army" of migrant farmworkers in the region and how accidents damaged or ended their lives: "some workers also get struck by cars when riding bicycles...It usually happens after work when they ride into town to do their shopping or use the phone. We usually have six to 10 bike accidents or deaths a year." ${ }^{, 136}$ In Abbotsford, three female IndoCanadian farmworkers killed in a van accident in 2007 led to Abbotsford's City Council approving the construction of a Golden Tree Memorial in tribute to workers who perished with the Abbotsford Times covering the construction of the memorial. ${ }^{137}$

In addition, Canadian journalists depicted workers as agents of change, covering union certifications or the migrant as protestor. Migrant encounters with Canada's

\footnotetext{
${ }^{132}$ See Denise Ryan, “Lack of enforcement fosters 'replaceable, disposable' workforce," The Vancouver Sun, Monday, August 12, 2013, A1.

${ }^{133}$ Bauder, "Foreign Farm Workers," 104.

${ }^{134}$ See, for example, Kate Allen, Niamh Scallan, Jayme Poisson, and Wendy Gillis, "Community Shattered by Deaths: Farm Crash Mirrors 2004 Tragedy," The Toronto Star, February 7, 2012.

${ }^{135}$ Scott Taylor, “Deadly Year for Migrant Workers in Southwestern Ontario," Toronto Sun, August 16, 2012.

${ }^{136}$ Ibid.

${ }^{137}$ Rochelle Baker, "Memorial Takes Root at Mill Lake: Abby Council approves Golden Tree to Honour Fallen Farmworkers," Abbotsford Times, April 5, 2012.
} 
judiciary equally figured prominently in the media. The logistical needs of farmers was another common interpretation in addition to cases of labour conflict. ${ }^{138}$ Another popular media framing was that of family members left behind. Agricultural workers were also often problematically depicted as interconnected with rural landscapes, or as a foreign presence dotting those landscapes. ${ }^{139}$ Offshore programs were also depicted as geographical "fixes," with labour procured from afar to solve local problems. ${ }^{140}$ While sparse attention to children of farmworkers has surfaced in Canadian media accounts, the theme has pervaded U.S. narratives and programs of outreach and social progressivism and change. ${ }^{141}$ Variability in journalistic narrative was not only a product of varied Canadian interpretations of the program, but also of the complexity of experiences faced by foreign farm workers in shifting Canadian contexts. As attention to guest workers has grown in the twenty-first century to accompany a growing presence of multi-national workforces, smaller disputes and national concerns often collided in journalistic discourse, imbuing local events and actors with a meaning often masked by larger complexities that often reach far beyond Canada's borders.

\footnotetext{
${ }^{138}$ See Claire Ogilvie, "Migrant Mexicans Face More Health Checks, Workers in Demand by B.C. Fruit, Veggie Growers." Province (Vancouver), April 28, 2009, Carol Sanders, "Rally Prompts Province," Aldo Santin, "Manitoba Migrant Farmworkers Vote to Leave Union," Winnipeg Free Press, August 8, 2009, Montpetit, "Migrant Workers Await Labour Board Ruling," and Megan O’Toole, "Migrant Workers Calling for Changes to Coroners Act After Office Refused to Hold Inquest into Jamaican Man's Death," Nation Post, June $28,2013$.

${ }^{139}$ Harald Bauder, "Landscape and Scale in Media Representations: The Construction of Offshore Farm Labour in Ontario, Canada," Cultural Geographies 12 (2005): $42-7$.

${ }^{140}$ Bauder, "Foreign Farm Workers," 115.

${ }^{141}$ See Jill Replogle, "Migrant Education Program Gives Farmworkers a Boost," Fronteras: The Changing Americas Desk, November 7, 2013. The Migrant Education Program enables children of migrant farmworkers to improve their lives and its serves 80,000 children in California alone.
} 


\subsection{The Migrant as Modern? Conclusions}

As Nestor Garcia Canclini suggests, "The turmoil experienced in migration, ineffective borders, and travel evinces the fractures and segregations of globalization. This is also why stories by migrants and exiles are replete with such narratives and metaphors." 142 This chapter has sought out engagement with a diversity of subjects, including culture, gender, migrants' rights, and the Canadian legal landscape to help discern a better picture and make efforts to write an alternate narratative and reading of contemporary farm labour migration patterns as they have played out in postwar Canada. As migrant farmworkers increasingly occupied and inhabited unique spaces in Canada, their relative visibility could grow, both in Canadian print culture and in the shifting contexts of urban and rural life. As farmworkers and their advocates increasingly sought to claim migrants' rights, divisions between the migrant class and Canadian society at large underwent increased erosion in the public sphere. Working against the odds of structural realities that rendered seasonal farmworkers separate and not equal vis-à-vis the common Canadian worker, seasonal farmworkers in Canada made a number of small victories in the sphere of labour rights. Despite this, massive politico-legal hurdles remain. .

In exploring questions that move beyond economic or political interpretations, this chapter has sought to address the question of what it means to be trans-national in a globalizing world. Thus, while I have not framed cultural questions introduced here in terms of the history of identity politics per se, I have drawn on a well-developed literature that has delineated the nuances and cultural ramifications of contemporary Mexican migration and trans-national community development. As occupiers of a

${ }^{142}$ Nestor Garcia Canclini, Imagined Globalization (Durham: Duke University Press, 2014), xxxviii. 
“third space," Mexicans abroad formed new cultural niches that provided both economic and social forms of sustainability that worked "beneath" the nation, and also in concert with pre-existing "corridors" of mobility as well as newly formed ones. Homi K. Bhabha, the prominent theorist of global anthropology, points to the concept of "contra-modernity" to denote the ways in which neo-colonial structures and the reorientation of global divisions of labour have worked to reconfigure modernity in new ways defined by culture and geography. As Bhabha observes in The Location of

\section{Culture:}

It is in the emergence of the interstices - the overlap and displacement of domains of difference - that the intersubjective and collective experiences of nationness, community interest, or cultural value are negotiated...How do strategies of representation or empowerment come to be formulated in the competing claims of communities where, despite shared histories of deprivation or discrimination, the exchange of values, meanings and priorities may not always be collaborative and dialogical, but may be profoundly antagonistic, conflictual and even incommensurable?...Postcoloniality, for its part, is a salutary reminder of the persistent 'neo-colonial' relations within the 'new' world order and the multinational division of labour. Such a perspective enables the authentication of histories of exploitation and the evolution of strategies of resistance. Beyond this, however, postcolonial critique bears witness to those countries and communities in the North and the South, urban and rural — constituted, if I may coin a phrase, 'otherwise than modernity'. Such cultures of a postcolonial contra-modernity may be contingent to modernity, discontinuous or in contention with it, resistant to 
its oppressive, assimilationist technologies; but they also deploy the cultural hybridity of their borderline conditions to 'translate', and therefore reinscribe, the social imaginary of both metropolis and modernity. ${ }^{143}$

Roger Rouse further conceives of the post-modern condition as a confusing world, a world of criss-crossed economies, intersecting systems of meaning, and fragmented identities...Symptomatic of the unfolding shift to transnational capitalism, migration between rural Mexico and the United States since the Second World War, and especially since the mid-1960s, has been obliging us ever more insistently to develop an alternative cartography of social space. ${ }^{144}$ Riding bicycles in landscapes dominated by cars, patronizing second-hand and dollar stores for food, work wear and gifts, and working with an often-precarious status, migrant farmworkers in Canada have consistently occupied in-between and marginal spaces within the nation. At the same, working on organic farms and vineyards and shopping at megastores and supermarkets, SAWP workers have additionally tapped into contemporary opportunities and consumer spaces. In conceptualizing migrant workers as a consistently part of modernity, but also, as occupiers of its interstices and neo-colonial arrangements, the "culture" of migration might be better framed and understood.

\footnotetext{
${ }^{143}$ Homi K. Bhabha, The Location of Culture (New York: Routledge, 1994), 2, 9.

${ }^{144}$ Roger Rouse, "Mexican Migration and the Social Space of Post-Modernism," Diaspora 1.1 (1991): 8, 12.
} 263 


\section{"How it Found its Way to Our Table": Conclusions}

"Excavation is always a two-part process. First you dig, and then you struggle to identify what you found." - Florencia Mallon ${ }^{1}$

Canada's "quest for order" in the complex, tangled, and disorderly world of migration from the South has shaped and defined its position toward agricultural guest workers since $1966 .{ }^{2}$ The social history of agricultural migration in postwar Canada might be filtered down to the day-to-day relationships formed on the ground in Canada, but was also inflected by mediating actors participating in processes of recruitment, transit, and management along the way. If, as Tony Ballantyne suggests, historians should "explore the co-existence of cross-cultural intimacy and distance, the place of both love and hatred across the boundaries of race, and histories of connection and distance," then an expanded definition of intimacy in the context of migrant histories is needed. ${ }^{3}$ In this context, intimacy can help denote the ways in which migrants have endeavoured to carve out worlds for themselves far away from home.

Frank Bardacke refers to word aguantar as a key theme for locating farm worker struggles. The word indicates one's capacity to "endure, bear, or put up with" a given set of conditions or circumstances, and in suggesting that Mexicans do not

\footnotetext{
${ }^{1}$ Florencia E. Mallon, Peasant and Nation: The Making of Postcolonial Mexico and Peru (Berkeley and Los Angeles: University of California Press, 1995), 330.

2 On the quest for order in a disordered world in the context of international migrations see Antoine Pécoud, Depoliticizing Migration, 78. Pécoud describes a climate in which international migration bodies search for balance, order, predictability, coherence, and other qualities denoting order when formulating their picture of ideal migration policies for states. Pécoud also deconstructs the category of international migrant commonly used in international organization (IO) jargon (see 83). Also critically, Pécoud points to the ways in which international migration narratives depoliticize migration while, from the point of view of states, migration remains a highly politicized issue (see 125).

${ }^{3}$ Tony Ballantyne, "Strategic Intimacies: Knowledge and Colonization in Southern New Zealand," Journal of New Zealand Studies, NS14 (2013), 16.
} 
"have an exclusive franchise on the ability to tolerate hard work," a political statement is offered to revisit the wider structural features that have shaped the history of agricultural labour relations in North America. ${ }^{4}$ Tanya Basok's "unfreedom" thesis here remains an important consideration. ${ }^{5}$ Securing a subaltern archive of voices through forty-three interviews in two provinces was by no means an easy task. While the archive offers clues into histories of farm labour management, for the most part it occludes the voices of workers, while interviews and migrant justice media do much to decode official accounts. As Alessandro Portelli suggests,

What allows oral history not only to enrich standard, documentary, and archival historiography but also change and even disrupt it is that, in oral sources, factual recollection merges with symbolic imagination to an extent unequalled by other sources. ${ }^{6}$

Similarly, in discussing residential schools in Canada, Marianne McLean observes, "all the documents were written from the point of view of government, of the churches, sometimes the Mounties. But they were not written from the point of view of the people who were there, either the parents or the children. That's what the survivor testimony provides. ${ }^{, 7}$ In my own interviews, in some cases Canadian contracts were described good, and in others, long, difficult or exhausting. As findings came to increasingly disrupt scholarly emphases from studies of Ontario, the role played by regional nuances in defining migrant rural experiences in Canada increasingly took

\footnotetext{
${ }^{4}$ Bardacke, Trampling out the Vintage, 32. Other studies have highlighted this theme of endurance in farm work. See, for e.g., Ismael Garcia-Colon and Edwin Melendez, "Enduring Migration: Puerto Rican Workers on U.S. Farms,” Journal of the Center for Puerto Rican Studies 25.2 (Fall 2013): 96-119.

${ }^{5}$ Tanya Basok, "Free to Be Unfree: Mexican Guest Workers in Canada," Labour, Capital and Society 32.2 (1999): 192-221.

${ }^{6}$ Allessandro Portelli, The Text and the Voice: Writing, Speaking, and Democracy in American Literature (New York: Columbia University Press, 1994), 53.

${ }^{7}$ Simona Chiose, "Gathering the Stories at the Heart of Residential School History," The Globe and Mail December 28, 2015. 
shape.

From an historical vantage point, culture is a category filled with the possibilities of agency "from below" or within with the ability to cut across individual experience. Migration scholars have documented how Mexicans reproduced their culture over time and across vast geographical distances. Indeed, to reduce Mexican culture to a single category risks simplifying a regionally vibrant mosaic that is the Mexican reality. Migrant identities were complicated by other factors, such as indigeneity, occupation, or family structure. Worker emotions offered vivid access points to reposition histories of farm work, while workers psychologies had the powerful ability to indicate ennobling sensibilities of dignity or pride. ${ }^{8}$ Landscapes of consumption would also define farmworker identities and histories. In addition, countless metabolic acts performed by Canadians, from cooking cauliflower for dinner in a suburban home or ordering French fries in a restaurant to purchasing asparagus at a small town supermarket were unavoidably influenced by an often-hidden world of migrant labour.

Tensions between archival and state knowledge on the one hand and migrant knowledge on the other, concerning migrant worker programs and discourses of opportunity, capability, or resilience help define the numerous ways through which farmworker histories have been narrated. While the archive, along with judicial and journalistic discourses, proved an indispensable resource, oral knowledge could transcend official narratives in offering peoples' histories and views of a bureaucratized past that allowed international integration and exclusion to co-exist in diverse rural

\footnotetext{
${ }^{8}$ Susan Broomhall called emotions "vital" to the approach pursued by historians of the household, society and the "self," and in the case of farmworkers, emotional experiences were often shaped by cultural distance from their home region and memories of family. See Susan Broomhall, ed. Emotions in the Household, 1200-1900 (London: Palgrave Macmillan, 2008), 7.
} 
contexts. Archival holdings are challenging to obtain when under restricted access, and may often preclude the writing of a comprehensive official account. ${ }^{9}$ While migration history often sits uncomfortably alongside immigration history in a somewhat more ambiguous position, especially in Canada, the two are intertwined, with the former dependent on developments linked to the evolution of the latter.

Sandro Mezzadra, a theorist of migration, also incorporates the concept of corridors in his work and points out how migrant workers equally offer solutions and "problems" for host countries:

labor mobility has been a crucial 'resource' for capital, but...it has also been a problem. This means that multifarious limits to and attempts to 'tame' the mobility and 'freedom... of labor have characterized the history of capitalism. ${ }^{10}$ Restrictions on the freedoms of itinerant labour has roots in colonial America, where female indentured servants in the seventeenth-century Chesapeke had freedoms and rights circumscribed. ${ }^{11}$ Despite the spectrum of freedoms deprived of migrant farmworkers in contemporary Canada, the "staying power" of the Mexican worker would give him an enhanced status as the preferred worker in numerous instances, including on Manitoba farms. The Mexican worker's industriousness and capability for job performance in Canada led to a gradual and then ultimately, formidable rise in numbers from program's onset in 1974; in present-day Canada an estimated 45,000

\footnotetext{
${ }^{9}$ The Archives of Ontario at York University, Toronto, also holds a significant number of files relating to the Seasonal Agricultural Workers Program, however, many of these holdings are classified and would require welltimed requests weeks in advance of a visit. On my own visit to the archive I was unable to access the record group I had requested, however I would encourage future scholars working on the area of the SAWP's bureaucratic history to make efforts to do so in order to gain an expanded understanding of the governmentality associated with the program and its history in Ontario as well as nationally.

${ }^{10}$ Sandro Mezzadra, "The Multiplication of Labor: An Interview," View Point, September 15, 2013. See also Mezzadra, Border as Method, or the Multiplication of Labor (Durham and London: Duke University Press, 2013).

${ }^{11}$ Clare A. Lyons, "Discipline, Sex and the Republican Self," in Edward G. Gray and Jane Kamensky, The Oxford Handbook of the American Revolution (New York: Oxford University Press, 2013), 562.
} 
agricultural farm hands and food processing workers are now sourced each year through temporary avenues. Imperial cultures and their consumptive demands have additionally promoted labour mobility and marginality, with farm labour mobility in the contemporary would often taking place across and "beneath" the nation.

The enterprise of agriculture and farm work was long cherished in Canada as central to the integrity and development of the nation. Depictions of the noble aspects of rural labour in Alberta from 1914 located rural existence on the land as a means to "earn a comfortable living...for that is after all the main purpose in any man's work." ${ }^{, 12}$ While this paradigm was disrupted with the rise of cities and urban economies, a renewed interest in locating, as Michael Pollan suggests, "What it is we're eating. Where it came from. How it found its way to our table. And what, in a true accounting, it really cost,"13 has re-inscribed efforts to bridge urban and rural divides. The movement to reengage with the rural and "local," to extend efforts to support and maintain local food systems and food-ways in the face of the sometime-chaotic capitalistic consumer landscapes of North America, still continues to intersect with questions relating to migrant agricultural labour in powerful ways. While a Latinization of Canadian agriculture has indisputably occurred, to many Canadian observers, the phenomenon is still sometimes presented as novel.

In many ways, migrant labour schemes have promoted "openness" and change, drawing faraway workers into new social and national geographies and spaces of production. Yet the idea that offering jobs to foreign temporary workers constitutes a form of development aid, as promoted in countries like New Zealand, is still problematic,

\footnotetext{
${ }^{12}$ Annual Report of the Department of Agriculture of the Province of Alberta (J.W. Jeffery, Government Printer, 1915), 8.

${ }^{13}$ Michael Pollan, The Omnivore's Dilemma: A Natural History of Four Meals (New York: Penguin, 2007) 411.
} 
especially since aid is rarely infused from above but rather, from below, through the everyday contributions of workers. Canada's half-open door with respect to its migrant farm workforce gave a partial sense of opportunity without citizenship and has defined Canada's record in foreign migrant management in agriculture, and New Zealand's recent turn toward Melanesia for seasonal orchard and vineyard workers in 2007 has closely mirrored this trend.

The late Tony Judt referred to a cult of privatization associated with the last decades of the twentieth century in which "economic calculations" were privileged above all; Judt's era of privatization also signaled a blow to society itself, the "reduction of 'society' to a thin membrane of interactions between private individuals." 14 This reduction in social purpose accompanied privatization waves that characterized the neoliberal era as agribusiness incurred a global race to the bottom. Notorious segregation policies emerged in Canada toward workers of Caribbean origin, when a commercial vegetable farm in the Montreal area had a segregated cafeteria dividing black from white workers since 1998, a signal of continued patterns of cultural intolerance. ${ }^{15}$ Indebtedness to company stores in Sinaloa, which exports produce to American consumer markets, shaped exportoriented agriculture in Mexico while extreme poverty and injustice among Caribbean and Mexican migrant farmworkers in Florida marked trends of exploitation in industrial agriculture that draws from a pool of regionally integrated workers without rights or protections. ${ }^{16}$ When braceros went on

\footnotetext{
14 Tony Judt, Ill Fares the Land (New York: Penguin Books, 2010), 108; 116; 118-9.

${ }^{15}$ Karl Flecker, "What Jason Kenney Doesn't Want You to Know About Canada's Temporary Foreign Worker Program,” Rabble, January 9, 2013.

${ }^{16}$ The Coalition of Immokalee Workers has done much to combat these trends, especially its Fair Food
} 
strike, retribution was not uncommon: workers were threatened with jail or faced physical assault from farmers.

Many had considered the Bracero Program to be inherently exploitative, and its end marked the dissolution of large-scale legal frameworks for Mexican mobility across borders. Irregular migrations were not wholly solved in 1986 with the Immigration Reform and Control Act, its measures of amnesty, and introduction of a Special Agricultural Worker scheme. Both the SAWP and the Bracero Programs demonstrated Mexico's desire to engage in the very programs that offered opportunities that were circumscribed by less than perfect conditions. Just as the SAWP has proven controversial, the Bracero Program secured a tarnished image. Public discourses debating the program's utility were discussed at the highest levels of government and among farmworker advocates and organized labour, while in Mexico, bracero contracts were often highly coveted, despite practices of exploitation and overwork that the program incurred. ${ }^{17}$ In Manitoba, political opposition to the SAWP emerged among the NDP during the program's first years of operation. Still, the Mexican Farm Labour Program of 1942, and Mexican SAWP of 1974 were both imbued with a bilateral legality that gave participants a chance to traverse borders without having to render their status invisible.

While managed migration schemes were often championed under the auspices of development, they still risked institutionalizing capitalist regimes of production, making little room for social change or real mobility running in the direction of worker interests.

Program, established now for $90 \%$ of the Floridan tomato industry to prevent abusive practices, resolve complaints, audit conditions on farms, and ensure legal consequences for human rights violations.

${ }^{17}$ Competition for seasonal farm labour contracts in New Zealand through the Recognized Seasonal Employer (RSE) scheme was similarly strong. 
Matt Bakker suggests that neither the U.S. or Mexico have been "interested in working together" to better manage migration flows between the two nations. ${ }^{18}$ David McNally adds that "It's not that global business does not want immigrant labour to the West...it simply wants this labour on its own terms: frightened, oppressed, vulnerable." 19 The convulsions that reworked Mexican politics and economic life in the twentieth century would also form a backdrop for migration patterns of the postwar era. Constituting modernity for some and displacement for others, the neo-liberal economic paradigm propelled working Mexicans, at home and abroad, into modified relationships with their neighbors.

Despite a UFCW contention that the SAWP is culpable for gender discrimination, recruiting disproportionate numbers of men, a critical divergence from the Bracero Program was Canada's eventual recruitment of migrant women workers in agriculture. Canada's dependence on migrant workers was a product of material forces, with jobs made accessible by northern economies proving attractive to the labour pools of the South. Still, precarity in agricultural work has not been limited to the Canadian experience..$^{20}$ The 1970 s in Mexico were marked by decreased corn and bean crop production and for many peasant families corn was "produced as insurance against starvation.. ${ }^{21}$ Mexico's peasant economy became partially dissolved, as the

\footnotetext{
${ }^{18}$ Matt Bakker, "From 'The Whole Enchilada' to Financialization: Shifting Discourses of Migration Management in North America," pp. 271-294 in Geiger and Pecoud, eds. The Politics of International Migration Management.

${ }^{19}$ McNally as cited in Harsha Walia, "Canada's Managed Migration Policy: Working for Business, Not People," in The Harper Record, 2008-2015 (Ottawa: CCPA, 2015), 165. South American Pink Tide movements, responding to economic imperialism from the North, were often supplanted by adaptations to neoliberalism in countries like Bolivia, this process sometimes referred to as "neo-structuralism," wherein states initially opposed to northern economic exploitation began to play more tacit roles in enabling private capital accumulation. In Mexico, a version of this process occurred as powerful and prosperous middle classes played crucial roles in determining the pathways of national development. Failed revolutionary governments often paved the way for the onset of neoliberal restructuring. Mexico's peasant union, Confederación Nacional Campesina (CNC) proved more a symbol than a manifestation of unity in the defense of peasants' rights.
} 
"dominant tendency in Mexican agriculture" was "clearly towards de-peasantisation," this leading to a predicted emergent dependence on "temporary or seasonal jobs in the capitalist market." 22

Perhaps more than anything, local conditions of production and seasonal economies in host societies impacted the lives of farm workers who forged new relationships with host towns and employers that were at once marginal and inclusive. While Mexican labour formed a more concrete backbone for American agriculture in 1942, in Canada, the critical year for the extension of labour from Mexico was 1974. The program's onset might be also be viewed as an extension of Canadian economic prowess, or in terms of a longer progression of Canadian rural history in which immigrants and an agriculturally-oriented state set a foundation for production, as land was offered up for cultivation and "improvement." The Canadian state often took on a principal role as a demographic and spatial director over agricultural labour concerns and this legacy would evolve and undergo a series of transformative shifts.

In postwar, Cold War Canada, the state surfaced as a new gatekeeper over refugee inflows from postwar Europe in the face of mass immigrations and the cultural reconstitution of the nation; in urban Toronto, a new need to educate, assimilate, and incorporate migrant speakers of foreign tongues would emerge. ${ }^{23}$ Jennifer Bagelman's work on the "city as sanctuary" reads modern migration flows on psychological and

\footnotetext{
${ }^{20}$ An agrarian crisis in Mexico, which surfaced in the 1970s, sparked widespread and varying forms of protest including public marches to cities. See Roger Bartra and Gerardo Otero, "Agrarian Crisis and Social Differentiation in Mexico,” Journal of Peasant Studies 14.3 (1987), 334.

${ }^{21}$ Ibid., 347. On the neoliberal corn regime and its impact on the peasantry and by extension, labour migration patterns in Mexico see Elizabeth Fitting, The Struggle for Maize: Campesinos, Workers and Transgenic Corn in the Mexican Countryside (Durham and London: Duke University Press, 2010).

22 Ibid., 347; 353

${ }^{23}$ See Franca Iacovetta, Gatekeepers: Reshaping Immigrant Lives in Cold War Canada (Toronto: Between the Lines Press, 2006). 
geographic terms to engage with discourses of fear and unpredictability as they have intersected with the migrant question. ${ }^{24}$ In extending Franca Iacovetta's state as "gatekeeper" concept to the history of migrant work in Canada, albeit in rural contexts, we can discern how the state functioned as an active policer of its own borders and as a bureaucratic agent in search of policies that would serve the best interests of its own. Canada's gatekeeping role extends to the nineteenth century, when the interests of industry often conflicted with the demographic preferences of an embryonic British colony-state. The Canadian Pacific Railway promoted the mobility of a foreign working class to serve its needs. Later on, the state would take a more active role as a "manager" over agricultural migrants, in domestic, intra-provincial, and inter-provincial contexts: in World War Two, farm labour needs were "solved" by Japanese interns, who were translocated and mobilized to meet rural work shortages, while, in the mid-1960s, Aboriginal workers were transferred from Northern Ontario to Southwestern Ontario to fill farm jobs soon after taken up by arrivals from the Caribbean.

In postwar decades, Canadian farmers veered increasingly toward contract systems dependent on itinerant workers subjected to employer arbitrariness and limited freedoms, but who also gained wage earning opportunities that were competitive in relation to economic conditions in sending countries. Migrant farmworkers showed resiliency in a dangerous and precarious sector, with "victories and...disappointments along the way." 25 To complicate matters, Canada often neglected migrants' rights as networks,

24 See Jennifer Bagelman, “Sanctuary: A Politics of Ease?” Alternatives: Global, Local, Political 38.1 (2013): 49-62. On the politics of global movement see also Kim Rygiel and Peter Nyers, Citizenship, Migrant Activism and the Politics of Global Movement (London: Routledge, 2012).

${ }^{25}$ Agricultural Workers Alliance Blog, http://awa-ata-blog.blogspot.ca/2010/03/agriculture-workers-alliance-blog.html Accessed October 1, 2014. 
organizations, and Canadian unions had to step in to fill the gap left by the state to bring migrant causes to light. In response to emerging problems and ambiguities in the Canadian legal landscape, migrant support networks catered to the arrival of Mexican farm workers and this tendency was reflected in diverse contexts of migrant justice work worldwide. Non-state actors took the causes unresolved by global capitalism under their purview, working at local as well as international levels.

Mexicans have long been forced to migrate in order to survive. A new wealth of scholarship in borderlands studies has reinvigorated historians' attention to questions of settlement, labour, and migration as they have intersected with the shifting political terrain of borderland regions, and a borderlands approach has enabled new critical directions in research. John Weber's recent work, From South Texas to the Nation: The Exploitation of Mexican Labour in the Twentieth Century, repositions South Texan labour history in a context of outmigration from Texas to other contexts of life and work in America. As the diverse threads of this study show, the world of migration and its history is nuanced and complex, and can never be fully written or known. Since migration is a potentially measurable phenomenon, it might be seen as something easily reduced to statistics, however, from a social history vantage point, the interstitial human spaces that sit in between the statistics often reveal a far more diverse and meaningful picture.

This study has charted what might be understood as the "knowable truths," using the toolkit of the historian to better paint a picture of Mexican migrant pasts in Canada. One of my initial research questions was to discover whether or not the SAWP was a model program or ridden with contradictions; while migrants' lives were 
sometimes touched by tragedy, the SAWP still offered many a sense of opportunity. This created a climate in which return migrations to Canada were common. Many studies of migration and its management from institutions and academia are, as Geiger and Pécoud suggest, "of an advocacy nature" that promote policy suggestions instead of "investigat[ing] what is happening," an approach that often "leaves little room" for independent thought. ${ }^{26}$ While institutional reports on farmworkers in Canada did often provide discernable facts, they were often marked by enlightened opinions about how the SAWP ought to work or operate, on idealist terms. In addition, despite the prevalence of such reports and academic studies, the degree of visibility of agricultural workforces continues to remain often highly muted.

The Canadian “Offshore Program,” later the Seasonal Agricultural Workers' Program, represented an extension of labour links between Canada and nearby North American labour sending regions, rather than an immediate solution to an overt labour crisis, as was the case with the Bracero Program in the United States. The SAWP redrew the borders of the Canadian state, offering a flexible "trap door" for labour that provided an often uncertain terrain of temporary work contracts. As an extension of Canadian agricultural labour policies, the program fits in with a broader history and historiography of immigration, statecraft, international policymaking, and diplomacy, reflective primarily of domestic economic needs, but also of political possibilities, enabled from above. In focusing on foreign farm labour through a case study of

\footnotetext{
${ }^{26}$ Geiger and Pecoud, eds. The Politics of International Migration Management, 1.
} 
of two provinces, this study's contribution is to better help define how and why such trans-national recruitment schemes came to be manifest not only at a national level, but in terms of local requirements, shifting positions, and changing opinions. More broadly, it is intended as an historical study of social history that bridges themes common to national histories elsewhere: those of marginality and exclusion, of "race," place and the crafting of nations, and the continued trials faced by minority groups. Indeed, there is much to be done if Canada aims to improve its record as an employer of temporary migrant labour in agriculture, and as new studies continue to shed light on the phenomenon of migration and migrant work in Canada from a wide range of disciplines, better and more informed policy and judicial choices can be made. 


\section{$\underline{\text { 1. Oral History Interviews }}^{1}$}

\section{Bibliography}

\section{Manitoba}

Interview with “Antonio.” Interview with “Gerardo.” Interview with "Luis.” Interview with "Manuel.” Interview with "Mariano.” Interview with "Segundo.” Interview with “Bernardo.” Interview with “Alejandro.” Interview with “Jorge.” Interview with “Carlos.” Interview with “Jesús.” Interview with “Armando.” Interview with “José." Interview with “Diego.” Interview with “Rodrigo.” Interview with “Arturo.”

\section{British Columbia}

Interview with "Alfredo." Interview with "Chico." Interview with "Francisco." Interview with "Lazaro.” Interview with "Victor.” Interview with "Magdalena." Interview with "Gabriela.” Interview with "Miguel Ángel.” Interview with "Pablo." Interview with “César.” Interview with "Juan.” Interview with "Miguel.” Interview with "Enrique." Interview with "Pedro." Interview with "Maria.” Interview with “Fernando.” Interview with "Manuel Alejandro." Interview with “Gonzalo.” Interview with "Epifanio." Interview with "Patricio." Interview with "Hernando.” Interview with “Felipe.” Interview with “Orlando.” Interview with "Pepe.” Interview with "Feliciano." Interview with "Vicente."

\section{Quebec}

Interview with "Modesto."

\section{Newspapers and Magazines}

Abbotsford Times (British Columbia)

ABC News Australia

Blackburn News (Ontario)

Briarpatch Magazine

\footnotetext{
${ }^{1}$ See Appendix 2: Log of Oral Histories, for a list of the locations and dates when interviews were conducted.
} 
CBC News / The Current

Chatham Daily News (Ontario)

El Provincia, Diario Grande de Michoacán (Mexico)

Guardian, The

Globe and Mail, The

Huffington Post

Informador (Mexico)

Isthmus (Madison, WI)

Journal of Commerce (Burnaby, B.C.)

King 5 News (Seattle)

National Post

News, The (New Glasgow, Nova Scotia)

New York Times

Otago Daily Times (New Zealand)

Our Times: Canada's Independent Labour Magazine

Public Radio International (United States)

Province (Vancouver)

Rabble

Regiones, Suplemento de Antropología (Mexico)

Science Daily (United States)

Seattle Times

Sustain Ontario

This Magazine

Times Herald-Record, (Middletown, New York)

Terra (Mexico)

Toronto Sun

Tyee, The (British Columbia)

Weekend Press (Christchurch, New Zealand)

Windsor Star

Winnipeg Free Press

Wisconsin Watch 
Vancouver Sun

Viewpoint Magazine

Washington State Magazine

\section{Archives and Special Collections}

\section{Archives of Chilliwack, British Columbia}

"Mexicans would be 'good workers." Chilliwack Progress, Wednesday, December 4, 1974.

\section{Archives of Manitoba}

IC-S-30a - INTERLAKE COMMUNITIES - Selkirk - Farm near Selkirk (Colour Photograph), [1972], A 0222, GR0107, CV 167-2. Digital Image GR13001997.JPG

“Entire Male Animals at Large; Engage Farm Help Now - November 1920.” [Digitized Image of Manitoba Bank Bulletin Intelligence Service, Winnipeg, Nov. 1920] Agricultural Instruction Posters, A 0236, GR8299.

“102-28 Speech from the Throne - Opening of Legislature.” 14 Aug. 1969. LA 0009 GR0646 B -1-3-17.

CBC Winnipeg English Television Productions, “Country Calendar.” [Feb. 23 1955] 1 Film Reel; Kinerecording, Black and White, 28 min. F3505.

Mrs. W.H. Lowe, Sr. "Homesteading in Manitoba.” [pre-1924] F.H.H. (Harry) Lowe Fonds, P7276/12.

\section{Archives of Ontario}

"Dutch farm hands reaping the tomato crop in Leamington." [1928] Multicultural History Society of Ontario Fonds. F 1405.Ministry of Agriculture, Food and Rural Affairs. "Mechanically Harvesting Tomatoes, Leamington.” [Sept. 10, 1986] RG 16276 1, 86 B1915.

\section{Bancroft Library Manuscripts, University of California Berkeley}

Taylor, (Paul S.) Papers, 1895-1984, BANC MSS 84/38 c, Social Science 
Research Council: Mexican Labour in the United States (1927-1933), 1919-1934

Stephens, Elizabeth and Linda Jordan; Bancroft Library. "Guide to the Paul Schuster Taylor Papers, 1660-1997 (bulk 1895-1984).” Berkeley: University of California Berkeley, 1998.

\section{B.C. Archives, Victoria}

Horticultural Branch Records, 1975. GR 1461.

Publications of the Horticultural Branch, 1920-1963. GR1189.

British Columbia Department of Land and Works. GR 0567.

Fonds PR-1993 - Reynoldson Research and Studies Oral History Collection Maya Koizumi. Takeo Arakawa Interview [sound recording] 1972-0421.

\section{Bracero History Archive, Smithsonian Institution}

Galaviz, Sal. "The Promised land," [Oral Interview]

Martinez, Juan D. "Bracero Memorial highway," [Oral Interview] Perez, Mario. "The Lemons are Freezing!” [Oral Interview]

Plutarco Chávez-Ruiz, “Bracero in Field.” [Digital Image] Item 3019

"An official examines a bracero's hands for calluses during processing at the

Monterrey Processing Center, Mexico.” [Digital Image] NAD-200401381138

"Braceros pick lettuce and fill it into Toro lettuce boxes in a field in the Salinas

Valley, California.” [Digital Image] NAD-200401385507

"Braceros cross the Mexico-U.S. border while walking over the bridge from

Reynosa, Mexico to Hidalgo, Texas.” [Digital Image] NAD-200401380230.

"Portrait of a bracero standing in a Californian field." [Digital Image]

NAD-2004.01038.56.15

"Braceros pick strawberries and fill them into boxes in a field in the Salinas

Valley, California.” [Digital Image] NAD-2004.0138.52.07

"Braceros sit in beds in a living quarter of a Californian camp." [Digital Image] NAD 2004.0138.41.21 
"Braceros pick onions in a field in the Salinas Valley, California." [Digital Image]

NAD- 2004.0138.31.15

"Two braceros lean each on a living quarter in a bracero camp in Gonzalez, California."

[Digital Image] NAD-2004.0138.31.29

"A bracero lies on a stretcher and receives medical treatment while the doctor

examines another bracero in his clinical practice in the Salinas Valley,

California." [Digital

Image] NAD-2004.0138.25.12

\section{City of Vancouver Archives}

Central Fraser Valley Regional District Planning Dept.; E.L. Lee, Regional Planner Regional Farmland Study; Central Fraser Valley Regional District.” Abbotsford, B.C., September 1972. HD 316 V2 1972.

\section{Institute of Oral History, University of Texas at EI Paso, Digital Commons}

“Plutarco Chávez-Ruiz.” Interviewed by Mireya Loza, July 20, 2007. Interview no. 1281. http://digitalcommons.utep.edu/interviews/1281/, Accessed 1 Dec. 2015.

\section{Kelowna Public Archives}

Battye, Clement. Reminiscences of a Nonagenerian Throughout the $20^{\text {th }}$ Century.

Doug Findlater Fonds. "Okanagan Fruit

Pickers.” Fruit Industry - Packing and Storage.

Fruit Industry - Fruit and Vegetable Workers' Union.

Fruit Industry - Cherries: Information Sheet. Province of British Columbia Ministry of Agriculture and Fisheries.

Lanther, Mario. "A History of Social Discrimination Against Farmworkers in the Okanagan-Similkameen, 1890-1983.” Kelowna, August 1984.

\section{Library and Archives Canada (LAC)}

Government of Canada. "Canada-Mexico MOU on Cooperative Labour Activities.” [Nov. 15, 1992] RG25-A-4. Department of External Affairs 
Records.

“Mexican Seasonal Workers.” [1974] Records of the Immigration Branch.

"Submission to be presented by Federation Delegation to the Canadian Labour Congress, March 31 $1^{\text {st }}$, 1958." Local Unions No. 1 to 12, British Columbia Submission to BC Department of Labour, Board of Industrial Unions, Re: Hours of Work and Minimum Wages [1958] MG28-I103. File part of BC Federation of Fruit and Vegetable Workers' Unions, Secretary-Treasurer's Files, R5699-41-7-E. Canadian Congress of Labour Records.

Dominion Marketing Board. B.C. Interior. [1934-1935] R194-53-1-

E. Dominion Marketing Board Correspondence. R194-53-1-E.

\section{Online Archive of California}

“First Braceros,” photonegative, ca. 1942, Gift of Paul S. Taylor, A67.137.42042.7, Lange (Dorothea) Collection, 1919-1965. Oakland Museum of California.

Bassett, W.J., Correspondent, “'Letter, 1963, May 23, Los Angeles, California, to Honourable Augustus F. Hawkins," Courtesy of Dept. of Special Collections/UCLA Library, A1713, Charles E. Young Research Library.

Brown, Frank Q. "Mexican workers await legal employment in the United States, Mexicali (Mexico)," photograph, February 3, 1954. Part of L.A. Times Photographic Archives, ca. 1918-1990, Library Special Collections, Charles E. Young Research Library, University of California Los Angeles.

\section{Salt Spring Island Archives}

“Salt Spring's Japanese Canadian Community," excerpt from Charles Kahn, Salt Spring: The Story of an Island (Harbour, 1998).

\section{Stanford University Cecil H. Green Library}

Coles, Robert. The Migrant Farmer: A Psychiatric Study. Atlanta: Southern Regional Council, 1965.

Durand, Jorge (introducción, compilación y notas). Braceros: Las Miradas Mexicana y Estadounidense: Antología (1945-1964). 1 ed. México: Senado de la 
República, LX Legislatura, 2007.

Fisher, Lloyd H. The Harvest Labor Market in California. Cambridge:

Harvard University Press, 1953.

\section{University of Florida Digital Collections, http://ufdc.ufl.edu}

“The West Indies (BWI) Temporary Alien Labor Program: 1943-1977.” A Study

Prepared for the Subcommittee on Immigration of the Committee on the Judiciary United States Senate. Washington: U.S. Government Printing Office, 1978.

\section{University of Texas Arlington Special Collections}

"Mexican Farm Workers Collection: A Guide," Historical Note to Mexican American Farm Workers Collection, [1969-87].

\section{University of Washington Special Collections}

“Two men cooking in a kitchen of migrant camp, 1944." Staff Photographer, Seattle Post-Intelligencer, 1944, [1986.5.2905.2]

\section{Vernon Museum and Archives}

"A young woman on a ladder picking apples from the top branches of a local apple tree.” Doug Kermode, Photographer. [c.1950]. GVMA 5998

\section{Walter P. Reuther Library, Wayne State University}

"Dolores Huerta, at podium, speaks during an unidentified meeting in Delano, California. Also pictured are Philip Vera Cruz (second from right) and Pete Velasco (far right), 1974.” [Image 186] Ben Garza Photographer. United Farm Worker Collection, Archives of Labor and Urban Affairs.

“United Farm Workers Officials.” June 10, 1976. [Image 252] Photographer Cathy Murphy. United Farm Worker Collection, Archives of Labor and Urban Affairs.

“(219) Fasts, Cesar Chávez, Procession, Pheonix, Arizona, 1972.” [Image 219] 
Filed in The Labour Movement and Organizations, United Farm Workers.

\section{Washington State University Manuscripts, Archives, and Special Collections}

“Adult and Children Workers," 1968, Irwin Nash Photographs of Yakima Valley Migrant Labor, 1967-1976. [pc089b5f198r3c2].

Catherine May Congressional Staff, "Form letter to House members regarding the Bracero Program, ca. 1963.” Washington State University Digital Collections, Catherine May Congressional Papers, 1959-1970.

\section{Published Government Documents, Reports and Pamphlets}

Citizenship and Immigration Canada; Government of Canada. "Understand your Rights - Temporary Foreign Workers." http://www.cic.gc.ca/english/work/tfw-rights.asp, Accessed 1 July 2014.

Department of Agriculture, Province of Alberta. Annual Report of the Department of Agriculture of the Province of Alberta, 1914. Printed by the Order of the Legislative Assembly. Edmonton: J.W. Jeffery, Government Printer, 1915. Department of Agriculture, Province of Manitoba. 1975 Yearbook, Manitoba Agriculture. Manitoba Department of Agriculture, by Authority of Hon. Samuel Uskiw, Minister of Agriculture, Province of Manitoba.

Department of Agriculture, Province of Ontario. "Farm Labor Service." The Minister of Agriculture's report for the fiscal year ending March 31, 1966. Toronto: Legislative Assembly of Ontario Sessional No. 21; Frank Fogg, Printer to the Queen's Most Excellent Majesty, 1966.

Elgersma, Sandra. Temporary Foreign Workers. Library of Parliament Political and Social Affairs Division, Parliamentary Information and Research Service, 7 September 2007.

Ellis, J.H. The Ministry of Agriculture in Manitoba, 1870-1970. Winnipeg, MB: Manitoba Department of Agriculture, December 1970.

Government of Mexico, Chamber of Deputies / Cámara de Diputados. "Response to point resolution passed by the House of Representatives to Congress calls on the Executive to meet federal structurally comprehensive and human management of 
temporary employment programs abroad, inviting Secretaries Foreign Affairs and Labour and Social Welfare to respect particularly the right of association."

Parliamentary Gazette XV 3542, June 27, 2012.

Immigration New Zealand. "WH1.1 Objectives and Overview - RSE Instructions," and WH1.20 Requirements for employment agreements under RSE Instructions," http://www.immigration.govt.nz/opsmanual/, Accessed Sept. 9, 2011 .

Macdonald, K.M. Journals of the Legislative Assembly of Manitoba. Vol. CXVI. From the $31^{\text {st }}$ Day of January, 1974 to the $14^{\text {th }}$ Day of June, 1974. Printed by Order of the Legislative Assembly. Winnipeg: R.S. Evans, Queens Printer for the Province of Manitoba.

Manitoba Agriculture Employment Development Committee. “The Keys to Good Farm Labour Relations.” Employment and Immigration Canada, 1987. Manitoba Agriculture Food and Rural Initiatives. Annual Report 2008-2009. Winnipeg: Government of Manitoba, 2009. . Manitoba Agriculture Yearbooks, 2006; 2004; 2002; 1992; 1983 and 1982. Winnipeg: Manitoba Agriculture, Food and Rural Initiatives, 2006, 2004; 2002; 1992; 1983 and 1982.

Manitoba Labour Board, Government of Manitoba. "Case No. 595/06/LRA IN THE MATTER OF: The Labour Relations Act - and - IN THE MATTER OF: An Application by United Food and Commercial Workers Union, Local No. 832, Applicant, - and MAYFAIR FARMS (PORTAGE) LTD., Employer/Respondent.” Winnipeg, 26 June 2007.

Ministry of Agriculture, Province of Ontario. Annual Report for the Fiscal Year ending March 31, 1969 of the Minister of Agriculture and Food. Printed by the Order of the Legislative Assembly of Ontario.

Ontario Department of Agriculture Bureau of Industries. "Crop Bulletin 121.” Toronto: Ontario Department of Agriculture, November 2, 1914.

Province of British Columbia. "Ministry of Labour Annual Report 1983-84." Printed by Authority of the Legislative Assembly. Official Report of Debates of the Legislative Assembly. 
February 18,1975 -June $26,1975.5^{\text {th }}$ Session, $30^{\text {th }}$ Parliament.

Stinson, F.A. and H.F. Murwin. Flue-cured tobacco growing in Ontario. Ottawa:

Published by the authority of Hon. James Goldiner, Minister of Agriculture, 1941.

Tobacco Division, Central Experimental Farm, Ottawa, Dominion Experimental Farm,

Harrow, ON, and Dominion Experimental Substation, Delhi, ON. Flue-curing

Tobacco in Ontario. Experimental Farms Service Canada, Department of

Agriculture, 1958.

Wachtel, Eleanor; Human Rights Commission of British Columbia. What this Country

Did to Us, it Did to Itself: A Report of the B.C. Human Rights Commission on

Farmworkers \& Domestic Workers. Victoria: Human Rights Commission of

British Columbia, February 1983.

\section{Primary Resources}

Affected Workers of the Golden Eagle Group Farm, Pitt Meadows, British Columbia

"Letter of Concern from the Mexican Agricultural Workers of the Golden Eagle Group Farm, Pitt Meadows / Carta de preocupación de los trabajadores agrícolas mexicanos de la granja Golden Eagle Group, Pitt Meadows." Justicia 4 Migrant Workers.

Agricultural Workers Alliance Surrey. "Join the Community Trial.” Email Correspondence, May 18, 2012.

Chávez, César Estrada. Plan of Delano. California Department of Education César Chávez Research Site.

http://chavez.cde.ca.gov/ModelCurriculum/teachers/Lessons/resources/document s/plan_of_delano.pdf, Accessed Sept. 4, 2013.

Consulado General de México en Montreal. "Seasonal Agricultural Worker

Program." http://consulmex.sre.gob.mx/montreal/index.php/en/seasonalagricultural- workers-program, Accessed 30 January 2014.

Consulate General of Mexico in Toronto. "Agricultural Workers Program." http://www.consulmex.com/eng/agriculturalworkersprogram.asp, Accessed Sept. 1, 2013.

Diocese of London. "Migrant Workers," "Migrant Workers in London Diocese," 
(Migrant Workers Ministry), A Snapshot in Time: Report on the Migrant Workers Ministry. 2011. Available at: http://wp.dol.ca/webportal/uploads Snapshot_report_in_PDF_Current_Realities1.pdf

Dorff, Eric; Statistics Canada. "The Changing Face of the Canadian fruit and vegetable sector." Canadian Agriculture at a Glance Analytical Paper, Statistics Canada.

Fuentes, Carlos; Margaret Sayers Peden (trans. and selected), Burnt Water (Short Stories), Farrar, Straus and Giroux, 1980.

International Organization for Migration; Ministry of Foreign Affairs and Ministry of Labor and Social Provision, Guatemala. Working Notebooks on Migration (25): Second Evaluation - Temporary Agricultural Workers to Canada. Guatemala, C.A.: March, 2008.

Judgments of the Supreme Court of Canada, Lexum Collection. "Dunmore v. Ontario (Attorney General), [2001] 3 S.C.R. 1016, 2001 SCC 94." Market Analysis and Information Section, Horticulture and Cross Sectoral Division, Agriculture and Agri-Food Canada, Government of Canada. "A Snapshot of the Canadian Apple Industry, 2010." Her Majesty the Queen in Right of Canada, 2012.

Matthews, Brett (Attorney). "Victor Robles' Declaration." Courtesy of the Agricultural Workers' Alliance, Surrey, British Columbia.

Moodie, Susanna. Roughing it in the Bush; or, Life in Canada. Toronto: McClelland and Stewart, 1989.

National Association of Japanese Canadians, "Do You Need Farm Help?" (Advertisement), Farmers of the Red River Valley and Adjacent Municipalities, http://www.najc.ca/thenandnow/experience1c.php, August 1, 2014.

National Centre for Farmworker Health Inc. "National Centre for Farmworker Health Factsheet.” September 2012. www.ncfh.org, Accessed 25 June 2014.

Paz, Octavio (transl. Lysander Kemp, Yara Milos and Rachel Phillips Belash). El Laberinto de la Solidad / The Labyrinth of Solitude. New York: Grove Press, 1985.

Statistics Canada; Jake Purdy. “High-tech Vegetables: Canada's Booking 
Greenhouse Vegetable Industry." Statistics Canada: Vista on the Agri-Food Industry and the Farm Community, March 2005.

Treaty Relations Commission of Manitoba. "Treaties 1 and 2 between Her Majesty the Queen and the Chippewa and Cree Indians of Manitoba and Country Adjacent with Adhesions."

United Nations. "International Convention on the Protection of the Rights of All Migrant Workers and Members of Their Families," (A/RES/45/158), General Assembly United Nations Resolution, 69 ${ }^{\text {th }}$ Plenary Meeting, 18 December 1990.

United States Citizenship and Immigration Services. "H-2B Temporary Non-

Agricultural Workers.”www.uscic.gov, Accessed 23 June 2014.

United States Department of Labour. "The Migrant and Seasonal Agricultural

Worker Protection Act (MSPA).” Available at http://www.dol.gov

University of Otago. Pacific Research Protocols. Approved by the University

Council Nov. 2011.

Washington State Department of Agriculture. "Skagit Valley Bounty." Washington

State Tourism \& Washington State Department of Agriculture.

http://agr.wa.gov/Marketing/SmallFarm/docs/SkagitValley.pdf, Accessed 9 Nov., 2013.

\section{Film and Radio Resources}

Agricultural Workers Alliance. "International Scholars visited AWA centre in Virgil, ON," Video posted to AWA Facebook, July 2, 2014.

Bardacke, Frank. "United Farm Workers." [Interview] Against the Grain, KPFA Radio, December 6, 2011. Available on Against the Grain Program Archive. . "UFW’s Rank and File." [Interview] Against the Grain, KPFA

Radio, July 28, 2015.

Black, Stephanie (dir.). H-2 Worker. Valley Filmworks, 1990.

Brown, Kevin. "Vivian Price on the Bracero Program," History for the Future

(H.F.T.F.) [Radio Interview with Vivian Price]

Chang, Yung. Earth to Mouth. National Film Board of Canada, 2002.

Dunn, Joe [Interviewed by Melissa Block] "Remembering California's Deportation 
Program, January 2, 2006, National Public Radio (NPR/ United States)

Germano, Roy. "Immigrant America: They Steal our Jobs?" Vice Media, July 23, 2014.

Gonzales, Gilbert G. and Vivian Price. Harvest of Loneliness. New York: Films Media Group, Films for the Humanities and Social Sciences, 2010.

Isacsson, Magnus (dir.) The Emperor's New Clothes. National Film Board of Canada, 1995.

Lee, Min Sook (dir.). El Contrato (The Contract). National Film Board of Canada, 2003.

Méndez Esparza, Antonio (dir.) Here and There / Aquí y allá (110 mins.), Aquí y Allí Films, Torch Films, 2012.

Moore, Joe. “Author Interview: Seth Holmes Talks about Farmworkers' 'Broken Bodies.' "Valley Public Radio KVPR, Sept 3, 2013.

Murrow, Edward R. "Harvest of Shame.” CBS News, 1960.

Novak, Thomas. "Mud and Water." CKUW 95.95 FM Radio Broadcast, June 27, 2013.

Pawell, Miriam. "The Crusades of César Chávez.” New Books in History, May 29, 2015.

Pearcy, Glen, with Luis Valdez and Peter Matthiessen. Fighting for Our Lives [documentary]. National Farmworkers Services Centre, Inc. 1975.

Virma, Veena. "Remembering and Responsibility." LegalEase C.K.U.T. 90.3 Montreal, Radio Cast Episode 27, Nov. 2011.

\section{Academic Presentations and Talks}

Flores Ulysses, Monique. “' Despedida de un norteño': American Empire and the Corridos of Mexican Migration, 1917-1932," Paper presented at Graduate History Symposium, University of Toronto, May 7-8, 2015. In Attendance.

Hahn, Elise. "You Wanna Go Home? Subjection and Surveillance in Canada's Seasonal Agricultural Worker Program." Paper presented at Canadian Association of Latin American and Caribbean Studies (CALACS), Laval University, May 1618, 2014. In Attendance. 
Hann, Charity-Ann, Harald Bauder and John Shields. "Towards a Living Wage For All: Illegalized Migrant Workers in Canada and the Role of NGOs in Advocating for their Protection." Paper presented at Alternate Routes Conference, Ryerson, March 27, 2015. In Attendance.

Martin del Campo, Francisco. "Environment, Leadership and Union Building in California Agriculture during the Strike Wave of 1933." American Society for Environmental History, Seattle, WA, March 30, 2016. In Attendance.

Matsumoto, David Mas. "Mas Matsumoto Keynote," $10^{\text {th }}$ Annual OSU Oregon State University Small Farms Program, https://vimeo.com/73247928 Accessed 12 December 2015.

\section{Migrant Justice, NGO and Labour Resources}

Agricultural Workers Alliance. "Blog," "AWA Team Blog," "History of Agricultural Workers in Canada." And "Agricultural Workers' Alliance Year of Action." http://awa-ata-blog.blogspot.ca, Accessed October 12014.

American Federation of Labour-Congress of Industrial Organizations (AFL-CIO). Mike Hall, “AFL-CIO Backs Baja Farm Workers' Rights,” AFL-CIO, April 1, 2015. http://www.aflcio.org/Blog/Global-Action/AFL-CIO-Backs-BajaFarm-Workers-Rights Accessed 1 December 2015.

Amnesty International, 2003. "Mexico: Intolerable Killings - Ten Years of Abductions and Murders of Women in Ciudad Juárez and Chihuahua." AMR 41/026/2003. 11 August.

AWA-ATA E-News. "Migrant Workers Protest at Canada's Embassy in Guatemala." Virgilio Ayala (contact). E-News Vol. 3 Issue 23; "Migrant Workers March to Canada's Embassy in Mexico City," E-News Vol. 3 Issue 17; "Sidhu

Certification Stands.” Vol. 3 Issue 13, Agricultural Workers Alliance, 2010, and "Migrant Workers left unpaid at Ontario, Canada farm."

Canadian Auto Workers. "CAW Champions Human Rights Case of Temporary Foreign Workers,” February 21, 2012, http://www.caw.ca/en/10969.htm, Accessed 1 July 2014.

Canadian Centre for Policy Alternatives (C.C.P.A.) B.C. Office. "Farmworkers 
Relegated to Second Class Status: Study." Ottawa: Canadian Centre for Policy Alternatives, 2008.

Canadian Labour Congress, Karl Flecker. “Canada’s Temporary Foreign

Worker Program (TFWP): Model Program or Mistake?” Ottawa:

Canadian Labour Congress, 2011.

, Teresa Healy. "Deep integration in North America:

Security and Prosperity for Whom?” Ottawa: Canadian Labour Congress, 2007. , Hadrian Mertins-Kirkwood, "Labour Mobility in Canada:

Issues and Policy Recommendations." Ottawa: Canadian Labour Congress, 2014.

Hughes, Christine. "Those Left Behind: Impacts of Migration on Guatemalan

Women.” FOCALPoint Publications Archive June 2011.

International Trade Union Confederation; Anti-Slavery International. International

Trade Union Confederation Guide. Brussels: ITUC; London: Anti-Slavery International, February 2011.

Justicia 4 Migrant Workers. "BC Government Violating Canada Health Act" March 22, 2006. http://www.justicia4migrantworkers.org/bc/pdf/bcviolating.pdf Accessed 5 December 2015.

Manitoba Federation of Labour. "Mexican Migrant Workers Say Union Yes;"

"Manitoba Extends Health Coverage to Migrant Farm Workers." May 15, 2013.

Migrant Worker Solidarity Network (Winnipeg). "Meeting Minutes." and "Concerns of the M.W.S.N.," circulated at April 26, 2012 meeting. In Attendance.

Niagara Migrant Workers Interest Group [Blog]. “AWA - Virgil Office Open

House" Available at http://nmwig.blogspot.ca

No One is Illegal. "Honour Migrant Workers." (Poster) . "No More Deaths: Justice and Status for Migrant Workers!"

February 17, 2012, http://toronto.nooneisillegal.org/mode/661 ; Tyler Shipley. "Peruvian migrant workers lives on in

Canada's conscience," No one is illegal Vancouver, February 10, 2012.

North-South Institute; Maxwell Brem. Migrant Workers in Canada: A Review of the 
Canadian Seasonal Agricultural Program: Policy Brief. Lois Ross, ed.

Ottawa: The North-South Institute, 2006. ; Andrew Downes and Cyrilene Odle-Worrell. "Canadian

Migrant Agricultural Workers' Program Research Project: The Caribbean Component." Ottawa: North-South Institute, 2002. ; Heather Gibb. "Farmworkers from Afar: Results from an International Study of Seasonal Farmworkers from Mexico and the Caribbean Working on Ontario farms.” Ottawa: North-South Institute, 2006. ; David Griffith. "The Canadian and United States Migrant Agricultural

Workers Programs: Parallels and Divergence between two North American Seasonal Migrant Agricultural Labour Markets with Respect to 'Best Practices."” Ottawa: North-South Institute, 2002.

Paz, Adriana (Justicia 4 Migrant Workers). "Harvest of Injustice: The Oppression of Migrant Workers on Canadian Farms.” Socialist Voice, June 22, 2008. http://www.socialistvoice.ca/?p=301, Accessed Dec. 5, 2015.

Rural Migration News; Philip Martin, ed. Rural Migration News 21. 2 April 2015.

UFCW/A.WA. "The Great Canadian Rip-Off! An Economic Case for Restoring Full EI Special Benefits Access to SAWP Workers." March 2014 Research Report. http://ufcw.ca/templates/ufcwcanada/images/directions14/march/1420/TheGreat- Canadian-Rip-Off-An-Economic-Case-for-Restoring-Full-EI-SpecialBenefits- Access-to-SAWP-Workers.pdf, Accessed 1 December 2015. UFCW Canada. "UFCW Canada Local 501 Campaign Gains New Quebec Agriculture Unit.” Montreal, October 2, 2013. . "The Status of Migrant Farm Workers in Canada, 2010-2011." Executive Summary.

\section{Local History Exhibitions and Online Archives}

BC Orchard Industry Museum Exhibition, Kelowna, British Columbia, August 2012. "Pamphlet and Panorama Illustration of the City of Kelowna, c. 1920s," and "B.C. Apologizes for Internments." 
BC Wine Museum, Kelowna, British Columbia, August 2012.

Elgin County Archives. "The Workers." Tobacco in Elgin County.

http:/www.elgin.ca/ElginCounty/CulturalServices/Archives/tobacco/workers.ht m 1, Accessed December 15, 2015.

Kelowna Heritage Museum, Kelowna, British Columbia, August 2012.

Town of Oliver Heritage Display, Oliver Archives, August 2012.

\section{Secondary Works}

Acuña, Rodolfo F. Corridors of Migration: The Odysseys of Mexican Labourers, 1600- 1933. Tucson: University of Arizona Press, 2007.

Aguiar, Luis, Patricia Tomic and Ricardo Trumper. Mexican Migrant Agricultural Workers and Accommodations on Farms in the Okanagan Valley, British Columbia. Vancouver, B.C.: Metropolis British Columbia, 2011. , Ann Marie McKinnon and Dixon Sookraj. "Racialization and the Repertoires of Racism: Reaction to Jamaicans in the Okanagan Valley." BC Studies 168 (Winter 2010/2011): 65-79, 115-116.

Agustín, Laura. "Migrant Farm Workers in Italy: Any Identity But Victims?” The Naked Anthropologist. http://www.lauraagustin.com/migrant-farm-workers-in-i italy-is- evacuation-rescue-or-eventual-deportation. Accessed June 1, 2015.

Alamillo, José M. Making Lemonade out of Lemons: Mexican American Labour and Leisure in a California Town, 1880-1960. University of Illinois Press: Urbana, 2006.

Anna, Timothy. Forging Mexico, 1821-1835. Lincoln: University of Nebraska Press, 1998.

Anzaldúa, Gloria. Borderlands/La Frontera. San Francisco: Aunt Lute Books, 1999.

Arcury, Thomas A. and Sara Quandt, eds. Latino Farmworkers in the Eastern United

States: Health, Safety and Justice. New York; London: Spring, 2009.

Arredondo, Gabriela F. Mexican Chicago: Race, Identity, and Nation, 1916-1939.

Champaign: University of Illinois Press, 2008.

Arrom, Silvia Marina. "Mexican Women: Historical Perspectives" in ReVista / Harvard 
Review of Latin America (Winter 1998). and Servando Ortoll, ed. Riots in the Cities: Popular Politics and the Urban Poor in the Latin America, 1765-1910. Wilmington: Scholarly Resources, 1996. The Women of Mexico City, 1790-1857. Stanford: Stanford University Press, 1985.

Aspler, Tony. The Wine Atlas of Canada. Singapore: Angel Edition for Random House Canada, 2006.

Avery, Donald. “Dangerous Foreigners”: European Immigrant Workers and Labour Radicalism in Canada, 1896-1932. Toronto: McClelland and Stewart, 1979. . Reluctant Host: Canada's Response to Immigrant Workers, 1896-1994. Toronto: McClelland and Stewart, 1995.

Axel, Brian Keith. The Nation's Tortured Body: Violence, Representation and the Formation of a Sikh “Diaspora.” Durham: Duke University Press, 2001. Babb, Sarah. Managing Mexico: Economists from Nationalist to Neoliberalism. Princeton and Oxford: Princeton University Press, 2001.

Bacon, David. Communities without Borders: Images and Voices from the World of Migration. Ithaca: ILR Press, 2006.

Bagelman, Jennifer. Sanctuary City: A Suspended State. Basingstoke et al.: Palgrave Macmillan, 2016.

. "Sanctuary: A Politics of Ease?" Alternatives: Global, Local, Political 38.1 (2013): 49-62.

Bajaras, Frank P. Mexican American Workers and Resistance in Oxnard, California, 1898-1961. Lincoln: University of Nebraska Press, 2012.

Bakan, Abigail and Daiva Stasiulis, eds. Not One of the Family: Foreign Domestic Workers in Canada. Toronto: University of Toronto Press, 1997.

Balderstron, Daniel and Donna J. Guy. Sex and Sexuality in Latin America. New York: New York University Press, 1997.

Ballantyne, Tony. "Strategic Intimacies: Knowledge and Colonization in Southern New Zealand."Journal of New Zealand Studies, NS14 (2013), 4-18. ."Thinking Local: Knowledge, Sociability and Community in Gore's 
Intellectual Life, 1875-1914.” New Zealand Journal of History, 44.2 (2010), 138. , ed. Textures of the Sikh Past: New Historical Perspectives. Oxford: Oxford University Press, 2008. Bodies in Contact: Rethinking Colonial Encounters in World History. Durham: Duke University Press, 2005. . Orientalism and Race: Aryanism in the British Empire. Basingstoke: Palgrave UK, 2002.

Bardacke, Frank. Trampling out the Vintage: César Chávez and the Two Souls of the United Farm Workers. London: Verso, 2011.

Barman, Jean. “Seeing British Columbia,” BC Studies No. 131 (Autumn 2011), 9-14. . The West beyond the West: A History of British Columbia. Toronto: University of Toronto Press, 1991.

Barr, Elinor. Swedes in Canada: Invisible Immigrants. Toronto: University of Toronto Press, 2015.

Bartra, Roger and Gerardo Otero. "Agrarian Crisis and Social Differentiation in Mexico." Journal of Peasant Studies 14.3 (1987): 334-362.

Barndt, Deborah. Tangled Routes: Women on the Tomato Trail. Boulder, CO: Rowman \& Littlefield, 2001. , ed. Women Working the NAFTA Food Chain: Women, Food and Globalization. Toronto: Sumach Press, 1999.

Basok, Tanya and Emily Carasco. "Advancing the Rights of Non-Citizens in Canada: A Human Rights Approach to Migrant Rights." Human Rights Quarterly 32.2 (2010): 342-366. . "Post-national Citizenship, Social Exclusion and Migrants Rights." Citizenship Studies, 8.1 (March 2004): 47-64. . "Human Rights and Citizenship: The Case of Mexican Migrants in Canada." UC San Diego; the Center for Comparative Immigration 
Studies, Working Paper 72 April 2003. Tortillas and Tomatoes: Transmigrant Mexican Harvesters in Canada.

Montreal: McGill-Queen's University Press, 2002.

"Free to Be Unfree: Mexican Guest Workers in Canada," Labour,

Capital and Society, 32.2 (1999): 192-221.

Basran, Gurcharn S. and B. Singh Bolaria. The Sikhs in Canada: Migration, Race, Class, and Gender. New Delhi: Oxford University Press, 2003.

Bauder, Harald. Immigration and Settlement: Challenges, Experiences, and Opportunities. Toronto: Canadian Scholars Press, 2012.

. "Foreign Farm Workers in Ontario (Canada): Exclusionary Discourse in the Newsprint Media." Journal of Peasant Studies 35.1 (2008): 100-118. - "Landscape and Scale in Media Representations: The Construction of Offshore Farm Labour in Ontario, Canada." Cultural Geographies 12.1 (2005), 41-58. and Margot Corbin. "Foreign Farmworkers in Ontario; Representations in the Newsprint Media." Immigrant Labour Project, University of Guelph, 2002.

Beasley, Edward. Mid-Victorian Imperialists: British Gentlemen and the Empire of the Mind. New York: Routledge, 2005.

Beezley, William H. and Michael C. Meyer, eds. The Oxford History of Mexico. Oxford; New York: Oxford University Press, 2010.

Bellasco, Warren and Philip Scranton, eds. Food Nations: Selling Taste in Consumer Societies. London: Routledge, 2002.

Bennett, Herman L. Africans in Colonial Mexico: Absolutism, Christianity and Afro- Creole Consciousness, 1750-1640. Bloomington: Indiana University Press, 2003.

Berger, Carl, ed. Contemporary Approaches to Canadian History. Toronto: Copp Clark Pitman, 1987.

Bhabha, Homi K. The Location of Culture. New York: Routledge, 1994.

Binford, Leigh. Tommorow We're All Going to the Harvest: Temporary Foreign Worker Programs and Neoliberal Political Economy. Austin: University of Texas, 2013. 
. "From Fields of Power to Fields of Sweat: the Dual Process of Constructing Temporary Migrant Labour in Mexico and Canada." Third World Quarterly, 30.3 (2009): 503-517.

Blackhawk, Ned. Violence over the Land: Indians and Empires in the Early American West. Cambridge, MA: Harvard University Press, 2006.

Broomhall, Susan, ed. Emotions in the Household, 1200-1900. London: Palgrave Macmillan, 2008.

Brown, Jennifer S. H. Strangers in Blood: Fur Trade Families in Indian Country. Vancouver: University of British Columbia Press, 1980.

Boyer, Christopher R. Becoming Campesinos: Politics, Identity, and Agrarian Struggle in Post-revolutionary Michoacán, 1920-1935. Stanford, CA: Stanford University Press, 2003.

Burns, Kathryn. Into the Archive: Writing and Power in Colonial Peru. Durham and London: Duke University Press, 2010.

Cadava, Geraldo L. Standing on Common Ground: The Making of a Sunbelt Borderland. Cambridge, MA: Harvard University Press, 2015.

Calavita, Kitty. Inside the State: the Bracero Program, Immigration and the I.N.S. New York: Routledge, 1992.

Calderón, Héctor. Narratives of Greater Mexico: Essays on Chicano Literary History, Genre and Borders. Austin: University of Texas Press, 2004.

Camacho, Alicia Schmidt. Migrant Imaginaries: Latino Cultural Politics in the U.S.Mexico Borderlands. New York and London: New York University Press, 2008.

Camfield, David. Canadian Labour in Crisis: Reinventing the Workers Movement. Blackpoint, NS: Fernwood, 2011.

Canclini, Nestor Garcia. Imagined Globalization. Durham: Duke University Press, 2014.

Candiani, Vera. Dreaming of Dry Land: Environmental Transformation in Colonial Mexico City. Stanford: Stanford University Press, 2014.

Cannadine, David. Ornamentalism: How the British Saw their Empire. Oxford: Oxford University Press, 2001. 
Cañeque, Alejandro. "The Political and Institutional History of Colonial Spanish America," History Compass 11.4 (2013): 280-291.

Cantú Jr., Lionel. The Sexuality of Migration: Border Crossings and Mexican Immigrant Men. Edited by Nancy A. Naples and Salvador Vidal-Ortiz. New York and London: New York University Press, 2009. and Eithne Lubhéid, eds. Queer Migrations: Sexuality, U.S.

Citizenship, and Border Crossings. Minneapolis: University of Minnesota Press, 2005

Carens, Joseph. The Ethics of Immigration. New York: Oxford University Press, 2013. . "Live-In Domestics, Seasonal Workers, and Others Hard to Locate on the Map of Democracy," Journal of Political Philosophy 16 (4) (2008): 419445 .

Carter, Sarah. Lost Harvests: Prairie Indian Reserve Farmers and Government Policy. Montreal and Kingston: McGill-Queen’s University Press, 1990.

Castañeda, Xóchitl, Beatriz Manz and Allison Davenport. "Mexicanization: A Survival Strategy for Guatemalans in the San Francisco Bay Area." Migraciones Internationales 1 (3) (July-December 2002): 102-123. . "Changing Constructions of Sexuality and Risk: Migrant Mexican Women Farmworkers in California." The Journal of Latin American Anthropology 8(2) (2003):126-151.

Cavalluzzo, Paul and Adrienne Telford. "Freedom of Association, the Right to Bargain Collectively and the Right to Organize.” Ottawa: Canadian Foundation for Labour Rights, March 2013.

Cecil, R.G. and Ebanks, G.E., "The Caribbean Migrant Farm Worker Programme in Ontario: Seasonal Expansion of West Indian Economic Spaces,” International Migration Review 30 (1): 19-36.

Chakrabarty, Dipesh. Provincializing Europe: Postcolonial Thought and Historical Difference. Princeton: Princeton University Press, 2000.

Chambers, Sarah. "The Paternal Obligation to Provide: Political Familialism in EarlyNineteenth Century Castile." American Historical Review 117.4 (October 2012): 1123-1148. 
Cherrington, John. The Fraser Valley: A History. Madeira Park, B.C.: Harbour Publishing, 1992.

Choko, Maude. "The Dialogue between Canada and the ILO on Freedom of Association: What Remains after Fraser." The International Journal of Comparative Labour Law and Industrial Relations 28.4 (2012): 398399.

Cholewinski, Ryszard. Migrant Workers in International Human Rights Law.

Oxford: Clarendon Press; New York: Oxford University Press, 1997.

Cleall, Esme, Laura Ishiguro and Emily Mantelkau, "Imperial Relations: Histories of Family in the British Empire.” Journal of Colonialism and Colonial History 14.1 (Spring 2013): n.a.

Clendinnen, Inga. Aztecs. Cambridge: Cambridge University Press, 1991. . Ambivalent Conquests: Maya and Spaniard in Yucatan, 1517-1570. Cambridge: Cambridge University Press, 2003.

Cockcroft, James D. Mexico's Revolution, Then and Now. New York: Monthly Review Press, 2010. . Mexico's Hope: An Encounter with Politics and History. New York: Monthly Review Press, 1998.

Cohen, Deborah. Braceros: Migrant Citizens and Transnational Subjects in the Postwar United States and Mexico. Chapel Hill: University of North Carolina Press, 2011.

"From Peasant to Worker: Migration, Masculinity, and the Making of Mexican Workers in the US.” International Labor and Working-Class History 69 (2006): 81-103.

Cohen, Jeffrey H. The Culture of Migration in Southern Mexico. Austin: University of Texas Press, 2004.

Colburn, Forrest D. Latin America at the End of Politics. Princeton: Princeton University Press, 2002.

Constant, Jean-Francois and Michel Ducharme, eds. Liberalism and Hegemony: Debating the Canadian Liberal Revolution. Toronto: University of Toronto Press, 2009. 
Cronon, William. Changes in the Land: Indians, Colonists and the Ecology of New England. New York: Hill and Wang, 2003.

Cumine, Adam. "From Sagebrush to Fruit Trees." $47^{\text {th }}$ Report of the Okanagan Historical Society, 1983, pp.131-136.

Curtis, James C. "Dorothea Lange, Migrant Mother, and the Culture of the Great Depression," Winterthur Portfolio 21.1 (Spring 1986): 1-20.

J. Cwiertka, Katarzyna, Megan J. Elias and Jeffrey Pilcher. "Editorial Introduction: Writing Global Food History," in Global Food History, 1.1 (2015): 5-12.

Davies, Hugh et al., "Cytogenetic analysis of South Asian berry pickers in British Columbia using the micronucleus assay in peripheral lymphocytes," Mutation Research 416 (1998): 101-113.

Davis, Mike. Planet of Slums. London: Verso, 2006.

De la Fuente, Alejandro. Havana and the Atlantic in the Sixteenth Century. Chapel Hill: University of North Carolina Press, 2011.

De la Mora, Sergio. Cinemachismo: Masculinities and Sexuality in Mexican Film. Austin: University of Texas Press, 2006.

De la Torre, Adela and Beatriz M. Pesquera. Building with our Hands: New Directions in Chicana Studies. Berkeley; Los Angeles, University of California Press, 1993.

Depatie-Pelletier, Eugenie and Khan Rahi, eds. Mistreatment of Temporary Foreign Workers in Canada: Overcoming Regulatory Barriers and Realities on the Ground. Montréal: Centre Métropolis du Québec Immigration et Métropoles, Dec. 2011.

Deveson, Morris. "The History of Agriculture in Manitoba (1812-2007)." Manitoba Agricultural Hall of Fame.

Devoretz, Don. "An Auction Model of Canadian Temporary Immigration for the $21^{\text {st }}$ Century," International Migration 46.1 (2008): 1-17.

Díaz, George. Border Contraband: A History of Smuggling Across the Rio Grande. Austin: University of Texas Press, 2015. 
Dick, Lyle. "The Seven Oaks Incident and the Construction of a Historical Tradition, 1816 to 1970," Journal of the CHA Revue de la Societe Historique du Canada, New Series No. 2 (1991): 91-113.

Dillingham, Alan Shane. “Indigenismo Occupied: Indigenous Youth and Mexico’s

Democratic Opening," The Americas: A Quarterly Review of Latin American History 72.4 (October 2015): 549-582.

Dim, Jordana and Karl Offer, eds. Mapping Latin America: A Cartographic Reader. Chicago: University Chicago Press, 2011.

Donaldson, Mike, et. al., eds, Migrant Men: Critical Studies of Masculinity and the Migration Experience. New York: Routledge, 2009.

Donovan, Kenneth. "Slaves and their Owners in Ile Royale, 1713-1760.” Acadiensis XXV, 1 (Autumn 1995): 3-32.

Drache, Daniel, ed. Big Picture Realities: Canada and Mexico at the Crossroads. Waterloo: Wilfrid Laurier Press, 2008.

Drinot, Paulo and Alan Knight, eds. The Great Depression in Latin America. Durham: Duke University Press, 2014.

Driscoll, Barbara A. The Tracks North: The Railroad Bracero Program of World War II. Austin: University of Texas Press, 1999.

Duany, Jorge. “A Transnational Colonial Migration: Puerto Rico’s Farm Labor Program," New West Indian Guide 84.3-4 (2010): 225-251.

Echevarría, Roberto Gonzáles. Cuban Fiestas. New Haven and London: Yale University Press, 2010.

Einaudi, Luca. "Legal and Irregular Migration for Employment in Italy and France," Kristof Tamas and Joakim Palme, eds., Globalizing Migration regions: New Challenges to Transnational Cooperation. Aldershot: Ashgate, 2006.

Elliot, Bruce. Irish Migrants in the Canadas: A New Approach. Montreal and Kingston: McGill-Queens University Press, 2004.

Epp, Marlene, Franca Iacovetta and Frances Swyripa, eds. Sisters or Strangers? Immigrant, Ethnic and Racialized Women in Canadian History. Toronto: University of Toronto Press, 2004. 
Erenburg, Mark. "Obreros Unidos in Wisconsin.” Monthly Labor Review (1968): 17-23. Estabrook, Barry. Tomatoland: How Modern Industrial Agriculture Destroyed Our Most Alluring Fruit. Kansas City: Andrews McMeel, 2011.

Estévez, Ariadna. Human Rights and Free Trade in Mexico: A Discursive and SocioPolitical Perspective. New York: Palgrave Macmillan, 2008.

Evans, Jennifer. "Queer Beauty: Image and Acceptance in the Public Sphere," Chapter Five in Globalizing Beauty: Consumerism and Body Aesthetics in the Twentieth Century, Edited by Thomas Kühne and Hartmut Berghoff. Basingstoke: Palgrave Macmillan, 2013.

Eyford, Ryan. White Settler Reserve: New Iceland and the Colonization of the Canadian West. Vancouver: UBC Press, 2016.

Fairey, David et al. Cultivating Farmworkers' Rights: Ending the Exploitation of Immigrant and Migrant Farmworkers in B.C. Vancouver: CCPA BC Office; J4MW; Progressive Intercultural Community Services; BC Federation of Labour, June 2008.

Farquhar, Stephanie et al. "Promoting the Occupational Health of Indigenous Farmworkers," Journal of Immigrant and Minority Health 10 (2008): 269-280.

Ferguson, Ted. A White Man's Country: An Exercise in Canadian Prejudice. Garden City, NY: Doubleday, 1975.

Fernández, Lilia. "Of Immigrants and Migrants: Mexican and Puerto Rican Labor Migration in Comparative Perspective, 1942-1964." Journal of American Ethnic History 29.1 (Spring 2010): 6-39.

Fernandez, Lynne. "Steeling the NDP's Resolve: Migrant farmworkers need access to public healthcare." Winnipeg: CCPA Manitoba Office, May 2010.

Fernández Armesto, Felipe. The Americas: A Hemispheric History. New York: RandomHouse, 2003.

Elizabeth Fitting, The Struggle for Maize: Campesinos, Workers Campesinos, Workers and Transgenic Corn in the Mexican Countryside. Durham and London: Duke University Press, 2010.

Fitzgerald, David Scott, and David Cook-Martín. Culling the Masses: The Democratic Origins of Racism Immigration Policy in the Americas. Cambridge, Mass.: 
Harvard University Press, 2014.

. A Nation of Emigrants: How Mexico Manages its Migration.

Berkeley: University of California Press, 2009.

Flores, Lori A. Grounds for Dreaming: Mexican Americans, Mexican Immigrants and the California Farmworker Movement. New Haven: Yale University Press, 2016.

Foley, Neil. Mexicans in the Making of America. Cambridge: Harvard University Press, 2014. . The White Scourge: Mexicans Blacks and Poor Whites in Texan Cotton Culture. Berkeley and Los Angeles: University of California Press, 1997.

Frisch, Michael. A Shared Authority: Essays on the Craft and Meaning of Oral and Public History Albany: State University of New York Press, 1990.

Flores, Sara Maria Lara, Jorge Pantaleón, and Martha J. Sánchez Gómez, eds. Hacia Otro Norte: Mexicanos en Canadá. Buenos Aires: Consejo Latinoamericano de Ciencias Sociales, 2015.

Florescano, Enrique. National Narratives in Mexico: A History. Norman: University of Oklahoma Press, 2006.

Foster, Jason. "From 'Canadians First' to 'Workers Unite': Evolving Union Narratives of Migrant Workers." Relations industrielles / Industrial Relations 69.2 (Spring 2014): 241-265.

Fox, Jonathan and Gaspar Rivera-Salgado, eds. Indigenous Mexican Migrants in the United States. La Jolla: UC San Diego, Center for Comparative Immigration Studies, 2004.

and Xochitl Bada. "Migrant Organization and Hometown Impacts in Rural Mexico" in Transnational Agrarian Movements Confronting Globalization. Edited by Saturnino Borras Jr., Marc Edelman and Cristóbal Kay. Chichester, UK: Wiley-Blackwell, 2008.

Francis, Daniel. National Dreams: Myth, Memory and Canadian History. Vancouver: Arsenal Pulp Press, 2002.

French, William and Katherine Elaine Bliss. Gender, Sexuality and Power in Latin America Since Independence. Lanham: Rowman and Littlefield. 
Friedland, William and Dorothy Nelkin. Migrant Agricultural Workers in America's Northeast. New York: Holt, Rinehart and Winston, 1971.

Friesen, Gerald. The Canadian Prairies: A History. Toronto: University of Toronto Press, 1987.

Gabriel, Christina and Laura Macdonald. "Domestic Transnationalism: Legal Advocacy for Mexican Migrant Workers’ Rights in Canada” Citizenship Studies 18:3-4 (June 2014): 243-258. . "Citizenship at the Margins: The Canadian Seasonal Agricultural Worker Program and Civil Society Advocacy." Politics and Policy 39:1 (2011): 45-67.

Gamboa, Erasmo. Mexican Labor and World War II: Braceros in the Pacific Northwest, 1942-1947. Austin: University of Texas Press, 1990.

Galarza, Ernesto. Merchants of Labor: The Mexican Bracero Story. Charlotte, CA: McNally and Loftin, 1964. . Strangers in our Fields. Joint United States-Mexico Trade Union Committee, Washington, D.C., 1956.

Garcia-Colon, Ismael and Edwin Melendez, "Enduring Migration: Puerto Rican Workers on U.S. Farms," Journal of the Center for Puerto Rican Studies, 25.2 (Fall 2013): 96-119.

Geertz, Clifford and George Marcus, eds. Writing Culture: The Poetics and Politics of Ethnography. Berkeley: University of California Press, 1986.

Geiger, Martin and Antoine Pécoud, eds. Disciplining the Transnational Mobility of People. Basingstoke et. al.: Palgrave Macmillan, 2013. , eds. The Politics of International Migration Management. Basingstoke et. al: Palgrave Macmillan, 2010. . "International Organizations and the Politics of Migration." Journal of Ethnic and Migration Studies 40.6 (2014): 865887.

Gibbings, Julie. “' 'The Shadow of Slavery’: Historical Time, Labor and Citizenship in Nineteenth-Century Alta Verapaz." Hispanic American Historical Review 96.1 (February 2016): 73-107. 
Gibbs, Holly, Belinda Leach and Charlotte A.B. Yeats. Negotiating Risk, Seeking Security, Eroding Solidarity: Life and Work on the Border. Halifax and Winnipeg: Fernwood, 2012.

Goett, R. Bruce. An Historical Survey of Okanagan Apple Varieties. Kelowna, B.C.: Kelowna Centennial Museum Association, 1985.

Goff, Hon. Phil, Minister of Trade New Zealand. "Making globalisation work for the Pacific." Pacific Connection 13, September-November 2007.

Gonzales-Berry, Erlinda and Marcela Mendoza. Mexicanos in Oregon: Their Stories, Their Lives. Corvallis: Oregon State University Press, 2010. Gordon, Linda. Dorothea Lange: A Life Beyond Limits. New York: Norton, 2009. and Gary Okihiro, eds. Impounded: Dorothea Lange and the Censored Images of the Japanese Internment. New York: Norton, 2006.

Gray, Edward G. and Jane Kamensky. The Oxford Handbook of the American Revolution. New York: Oxford University Press, 2013.

Gray, Margaret. Labor and the Locavore: The Making of a Comphrehensive Food Ethic. Berkeley: University of California Press, 2013. . "How Latin American Inequality becomes Latino Inequality: A Case Study of Hudson Valley Farmworkers" in Paul Gootenburg and Luis Reygadas, eds. Indelible Inequalities in Latin America: Insights from History, Politics and Culture. Durham: Duke University Press, 2010. and Emma Kreyche, "The Hudson Valley Farmworkers'

Report: Understanding the Needs and Aspirations of a Voiceless Population," and "Executive Summary," Bard College Migrant Labor Project.

Griffith, David. American Guestworkers: Jamaicans and Mexicans in the U.S. Labor Market. University Park: Pennsylvania State University Press, 2006. and Edward Kissam, with Jeronomo Camposeco et al. Working Poor: Farmworkers in the United States. Philadelphia: Temple University Press, 1995. "Labour Migration and Changing Peasant Agriculture in Jamaica." 
in John Brierley and Hymie Rubsenstein, eds. Small Farming and

Peasant Resources in the Caribbean. Winnipeg: Dept. of Geography, University of Manitoba, 1988.

. "Peasants in Reserve: Temporary West Indian Labor in the U.S.

Labor Market." International Migration Review (Winter, 1987).

Guerin-Gonzales, Camille and Carl Strikwerda, eds. The Politics of Immigrant

Workers: Labor Activism and Migration in the World Economy since 1830.

New York: Holmes and Meier, 1998.

Mexican Workers and American Dreams: Immigration,

Repatriation and Farm Labor, 1900-1939. New Brunswick: Rutgers

University Press, 1994.

Guidotti-Hernandez, Nicole. "Bracero Lives and the Lack of Idleness in 'Free

Time." Lusophone Journal of Cultural Studies 1.2 (2013): 275-285

Gummell, Hermann; Osoyoos and District Museum and Archives. "The Zucca

Melon." Excerpted from $45^{\text {th }}$ Report of the Okanagan Historical Society, 1981, pp. 137-38.

Gutiérrez, David, ed. Walls and Mirrors: Mexican Americans, Mexican Immigrants, and the Politics of Ethnicity Berkeley and London: University of California Press, 1995.

. Between Two Worlds: Mexican Immigrants in the United States.

Wilmington, Del: Scholarly Resources, 1996.

Gutman, Mayra Roffe and Annie Lapalme. "Cheap Labour: Seasonal Agricultural

Workers in Quebec." FOCAL Archive, Nov. 2010.

http://www.focal.ca/publications/focalpoint/352-november-2010-mayra-

roffe- gutman-and-annie-lapalme-en, Accessed 1 October 2015.

Gutmann, Matthew C. The Meanings of Macho: Being a Man in Mexico City.

Berkeley: University of California Press, 2007. , ed. Changing Men and Masculinities in Latin America.

Durham: Duke University Press, 2003.

Hackel, Steven. Children of Coyote, Missionaries of Saint Francis: Indian-Spanish Relations in Colonial California, 1769-1850. Chapel Hill: University of 
North Carolina Press, 2005.

Hahamovitch, Cindy. No Man's Land: Jamaican Guestworkers in America and the Global History of Deportable Labor. Princeton: Princeton University Press, 2011.

. "Creating Perfect Immigrants: Guestworkers of the World in Historical Perspective.” Labor History 44.1 (2003): 69-94. . The Fruits of their Labor: Atlantic Coast Farmworkers and the Making of Migrant Poverty, 1870-1945. Chapel Hill: University of North Carolina Press, 1997.

Hämäläinen, Pekka. The Comanche Empire. New Haven and London: Yale University Press, 2008.

Hamilton, Nora. Mexico: Political, Social and Economic Evolution. New York: Oxford University Press, 2011.

Harris, R. Cole. Making Native Space: Colonialism, Resistance, and Reserves in British Columbia. Vancouver: UBC Press, 2002. . The Resettlement of British Columbia: Essays on Colonialism and Geographical Change. Vancouver: UBC Press, 1997.

Harwood, Gary (photographs) and David Hasler. Growing Season: The Life of a Migrant Community. Kent, Ohio: Kent State University Press, 2006.

Healy, Teresa; Canadian Labour Congress. Gendered Struggles against Globalization in Mexico. Aldershot, U.K.: Ashgate Publishing Ltd., 2008. and Stuart Trew, eds. The Harper Record: 2008-2015. Ottawa: Canadian Centre for Policy Alternatives, 2015.

Heilman, Jaymie Patricia. Before the Shining Path: Politics in Rural Ayacucho, 18951980. Stanford: Stanford University Press, 2010.

Hellman, Judith Adler. The World of Mexican Migrants: The Rock and the Hard Place. New York: The New Press, 2008. . Mexican Lives. New York: The New Press, 1994; 1999 (2nd ed.). . Mexico in Crisis. New York: Holmes and Meier, 1983 (2nd ed.).

Henry, Frances. "The West Indian Domestic Scheme in Canada." Social and Economic 
Studies 17.1 (1968): 83-91.

Hernández, José Angel."From Conquest to Colonization: Indios and Colonization

Policies after Mexican Independence.” Mexican Studies/Estudios Mexicanos, 26.2 (Summer 2010): 291-322.

Herrera Robles, Luis Alfonso. Memorias de Braceros: Olvido y Abandono en el Norte de México. 1 ed. Cuidad Juárez: Colegio de Chihuahua, 2012.

Herrera-Sobek, María. The Bracero Experience: Elitelore versus Folklore. Los Angeles: UCLA Latin American Center Publications, 1979.

Hirsch, Jennifer S. A Courtship after Marriage: Sexuality and Love in Mexican Transnational Families. Los Angeles: University of California Press, 2003. Historians’ Mailbox. "INS Records for 1930s Repatriations.” March 3, 2014, Department of Homeland Security, US Citizenship and Immigration Services. Hodes, Martha. The Sea Captain's Wife: A True Story of Love, Race and War in the Nineteenth Century. New York: W.W. Norton \& Co., 2006.

Hoffman, Abraham. "An Unusual Monument: Paul S. Taylor's Mexican Labor in the United States Monograph Series." Pacific Historical Review 45.2 (1976): 255-270. . Unwanted Mexican Americans in the Great Depression: Repatriation Pressures, 1929-1939. Tucson: University of Arizona Press, 1974. - "Stimulus to Repatriation: The 1931 Federal Deportation Drive and the Los Angeles Mexican Community," Pacific Historical Review 42.2 (May 1973): 205-219.

Hogue, Michel. Metis and the Medicine Line: Creating A Border and Dividing A People. Chapel Hill: University of North Carolina Press, 2015.

Holmes, Seth. Fresh Fruit, Broken Bodies: Migrant Farmworkers in the United States. Berkeley: University of California Press, 2013.

Holtzmann, Jon D. "Food and Memory” Annual Review of Anthropology 35.1 (2006): 361-378.

Hudgins, Bert. "Tobacco Growing in Southwestern Ontario.” Economic Geography 14.3 (July1938): 223-32. 
Iacovetta, Franca. Gatekeepers: Reshaping Immigrant Lives in Cold War Canada. Toronto: Between the Lines Press, 2006. . Such Hardworking People: Italian Immigrants in Postwar Toronto. Montreal and Kingston: McGill-Queens University Press, 1993. Jagpal, Sarjeet Singh (Foreward by Jean Barman). Becoming Canadians: Pioneer Sikhs in their Own Words. Madeira Park, Vancouver: Harbour Publishing, 1994.

Jameson, Elizabeth and Sheila McManus, eds. One Step Over the Line: Toward a History of Women in the North American Wests. Edmonton: University of Alberta Press, 2008.

Johnson, Benjamin and Andrew R. Graybill. Bridging National Borders in North America: Transnational and Comparative Histories. Durham: Duke University Press, 2010.

Johnston, Hugh J.M. Jewels of the Qila: The Remarkable Story of An IndoCanadian Family. Vancouver: UBC Press, 2011. ."The Sikhs of British Columbia: Their Philanthropy in Punjab." Pp169-183 in Verne A. Dusenbery and Darshar S. Tatla, eds. Sikh Diaspora Philanthropy in Punjab. New Delhi: Oxford University Press, 2009.

The Voyage of the Komagata Maru: The Sikh Challenge to Canada's Colour Bar. Vancouver: University of British Columbia Press, 1989.

Johnson, Sara. Nga Taonga Sound and Vision Blog. "An Apple A Day...” February 10, 2016. http://www.ngataonga.org.nz/blog/nz-history/an-apple-a-day/

Jonas, Susan (University of California, Santa Cruz). "Guatemalan Migration in Times of Civil War and Post-War Challenges," Migration Information Source / Migration Policy Institute, Washington, DC: March 2013.

Judt, Tony. Ill Fares the Land. New York: Penguin, 2010.

Jones, Robert Leslie. History of Agriculture in Ontario, 1613-1880. Toronto: University of Toronto Press, 1946. 
Katz, Elizabeth and Maria Correia, eds. The Economic of Gender in Mexico:

Work, Family, State and Market. Washington: World Bank, 2001.

Keller, Renata. Mexico's Cold War: Cuba, the United States, and the Legacy of the Mexican Revolution. Cambridge: Cambridge University Press, 2015.

Ketchell, Shelly Ikebuchi. "Carceral Ambivalence: Japanese Canadian 'Internment' and the Sugar Beet Programme during World War II," Surveillance \& Society 7.1 (2009): 21-35.

Kinnear, Mary. A Female Economy: Women's Work in a Prairie Province, 1870-1970. Montreal; Ithaca: McGill-Queens University Press, 1998.

Knight, Alan. "Mexican National Identity.” Pp.192-214 in Mexican Soundings: Essays in Honour of David A. Brading. Edited by Susan Deans-Smith and Eric Van Young. London: Institute for the Study of the Americas, 2007.

LaBrack, Bruce. "Occupational Specialization among Rural California Sikhs: the Interplay of Culture and Economics.” Amerasia 9:2 (1982): 29-56. . "First Sikhs Face Major Problems: The History of the Sikhs." Sikh Sansar, June 1974.

LaRosa, Michael J. and Germán R. Mejía, Colombia: A Concise Contemporary History.Lanham: Rowman and Littlefield, 2012.

Lavrín, Asunción. Brides of Christ: Conventual Life in Colonial Mexico. Stanford: Stanford University Press, 2008.

Leonard, Karen. Making Ethnic Choices: California's Punjabi Mexican Americans. Philadelphia: Temple University Press, 1994. . "Punjabi Farmers and California's Alien Land Law." Agricultural History, 59.4 (Oct. 1985): 549-562.

Llewellyn, Kristina, Alexander Freund and Nolan Reilly, eds. The Canadian Oral History Reader. Montreal and Kingston: McGill-Queens University Press, 2015.

Li, Peter S. “Constructing Immigrants’ Work Worlds from Oral Testimonies.” Pp.149155 in Work, Ethnicity and Oral History, Edited by Dorothy E. Moore and James H. Morrison. International Education Centre, 1988.

Lockhart, James. We People Here: Nahuatl Accounts of the Conquest of Mexico. 
Berkeley: University of California Press, 1994.

Loewen, Royden. Village among Nations: "Canadian” Mennonites in a

Transnational World, 1916-2006. Toronto: University of Toronto Press, 2013.

and Gerald Friesen, eds., Immigrants in Prairie Cities: Ethnic

Diversity in Twentieth-Century Canada Toronto: University of Toronto Press, 2009.

Lowe, Lisa. The Intimacies of Four Continents. Durham and London: Duke University Press, 2015.

Lowry, Michelle and Peter Nyers, eds. "Global Movements for Refugee and Migrant Rights." Special issue of Refuge: Canada's Periodical on Refugees 21:3 (May 2003).

Lundy, Alice. "Father Pandosy Mission Site Turns 150 Years Old in 2010.” Pp. 140-8 in $74^{\text {th }}$ edition of the Okanagan Historical Society. Richmond, B.C.:

Thunderbird Press, 2010.

Lytle-Hernández, Kelly. Migra! A History of the U.S. Border Patrol. Berkeley and Los Angeles: University of California Press, 2010.

MacLachlan, Colin and William Beezley, eds. El Gran Pueblo: A History of Greater

Mexico. Upper Saddle River, NJ: Pearson, 2004.

Macías-González, Victor M. and Anne Rubenstein, eds. Masculinity and Sexuality in Modern Mexico. Albuquerque: University of New Mexico Press, 2012.

Mallon, Florencia E. Peasant and Nation: The Making of Postcolonial Mexico and Peru. Berkeley and Los Angeles: University of California Press, 1995.

Martin, Philip. "Good Intensions gone awry: IRCA and U.S. Agriculture." The Annals of the Academy of Political and Social Science 534 (July 1994): 44-57. Harvest of confusion: Migrant Workers in U.S. Agriculture. Boulder: Westview Press, 1988. and J. Edward Taylor. Harvest of Confusion: $S A W s, R A W s$, and and Farmworkers. Washington, D.C.: Urban Institute, 1988. Martinez, Jenny S. The Slave Trade and the Origins of International Human Rights Law. New York: Oxford University Press, 2014. 
Martinez, Oscar J. "Border People: Life and Society in the U.S.-Mexico Borderlands," The Oral History Reader 24.1 (1997): 132-6. Troublesome Border. Tucson: University of Arizona Press, 1988.

Massey, Douglas S., Jorge Durand, and Nolan J. Malone. Beyond Smoke and Mirrors: Mexican Immigration in an Era of Economic Integration. New York: Russell Sage Foundation, 2002.

Matheson Henderson, Anne. "The Lord Selkirk Settlement at Red River, Part 1. Manitoba Pageant 13.1 (1967). Manitoba Historical Society.

Matsumoto, Valerie. Farming the Home Place: A Japanese American Community in California, 1919-1982. Ithaca, NY: Cornell University Press, 1993.

McAllister, Kirsten Emiko. Terrain of Memory: A Japanese Canadian Memorial Project. Vancouver and Toronto: UBC Press, 2010.

McClaren, Arlene Tigar, and Mark Thompson. "Harvest of Shame." Ottawa: Canadian Centre for Policy Alternatives, June 19, 2008.

McClure, Julia McClure. "Poverty, Power and Knowledge: An Early Entangled History of Hispaniola," Canadian Journal of Latin American and Caribbean Studies, 38. 2 (2013): 197-219.

McLaughlin, Janet. "Migration and Health: Implications for Development: A Case Study of Mexican and Jamaican migrants in Canada's Seasonal Agricultural Workers Program.” Ottawa: FOCAL, October 2009.

McManus, Sheila. The Line Which Separates: Race, Gender, and the Making of the Alberta-Montana Borderlands. Edmonton: University of Alberta Press, 2005 .

McNab, David. "Herman Merivale and Colonial Office Indian Policy in the MidNineteenth Century." Canadian Journal of Native Studies 1.2 (1981), 27793.

. "The Colonial Office and the Prairies in the Mid Nineteenth Century." Prairie Forum 3.1 (1978): 21-38.

. "Herman Merivale and the Native Question, 1837-1861." Albion: A Quarterly Journal Concern with British Studies, 9.4 (Winter 1977), 359384. 
Melton, Michele et. al. "Maltreatment \& Injustice: An Overview of the Plight of Latin Forest Workers in the Southeast." Santa Fe: Research Paper, August 2007.

Mezzadra, Sandro and Brett Neilson. Border as Method, or the Multiplication of Labor.Durham and London: Duke University Press, 2013.

Mills, Sean. A Place in the Sun: Haiti, Haitians, and the Remaking of Quebec. Montreal and Kingston: McGill-Queens University Press, 2016.

Mirandé, Alfredo. Hombres y Machos: Masculinity and Latino Culture. Boulder, CO: Westview, 1997.

Miron, Janet, ed. A History of Human Rights in Canada: Essential Issues.

Toronto: Canadian Scholars' Press, 2009.

Mize, Ronald L. and Alicia C.S. Swords. Consuming Mexican Labor: From the Bracero Program to NAFTA. Toronto: University of Toronto Press, 2011.

Monto, Alexander. The Roots of Mexican Labor Migration. Westport, CT: Praeger Publishers, 1994.

Mraz, John. Looking for Mexico: Modern Visual Culture and National Identity. Durham: Duke University Press, 2009. and Jaime Vélez-Storey. Uprooted: Braceros in the Hermanos Mayo Lens. University of Houston: Arte Público Press, 1996) / Trasterrados: Braceros Vistos por los Hermanos Mayo. Mexico, D.F.: Secretaría de Gobernación, Archivo General de la Nacion, México: Universidad Autónoma Metropolitana, 2005.

Mysyk, Avis. Manitoba Commercial Market Gardening, 1945-1997: Class, Race and Ethnic Relations. Regina: Canadian Plains Research Centre, University of Regina, 2000. . "The Role of the State in Manitoba Farm Labour Force Formation.” Pp. 169-182 in The Dynamics of Hired Farm Labour, Edited by Jill L. Findeis, A.M. Vanderman, J.M. Larson and J.L. Runyan. Wallingford, U.K.: CABI, 2002. Napolitana, Valentina. “The Virgin of Guadalupe: A Nexus of Affect," Journal of the Royal Anthropological Institute, 15.1 (2009), 96-112.

Narushima, Miya and Ana Sanchez. “Employers' Paradoxical Views about Temporary 
Foreign Migrant Workers' Health: A Qualitative Study in Rural Farms in Southern Ontario.” International Journal for Equity in Health 13.65 (2014), 121.

Neuberger, Bruce. Lettuce Wars: Ten Years of Work and Struggle in the Fields of California. New York: Monthly Review Press, 2013.

Newson, Linda and John King, eds. Mexico City Through History and Culture. New York and Oxford: British Academy and Oxford University Press, 2009.

Norris, Jim. North for the Harvest: Mexican Workers, Growers and the Sugar Beet Industry. St. Paul: Minnesota Historical Society Press, 2009.

Novo, Carmen Martínez. Who Defines Indigenous? Identities, Development, Intelligence, and the State in Northern Mexico. Piscataway: Rutgers University Press, 2006.

O'Brien, John. George G. Higgins and the Quest for Worker Justice: The Evolution of Catholic Social Thought in America. Lanham: Rowman and Littlefield, 2005.

Orkin, Aaron M., et al. "Medical Repatriation of Migrant Farm Workers in Ontario: A Descriptive Analysis.” Canadian Medical Association Journal 2.3 (2014): 192198.

Otero, Gerardo. 'Neoliberal Globalization, NAFTA and Migration: Mexico's Loss of Food and Sovereignty.” Journal of Poverty 15.4(2011): 384-402. and Kerry Preibisch. “The Wild West? Migrants' workplace health and safety conditions in British Columbia horticulture." Annual Meeting of the Canadian Association for Studies in International Development. Vancouver 2008 . , ed. Mexico in Transition: Neoliberal Globalism, the State and Civil Society. London and New York: Zed Books, 2004. . Farewell to the Peasantry? Political Class Formation in Rural Mexico. Boulder, CO: Westview Press, 1999.

Padilla, Tanalís. Rural Resistance in the Land of Zapata: The Jaramillista Movement and the Myth of the Pax Priísta. Durham: Duke University Press, 2008.

Pawell, Miriam. The Union of their Dreams: Power, Hope and Struggle in 
César Chávez's Farm Worker Movement. New York: Bloomsbury Press, 2009.

Peck, Gunther. Reinventing Free Labor: Padrones and Immigrant Workers in the North American West, 1880-1930. Cambridge and New York: Cambridge University Press, 2000.

Pécoud, Antoine. Depoliticizing Migration: Global Governance and International Migration Narratives. Basingstoke, UK: Palgrave, 2015.

Perks, Robert and Alistair Thompson. The Oral History Reader (Second ed). London: Routledge, 2006.

Perry, Adele. Colonial Relations: The Douglas-Connolly Family and the Nineteenth Century Imperial World. Cambridge: Cambridge University Press, 2015.

. 'Is Your Garden in England, Sir: James Douglas' Archive and the Politics of Home." History Workshop Journal 70 (Autumn 2010): 67-85. . On the Edge of Empire: Gender, Race and the Making of British Columbia, 1849-1871. Buffalo, NY: University of Toronto Press, 2001. Phillips, Rod. Ontario Wine Country. North Vancouver: Whitecap Books, 2006. Pietropaolo, Vincenzo. Harvest Pilgrims: Mexican and Caribbean Migrant Farm Workers in Canada. Toronto: Between the Lines Press, 2009.

Pilcher, Jeffrey. Planet Taco: A Global History of Mexican Food. Oxford, New York: Oxford University Press, 2012.

. The Sausage Rebellion: Public Health, Private Enterprise, and Meat in Mexico City, 1890-1917 Albuquerque: University of New Mexico Press, 2006. - ¿Que vivan los tamales! Food and the Making of Mexican Identity. Albuquerque: University of New Mexico Press, 1998.

Piper, Nicola and Amber. "Do Women Benefit from Migration?" Diversities 13.1(2011): 1-4.

Pollan, Michael. The Omnivore's Dilemma: A Natural History of Four Meals. New York: Penguin, 2007.

. The Botany of Desire: A Plant's Eye View of the World. New York: 
Random House, 2002.

Portelli, Allessandro. The Text and the Voice: Writing, Speaking, and Democracy in American Literature. New York: Columbia University Press, 1994. . The Death of Luigi Trastelli and Other Stories: Form and Meaning in Oral History. Albany: State University of New York Press, 1991. Preibisch, Kerry and Jenna Hennebry. "Temporary Migration, Chronic Effects:

The Health of International Migrant Workers in Canada." Canadian Medical Association Journal 183.9 (2011): 1033-1038. "Pick-Your-Own Labor: Migrant Workers and Flexibility in Canadian Agriculture. International Migration Review 44.2 (2010): 404-441. and Evelyn Encalada. Migrant Women Farm Workers in Canada.

Guelph: Rural Women Making Change, University of Guelph, July 2008. . "Migrant Agricultural Workers and Processes of Social Inclusion in Rural Canada: Encuentros and Desencuentros." Canadian Journal of Latin American and Caribbean Studies 29.57 and 58(2004): 203-239. Prouty, Marco G. César Chávez, the Catholic Bishops, and the Farmworkers' Struggle for Social Justice. Tucson: University of Arizona Press, 2006.

Quezada, Noemí. Sexualidad, Amor y Erotismo. Mexico Prehispánico y Mexico Colonial. México: UNAM, Instituto de Investigaciones Antropológicas, Primera Reimpresion, 2002.

Rabasa, José. Without History: Subaltern Studies, The Zapatista Insurgency, and the Specter of History. Pittsburgh: University of Pittsburgh Press, 2010.

Raibmon, Paige. "Meanings of Mobility on the Northwest Coast." Pp. 175-195 in New Histories for Old: Changing Perspectives on Canada's Native Pasts, Edited by Susan Neylan and Ted Binnema. Vancouver: UBC Press, 2007. . "The Practice of Everyday Colonialism: Indigenous Women at Work in the Hop Fields and Tourist Industry of Puget Sound." Labor: Studies on Working Class History of the Americas 3.3 (2006): 23-56.

Ramirez, Hernan and Pierrette Hondagneu-Sotelo, "Mexican Gardeners in the USA," pp. 122-148 in Majella Kilkey, Diane Perrons, and Ania Plomien. Gender, 
Migration and Domestic Work: Masculinities, Male Labour and Fathering in the UK and USA. New York: Palgrave Macmillan, 2013.

Ramirez, Josué. Against Machismo: Young Adult Voices in Mexico City. New York York: Berghahn Books, 2008.

Read, Jodi, Sarah Zell and Lynne Fernandez. "Migrant Voices: Stories of Seasonal Agricultural Workers in Manitoba." Canadian Centre for Policy Alternatives, Manitoba Office, May 2013.

Reisler, Mark. By the Sweat of Their Brow: Mexican Immigrant Labor in the United States, 1900-1940. Westport: Greenwood Press, 1976.

Replogle, Jill. "Migrant Education Program Gives Farmworkers a Boost,” Fronteras: The Changing America Desk, Nov. 072013.

Riley, Mark and David Harvey. "Talking Geography: On Oral History and the Problem of Geography." Social and Cultural Geography 8.3 (2007): 345-351.

. "Oral histories, farm practice and uncovering meaning in the countryside." Social and Cultural Geography 8.3 (2007): 391-415.

Roberts, Julia. In Mixed Company: Taverns and Public Life in Upper Canada Vancouver: UBC Press, 2009.

Rodriguez, Jeanette. Our Lady of Guadalupe: Faith and Empowerment among Mexican-American Women. Austin: University of Texas Press, 1994. Rodriguez, Marc Simon. Rethinking the Chicano Movement. New York: Routledge, 2015. . The Tejano Diaspora: Mexican Americanism and Ethnic Politics in Texas and Wisconsin. Chapel Hill: University of North Carolina Press, 2011.

Rosas, Ana Elizabeth. Abrazando el Espíritu: Bracero Families Confront the U.S.Mexico Border. Berkeley and Los Angeles: University of California Press, 2014.

Rothenberg, Daniel. With These Hands: The Hidden World of Migrant Farmworkers Today. Berkeley: University of California Press, 2000.

Rouse, Roger. "Mexican Migration and the Social Space of Post-Modernism," Diaspora 1.1 (1991): 8-23. 
Roy, Patricia E. and John Herd Thompson. British Columbia: Land of Promises.

Oxford: Oxford University Press, 2005.

Ruiz, Vicki L. “Class Acts: Latina Feminist Traditions, 1900-1930,” AHA

Presidential Address, American Historical Review 121.1 (2016), 1-16.

. Cannery Women, Cannery Lives: Mexican Women, Unionization and

the California Food Processing Industry, 1930-1950. Albuquerque:

University of New Mexico Press, 1987.

Russo, Robert Marc. “Temporarily Unchained: The Drive Unionize Foreign Seasonal Agricultural Workers in Canada - A Comment on Greenway Farms and UFCW.” BC Studies 169 (Spring 2011): 131-141.

Rygiel, Kim and Peter Nyers. Citizenship, Migrant Activism and the Politics of Global Movement. London: Routledge, 2012.

Saldaña-Portillo, María Josefina. Indian Given: Racial Geographies Across Mexico and the United States. Durham and London: Duke University Press, 2016.

Salesa, Damon I. Racial Crossings: Race, Intermarriage and the Victorian

British Empire. Oxford: Oxford University Press, 2012.

Samuel, Raphael. Theatres of Memory: Past and Present in Contemporary Culture. London: Verso, 1994.

Sanchez, George. Becoming Mexican American: Ethnicity, Culture and Identity in Chicano Los Angeles, 1900 - 1945. New York: Oxford University Press, 1993.

Sandwell, Ruth. Contesting Rural Space: Land Policy and the Practices of Settlement, Saltspring Island, British Columbia, 1859-91. Kingston and Montreal: McGill- Queen's University Press, 2005.

Sarathy, Brinda. Pineros: Latino Labor and the Changing Face of Forestry in the Pacific Northwest. Vancouver: University of British Columbia Press, 2011. ."The Marginalization of Pineros in the Pacific Northwest," Society and Natural Resources 21. 8 (Sept. 2008): 671-686. and Vanessa Casanova. "Guest Workers or Unauthorized Immigrants? The Case of Forest Workers in the United States." Policy Sciences, 41.2 (2008): 95-114. 
Satzewich, Victor. Racism and the Incorporation of Foreign Labour: Farm Labour Migration to Canada since 1945. London and New York: Routledge, 1991. Servín, Elisa, Leticia Reina, and John Tutino, eds. Cycles of Conflict, Centuries of Change: Crisis, Reform and Revolution in Mexico. Durham: Duke University Press, 2007.

Scott, James. Seeing Like a State: How Certain Schemes to Improve the Human Condition have Failed. New Haven: Yale University Press, 1999.

Sheftel, Anna and Stacey Zembrzycki, eds. Oral History off the Record: Toward an Ethnography of Practice. New York: Palgrave Macmillan, 2013.

Shipley, Tyler. "Enclosing the Commons in Honduras." American Journal of Economics and Sociology 75.2 (2016): 456-487.

Sifuentez, Mario Jimenez. Of Forests and Fields: Mexican Labor in the Pacific Northwest. New Brunswick, NJ: Rutgers University Press, 2016.

Sigal, Pete. Infamous Desire: Male Homosexuality in Colonial Latin America. Chicago: University of Chicago Press, 2003.

. "To Cross the Sexual Borderlands: The History of Sexuality in the Americas." Radical History Review 82 (2002): 171-185.

Sleeper-Smith, Susan. Indian Women and French Men: Rethinking Cultural Encounter in the Western Great Lakes. Amherst: University of Massachusetts Press, 2001.

Sluis, Ageeth. Deco Body, Deco City: Female Spectacle and Modernity in Mexico City, 1900-1939 Lincoln: University of Nebraska Press, 2016.

Smith, Adrian A. "Troubling 'Project Canada': The Caribbean and the Making of Unfree Migrant Labour." Canadian Journal of Latin American and Caribbean Studies 40.2 (July 2015) 274-293.

Smith, Linda Tuhiwai. Decolonizing Methodologies: Research and Indigenous Peoples. London: Zed Books, 1999.

Smith, Richard Cándida. "Analytic Strategies for Oral History Interviews," pp. 711731 in Handbook of Interview Research: Context and Method. Edited by Jaber Gubrium and James Holstein. Thousand Oaks: Sage Publications, 2002. 
Snodgrass, Michael. "Patronage and Progress: The Bracero Program from the Perspective of Mexico.” Pp. 245-266 in Leon Fink, ed. Workers across the Americas: The Transnational Turn in Labor History. New York: Oxford University Press, 2011.

Sowards, Stacey. "Rhetorical Agency as Haciendo Caras and Differential Consciousness Through Lens of Gender, Race, Ethnicity, and Class: An Examination of Dolores Huerta's Rhetoric," Communication Theory 20 (2010): 223-247.

Steinmetz, George, ed. The Politics of Method in the Human Sciences: Positivism and its Epistemological Others. Durham and London: Duke University Press, 2005.

Stephen, Lynn. The Story of PCUN and the Farmworker Movement in Oregon. Eugene: University of Oregon Center for Latino/a and Latin American Studies, July 2012.

Stern, Steve. The Secret History of Gender: Women, Men and Power in Late Colonial Mexico. Chapel Hill: University of North Carolina Press, 1997.

Street, Richard Steven. Beasts of the Field: A Narrative History of California Farmworkers, 1769-1913. Stanford: Stanford University Press, 2004.

Storey, Kenton. Settler Anxiety at the Outposts of Empire: Press Coverage of Indigenous Resistance and Rebellion. Vancouver: UBC Press, 2016.

Suárez Findlay, Eileen J. We are left without a Father Here: Masculinity, Domesticity and Migration in Postwar Puerto Rico. Durham and London: Duke University Press, 2014.

Sugiman, Pamela. "'Life is Sweet': Vulnerability and Composure in the Wartime Narratives of Japanese Canadians.” Journal of Canadian Studies 43.1 (2009) 186- 218.

Summers Sandoval, Tomás. "Disobedient Bodies: Racialization, Resistance and the Mass (Re)Articulation of the Mexican Immigrant Body." American Behavioral Scientist 52.4 (December 2008): 580-597.

Surak, Kristin. “Guest Workers: A Taxonomy.” New Left Review 84 (2013) 84-102.

Swyripa, Frances. Storied Landscapes: Ethno-religious Identity and the 
Canadian Prairies. Winnipeg: University of Manitoba Press, 2015.

Taylor, Paul S. "Migratory Farm Labor in the United States." Monthly Labor Review 44, no. 3 (March 1937): 537-47.

. Mexican Labour in the United States, Vol. I. University of

California Publications in Economics, Vol. 6, 1928-1930. Berkeley, Calif.:

University of California Press, 1930.

Thiessen, Janis. Not Talking Union: An Oral History of Mennonites and Labour.

Montreal and Kingston: McGill-Queens University Press, 2016.

Thompson, Mike, David Fairey, and Arlene Tiger McClaren. "Unfree Farm Labour in British Columbia?" Ottawa: CCPA, Sept 25, 2008.

Thompson, Tracey L. "Remembering 'The Contract': Recollections of Bahamians."

The International Journal of Bahamian Studies 18, 6-12 (2012).

Tomic, Patricia, Ricardo Trumper, and Luis Aguiar. "Housing Regulations and

Living Conditions of Mexican Migrant Workers in the Okanagan Valley, B.C."

pp. 78-82 Canadian Issues / Thèmes Canadiens, Spring / Printemps 2010.

Tonkiss, Katherine. Migration and Identity in a Post-National World. Houndmills,

Basingstoke, Hampshire; New York, NY: Palgrave Macmillan, 2013.

Vaithees, V. Ravi. Religion, Caste and Nation in South India: Maraimalai Adigal, the Neo-Salvite Movement, and Tamil Nationalism. New Delhi: Oxford University Press India, 2015.

Valerio-Jiménez, Omar S. River of Hope: Forging Identity and Nation in the Rio-

Grande Borderlands. Durham: Duke University Press, 2012.

Valverde, Mariana. The Age of Light, Soap and Water: Moral Reform in English Canada, 1885-1925. Toronto: University of Toronto Press, 2008.

Van Kirk, Sylvia. Many Tender Ties: Women in Fur Trade Society, 1670-1870.

Winnipeg: Watson and Dwyer, 1996.

Van Maanen, John. Tales of the Field: On Writing Ethnography $\left(2^{\text {nd }}\right.$ ed.) (London and Chicago: University of Chicago Press, 1988; 2011

Von Kirsch, Patrick. A Shark Going Inland is my Chief: The Island Civilization of Ancient Hawai 'i. Berkeley: University of California Press, 2012.

Walsh, Casey. "Eugenic Acculturation: Manuel Gamio, Migration Studies and the 
Anthropology of Development in Mexico, 1910-1940," Latin American Perspetives 31.5 (2004), 118-145.

Walters, William. Governmentality: Critical Encounters. Oxon; New York: Routledge, 2012.

Ward, Peter. A History of Domestic Space: Privacy and the Canadian Home. Vancouver: UBC Press, 2009. . White Canada Forever: Popular Attitudes and Public Policy

Toward Orientals in British Columbia. Montreal and Kingston: McGillQueen's University Press, 2002. and A.J. McDonald. British Columbia: Historical Readings.

Vancouver: Douglas McIntyre, 1981.

Wasley, Andrew. "Bitter Harvest: How Exploitation and Abuse Stalks Migrant Workers on UK farms." Ecologist, 10 October, 2011. . "Scandal of the 'Tomato Slaves' Harvesting Crop Exported to UK." The Ecologist, September, 2011.

Weber, David J. Bárbaros: Spaniards and their Savages in the Age of Enlightenent. New Haven; Yale University Press, 2005.

Weise, Julie M. Corazón de Dixie: Mexicanos in the U.S. South since 1910. Chapel Hill: University of North Carolina Press, 2015.

Werne, Joseph Richard. The Imaginary Line: A History of the United States and Mexican Boundary Survey, 1848-1857. Fort Worth: Texas Christian University, 2007.

White, Richard. The Middle Ground: Indians, Empires and Republics in the Great Lakes Region, 1650-1815. New York: Cambridge University Press, 1991; $20^{\text {th }}$ Anniversary Edition, 2011.

Wilson, Tamar Diana. Women's Migration Networks in Mexico and Beyond. Albuquerque: University of New Mexico Press, 2009.

Wise, Raúl Delgado. “The Migration and Labor Question Today: Imperialism, Unequal Development, and Forced Migration." Monthly Review 64.9 (Feb. 2013): 25-38.

Zamudio, Patricia. "Mexican International Migration” pp. 129-146 in Maura Isabel 
Toro-Morn and Marixsa Alicea, Migration and Immigration: A Global View. Westport, CT: Greenwood, 2004.

Zavella, Patricia. I'm Neither Here nor There: Mexican's Quotidian Struggles with Migration and Poverty. Durham: Duke University Press, 2011.

\section{Theses}

Calnitsky, Naomi Alisa. "Colonized Pasts, Labour Circuits and Post-1945 Mobility to New Zealand: A Case Study of Samoa and Vanuatu.” M.A. Thesis, Otago, 2008.

DiGiano, Maria Louise “Privatizing the Commons? A Political Ecology of Mexico's 1992 Agrarian Reform in Quintana Roo, Yucatan Peninsula.” PhD Thesis, University of Florida, 2011.

Harris, Ruth L. The Transformation of Canadian Policies and Programs to Recruit Foreign Labor: the Case of Caribbean Female Domestic Workers, 1950s1980s. Ph.D. Thesis, Michigan State University, 1988.

Healy, Teresa. “Contesting Restructuring, Transforming Representation: Autoworkers and the Gendered Struggle for Counter-Hegemony in Mexico.” Ph.D Thesis, Carleton, 1999.

Hennebry, Jenna. "Globalization and the Mexican-Canadian Seasonal Agricultural Worker Program: Power, Racialization and Transnationalism in Temporary Migration.” PhD, Sociology, University of Western Ontario, 2006.

Hinnenkamp, Katie Marie. "Bicycles Travelling in the Rain: A Participatory, ArtsInformed Account of Mexican Farmworkers in Canada.” M.A., Education, University of Toronto, 2007.

Ketchell, Shelley D. "Relocating Japanese Canadian History: Sugar Beet Farms as Carceral Sites in Alberta and Manitoba, February 1942-January 1943.” M.A. Thesis, University of British Columbia, 2005.

Knowles, Kimberly. The Seasonal Agricultural Workers Program in Ontario from the Perspective of Jamaican Migrants. M.A. Thesis, University of Guelph, 1997.

Levario, Miguel. "Cuando Vino la Mexicanada: Authority, Race and Conflict in 
West Texas, 1895-1924.” PhD Thesis, University of Texas at Austin, 2007.

Muñoz Arguello, Nery M. "Mexican Agricultural Workers in Canada;

Benefits of Bilateral Collaboration.” M.A. Thesis, Carleton, 1999.

Morse, Robert. J. "Seasonal Agricultural Employment in the Flue-cured Tobacco

Farming Industry of Southern Ontario.” M.A. Thesis, University of Guelph, 1985.

Paz Ramirez, Adriana Gabriela, "Embodying and Resisting Labour Apartheid: Racism and Mexican Farm Workers in Canada's Seasonal Agricultural Workers Program,” M.A. Thesis, UBC, 2013.

Russo, Robert Marc. "Solidarity Forever, Canadians Never: SAWP Workers in Canada." PhD Thesis (Law), UBC, 2012.

Sandwell, Ruth. "Reading the Land: Rural Discourse and the Practice of Settlement, Salt Spring Island, British Columbia, 1859-1891.” PhD Thesis, Simon Fraser University, 1997.

Segal, Sean. "Early Church Involvement in U.S. Farm Labor." Senior Thesis, Catholic University of America, 2000.

Wong, Lloyd. "Migrant Seasonal Agricultural Labour: Race and Ethnic Relations in the Okanagan Valley.” Ph.D. Thesis, York University, 1988.

Zembrzycki, Stacey Raeanna. "Memory, identity, and the challenge of community among Ukrainians in the Sudbury region, 1901-1939." Ph.D. Thesis, Carleton University, 2007. 


\section{Appendix 1: Bracero Era Photographs}

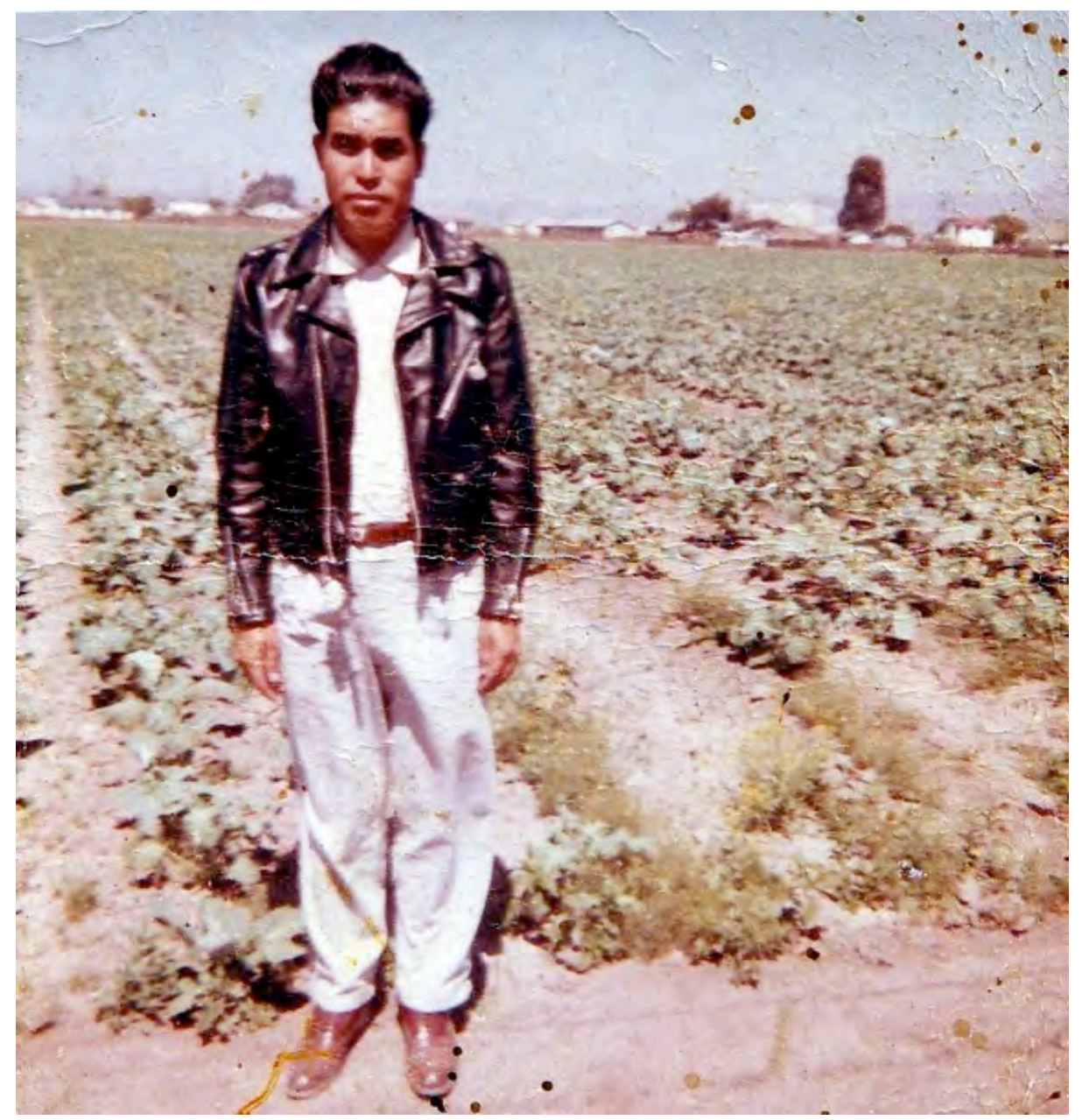

Fig. 15 Plutarco Chávez-Ruiz, "Bracero in Field"

(Bracero History Archive, Item \#3019)

Note the superimposition in this portrait of "culture" (or urban attire)

upon "nature" (the field in the background) and the sense of transnational transplantation projected by the subject.

\footnotetext{
${ }^{3}$ Figs. 15-21 are reproduced here courtesy of the Division of Work \& Industry, National Museum of American History, Smithsonian Institution, for use in dissertation only, released on April. 292013 for use in this dissertation by Kay Peterson, Archives Center, Kenneth E. Behring Center, Washington, D.C. and may not be duplicated for use in any additional article, book, film production, still photography, advertising, merchandising, exhibit or related use.
} 


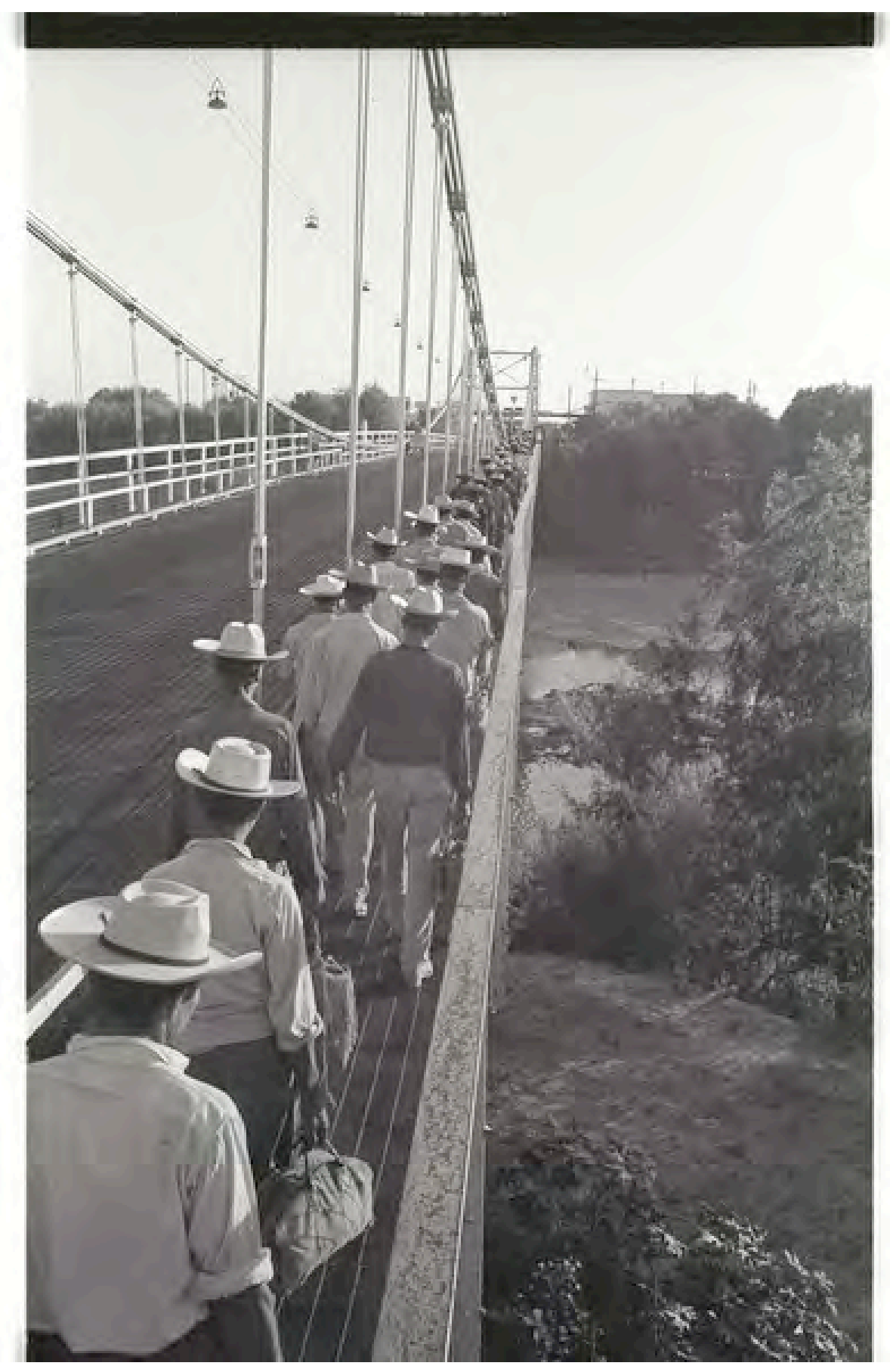

Fig. 16 "Braceros cross the Mexico-U.S. border while walking over the bridge from Reynosa, Mexico to Hidalgo, Texas."

(Bracero History Archive, Leonard Nadel, NAD - 200401380230)

Note the limited amount of luggage taken over by each individual worker, and also, the uniformity of their attire. 


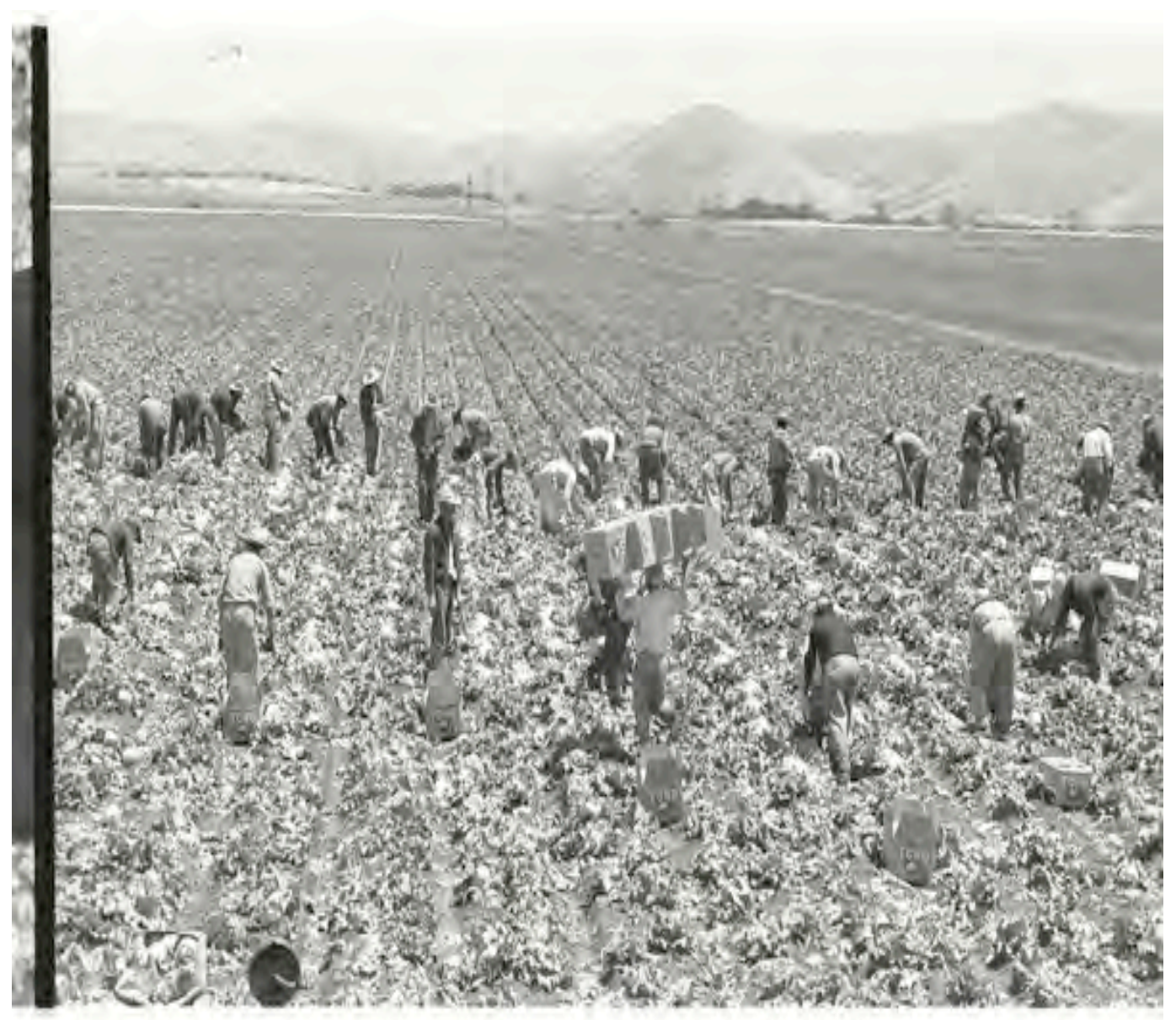

Fig. 17 "Braceros pick lettuce and fill it into Toro lettuce boxes

\section{in a field in the Salinas Valley, California."}

(Bracero History Archive, Leonard Nadel, NAD - 200401385507)

Note how this American working landscape is inflected by the geography of the valley, and how the orderly lines of planting signify the industrious use of the land. 


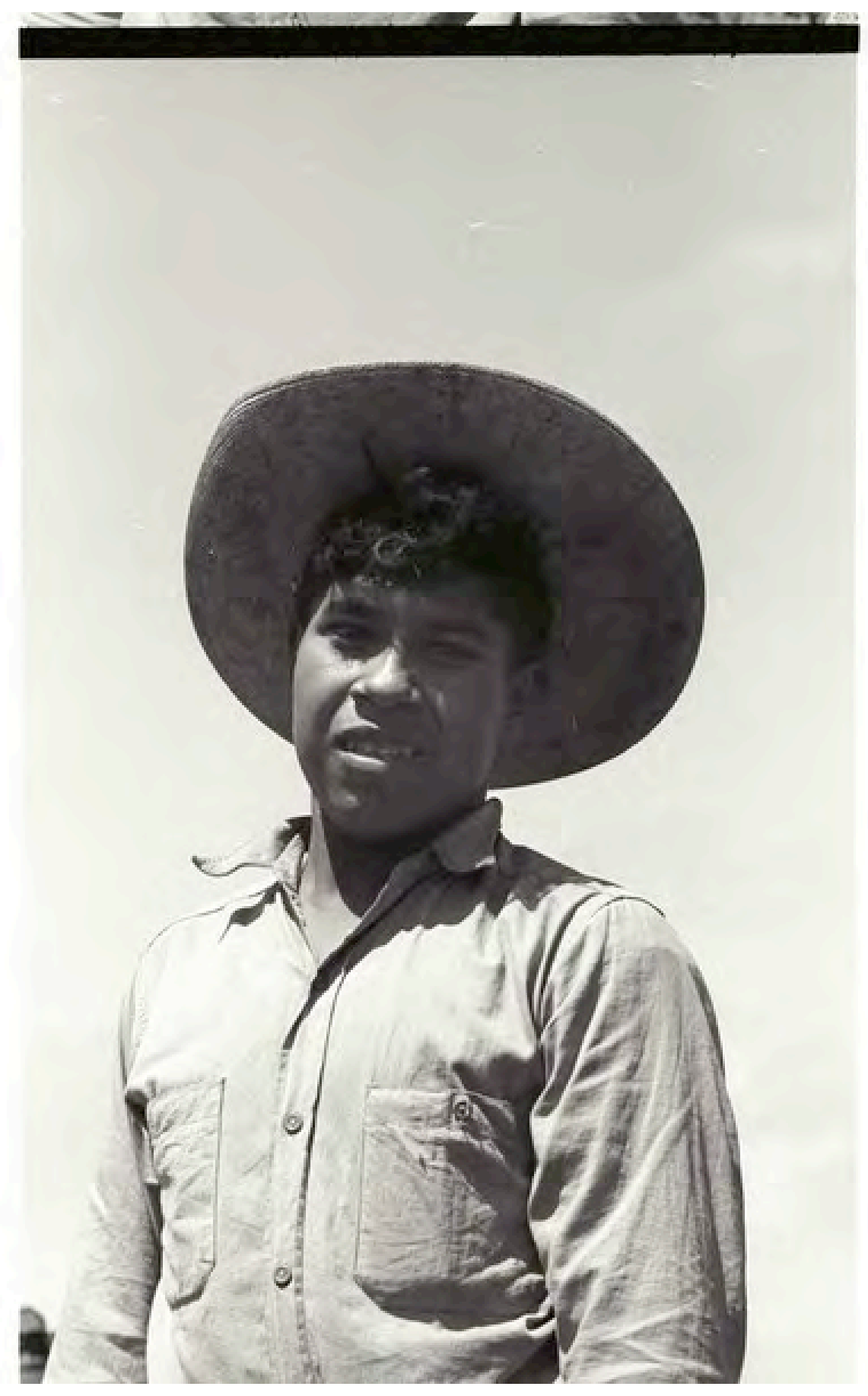

Fig. 18 "Portrait of a bracero standing in a Californian field."

(Bracero History Archive, Leonard Nadel, NAD-2004.01038.56.15)

This is a good example of a bracero portrait captured during this period; in this case, Nadel's direct style is strikingly similar to Ansel Adams' wartime photographic portraits. 


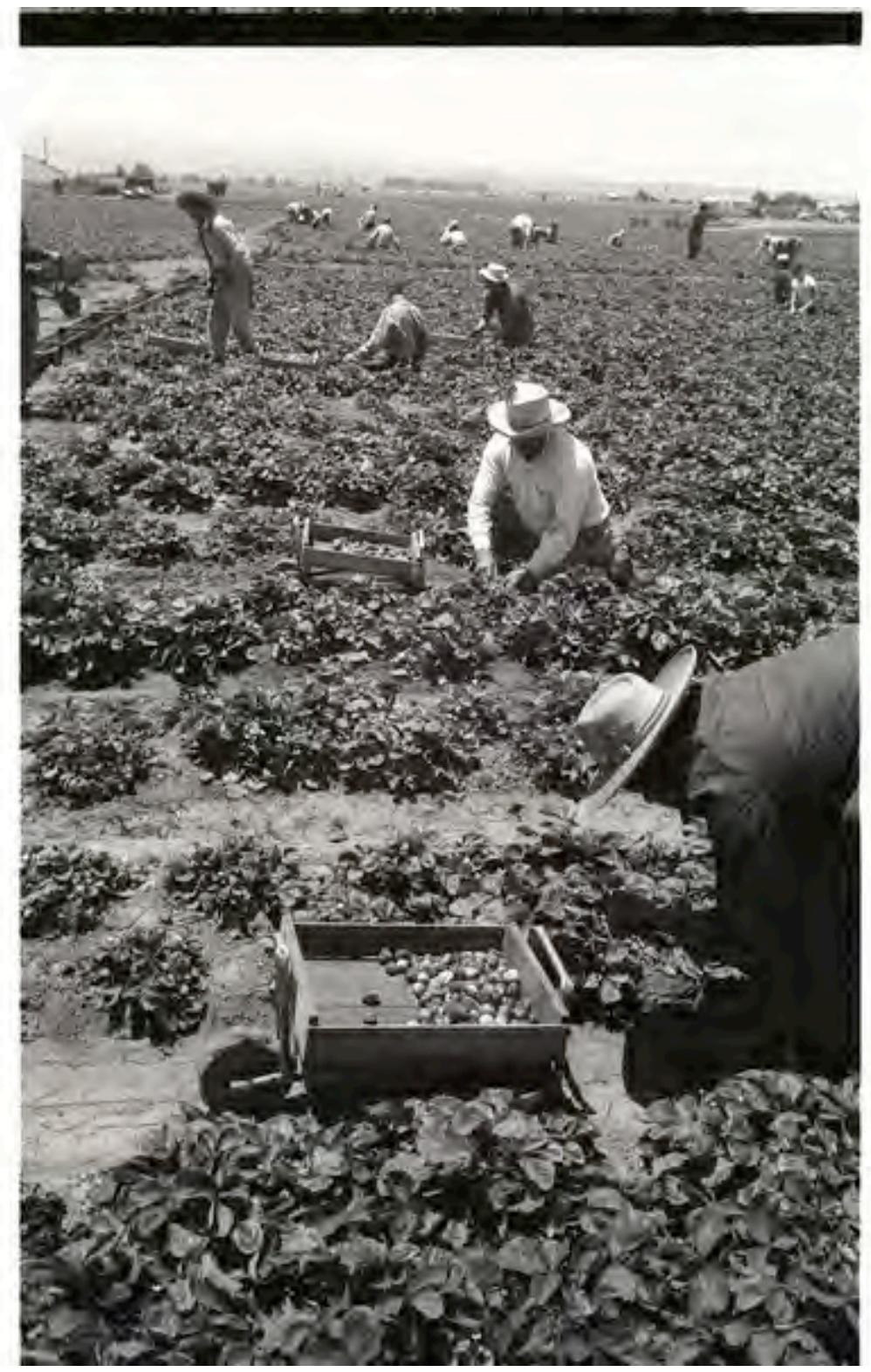

Fig. 19 "Braceros pick strawberries and fill them into boxes in a field in the Salinas Valley, California."

(Bracero History Archive, Leonard Nadel, NAD-2004.0138.52.07) Note again the separation between labour and nature (the bracero worker and field) as well as "culture" (the box of harvested strawberries, suited for the American market and economic gain). Note also the stoop labour required for this kind of harvest work. 


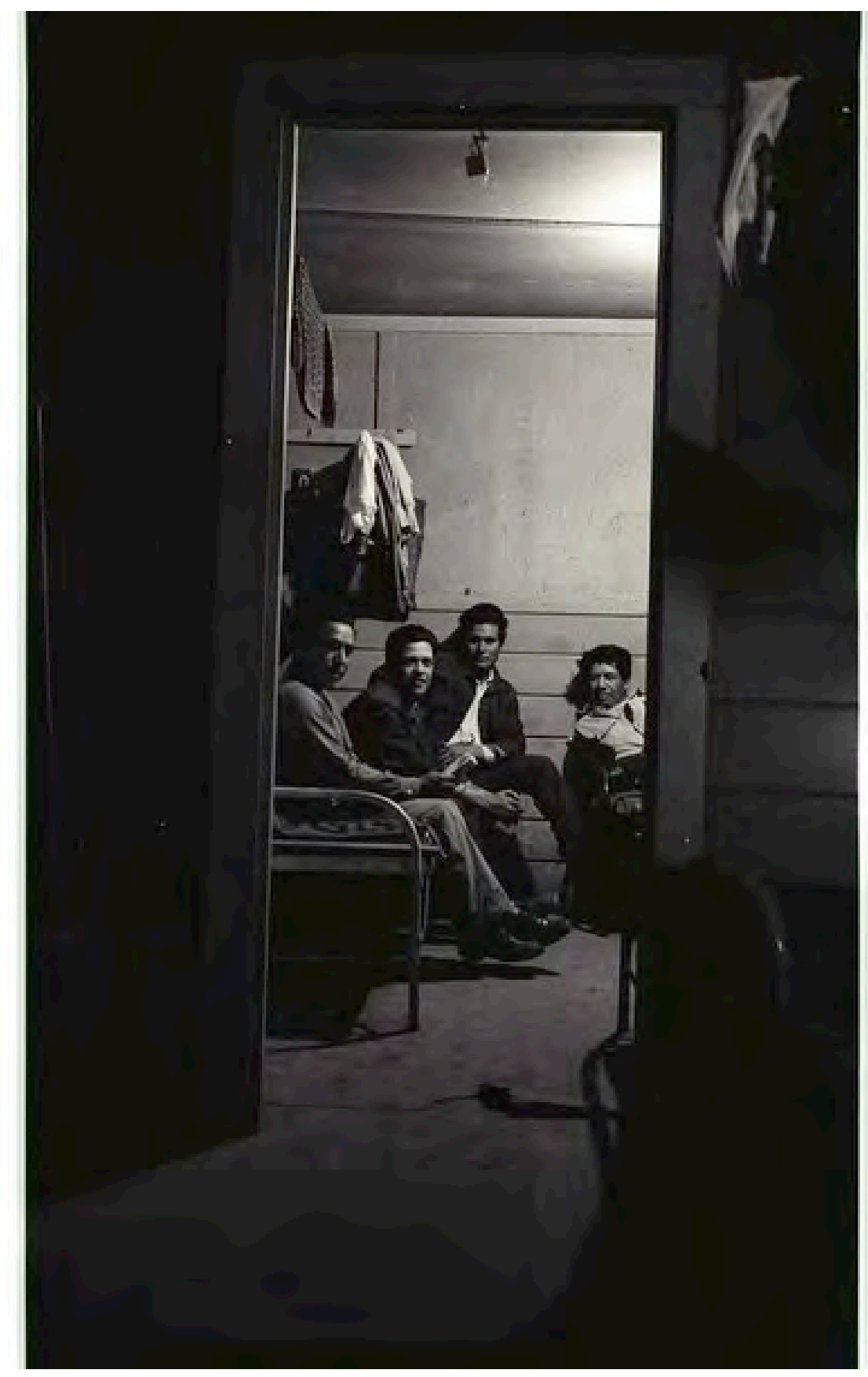

Fig. 20 "Braceros sit in beds in a living quarter of a Californian camp."

(Bracero History Archive, Leonard Nadel, NAD - 2004.0138.41.21)

Note the shared living quarters at this bracero camp and the directionality of the photographer's gaze. Note also the subjects relaxing after hours in their common housing, with the visual interplay of shadow and light. 


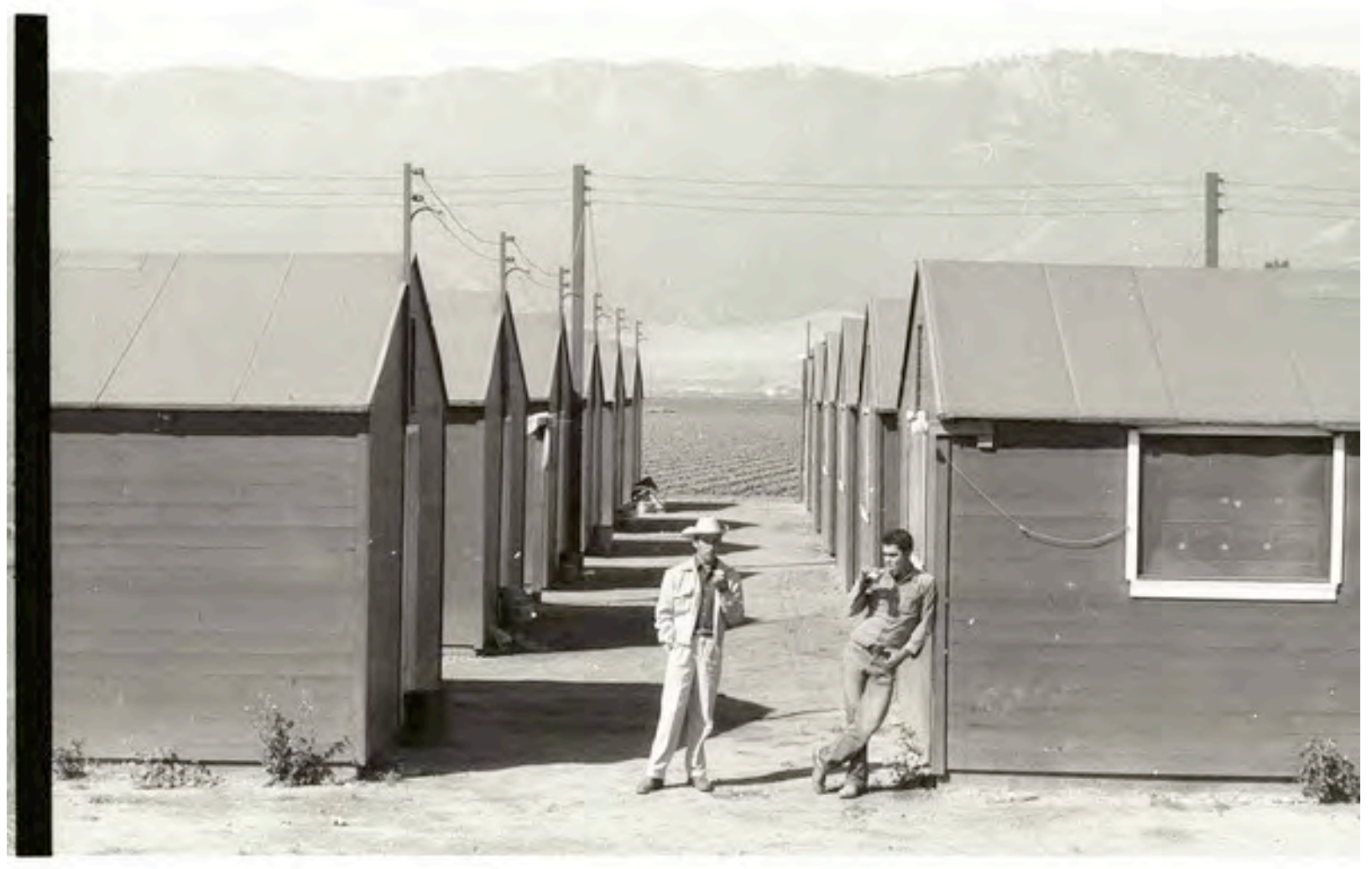

Fig. 21 "Two braceros lean each on a living quarter in a bracero camp in Gonzalez, California.” (Bracero History Archive, Leonard Nadel, NAD-2004.0138.31.29)

The constructed onsite worker housing in this photograph denotes orderliness, but also, a stark sense of separation from what "home" might look like. 


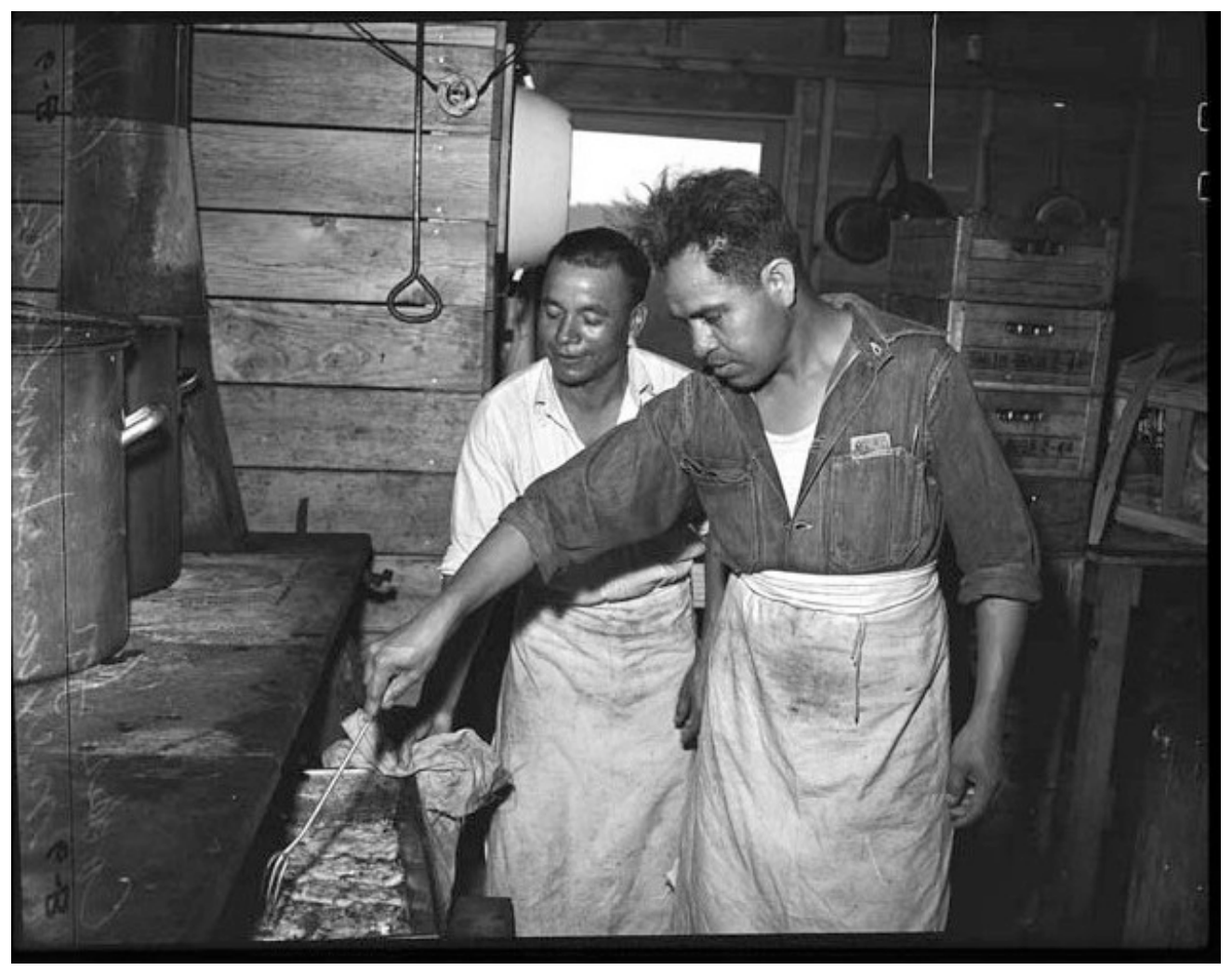

Fig. 22 "Two Men Cooking in a Kitchen of Migrant Camp, 1944."4

(Museum of History and Industry, Univesrity of Washington Special

Collections, Seattle Post-Intelligencer Collection, Image 1986.5.2905.2)

Note the sense of detachment from work and also agency of the subjects

in this photograph through the performance of cooking.

\footnotetext{
${ }^{4}$ Reproduced with permission, courtesy of Museum of History and Industry (MOHAI) Resource Centre, University of Washington Special Collections, Seattle Post-Intelligencer Collection, Digital Photograph Collection.
} 


\section{Appendix 2: Log of Oral Histories}

Interview with “Antonio,” East Selkirk, August 2012.

Interview with “Gerardo,” Portage La Prairie, July 2012.

Interview with "Luis," Winnipeg, August 2012.

Interviews with "Manuel," Portage La Prairie, August and October 2013 and June 2014.

Interview with "Mariano," East Selkirk, June 2014, and Winnipeg-Morelos, December $22,2015$.

Interview with "Segundo," East Selkirk, June 2014.

Interview with "Bernardo,” East Selkirk, June 2014.

Interview with “Alejandro,” East Selkirk, June 2014.

Interview with “Jorge,” East Selkirk, June 2014.

Interview with “Carlos,” East Selkirk, June 2014, Winnipeg-Selkirk, June 22, 2014 and

Winnipeg-Veracruz, December 22, 2015.

Interview with “Jesús,” East Selkirk, June 2014.

Interview with “Armando,” Winnipeg, August 2014.

Interview with “José," Winnipeg, August 2014.

Interview with "Diego,” Winnipeg, August 2014.

Interview with "Rodrigo," Winnipeg, August 2014.

Interviews with “Arturo,” Winnipeg, June 2012 and August 2014.

Interview with “Alfredo,” Kelowna, August 2012.

Interview with “Chico,” Kelowna, August 2012.

Interview with “Francisco,” Kelowna, August 2012.

Interview with “Lazaro,” Kelowna, August 2012.

Interview with "Victor," Kelowna, August 2012.

Interview with “Magdalena,” Oliver, August 2012.

Interview with “Gabriela,” Oliver, August 2012.

Interview with "Miguel Ángel," Oliver, July 2012.

Interview with "Pablo," Oliver, August 2012.

Interview with “César,” Oliver, August 2012. 
Interview with “Juan,” Oliver, August 2013.

Interview with "Miguel," Oliver, August 2013.

Interview with "Enrique," Oliver, August 2013.

Interview with "Pedro," Winfield, August 2013.

Interview with "Maria," Winfield, August 2013.

Interview with “Fernando,” Winfield, August 2013.

Interview with “Manuel Alejandro,” East Vancouver, August 2013.

Interview with “Gonzalo,” Abbotsford, September 2014.

Interview with "Epifanio," Abbotsford, September 2014.

Interview with "Patricio," Abbotsford, September 2014.

Interview with "Hernando," Abbotsford, September 2014.

Interview with "Felipe," Abbotsford, September 2014.

Interview with “Orlando," Oliver, October 2014.

Interview with "Pepe," Oliver, October 2014.

Interview with "Feliciano," Oliver, October 2014.

Interview with “Vicente," Oliver, October 2014.

Interview with “Modesto,” Montreal, May 2014. 


\section{Appendix 3: Letter of Concern, Excerpts}

"Letter of Concern from the Mexican Agricultural Workers of Golden Eagle Group Farm, Pitt Meadows" / “Carta de preocupación de los trabajadores agrícolas mexicanos de la granja Golden Eagle Group, Pitt Meadows." April 7, 2006.

...We are asking for the prompt intervention of the relevant authorities given that many problems exist for us... who feel disappointed and harmed, both morally and economically, with regards to the Seasonal Agricultural Worker Program between Mexico and Canada. This is due to the fact that many irregularities exist at the job, some of which are for example in the economic aspect given that many of us had to get into debt to leave a little money for our families while we were beginning to make money to send them here in Canada... after living through the experience in this farm we realize that we are never going to prosper economically since they only give us a few hours of work because the company does not authorize more than 8 hours a day of work... the work days are very difficult and the salary of $\$ 8.60$ an hour does not compensate for the effort and the risk of illness to which we are exposed...As a consequence of the weather some workers get sick with a cold or cough...

In Mexico we were informed in writing that we were coming to tomato and vegetable greenhouses, and this was a lie because in the work contract it says "greenhouse" and here we are in a blueberry farm, in other words it was all a sham since we left Mexico...In the fields we do not have proper places to eat; we eat on the ground and 
under the rain because they forbid us to get on the bus. Also there are not enough bathrooms in the blueberry area...There was a worker who became gravely ill from a cold, had a temperature for various days, swollen throat, body aches, and the worst is that he almost couldn't breathe, as if he had asthma. Even so he worked as long as his strength allowed him to and all his illness could have been avoided... if we get sick and don't work, then they won't pay us and that also medical attention costs us approximately $\$ 80$ plus medicine and the taxi from the farm to the medical clinic.... the houses are very small for the number of workers in each one, in one of the houses the kitchen is very small and there are only two refrigerators for 10 people and the fan in the kitchen doesn't work, because it doesn't have the necessary tubing to remove the smoke and as a result the house fills with heavy smoke and the fire alarms go off a lot....In the transport that takes the workers to the cranberry fields, a van often takes 10 workers crammed inside, and after we finish work and are about to go they order us to remove our rain clothes outside in the open so as not to dirty the inside of the van, and in that way exposing us to getting pneumonia...

...These managers from the beginning have treated us with screams, humiliations, intimidations; they also forbid us to talk, sing, or whistle and have even pushed a worker, who for fear and ignorance of his rights did not want to report the incident. What makes our situation more humiliating is that the managers who are originally from India, to their co-nationals who work near us, they allow them what they forbid us, they don't rush them and they even play and laugh with them...we beg the authorities to find a solution to these problems... 


\section{Appendix Four: Oral Consent Form}

\section{Carleton U N I V R S I T Y \\ Canada's Capital University}

Research project: "Harvest Histories: A Social History of Mexican Farm Workers in Canada Since 1974"

Date of original ethics clearance: April 14, 2011.

I, volunteer to participate in a study on the experience of Mexican seasonal workforces in Canada as part of the Seasonal Agricultural Workers' Program in Manitoba and British Columbia.

This project is conducted by Naomi Alisa Calnitsky, Doctoral Candidate in History, Carleton University, and is under the supervision of Drs. Sonya Lipsett-Rivera and Marilyn J. Barber, Department of History, Carleton University. The study is conducted in questionnaire format and the interview should not exceed two hours. Should the participant experience discomfort or emotional or psychological inconvenience at any time he may withdraw. The identities of participants will under no circumstances be revealed in any published work. You may withdraw from the study at any time and may contact me via email to request withdrawal. Participants may decline from answering any question and may withdraw from the study by December 31 2011 after the interview has taken place. The information you provide will under no circumstances be released to any S.A.W.P. employer and shall remain wholly confidential except for use of an academic nature. Research findings will be available to the participants, accessible in the form of a file, which shall be made available to participants upon email request. Participants will be ensured their responses will remain wholly confidential and may access data from the study after its completion.

This project was reviewed and received ethics clearance by the Carleton University Research Ethics Board.

Contact information for the REB chair: Leslie Macdonald Hicks, 510B Tory Bldg., Carleton University, Tel.613-520-2517, ethics@carleton.ca

Researcher Contact information: Naomi Alisa Calnitsky, Doctoral Candidate in History, Carleton University, ncalnits@connect.carleton.ca, Tel. (613) 520-2828.

\footnotetext{
${ }^{1}$ This form was modified from an earlier written consent form after an initial year of research in $2012^{\circ}$
} 


\section{Appendix 5: Interview Questionnaire}

1. How did you initially hear about the SAWP program?

2. What region or town are you from in Mexico? How would you compare your life working in Canada to life at home?

3. What kinds of work have you engaged in prior to gaining seasonal employment in Canada? What kind of schooling or training did you have in Mexico?

4. How long have you participated in the program?

5. Can you describe your travel route to arrive to your work site in Canada?

6. How many different employers have you worked with in Canada? Can you describe differences in the contracts?

7. Are you satisfied with your housing in Canada? Are your housing conditions adequate? What would be your ideal housing situation or what could be done to improve it?

8. What does your weekly work schedule look like?

9. How has the SAWP contract benefitted you?

10. What sorts of living costs do you face in Canada?

11. Are relations with the employer positive, negative, or neutral? Have you ever experienced conflicts with your employers?

12. Can you describe the conditions in your home region which fuelled migration to Canada for work, including local area conditions and employment opportunities at home?

13. What strategies do you undertake to maintain family connections during periods of overseas work?

14. Do you ever experience language challenges in the workplace?

15. How much free time do you have, and how do you usually spend it?

16. How often do you usually take meals and how long are your breaks? What kinds of foods do you eat in Canada and how do they differ from what you normally have at home?

17. How much interaction do you have with local communities in Canada? Describe if possible.

18. Have you experienced any physical risks associated with the job?

19. Have you experienced any job-related physical problems or illnesses?

20. Have you experienced any homesickness while on contract?

21 . What changes would you make to your contract if you could improve it in any way? 


\section{Appendix 6: Table of Interviews with Location of Employment, Region/Town of Origin and Occupational Background}

\begin{tabular}{|c|c|c|c|}
\hline Worker Pseudonym & Site of Interview & Home Town/Region & Orig. Occupation \\
\hline Antonio & East Selkirk & Oaxaca/Federal District & Construction \\
\hline Gerardo & Portage La Prairie & Monterrey & - \\
\hline Luis & Winnipeg & - & - \\
\hline Manuel & Portage La Prairie & Estado de San Luis Potosí & Oranges \\
\hline Mariano & East Selkirk & Morelos & Tomatoes \\
\hline Segundo & East Selkirk & Estado de México & - \\
\hline Bernardo & East Selkirk & - & - \\
\hline Alejandro & East Selkirk & Veracruz & - \\
\hline Jorge & East Selkirk & - & - \\
\hline Carlos & East Selkirk & Veracruz (South) & Sugarcane/Taxi \\
\hline Jesús & East Selkirk & Acapúlco & - \\
\hline Armando & Winnipeg & Sinaloa & Cows \\
\hline José & Winnipeg & Estado de San Luis Potosí & Oranges \\
\hline Diego & Winnipeg & Morelos & Taxi \\
\hline Rodrigo & Winnipeg & Tlaxcala & Construction \\
\hline Arturo & Winnipeg & Guadalajara & - \\
\hline Alfredo & Kelowna & Zacatecas & Ranching \\
\hline Chico & Kelowna & Tlaxcala & - \\
\hline Francisco & Kelowna & Veracruz & - \\
\hline
\end{tabular}




\begin{tabular}{|c|c|c|c|}
\hline Worker Pseudonym & Site of Interview & Home Town/Region & Orig. Occupation \\
\hline Lazaro & Kelowna & Puebla & - \\
\hline Victor & Kelowna & Salina Cruz, Oaxaca & Oil Refinery \\
\hline Magdalena & Oliver & San Luis Potosí & - \\
\hline Gabriela & Oliver & - & - \\
\hline Miguel Ángel & Oliver & Chiapas & - \\
\hline Pablo & Oliver & Toluca & Plumber \\
\hline César & Oliver & Veracruz & Coffee \\
\hline Juan & Oliver & Chiapas & - \\
\hline Miguel & Oliver & Sinaloa & Ranching \\
\hline Enrique & Oliver & Federal District & - \\
\hline Pedro & Winfield & Near Federal District & Tobacco (U.S.) \\
\hline Maria & Winfield & Michoacán & - \\
\hline Fernando & Winfield & Nayarit & Rancho/Farm \\
\hline Manuel Alejandro & Vancouver & Puebla & - \\
\hline Gonzalo & Abbotsford & Tlaxcala & - \\
\hline Epifanio & Abbotsford & Tepic & Tomatoes \\
\hline Patricio & Abbotsford & Tepic & Tomatoes \\
\hline Hernando & Abbotsford & Michoacán & Tree Fruits \\
\hline Felipe & Abbotsford & Nayarit & Farm Work \\
\hline Orlando & Oliver & Guadalajara & - \\
\hline Pepe & Oliver & Oaxaca & - \\
\hline Feliciano & Oliver & Tlaxcala & Farm Work (US.) \\
\hline Vicente & Oliver & Aguascalientes & - \\
\hline Modesto & Montreal & Guatemala City & - \\
\hline
\end{tabular}




\section{Appendix Seven: Glossary of Spanish Terms}

\begin{tabular}{|c|c|}
\hline adelita & a female soldier of the Revolution \\
\hline aguantar & to bear, to endure, to tolerate \\
\hline bracero & $\begin{array}{l}\text { Mexican field hand hired through a bi-national labour program in } \\
\text { the United States (1942-1964), one who works with his arms }\end{array}$ \\
\hline bregar & to negotiate, to extract the best possibilities \\
\hline caña de azúcar & cane sugar \\
\hline campesino & peasant, farmer, one of a rural class \\
\hline encomienda & $\begin{array}{l}\text { defined legally in } 1503 \text {, when a Spanish colonist was entrusted } \\
\text { with land and the responsibility to evangelize and exact }\end{array}$ \\
\hline & Amerindian labour or tribute \\
\hline granja & farm \\
\hline hierba & herb \\
\hline machismo & a sense of being manly, strong masculinity, masculine pride \\
\hline mestizo & person of mixed descent, most commonly Spanish and Indian \\
\hline mica & $\begin{array}{l}\text { plastic card carried by braceros allowing them to return to the } \\
\text { same employer }\end{array}$ \\
\hline migra & informal term for U.S. Immigration and Customs enforcement \\
\hline $\begin{array}{l}\text { Náhuatl } \\
\text { patrón }\end{array}$ & $\begin{array}{l}\text { indigenous language common to Central Mexico and the Aztecs } \\
\text { boss }\end{array}$ \\
\hline Pinero & a forestry worker on a temporary work contract (U.S.) \\
\hline Porfiriato & $\begin{array}{l}\text { a long period of rule (1876-1910) in Mexico under Porfirio Diaz, } \\
\text { during which time Mexico courted foreign investment, underwent } \\
\text { intensive modernization and economic growth }\end{array}$ \\
\hline Raza Cósmica, La & $\begin{array}{l}\text { An idea about race in the Americas originally presented in } 1925 \text { by } \\
\text { José Vasconcelos, who predicted the utopian ascendance of a } \\
\text { mixed race defined by the aesthetic qualities of joy, love and } \\
\text { creativity and the breaking down of racial obstacles; also an idea } \\
\text { embraced by the post-revolutionary Mexican state }\end{array}$ \\
\hline & shop, store \\
\hline trabajadores & workers \\
\hline
\end{tabular}

